\title{
Especificação, Instanciação e Experimentação de um Arcabouço para Criação Automática de Ligações Hipertexto entre Informações Homogêneas ${ }^{1}$
}

\author{
Alessandra Alaniz Macedo \\ Orientadora: Profa. Dra . Maria da Graça Campos Pimentel
}

Tese apresentada ao Instituto de Ciências Matemáticas e de Computação, da Universidade de São Paulo, como parte dos requisitos para obtenção do título de Doutor em Ciências - Área: Ciências de Computação e Matemática Computacional.

USP - São Carlos

Maio de 2004

\footnotetext{
${ }^{1}$ Trabalho realizado com o apoio da FAPESP (99/11527-0).
} 
Dedico esta tese aos meus pais e ao meu marido. 


\section{Agradecimentos}

A Deus pela presença na minha vida.

À Fundação de Amparo à Pesquisa do Estado de São Paulo (FAPESP), que incentiva, financia e dá suporte à pesquisa neste país.

À minha orientadora e amiga, Graça Pimentel, por seus ensinamentos, críticas e sugestões que muito me ajudaram no desenvolvimento do trabalho.

Aos professores Agma Traina, Berthier Ribeiro-Neto, Dilvan Moreira, Dorival Leão, Graça Nunes, Renata Pontim M. Fortes e Sandra Aluísio pelo socorro e conselhos nas horas difíceis.

Aos professores Gregory Abowd e Lonnie Harvel pelo apoio a realização da etapa do meu doutorado no Georgia Tech. Institute em Atlanta-USA.

Ao pessoal do laboratório Intermídia, especialmente Renato-Taciana, Juninho Arruda, Renan, Rudinei, Andréa, Elaine, Valter, Laércio, Carlos "Patrão" pela ajuda em muitas etapas do doutorado.

Às secretárias da Pós-Graduação, Beth, Laura e Ana Paula; à Tatiana, Enza e outros do Departamento Financeiro pelos esclarecimentos e ajuda.

À minha família e amigos pelo apoio, carinho e amor eternos.

Aos meus sogros e familiares distantes que, mesmo a milhares de quilômetros, sempre me incentivam e enviam muita energia positiva.

Ao meu marido, José Antonio Camacho-Guerrero, pelo seu apoio e companheirismo inestimáveis!! 


\section{Sumário}

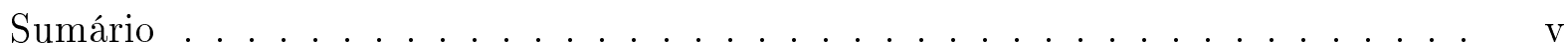

Lista de Figuras . . . . . . . . . . . . . . . . . . vii

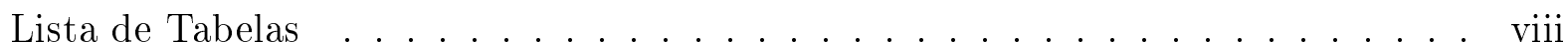

1 Introdução $\quad 1$

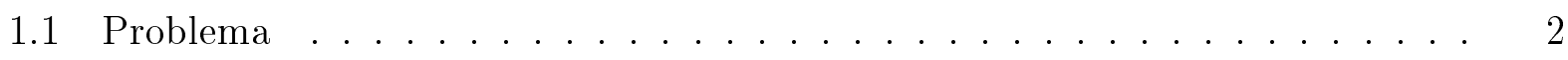

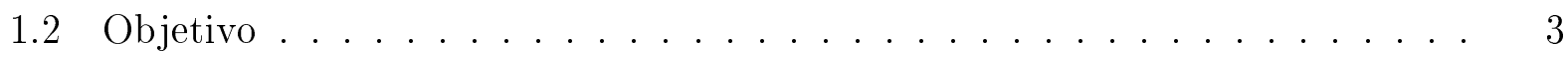

1.3 Trabalho Realizado . . . . . . . . . . . . . . . . . . . 3

1.4 Contribuições . . . . . . . . . . . . . . . . . . . 5 5

1.5 Limitações . . . . . . . . . . . . . . . . . . . . 6

1.6 Organização do Texto . . . . . . . . . . . . . . . 6

2 Estado da Arte $\quad 8$

2.1 Considerações Iniciais . . . . . . . . . . . . . . . . . . 8

2.2 Criação de Ligações Hipertexto a partir de Técnicas de Recuperação de Informação . . . . . . . . . . . . . . . . . . . 9 9

2.2.1 Análise Textual para Criação de Ligações Hipertexto . . . . . . . . . 9

2.2.2 Análise de Estrutura de Relacionamentos entre Documentos para Recuperação de Informação . . . . . . . . . . . . . . . . . 11

2.3 Relacionamento de Informações por Sistemas de Recomendação . . . . . . . 14

2.3.1 Recomendação de Informação a partir de Interação Explícita de Usuários 15

2.3.2 Recomendação de Informação a partir de Interação Implícita de Usuários 17

2.3.3 Aspectos de Privacidade e Convenções Sociais para Recomendação de Informação . . . . . . . . . . . . . . . . . 19

2.4 Definição de Relacionamentos a partir de Informações Capturadas em Ambientes Ubíquos . . . . . . . . . . . . . . . . . . . . .

2.4.1 Relacionamento de Informações a partir da Sincronização da Captura de Experiências ao Vivo . . . . . . . . . . . . . . .

2.4.2 Relacionamento de Informações a partir da Manipulação Textual de Informações advindas da Captura de Experiências ao Vivo . . . . . . 
2.5 Tecnologias Hipermídia para relacionar Experiências dos Mundos Real e Virtual 25

2.6 Considerações Finais . . . . . . . . . . . . . . . . . . . . 26

3 Recuperação de Informação $\quad 28$

3.1 Considerações Iniciais . . . . . . . . . . . . . . . . . . . . . 28

3.2 Conceitos Básicos . . . . . . . . . . . . . . . . . . 29

3.3 Modelos para Representação de Documentos . . . . . . . . . . . . . . . . 29

3.3 .1 Modelos Clássicos . . . . . . . . . . . . . . . . . 30

3.3.2 Modelos Estendidos e Modelos Alternativos . . . . . . . . . . . 35

3.4 Consultas . . . . . . . . . . . . . . . . . . . . 41

3.4.1 Consultas Baseadas apenas em Palavras . . . . . . . . . . . 42

3.4 .2 Consultas Booleanas . . . . . . . . . . . . . . 43

3.4.3 Consultas em Linguagem Natural . . . . . . . . . . . . . . . . 43

3.4.4 Consultas Baseadas na Estrutura dos Documentos . . . . . . . . . . . 44

3.4.5 Expansão de Consultas . . . . . . . . . . . . . . . 48

3.5 Avaliação Clássica de Sistemas de IR . . . . . . . . . . . . . . . . 52

3.5.1 Coleções de Referência . . . . . . . . . . . . . . 52

3.5 .2 Índice de Revocação . . . . . . . . . . . . . . . . . 53

3.5.3 Índice de Precisão . . . . . . . . . . . . . . . . . 53

3.6 Considerações Finais . . . . . . . . . . . . . . . . . . . 54

4 Análise do Domínio para Construção de Mecanismos de Criação Automática de

Ligações Hipertexto $\quad 56$

4.1 Considerações Iniciais . . . . . . . . . . . . . . . . . . . . . 56

4.2 Criação Automática de Ligações Lexicais . . . . . . . . . . . . . . . . . 57

4.2.1 Investigação do Domínio . . . . . . . . . . . . . . 57

4.2 .2 Trabalho Realizado . . . . . . . . . . . . . . . 58

4.2 .3 Resultados . . . . . . . . . . . . . . . . . 59

4.3 Criação Automática de Ligações Semânticas . . . . . . . . . . . . . . . 60

4.3 .1 Investigação do Domínio . . . . . . . . . . . . . . 60

4.3.2 Trabalho Realizado . . . . . . . . . . . . . . . . 60

4.3 .3 Resultados ......................... 63

4.4 Criação Automática de Ligações Semânticas em Repositórios Abertos . . . . 65

4.4 .1 Investigação do Domínio . . . . . . . . . . . . . . . . . 65

4.4.2 Trabalho Realizado . . . . . . . . . . . . . . . . . 65

4.4 .3 Resultados .......................... 68

4.5 Criação de Ligações com a Interação de Usuários . . . . . . . . . . . . . . 70

4.5.1 Investigação do Domínio . . . . . . . . . . . . . . . 70

4.5.2 Trabalho Realizado . . . . . . . . . . . . . . 70

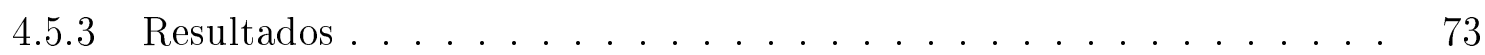


4.6 Criação Automática de Ligações entre Documentos Estruturados . . . . . . . 74

4.6 .1 Investigação do Domínio . . . . . . . . . . . . . . . . . 74

4.6.2 Trabalho Realizado . . . . . . . . . . . . . . 75

4.6 .3 Resultados . . . . . . . . . . . . . . . . 76

4.7 Criação Configurável de Ligações . . . . . . . . . . . . . . . . . 78

4.7 .1 Investigação do Domínio . . . . . . . . . . . . . . 78

4.7 .2 Trabalho Realizado . . . . . . . . . . . . . . . 79

4.8 Limitações dos Serviços de Criação Automática de Ligações . . . . . . . . . 83

4.9 Considerações Finais . . . . . . . . . . . . . . . . . . . . . . 84

5 Arcabouço para Criação Automática de Ligações Hipertexto entre Informações Homogêneas $\quad 87$

5.1 Considerações Iniciais . . . . . . . . . . . . . . . . . . . . . 87

5.2 Identificação de Pontos Fixos e de Flexibilização . . . . . . . . . . . . . 88

5.3 Terminologia . . . . . . . . . . . . . . . . . 89

5.4 Diagrama de Classes . . . . . . . . . . . . . . . . . . . . 90

5.5 Descrição das Classes . . . . . . . . . . . . . . . . . . . . 92

5.5 .1 Coleta de Informação . . . . . . . . . . . . . . . . . 92

5.5 .2 Pré-processamento da Informação . . . . . . . . . . . . . . . . 94

5.5.3 Identificação de Relacionamentos . . . . . . . . . . . . . . 95

5.5.4 Relação Semântica . . . . . . . . . . . . . . . . . 97

5.5 .5 Relação Lexical . . . . . . . . . . . . . . . . . . . . 98

5.5 .6 Armazenamento . . . . . . . . . . . . . . . 98

5.5 .7 Acesso . . . . . . . . . . . . . . . . . 99

5.5 .8 Operação de Consulta . . . . . . . . . . . . . . . 100

5.5 .9 RelevanceFeedback . . . . . . . . . . . . . . . . . 101

5.6 Considerações Finais . . . . . . . . . . . . . . . . . . . . 101

6 Casos de Uso do Arcabouço para Criação Automática de Ligações Hiper$\begin{array}{ll}\text { texto } & 104\end{array}$

6.1 Considerações Iniciais . . . . . . . . . . . . . . . . . . . . 104

6.2 Criação Automática de Ligações Compartilhadas para Navegação na Web . . 105

6.2.1 Investigação do Contexto de Sistemas de Recomendação de Informações105

6.2.2 Instanciação do Arcabouço CARe para um Sistema CSCW . . . . . . 105

6.2.3 Experimentação do Sistema CSCW Instanciado . . . . . . . . . . . . 112

6.3 Criação Automática de Ligações entre Informações Capturadas em Ambientes Ubíquos de Captura e Acesso . . . . . . . . . . . . . . . . . 116

6.3.1 Investigação do Contexto de Sistemas de Captura e Acesso . . . . . . 116

6.3.2 Instanciação do Arcabouço CARe para um Sistema Ubíquo de Captura e Acesso . . . . . . . . . . . . . . . . . . . . 117

6.4 Considerações Finais . . . . . . . . . . . . . . . . . . 124 


\section{Conclusão}

7.1 Resumo do Trabalho Realizado . . . . . . . . . . . . . . . . . 125

7.2 Contribuições . . . . . . . . . . . . . . . . . 126

7.3 Limitações . . . . . . . . . . . . . . . . . . . . . . 127

7.4 Trabalhos em Andamento . . . . . . . . . . . . . . . 127

7.5 Trabalhos Futuros . . . . . . . . . . . . . . . . 128

Referências 


\section{Lista de Figuras}

4.1 Infra-estrutura definida para ilustrar a geração automática de ligações baseadas nos conceitos de Análise da Semântica Latente (adaptada de (Macedo et al.

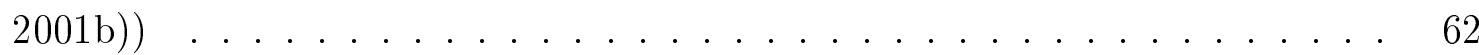

4.2 Ligações manuais (preto), ligações lexicais automáticas (branco) e ligações semânticas latentes automáticas (cinza), separadas nas 18 aulas de um curso de seminário capturado pelo eClass . . . . . . . . . . . . . . . . 64

4.3 Infra-estrutura para ilustrar os módulos do serviço aberto de criação automática de ligações semânticas (adaptada de (Macedo et al. 2002b)) . . 67

4.4 (a) Interface de ativação do LinkDigger e (b) Interface de resultados . . . . . 69

4.5 Infra-estrutura para geração de ligações semânticas entre repositórios Web com a participação do usuário por meio de relevance feedback (adaptada de (Macedo et al. 2002a) ) . . . . . . . . . . . . . . . .

4.6 Infra-estrutura para geração de ligações semânticas entre documentos estruturados . . . . . . . . . . . . . . . . . . . . 75

4.7 Interface de acesso às estruturas dos documentos . . . . . . . . . . . . 78

4.8 Infra-estrutura configurável para a geração automática de ligações Web . . . 80

4.9 Interface do LinkDigger para configuração dos parâmetros . . . . . . . . . . 82

5.1 Diagrama de Classes do arcabouço CARe para apoio à criação automática de ligações entre repositórios homogêneos de informações . . . . . . . . . . . . . 91 
6.1 Infra-estrutura do WebMemex: (a) comunicação entre o servidor proxy na Web e um navegador-cliente, (b) manutenção de autenticação de usuários, (c) comunicação para cada requisição HTTP, (d) inicialização do componente de captura (composto pelas classes ci e $p p$ do arcabouço CARe), (e) processamento do componente de criação de ligações, (f) componente de criação de ligações (classes ir e oc do CARe), (g) componente de armazenamento (classe ar do CARe), (h) inicialização do componente de acesso (classe ac do CARe), (i) lista de páginas Web similares aos documentos, (j) fluxo de execução de acesso (thread) para apresentar recomendações (adaptada de (Macedo et al.

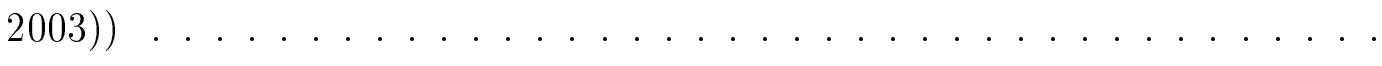

6.2 O protótipo do WebMemex. Interfaces de usuários para: (a) configuração do servidor proxy do WebMemex, (b) inicialização da sessão de navegação, (c) autenticação de usuários, (d) apresentação dos endereços de páginas Web relacionadas (adaptado de (Macedo et al. 2003)) . . . . . . . . . . . .

6.3 As ligações para as páginas Web sugeridas são apresentadas em uma pequena janela em primeiro plano - diferentes cores são utilizadas para indicar vários níveis de relevância. Nessa interface, usuários habilitam e desabilitam os componentes de captura e de acesso (adaptada (Macedo et al. 2003)) . . . . . .

6.4 Combinações das classes do arcabouço CARe são integradas em todas as fases de uma aplicação de captura e acesso . . . . . . . . . . . . . . . . . . 118

6.5 Criação de ligações hipertexto na fase de pré-produção permite a reutilização de informações através de sugestões de material do repositório manipulado, enquanto os autores preparam nova sessões. (a) Um vetor de consulta é criado com informações automaticamente extraídas de slides e metadados de sessões (título da sessão, por exemplo). (b) O vetor de consulta pode ser expandido com palavras-chave fornecidas por usuários. (c) O vetor de consulta é enviado à classe $i r$. (d) As ligações resultantes são apresentadas como recomendações na interface de preparação . . . . . . . . . . . . . . . . . . . .

6.6 Criação de ligações na fase de captura. Anotações eletrônicas capturadas a partir do componente de captura da lousa eletrônica são utilizadas para compor um vetor de consulta juntamente com textos extraídos automaticamente de slides pré-preparados. A ativação da consulta é realizadas por comandos de voz. As recomendações resultantes são apresentadas em uma janela em primeiro plano . . . . . . . . . . . . . . . .

6.7 Criação de ligações hipertexto na fase de acesso: (a) palavras-chave são fornecidas por usuários para serem utilizadas como um vetor de consulta; (b) o vetor de consulta é enviado à classe ir; (c) ligações semânticas são definidas entre o vetor de consulta e o material capturado. As ligações definidas são apresentadas na interface de acesso . . . . . . . . . . . . . . . 


\section{Lista de Tabelas}

3.1 Esquemas de atribuição de pesos . . . . . . . . . . . . . . 33

4.1 Mapeamento entre as classes do WLS e os objetos do SACALS (adaptada de (Macedo et al. 2002b)) . . . . . . . . . . . . . . 66 66

4.2 Informações obtidas a partir do experimento com LinkDigger considerando relevance feedback (adaptada de (Macedo et al. 2002a)) . . . . . . . . . . . . 74

6.1 Características dos dois experimentos com o WebMemex . . . . . . . . . 113

6.2 Informações do primeiro experimento com o WebMemex: (a) número de páginas Web recomendadas pelo sistema para cada usuário e (b) número de recomendações criadas para outros usuários a partir das páginas navegadas pelo usuário em questão . . . . . . . . . . . . . . . . . . . . . . . . 114

6.3 Informações do segundo experimento com o WebMemex: (a) número de páginas Web recomendadas pelo sistema para cada usuário e (b) número de recomendações criadas para outros usuários a partir das páginas navegadas pelo usuário em questão . . . . . . . . . . . . . . . . . . . . . 115 


\section{Declaração}

As seguintes publicações internacionais são oriundas do trabalho reportado nesta tese. Vale ressaltar que a Conferência ACM Hypertext and Hypermedia é a conferência mais importante da área da doutoranda.

Macedo, A. A., J. A. Camacho-Guerrero, R. G. Cattelan, V. R. Inácio Jr and M. G. C. Pimentel (2004c, August). Interaction alternatives for linking everyday presentations. In Proceedings of the ACM Conference on Hypertext and Hypermedia, Santa Cruz, CA, USA, $2 \mathrm{p}$ (to appear). ACM Press.

Camacho-Guerrero, J. A., A. A. Macedo and M. G. C. Pimentel (2004d, October). A look at some issues during textual linking of homogeneous Web repositories. In Proceedings of ACM Document Engineering, Milwaukee, Wisconsin, USA, 10p (to appear). ACM Press.

Macedo, A. A., K. N. Truong, J. A. Camacho-Guerrero, \& M. G. C. Pimentel (2003, August). Automatically sharing Web experiences through a hyperdocument recommender system. In Proceedings of the ACM Conference on Hypertext and Hypermedia, Nottingham, UK, pp. $48-56$. ACM Press.

Macedo, A. A., M. G. C. Pimentel, \& J. A. C. Guerrero (2002, June). An infrastructure for open latent semantic linking. In Proceedings of the ACM Conference on Hypertext and Hypermedia, College Park, Maryland, USA, pp. 107 - 116. ACM Press.

Macedo, A. A., M. G. C. Pimentel, \& J. A. C. Guerrero (2001, November). Latent semantic linking over homogeneous repositories. In Proceedings of the ACM Symposium on Document Engineering, Atlanta, GA, USA, pp. 144 - 151. ACM Press.

Pimentel, M. G. C., A. A. Macedo, \& G. D. Abowd (2001, April). Linking homogeneous Web-based repositories. In Proceedings of International Workshop on Information Integration on the Web, Rio de Janeiro, RJ, Brazil, pp. 35 - 42.

As seguintes publicações regionais e nacionais são oriundas do trabalho aqui reportado: 
Macedo, A. A., M. G. C. Pimentel (2003, November). Definição automática de ligaçõoes hipertexto entre informações homogêneas geradas por captura. In Anais do VIII WebMidia - Workshop de Teses e Dissertações, Salvador, BA,Brazil, pp. 581 - 584 .

Camacho-Guerrero, J. A., A. A. Macedo, \& R. P. M. Fortes (2002, October). Uma infraestrutura configurável para serviços de criação automática de ligações. In Anais do VIII Brazilian Symposium on Multimedia and Hypermedia System, Fortaleza, CE, Brazil, pp. $298-305$.

Macedo, A. A., J. A. Camacho-Guerrero, \& M. G. C. Pimentel (2002, November). Incluindo abordagens de recuperação de informação em serviços de criação de hiperligações. In XXVIII Conf. Latinoamericana de Informática, Montevideu, Uruguai.

Macedo, A. A., R. F. Bulcão Neto, M. G. C. Pimentel (2001, Setembro). Autoria Colaborativa na Web: Experiências e Reflexões sobre a CoWeb. Revista Brasileira de Informática na Educação (RBIE), N.9, 15p.

Além das publicações apresentadas, algumas publicações internas ao Instituto de Ciências Matemáticas e de Computação (ICMC) da USP de São Carlos foram:

Macedo, A. A., J. A. Camacho-Guerrero, R. G. Cattelan, V. R. Inácio Jr. and M. G. C. Pimentel (2004, Abril). Interaction Alternatives for linking everyday presentations. Relatório Técnico 230, Instituto de Ciências Matemáticas e de Computação da USP.

Macedo, A. A., L. A. Baldochi, J. A. Camacho-Guerrero, and M. G. C. Pimentel (2003, Setembro). Automatically linking live experiences captured through a ubiquitous infrastructure. Relatório Técnico 211, Instituto de Ciências Matemáticas e de Computação da USP.

Macedo, A. A., R. F. Bulcão Neto, M. G. C. Pimentel (2000, Outubro). Autoria Colaborativa na Web: Experiências e Reflexões. Relatório Técnico do ICMC/USP-São Carlos, N.123.

Além das publicações apresentadas, alguns artigos foram submetidos e aguardam avaliação:

Macedo, A. A., L. A. Baldochi Jr, J. A. Camacho-Guerrero and M. G. C. Pimentel (2004a). Automatically linking live experiences captured through a ubiquitous infrastructure. Submitted to Multimedia Tools and Applications (MTAP) Journal.

Macedo, A. A., J. A. Camacho-Guerrero and M. G. C. Pimentel (2004). A Bilingual Linking Service for the Web. Submitted to 6th ACM International Workshop on Web Information and Data Management (WIDM 2004), November 12-13, 2004, Washington, DC, USA, 10p. 


\section{Lista de Siglas e Abreviaturas}

ACM Association for Computing Machinery

API Application Programming Interface

AutorE Sistema aberto de Autoria Evolucionária de documentos

BD Banco de Dados

CACM Communication of the ACM

CARe Arcabouço para Criação Automática de Relacionamentos

CIIR Center for Intelligent Information Retrieval

CoWeb Collaborative Website

CF Cystic Fibrosis

CNN Cable News Network LP

CSCW Trabalho Cooperativo Suportado por Computador (do inglês Computer Supported Cooperative Work)

DARPA Defense Advanced Research Projects Agency

DCT Discrete Cosine Transformation

DNF Disjunctive Normal Form

DTD Document Type Definition

eClass Electronic Classroom (antigo Classroom 2000)

EDI Electronic Data Interchanged

FAQ Frequently Asked Questions 
GATECH Georgia Tech Institute

GNU General Public License

HDM Hypertext Design Model

HTML HyperText Markup Language

HTTP Hypertext Transfer Protocol

iClass Interactive Classroom

ID Identificadores de Usuários

IDF Freqüência Inversa do Documento (do inglês Inverse Document Frequency

IRF Information Retrieval Framework

INCA Infrastructure for Capture and Access

IR Recuperação de Informação (do inglês Information Retrieval)

iView Infra-estrutura de Visualização de Informação Evolucionária na Web

JSAPI Java Speech API

LW Projeto Lácio-Web

LSA Análise da Semântica Latente (do inglês Latent Semantic Analysis)

LSI Indexação da Semântica Latente (do inglês Latent Semantic Indexing)

MCA Modelo de Contextos Aninhados

NIST National Institute of Standards and Technology

NYP New York Post

NYT New York Times

OESP O Estado de São Paulo

OOHDM Oject-Oriented Hypermedia Design Method

OQL Object Query Language

OHP Open Hypermedia Protocol

OHS Open Hypermedia Systems

PHOAKS People Helping One Another Know Stuff 
RDF Resource Description Framework

RMM Relationship Management Methodology

SACAL Serviço Aberto de Criação Automática de Ligações

SERVE Infra-estrutura para Armazenamento, Recuperação, Visualização e Extensão de Informação Hipermídia Evolucionária

SCALDE Serviço de Criação Automática de Ligações entre Documentos Estruturados

SCALL Serviço de Criação Automática de Ligações Lexicais

SCALS Serviço de Criação Automática de Ligações

SCLIU Serviço de Criação de Ligações baseado em Interações de Usuários

SGML Standard Generalized Markup Language

SOM Self-Organizing Map

SQL Structured Query Language

SMIL Synchronized Multimedia Integration Language

SVD Decomposição de Valores Singulares (do inglês Singular Value Decomposition)

TIX Álgebra para consultas em texto XML (do inglês Text In XML)

TF Freqüência do Termo (do inglês Term Frequency)

TREC Text REtrieval Conference

URL Uniform Resource Locator

vizIR Framework for Visual Information Retrieval

W3C World Wide Web Consortium

WLS Web Linking Service

wView Infra-estrutura de apoio à geração automática de aplicações Web

xHTML Extensible HyperText Markup Language

xINCA Extended INCA

XML Extensible Markup Language

XML-QL A Query Language for XML

XPath A language for addressing parts of an XML document 
XPointer XML Pointer Language

XSLT Extensible Stylesheet Language Transformations

XQIRL An XML Query Language based on Information Retrieval concepts (Lê-se circle)

XQuery An XML Query Language

XMLSchema Esquema para definição de documentos XML

ZPRISE Z39 UNIX PRototype Indexing and Search Engines 


\title{
Resumo
}

\author{
Macedo, Alessandra A. (2004, Maio). Especificação, Instanciação e Experimentação de um \\ Arcabouço para Criação Automática de Ligações Hipertexto entre Informações Homogêneas. \\ Tese de Doutorado, Universidade de São Paulo, São Carlos - SP., Brasil
}

Com a evolução da informática, diferentes meios de comunicação passaram a explorar a Web como um meio de divulgação de suas informações. Diferentes fontes de informações, diferentes estilos de escrita e a curiosidade nata do ser humano despertam o interesse de leitores por conhecer mais de um relato sobre um mesmo tema. Para que a leitura de diferentes relatos com conteúdo similar seja possível, leitores precisam procurar, ler e analisar informações fornecidas por diferentes fontes de informação. Essa atividade, além de exigir grande investimento de tempo, sobrecarrega cognitivamente usuários. Faz parte das pesquisas da área de Hipermídia investigar mecanismos que apóiem usuários no processo de identificação de informações em repositórios homogêneos, sejam eles disponibilizados na Web ou não. No contexto desta tese, repositórios com informações de conteúdo homogêneo são aqueles cujas informações tratam do mesmo assunto. Esta tese tem por objetivo investigar a especificação, a instanciação e a experimentação de um arcabouço para apoiar a tarefa de criação automática de ligações hipertexto entre repositórios homogêneos. $\mathrm{O}$ arcabouço proposto, denominado CARe (Criação Automática de Relacionamentos), é representado por um conjunto de classes que realizam a coleta de informações a serem relacionadas e que processam essas informações para a geração de índices. Esses índices são relacionados e utilizados na criação automática de ligações hipertexto entre a informação original. A definição do arcabouço se deu após uma fase de análise de domínio na qual foram identificados requisitos e construídos componentes de software. Nessa fase, vários protótipos também foram construídos de modo iterativo. 


\title{
Abstract
}

\begin{abstract}
Macedo, Alessandra A. (2004, May). Especificação, Instanciação e Experimentação de um Arcabouço para Criação Automática de Ligações Hipertexto entre Informações Homogêneas. Doctor's Thesis, Universidade de São Paulo, São Carlos - SP., Brazil
\end{abstract}

With the evolution of the Internet, distinct communication media have focused on the Web as a channel of information publishing. An immediate consequence is an abundance of sources of information and writing styles in the Web. This effect, combining with the inherent curiosity of human beings, has led Web users to look for more than a single article about a same subject. To gain access to separate on a same subject, readers need to search, read and analyze information provided by different sources of information. Besides consuming a great amount of time, that activity imposes a cognitive overhead to users. Several hypermedia researches have investigated mechanisms for supporting users during the process of identifying information on homogeneous repositories, available or not on the Web. In this thesis, homogeneous repositories are those containing information that describes a same subject. This thesis aims at investigating the specification and the construction of a framework intended to support the task of automatic creation of hypertext links between homogeneous repositories. The framework proposed, called CARe (Automatic Creation of Relationships), is composed of a set of classes, methods and relationships that gather information to be related, and also process that information for generating an index. Those indexes are related and used in the automatic creation of hypertext links among distinct excerpts of original information. The framework was defined based on a phase of domain analysis in which requirements were identified and software components were built. In that same phase several prototypes were developed in an iterative prototyping. 


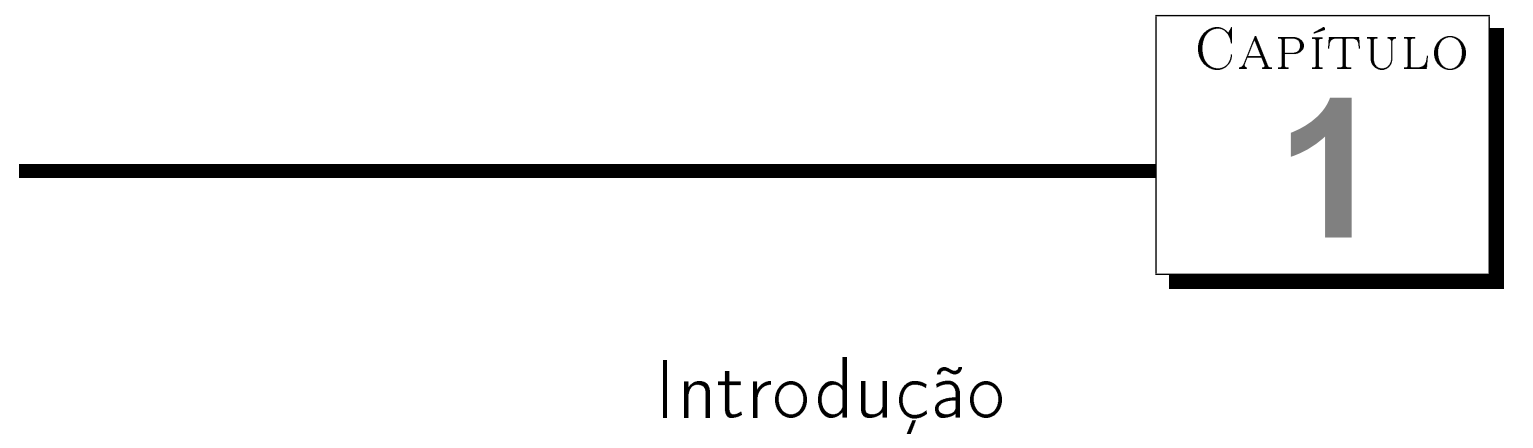

Com a evolução da informática e de suas tecnologias, diferentes meios de comunicação tais como jornais, revistas e televisão, e diferentes categorias de instituições tais como instituições governamentais e de ensino, passaram a explorar a Web como um meio de divulgação de suas informações. Nesse contexto tecnológico, mídias digitais armazenam informações relativas a pesquisas, fatos ou acontecimentos relatados diariamente.

Fontes diferentes de informação, estilos diferentes de escrita e a curiosidade nata do ser humano despertam o interesse de leitores por conhecer mais de um relato sobre um mesmo tema. No contexto de pesquisas científicas, por exemplo, a identificação de trabalhos relacionados é condição necessária para o desenvolvimento do trabalho. Para que a leitura de diferentes relatos com conteúdo similar seja possível, leitores precisam procurar, ler e analisar informações fornecidas por diferentes fontes de informação. Essa atividade, além de exigir grande investimento de tempo, sobrecarrega cognitivamente usuários que dedicam atenção tanto à informação lida quanto à trilha percorrida.

A leitura de documentos hipermídia ${ }^{1}$ na Web evidencia a sobrecarga cognitiva à qual usuários estão expostos durante a busca por documentos com conteúdo similar. Isso se deve à rede de interconexões entre informações que devem estar facilmente acessíveis para os usuários. Essa rede de informações compõe um hiperdocumento, sendo os "nós", as unidades de informação, e as "ligações hipertexto", as interconexões entre eles.

Pesquisadores de Hipermídia investigam mecanismos para criar (Price et al. 1998)(Pimentel et al. 2000) (Bulcão Neto et al. 2002), modelar (Halasz \& Schwartz 1994) (Soares et al. 2000) (Romero \& Correia 2003), identificar (Fortes 1996) (Macedo et al. 2002b) (Calado et al. 2003b), estender (Muchaluat-Saade et al. 2002) (Macedo et al. 2003), armazenar (Grønbæk \& Trigg 1994) (Grønbæk \& Trigg 1996) e apresentar (Johnson 1992) (Hearst

\footnotetext{
${ }^{1}$ Nesta tese, os termos documento hipermídia, hiperdocumento e hipertexto serão utilizados como sinônimos; ver Glossário.
} 
1999) (Synchronized Multimedia Working Group 2004) hiperdocumentos. Por exemplo, os processos de modelagem de hiperdocumentos envolvem a demanda por mapear o processo de manipulação de objetos do mundo real em correspondentes documentos digitais, os quais naturalmente possuem referências implícitas ou explícitas entre eles (Grønbæk et al. 2003). Além de pesquisadores de hipermídia, suportar a identificação de relacionamentos entre as informações de hiperdocumentos é um desafio para pesquisadores de diferentes áreas.

Pesquisadores de Recuperação de Informação (Information Retrieval - IR) investigam tecnologias para coleta, representação, indexação, recuperação e classificação de grandes coleções de informação. Com a evolução da área, pesquisadores de IR têm proposto diferentes maneiras de representar o relacionamento entre informações de conteúdo de documentos (Salton \& Lesk 1968) (Salton et al. 1983) (Furnas et al. 1988) (Dupret 2003). Outros buscam definir maneiras de representar o relacionamento entre documentos, explorando características da estrutura dos documentos (Fortes 1996) (Brin \& Page 1998) (Kleinberg 1999) (Henzinger et al. 1999) (Kleinberg 2000) (Calado et al. 2003c).

Alguns pesquisadores de hipermídia têm explorado técnicas de IR na definição de relacionamentos entre informações textuais (Green 1999) (El-Beltagy et al. 2001) (Paganelli \& Mounier 2003). A utilização de resultados de IR para definir ligações hipertexto entre documentos explora o fato de que pesquisas em IR propõem mecanismos para gerenciamento e recuperação de informações baseadas em conteúdo. Por exemplo, a definição de ligações que conectam semanticamente fragmentos de documentos é uma área de pesquisa desafiadora para pesquisadores de hipermídia e, portanto, é natural explorar técnicas de IR que definem a co-ocorrência de termos em documentos digitais.

\subsection{Problema}

Cada vez mais, provedores de informação organizam o conteúdo a ser disponibilizado como documentos Web que contêm informações textuais, ligações e outros tipos de mídia. A diversidade existente em termos da estruturação do conjunto de documentos, bem como da estruturação do conteúdo de cada documento, demanda esforço cognitivo por parte dos usuários. Outros fatores que sobrecarregam a tarefa dos usuários incluem a volatilidade e a grande quantidade de informações disponibilizadas na Web.

No contexto desta tese, repositórios com informações de conteúdo homogêneo são aqueles cuja informações tratam do mesmo assunto. Por exemplo, dois jornais diferentes publicam seções sobre esportes, cultura e política: as informações sobre esportes dos dois jornais tratam de conteúdo similar, apesar de estarem em repositórios diferentes — o mesmo acontecendo para informações dos demais cadernos dos dois jornais.

Um cenário que destaca fatores complicadores da identificação de informações relacionadas na Web é a leitura que assinantes de jornais on-line realizam diariamente. Para obter diferentes visões de uma mesma notícia, leitores acessam diferentes provedores, lêem os documentos que lhes interessam e os relacionam mentalmente - tarefas que demandam 
atenção ao conteúdo lido e ao caminho percorrido. Essas tarefas são ainda dificultadas pela quantidade de informações disponibilizadas e pelos diversos estilos de estruturação e de apresentação utilizados.

Faz parte das pesquisas da área de Hipermídia investigar mecanismos que apóiem usuários no processo de identificação de relacionamentos entre informações contidas em repositórios homogêneos, sejam eles disponibilizados na Web ou não (Green 1999) (Pimentel et al. 2001b)(Macedo et al. 2001b) (El-Beltagy et al. 2001) (Paganelli \& Mounier 2003). Esta tese trata do problema de identificar automaticamente relacionamentos entre informações armazenadas em repositórios homogêneos.

\subsection{Objetivo}

Esta tese tem por objetivo investigar a especificação, a instanciação e a experimentação de um arcabouço para apoiar a tarefa de criação automática de ligações hipertexto entre repositórios homogêneos.

O uso do conceito de arcabouço demandou a definição de estruturas de projeto (classes, métodos, relacionamentos e diagramas) e a implementação de classes e métodos a serem reutilizados por aplicações que tenham o mesmo objetivo.

O arcabouço proposto, denominado CARe (Criação Automática de Relacionamentos), é representado por um conjunto de classes, métodos e relacionamentos que realizam a coleta de informações a serem relacionadas e que processam essas informações para a geração de termos de índice. Esses termos de índice são relacionados e utilizados na criação automática de ligações hipertexto entre a informação original.

A definição do arcabouço se deu após uma fase de análise de domínio na qual foram identificados os requisitos e construídos componentes de software. Nessa fase, vários protótipos também foram construídos de modo iterativo.

\subsection{Trabalho Realizado}

A partir de pesquisas sobre técnicas de IR de indexação semântica, foi escolhida a técnica de Análise da Semântica Latente (Latent Semantic Analysis - LSA) para apoiar a definição de ligações hipertexto entre repositórios Web contendo informações homogêneas. A principal razão pela escolha dessa técnica é o fato de que ela é uma alternativa para os problemas de dependência de vocabulário associados a técnicas baseadas em comparações lexicais. Simples comparações lexicais podem omitir relacionamentos entre termos devido à variabilidade de palavras para descrever um mesmo objeto (sinonímia), ou mesmo, definir relacionamentos equivocados devido à utilização de uma mesma palavra para nomear diferentes objetos (polissemia).

Como um dos primeiros trabalhos, foi definido um serviço de criação automática de ligações hipertexto utilizando a técnica de LSA (Macedo et al. 2001b). Esse trabalho foi 
estendido com a definição de módulos que facilitam o armazenamento dos relacionamentos criados, inclusive permitindo o uso de bibliotecas de ligações (Macedo et al. 2002b). Para permitir a participação explícita de usuários no processo de definição de ligações hipertexto entre coleções similares, foram definidos módulos de consulta e de retroalimentação (feedback) de usuários (Macedo et al. 2002a). A cada extensão dos serviços de criação de ligações hipertexto, os módulos de programa desses serviços eram formalizados como APIs (Application Programming Interfaces) para facilitar o intercâmbio de funcionalidades. Com esse processo iterativo e evolucionário, esses módulos eram cada vez mais generalizados e se aproximavam das classes e métodos do arcabouço proposto no contexto desta tese.

Investigadas, especificadas e implementadas as classes definidas, as mesmas foram experimentadas considerando as funcionalidades e os requisitos definidos para os serviços de criação de ligações hipertexto. O objetivo era verificar se esses componentes do arcabouço podiam ser reutilizados em outros sistemas de modo a fornecer funcionalidades antes não suportadas pelos mesmos. Assim foi para o caso de um sistema CSCW de Recomendação de Informações, o WebMemex. Os módulos do arcabouço CARe correspondentes às classes de coleta de informações, de pré-processamento de informações, de definição de ligações, de consulta, de armazenamento e de acesso foram acoplados ao WebMemex que captura páginas navegadas na Web por grupos de usuário explicitamente formados para compartilhar informações (Macedo et al. 2003). Antes dessa integração, esse sistema coletava apenas meta-informação de páginas HTML, comparava lexicamente o conteúdo dessas informações para fornecer recomendações aos seus usuários. Esse tipo de atitude implicava na geração de poucas recomendações. Após a reutilização dos componentes do arcabouço por essa aplicação CSCW, todo o conteúdo de diferentes tipos de documentos Web visitados é coletado para a criação de ligações lexicais e semânticas. Os relacionamentos obtidos são armazenados em uma biblioteca de ligações, que pode ser explorada por outras aplicações.

No contexto de um ambiente de captura automática ${ }^{2}$ de experiências em sala de aula, foram estudadas maneiras de se reutilizar os módulos do arcabouço CARe para fornecer sugestões de informações já capturadas e relacionadas à atividade em andamento (Macedo et al. 2004a) (Macedo et al. 2004b). Nesse trabalho foram utilizados os módulos de coleta de informações, de pré-processamento dessas informações, de definição de relacionamentos semânticos e lexicais, de consultas, de armazenamento e de acesso dos resultados. Nas duas experimentações foram utilizados os mesmos módulos do arcabouço CARe devido ao domínio das aplicações. Tanto o sistema WebMemex como o ambiente de captura objetivavam definir relacionamentos entre documentos para oferecê-los como sugestões aos seus usuários. Por esse motivo, por exemplo, a classe de consulta está sendo utilizada para enviar as informações das atividades em andamento para serem comparadas com as informações armazenadas no sistema. No caso de uma aplicação que pretende definir relacionamentos entre o conteúdo de seus repositórios, essa classe consulta pode não ser necessária, uma vez que o conteúdo de

\footnotetext{
${ }^{2}$ Utilizando conceitos de computação ubíqua como - interação de usuários com dispositivos computacionais de modo transparente como, por exemplo, via lousa eletrônica.
} 
um repositório pode ser utilizado como pseudo-consultas sobre os ouros repositórios. Essa análise deixa claro que a classe consulta é um ponto de flexibilização do arcabouço CARe.

Nas duas oportunidades de utilização dos componentes de software, foram verificadas as vantagens de abstrair os módulos e as APIs para que pudessem ser reutilizados em outras aplicações. Como resultado, os módulos e as APIs construídos foram formalizados como o arcabouço CARe, principal contribuição desta tese.

\subsection{Contribuições}

As principais contribuições desta tese são a especificação, a instanciação e a experimentação do arcabouço CARe. Esse arcabouço oferece um conjunto de classes a serem combinadas e reutilizadas com o intuito de definir automaticamente relacionamentos entre informações homogêneas. Desse modo, projetistas e desenvolvedores de aplicações podem articular o conjunto de classes proposto no arcabouço e determinar quais desses componentes são necessários para o sistema alcançar os seus objetivos. Como resultado, o arcabouço oferece aos desenvolvedores de aplicações uma maneira poderosa de aumentar a reutilização de componentes de software abstraídos, uma vez que inúmeras aplicações podem ser criadas por meio de sua instanciação. Além disso, esses componentes podem ser utilizados de modo independente, proporcionando aos desenvolvedores a oportunidade de construir diferentes aplicações realizando combinações distintas dos componentes.

Outras contribuições decorrentes do arcabouço CARe são:

- a disponibilização de classes especificadas, formalizadas como APIs e implementadas em cada fase do desenvolvimento do arcabouço;

- a verificação da possibilidade de recomendação usando a criação de relacionamentos durante a navegação de grupos colaborativos na Web;

- a verificação da possibilidade de realização de recomendações usando a criação de relacionamentos em aplicações ubíquas de captura e acesso;

- disponibilização dos repositórios manipulados para os experimentos.

É importante mencionar que os trabalhos apresentados nesta tese contam com a participação de componentes de software desenvolvidos por outros pesquisadores como, por exemplo, a biblioteca de ligações do WLS (Bulcão Neto et al. 2002), o ambiente iClass (Cattelan et al. 2003) e o projeto inicial do WebMemex de Khai Truong (Macedo et al. 2003). Também foram utilizados resultados de pesquisas de terceiros, tais como a técnica de LSA (Furnas et al. 1988) e investigações de alternativas para melhoria da precisão dos serviços de criação de ligações (Camacho-Guerrero 2002). Finalmente, nas experimentações dos serviços foram utilizadas várias fontes de informação de diferentes instituições como, por exemplo, jornais eletrônicos (O Estado de São Paulo, The New York Post, The New York Times e CNN), a coleção Lácio-Ref do Projeto Lácio-Web disponibilizada no ICMC-USP, a 
coleção de referência da base de dados MEDLINE da National Library of Medicine (Shaw et al. 1991) e os repositórios de informações educacionais do eClass (Abowd 1999) e da CoWeb (Guzdial 1999).

\subsection{Limitações}

Algumas limitações do trabalho proposto nesta tese são:

- uso de técnicas e de pacotes de software específicos. Essas técnicas e pacotes foram escolhidos durante a especificação do arcabouço CARe. Apesar da flexibilidade das classes do arcabouço proposto, elas são compostas por um conjunto específico de métodos. Por exemplo, a classe de identificação de relacionamentos semânticos poderia usar outra técnica para determinar similaridades semânticas além da técnica de LSA (Furnas et al. 1988); limitações decorrentes de limitações das técnicas e pacotes utilizados. Os componentes do arcabouço CARe podem apresentar limitações decorrentes das abordagens e das ferramentas utilizadas como, por exemplo, as limitações do pacote de software para armazenamento de ligações hipertexto em bibliotecas de ligações, o WLS (Bulcão Neto et al. 2002);

- especificidades e limitações decorrentes de outras decisões de projeto como, por exemplo, em relação à determinação da granulosidade de cada componente do arcabouço CARe. Outra importante decisão de projeto foi a definição dos pontos de flexibilidade e dos pontos fixos do arcabouço CARe, uma vez que todas as classes do CARe possuem parâmetros e conseqüentemente métodos flexíveis apesar de algumas delas serem fixas para qualquer aplicação que reutilizá-las;

- um ponto não coberto pela proposta é o uso de linguagens de padrões para desenvolver um sistema com padrões de análise e de projeto. Esse tipo de abordagem poderia trazer mais flexibilidade ao arcabouço proposto quanto a esses aspectos de desenvolvimento de sistemas e também poderia guiar as tomadas de decisões de projeto. Essa limitação poderá ser tratada em trabalhos futuros.

As limitações são detalhadas no Capítulo 7 da tese.

\subsection{Organização do Texto}

Esta tese está organizada como segue. No Capítulo 2 são apresentados trabalhos que exploram a definição de relacionamentos entre informações e que envolvem pesquisas de Hipermídia, tecnologias Web, Recuperação de Informação, Sistemas CSCW de Recomendação de Informações e Ambientes de Captura Ubíqua. Esses relacionamentos podem ser apresentados como ligações hipertexto sejam eles gerados pela sincronização de informações capturadas, ou 
mesmo pela análise textual e estrutural das mesmas. Tais trabalhos fundamentam a pesquisa descrita nesta tese, como investigações que auxiliam usuários na busca por informações.

No Capítulo 3 são apresentados conceitos fundamentais de Recuperação de Informação com foco na representação e na busca de informações em documentos textuais. Pesquisas em Recuperação de Informação auxiliaram na definição das classes e de componentes do arcabouço CARe proposto nesta tese.

No Capítulo 4 é apresentado o processo de criação de diferentes componentes de software relacionados à análise do domínio e à construção de mecanismos de criação automática de ligações hipertexto. Foi por meio da abstração desses componentes que foram definidas as classes e os relacionamentos do arcabouço proposto.

No Capítulo 5 é apresentado o arcabouço de apoio à criação de aplicações que objetivam definir, automaticamente, relacionamentos entre informações homogêneas.

No Capítulo 6 são apresentadas duas aplicações que instanciaram classes do arcabouço proposto com o intuito de definir relacionamentos entre informações homogêneas. A primeira aplicação, WebMemex, utilizou classes do arcabouço para construir mecanismos que apóiam a definição de relacionamentos semânticos e lexicais entre informações capturadas a partir da navegação de grupos de usuários na Web. Esses relacionamentos foram utilizados como sugestões pela sistema de recomendações de informações WebMemex. Em uma segunda oportunidade, classes do arcabouço proposto foram utilizadas para definir relacionamentos entre informações capturadas pelo iClass, uma infra-estrutura de apoio à captura de informações que utiliza conceitos de computação ubíqua.

No Capítulo 7 são apresentadas as conclusões sobre as pesquisas e propostas apresentadas nesta tese. Também são apresentados trabalhos futuros que podem ser realizados a partir dos resultados aqui reportados. 


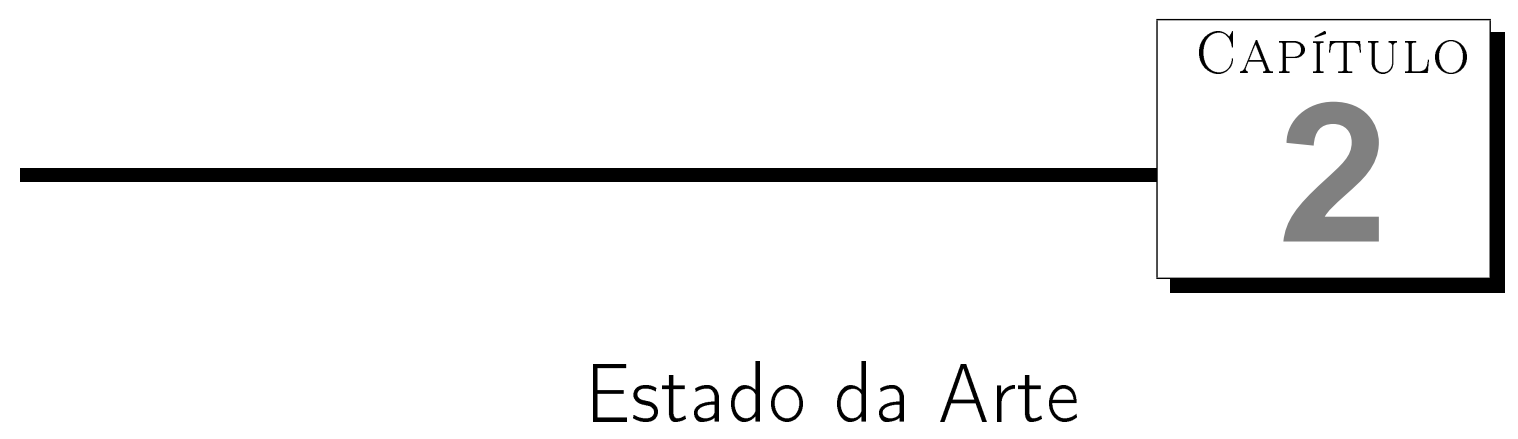

\subsection{Considerações Iniciais}

No final da década de 60, surgiram os primeiros catálogos bibliográficos on-line que, em alguns minutos, permitiam a recuperação de informações armazenadas. Para manusear informações, o usuário manipulava um ambiente de consulta utilizando um conjunto controlado de operações e linguagens pré-definidas. Naquela época, os computadores tinham baixo poder de processamento sobre grandes quantidades de informações. Entre os anos de 1970 e 1980, o tamanho das coleções de informações armazenadas e manipuladas pelos computadores cresceu de centenas para milhares de megabytes de informações. Finalmente, na década de 90, grande quantidade de informações estava disponível devido à popularização da Web; é difícil mensurar essa quantidade devido à natureza dinâmica da Web.

Para acompanhar o crescimento do volume de informação disponível, indústrias trabalham no desenvolvimento de máquinas com maior capacidade de armazenamento e de processamento. Paralelamente, pesquisadores de diferentes áreas da computação concentram esforços no desenvolvimento de mecanismos que promovam recuperação, integração das informações armazenadas e apresentação das mesmas.

Neste capítulo são apresentados trabalhos que exploram a definição de relacionamentos entre informações e que envolvam pesquisas de Hipermídia, Recuperação de Informação (Information Retrieval - IR), Sistemas CSCW (Computer Supported Cooperative Work CSCW) do tipo Sistemas de Recomendação de Informações, Ambientes de Captura Ubíqua e tecnologias Web. Esses relacionamentos entre informações podem ser apresentados como ligações hipertexto sejam eles gerados pela sincronização de informações capturadas em uma experiência ao vivo ou mesmo pela análise textual e estrutural das mesmas.

Os trabalhos apresentados motivam a pesquisa descrita nesta tese no sentido de buscar 
soluções na literatura para propor maneiras de auxiliar usuários na busca por informações relacionadas. Pretende-se utilizar o inter-relacionamento dessas áreas de pesquisa para aprofundar a contextualização do trabalho apresentado.

\subsection{Criação de Ligações Hipertexto a partir de Técnicas de Recupe- ração de Informação}

Recuperação de Informação (IR) é uma área dedicada a pesquisas de mecanismos para manipulação de coleções de informação em distintos formatos de apresentação. Algumas técnicas de IR exploram estatísticas de ocorrências de palavras-chave para definir termos de índice que representam os documentos da coleção. Após a indexação, comparações textuais podem revelar similaridades entre documentos que podem ser apresentadas como ligações hipertexto. Trabalhos nessa linha de pesquisa são apresentados na Seção 2.2.1.

Uma alternativa complementar à recuperação de informação explorando comparações textuais consiste em analisar os relacionamentos entre documentos com o intuito de classificar e recuperar documentos. Esses relacionamentos podem ser referências, citações bibliográficas em documentos tradicionais ou ligações hipertexto em hiperdocumentos. Pesquisadores de IR sugerem a utilização combinada de análise textual e análise de ligações para recuperar documentos. Esses trabalhos são apresentados na Seção 2.2.2.

\subsubsection{Análise Textual para Criação de Ligações Hipertexto}

Agosti \& Crestani (1993) apresentaram uma metodologia para modelagem, projeto e criação automática de hiperdocumentos a partir de informações recuperadas em sistemas clássicos de IR. Essa abordagem foi utilizada na conversão de uma coleção de documentos do tipo referências bibliográficas, resumos, e artigos completos de periódicos no formato textual linear para hiperdocumentos. Esses pesquisadores perceberam que para converter diferentes tipos de documentos seriam necessárias diferentes técnicas automáticas de transformação. No mesmo ano, Salton \& Allan apresentaram um estudo sobre métodos de comparação textual para identificar similaridades e definir operações de verificação de contexto para resolver ambigüidades bem como distinguir textos similares (Salton \& Allan 1993). Essa abordagem deu origem à criação de ligações entre coleções com conteúdo homogêneo. Posteriormente, Allan apresentou métodos para definição automática de ligações de informações relacionadas e descreveu um processo automático de atribuição de tipos a ligações (Allan 1996). Esse processamento automático dificultaria a manipulação de grandes e diversificadas coleções de informações. Uma alternativa para esse problema seria permitir que usuários atribuíssem tipos a conjuntos de ligações.

O sistema VOIR permitia que usuários realizassem buscas baseadas na definição de consultas e em interações com usuários (Golovchinsky 1997). As consultas recuperavam documentos com similaridades baseadas em comparações lexicais de informações. O sistema 
VOIR suportava recuperação interativa de informações aplicando técnicas de IR em estrutura hipermídia. Com o intuito de estender a definição de consultas baseadas na escrita de palavras-chave, outros pesquisadores propuseram a criação automática de ligações a partir de anotações de usuários durante a leitura de documentos em computadores portáteis do tipo tablet (Price et al. 1998). Uma das desvantagens da proposta de (Price et al. 1998) era o fato do sistema implementado, XLibris, prover apenas anotação em documentos armazenados localmente.

Explorando relações semânticas entre conteúdo textual em vez de apenas simples comparações lexicais, Green (1999) propôs a geração automática de hiperdocumentos pelo método de encadeamento lexical (lexical chaining). Esse método explora o descobrimento de seqüências de palavras relacionadas em um documento na tentativa de contornar problemas de sinonímia e polissemia, pois grande parte dos sistemas de geração automática de hipertextos é apoiada pela repetição de termos para calcular a relação dos documentos. Na mesma época, Tudhope \& Cunliffe (1999) apresentaram um estudo que questionava a possível relação entre palavras usando lexical chaining e a aproximação semântica definida pelo método, principalmente porque a proposta de Green (1999) era dependente de um único dicionário de sinônimos, o WordNet (Miller 1990). Outro problema do uso de dicionários como o WordNet é o fato deles não conterem categorias de palavras do tipo nomes próprios. Esse tipo de termo pode ser muito importante para representar documentos no método de encadeamento lexical.

Em 2001, Wacholder et al. (2001) apresentaram a ferramenta LinkIT para identificar tópicos significantes (índices) em informações textuais. Essa identificação ocorria por meio de análises textuais que incluíam informações de contexto na análise estatística de cálculo de freqüência de palavras-chave. Os índices identificados eram apresentados em um navegador Web que podia ser dinamicamente alterado pela mudança de contexto. Nesse trabalho, Wacholder et al. (2001) ressaltaram a boa qualidade dos índices gerados automaticamente, mas não propuseram uma aplicação prática do trabalho desenvolvido. Em outra pesquisa sobre abordagem adaptativa de criação de índices, El-Beltagy et al. (2001) definiram formas de geração adaptativa de ligações hipertexto a partir das necessidades de informação de usuários e do contexto definido em buscas anteriores de usuários. Esse processo dinâmico de geração de hiperdocumentos integrava uma arquitetura baseada em multi-agentes com conceitos de sistemas hipermídia abertos, e explorava similaridades semânticas em índices definidos por um modelo vetorial estendido por palavras-chave extraídas a partir de páginas Web visitadas por usuários. Nesse trabalho, El-Beltagy et al. (2001) não trataram de aspectos de privacidade e também não definiram convenções sociais para a captura do conteúdo das páginas navegadas por usuários.

Analisando aspectos cognitivos da informação transmitida via hiperdocumentos, Storrer (2002) defendeu a coerência como característica essencial de textos lineares e de hiperdocumentos. Esse estudo propôs que antes da geração de hiperdocumentos haja uma análise detalhada da estrutura do conteúdo a ser manipulado. Essa estrutura pode ser capturada 
em hierarquias de tópicos que podem ser transformadas em nós. Assim, usuários podem interagir com mapas de tópicos a fim de selecionar as informações que desejam conhecer. Para facilitar a geração de documentos hipertexto com conteúdo coerente, Storrer (2002) ainda defendeu a exploração de roteiros-guiados seguindo uma análise detalhada dos tópicos que contêm pré-requisitos de conhecimento para entender outros tópicos. Devido a essa análise cuidadosa da informação a ser transformada em nós e ligações hipertexto, Storrer (2002) não é favorável à geração automática de hiperdocumentos. Esse pesquisador acredita que a Web semântica possa apoiar usuários durante a construção de hiperdocumentos mais coerentes.

Halkidi et al. (2003) propuseram um sistema que considera o conteúdo de páginas Web de um conjunto-treinamento e o conteúdo de páginas relacionadas por ligações hipertexto à página em análise para definir ontologias que suportam a classificação dos documentos de treinamento. Finalizado o treinamento, o classificador definido pode ser utilizado em páginas Web. Esses pesquisadores propuseram o uso de informações de relacionamentos entre informações para auxiliar no treinamento do classificador.

Em uma abordagem diferente de definir classes, Paganelli \& Mounier (2003) propuseram um método de categorização de consultas de usuários e de unidades de informação (ex. parágrafos e entidades) para aprimorar a relevância da informação recuperada. Esses pesquisadores consideraram que a manipulação de consultas e de unidades de informação de mesma categoria favorecem a precisão dos resultados de sistemas de recuperação de informações. Além disso, também sugeriam a análise textual da informação contida nas consultas e nas unidades de informação para categorizá-las em Object e Pro, respectivamente, categoria de descrição de objetos e categoria de descrição procedural. Uma das grandes desvantagens da proposta de Paganelli \& Mounier (2003) é a dificuldade de categorizar automaticamente consultas de usuários, uma vez que muitas vezes elas podem ser compostas por alguns poucos termos. Outra desvantagem dessa abordagem é o fato do categorizador desenvolvido por Paganelli \& Mounier (2003) ser específico para o idioma francês.

\subsubsection{Análise de Estrutura de Relacionamentos entre Documentos para Recupe- ração de Informação}

Em 1973, Small (1973) propôs um método para quantificar a freqüência de relacionamentos de citações entre documentos. Essa pesquisa foi restrita ao ambiente científico literário. Posteriormente, outras medidas foram propostas por outros pesquisadores de IR (Kleinberg 1999) (Henzinger et al. 1999).

Brin \& Page (1998) propuseram um algoritmo, denominado PageRank, que utiliza a estrutura das ligações hipertexto na Web para inferir uma medida de popularidade para páginas Web. Um página é recursivamente definida como popular quando ela estiver relacionada com muitas outras páginas populares. Kleinberg (1999) propôs o algoritmo HITS no qual páginas assumem duas funções distintas: $h u b$ e authority. Uma boa página $h u b$ se relaciona com muitas páginas authority. Similarmente, uma boa página authority é relacionada por 
muitas páginas $h u b$ boas.

Outros pesquisadores definiram formas de utilizar informações dos hiperdocumentos da Web para encontrar e analisar relacionamentos entre páginas (Henzinger et al. 1999) (Henzinger 2001). Uma medida simples para classificar páginas Web é utilizar o número de páginas que referenciam cada página. Um aprimoramento qualitativo dessa medida sugere que não seja considerado apenas o número de páginas que referenciam uma determinada página, mas também a probabilidades de navegação de usuários em páginas Web (Henzinger et al. 1999). A aplicação Web Google ${ }^{1}$ utiliza informações da estrutura das ligações hipertexto na análise dos documentos manipulados (Henzinger 2001).

Com o intuito de combinar análise de estrutura com análise textual de documentos de coleções, Sugiyama et al. (2003) propuseram métodos para refinar representações de documentos baseadas em esquemas estatísticos de atribuição de pesos baseados em freqüência de palavras-chave. Os métodos propostos utilizam informações sobre a estrutura de ligações de documentos em diferentes níveis de hierarquia considerando as páginas vizinhas à página representada. Mais focados na apresentação das informações de estrutura, Weideman \& Kritzinger (2003) compararam a utilização de mapas de conceitos (concept mapping) e de listas de páginas Web com ligações hipertexto para organizar informações recuperadas por sistemas de IR. Esses pesquisadores verificaram em seus experimentos que estudantes de pós-graduação preferem manipular mapas de conceitos em vez de listas de páginas Web relacionadas ao conteúdo buscado.

A proposta de Kleinberg (1999) tinha a desvantagem de ser restrita aos documentos resultantes de buscas por consulta e aos documentos relacionados aos documentos retornados. Por outro lado, Brin \& Page (1998) propuseram um algoritmo aplicado a todos os documentos da coleção, porém esse algoritmo não era capaz de distinguir quais documentos eram os resultantes das buscas. Em vez de combinar a análise de estrutura de documentos da coleção com documentos resultantes, Sugiyama et al. (2003) combinaram informações de estrutura com informações de conteúdo para classificação de informações em mapas de conceitos. Esses pesquisadores não obtiveram bons resultados para sua abordagem, mas examinaram as diferenças de comportamentos entre usuários em relação as diferentes metáforas utilizadas para a apresentação dos relacionamentos definidos.

No Brasil, da Silva et al. (1999) expuseram outra proposta de combinar análise estrutural e de conteúdo. Eles exploraram um robô de coleta de páginas chamado CoBWeb para indexar e classificar uma coleção de páginas Web segundo os seguintes esquemas de atribuição de pesos aos documentos: (a) conteúdo da página Web, (b) grau de hub, (c) grau de authority, (d) conteúdo e grau de hub, (e) conteúdo e grau de authority e (f) conteúdo e grau de hub e de authority. Depois de classificadas, essas páginas foram recuperadas a partir de consultas retiradas da FAQ (Frequently Asked Questions) de uma ferramenta de buscas brasileira ${ }^{2}$. As consultas utilizadas eram pertinentes à coleção de treinamento inicialmente classificada.

\footnotetext{
${ }^{1}$ http://www.google.com

${ }^{2}$ http://www.todobr.com.br
} 
Os resultados desse experimento indicaram a superioridade do esquema de atribuição de pesos baseado em conteúdo seguido pelo esquema de estrutura hub. Os resultados para os esquemas combinados indicaram que a técnica combinada de conteúdo, hub e authority obteve resultados superiores se comparada às outras combinações de técnicas. Esse resultado apóia a utilização de estratégias combinadas (análise textual e análise das estruturas de ligações) de busca e classificação de informação. Esse experimento reafirma a constatação de Croft \& Turtle (1989) que sugeriram a utilização de combinações de análise textual e análise de ligações para estender o conjunto de documentos recuperados.

Silva et al. (2000) reutilizaram as definições de Kleinberg para páginas hub e authority e apresentaram um modelo para recuperação de hiperdocumentos baseado em redes bayesianas. As redes bayesianas foram utilizadas para representar, quantificar e combinar evidências no momento de classificar documentos representados por grafos dirigidos. Essa pesquisa se destaca devido ao tratamento formal aplicado à questão de análise da estrutura de ligações e aos resultados, considerados satisfatórios (Silva et al. 2000).

Em outras pesquisas no Brasil, Pereira Jr \& Ziviani (2003) compararam métodos de deteç̧ão de similaridade sintática de documentos com o intuito de identificar cópias de conteúdo. Os métodos comparados utilizam a estrutura dos documentos para identificar cópias de conteúdo.

Calado et al. (2003b) apresentaram um ambiente chamado Web-DL, que permite a composição de bibliotecas digitais a partir do reconhecimentos de padrões de estrutura e organização de informações Web. A arquitetura do sistema Web-DL é composta por protocolos padrão de comunicação via Web, mecanismos de IR, ferramentas de extração e reconhecimento de informações e aplicações de busca para bibliotecas digitais. Os experimentos com o Web-DL foram realizados com 9.000 teses e dissertações de diferentes instituições de ensino no mundo e obtiveram resultados satisfatórios (Calado et al. 2003b). Contudo, ao pensar em ampliar o alcance dessa ferramenta para qualquer documento Web, deve-se considerar uma possível dificuldade de definir estruturas para documentos semi-estruturados ou sem nenhuma estrutura em diferentes domínios. Uma solução para esse problema seria a adoção de documentos XML (Extensible Markup Language) na Web.

Em outra oportunidade, Calado et al. (2003a) investigaram diferentes medidas de similaridades baseadas na estrutura das ligações com o intuito de verificar a precisão dessas medidas para predizer categorias de documentos. Esses pesquisadores utilizaram redes bayesianas e um conjunto de documentos de treinamento para combinar as medidas de similaridades baseadas na estrutura com medidas de similaridade de conteúdo. Calado et al. utilizaram um diretório brasileiro de classificação de páginas $\mathrm{Web}^{3}$ para verificar o experimento proposto. Os pesquisadores concluíram que ligações hipertexto internas ao diretório manipulado não fornecem informação suficiente para classificar documentos. Portanto, para alcançar resultados expressivos, torna-se essencial a análise de ligações "de" e "para" páginas externas ao ambiente. Para esse experimento, medidas de similaridade que não consideravam ligações

\footnotetext{
${ }^{3}$ http://www.cade.com.br
} 
hipertexto externas foram consideradas ineficientes. A combinação de medidas baseadas em conteúdo com medidas de similaridade baseadas na estrutura levaram a resultados diversificados. Os estudos mostraram que similaridade de estrutura classificaram corretamente uma grande quantidade de páginas, mas incluíram ruídos. Já a similaridade de conteúdo eliminou ruídos, mas eliminou também documentos corretamente classificados de acordo com as medidas de similaridade por estrutura. Calado et al. concluíram que a combinação das medidas de similaridade dependiam da importância dada para cada fonte de evidência a ser combinada. Portanto, mais importância deve ser dada àquelas medidas que fornecem informações mais confiáveis. Esses pesquisadores concluíram declarando que encontrar o peso ideal para cada fonte de evidência a ser combinada continua sendo um importante foco de pesquisa.

Alguns pesquisadores denominam a informação de resposta a uma consulta de usuário como sendo informação de ligação local, e informação de ligação global como a informação derivada de todos os documentos da coleção. Calado et al. (2003c) compararam a eficiência do uso de informações de páginas $h u b$ e páginas authority para ligações locais e globais. Nessa comparação e combinação de evidências advindas das informações das ligações, esses pesquisadores utilizaram novamente redes bayesianas. Calado et al. verificaram que as informações de ligações locais aumentaram a precisão dos resultados dos documentos recuperados. Contudo, quando somente os dez primeiros documentos são analisados, como acontece na Web, em geral, para mecanismos de busca, ligações globais são mais precisas.

As propostas de Kleinberg (1999) e de Brin \& Page (1998) para exploração dos relacionamentos entre documentos apresentam as restrições mencionadas anteriormente. Para evitar esse tipo de problemas, Calado et al. (2003c) combinaram a análise de ligações para documentos a partir da respostas de sistemas de IR com documentos de toda a coleção. Apesar dos bons resultados reportados, o sucesso das abordagens de definição de relacionamentos entre documentos ainda depende do tipo de coleção manipulada.

Outras características da estrutura e de relacionamentos de hiperdocumentos também foram utilizadas em outras pesquisas de âmbito nacional (Fortes 1996) (Seraphim \& Fortes 2000). A próxima seção apresenta trabalhos de outras áreas de pesquisa que exploram a definição de relacionamentos entre informações.

\subsection{Relacionamento de Informações por Sistemas de Recomendação}

Sistemas de Recomendação de Informações são uma categoria de sistemas de informação que auxiliam e estendem o processo natural de solicitar recomendações a outras pessoas (Recommender Systems Site 1999). Algumas vezes sistemas de recomendação também são referenciados como filtros colaborativos, sistemas de filtragem social ou apenas sistemas colaborativos (Goldberg et al. 1992).

Um típico sistema de recomendação permite que pessoas forneçam recomendações de entrada para recipientes apropriados usando mecanismos de direcionamento do sistema. Em alguns casos, a computação inicial é a agregação de informações adicionais; em outros, é a 
realização de boas comparações textuais e de estrutura entre as informações fornecidas pelos sistemas e pelas pessoas interessadas em recomendações.

Sistemas de recomendação podem utilizar diferentes mecanismos para fornecer informações aos seus usuários, inclusive recomendar informações Web em diferentes tipos de mídias como páginas Web, arquivos de áudio ou vídeo, páginas de produtos, entre outros. As próximas sub-seções apresentam diferentes abordagens adotadas por sistemas de recomendação de informação encontrados na literatura. Em todas os trabalhos apresentados, o principal objetivo do sistema de recomendação é auxiliar na busca por informações relacionadas à informação buscada.

\subsubsection{Recomendação de Informação a partir de Interação Explícita de Usuários}

ScentTrails é um sistema de apoio à navegação na Web que integra busca explícita de informações, por meio de formulações de consultas, e o caminho de navegação na Web com o intuito de recomendar informações ressaltando âncoras de ligações hipertexto durante a navegação (Olston \& Chi 2003). As âncoras ressaltadas indicam os caminhos recomendados a partir dos resultados das buscas. ScentTrails utiliza palavras-chave fornecidas como consultas por usuários durante a navegação, o conteúdo das páginas navegadas e relacionadas a essas palavras-chave e as distâncias do caminho percorrido são utilizados para realçar novos destinos de navegação.

Ribak et al. (2002) realizaram experimentos com um sistema denominado ReachOut para defender a idéia de que é importante aconselhar-se antes de começar a procurar uma informação. ReachOut propõe maneiras de manipular problemas de localização, seleção e aproximação do grupo de potenciais usuários que possam fazer sugestões sobre determinados assuntos. O problema de localização foi tratado por meio de comparações textuais de perfis de usuários. Depois da comparação, uma lista de pessoas ou grupos definidos a partir das comparações é retornada ao usuário, que deve selecionar um potencial aconselhador para suas dúvidas. Finalmente, o usuário pode iniciar suas perguntas através de uma sessão de bate-papo ou mesmo em sessões assíncronas, conforme acordado entre os usuários em questão.

Glance (2001) descreveu um agente de software e uma comunidade de assistentes de busca que recomendam buscas relacionadas a usuários de mecanismos de busca na Web. A comunidade de assistentes capacita comunidades de usuários a buscar informações de modo colaborativo. Todas as consultas de usuários submetidas pela comunidade são armazenadas na forma de vértices de um grafo e os arcos entre os vértices são definidos como os relacionamentos entre as consultas. Apoiados por esse grafo, usuários podem examinar com atenção a rede de consultas até encontrarem o resultado da busca. A idéia por trás do uso de consultas mapeadas em grafos é o fato de que a determinação dos relacionamentos de informações depende dos documentos retornados a partir das consultas formuladas e não apenas dos termos da consulta atual. Outro benefício oferecido pelo agente de software de Glance é que a formulação do grafo de consultas transforma o uso isolado de mecanismos 
de buscas em colaborativo - todos os usuários podem recomendar resultados de buscas para outros usuários.

McDonald \& Ackerman (2000) descreveram uma arquitetura de recomendação de informação e sua instanciação por meio da implementação de um sistema de recomendação de informações específico para desenvolvedores de sistemas médicos. Utilizando perfis de usuários do sistema de atendimento de dúvidas de clientes, o sistema permitia consultas explícitas a perfis de outros atendentes de apoio à manutenção de sistemas médicos ou de clientes com o intuito de consultar um especialista em determinados problemas que poderia ajudá-los a resolver a tarefa em questão no momento. McDonald \& Ackerman (2000) defenderam a generalidade de sua arquitetura anunciando que, para implementar outro sistema de recomendação com base nela, bastaria a inserção de novos módulos de identificação e de perfis de usuários.

Há vários sistemas de recomendação que utilizam as preferências dos usuários via requisição explícita de algum tipo de retroalimentação (feedback) do usuário após a apresentação de recomendações definidas implicitamente. Por exemplo, quando usuários navegam de uma página Web para outra, usuários indicam o seu nível de satisfação com a página atual. Para a pesquisa científica, McNee et al. (2002) exploraram a interação explícita de autores de artigos durante a análise de relevância de artigos automaticamente recomendados com base no artigo do autor em questão. A recomendação automática de artigos é suportada por um algoritmo que define o relacionamento entre artigos por meio de citações.

Alguns pesquisadores acreditam que os sistemas de recomendação que manipulam feedback de usuários como uma maneira de conhecer interesses em comum trabalham com um problema com variáveis muito esparsas (Huang et al. 2004). Essa situação desfavorece a identificação de similaridades entre os interesses dos usuários desse tipo de sistema. Huang et al. (2004) trataram desse problema aplicando um arcabouço e algoritmos de recuperação associativa para explorar associações transitivas entre usuários de sistemas de recomendação de acordo com suas atividades anteriores e feedbacks. Essas associações transitivas são uma valiosa fonte de informação para auxiliar a inferência de interesses de usuários que podem diminuir a esparsidade do problema. Para avaliar seu sistema, Huang et al. (2004) utilizaram sítios Web de comércio eletrônicos de livros e revistas.

Exemplos de alguns sistemas clássicos de recomendações que utilizam participação explícita de usuários são os sistemas Ringo, Fab e Alexa. Ringo é um sistema para personalização de recomendações de sítios de álbuns de músicas e artistas (Shardanand \& Maes 1995). Fab é um sistema de recomendação de informações baseado nos votos de usuários e no conteúdo após técnicas de filtragem (Balabanovi \& Shoham 1997). Alexa é um assistente de navegação na Web que fornece informações sobre sítios Web registrados nesse sistema; avaliações explícitas e estatísticas desses sítios podem também sugerir recomendações de sítios relacionados (Kahle \& Gilliat 1997). Porém, uma das desvantagens do assistente Alexa é que ele torna o navegador Web bastante lento.

Os sistemas apresentados nesta subseção podem sobrecarregar cognitivamente seus usuá- 
rios devido ao fato de que eles precisam interagir explicitamente com o sistema para receber recomendações de informações relacionadas. Essas participações explícitas podem ocorrer: (i) por meio da formulação de consultas como, por exemplo, no sistema ScentTrails; (ii) para compor grupos de usuários como no sistema ReachOut, ou (iii) para indicar a satisfação do usuário com o material recomendado como no caso do sistema Fab. Alguns dos sistemas apresentados utilizam, em segundo plano, mecanismos implícitos para avaliar e recomendar informações a seus usuários como, por exemplo, o assistente Alexa, que utiliza estatísticas, ou o sistema de McNee et al. (2002), que avalia co-citações durante a composição de suas recomendações. A seguir são apresentados sistemas de recomendação de informações que exploram primordialmente interações implícitas de usuários para a recomendação de informações.

\subsubsection{Recomendação de Informação a partir de Interação Implícita de Usuários}

Existem sistemas de recomendação que exploram as preferências de usuários de modo transparente, sem nenhuma interação explícita por parte dos mesmos. Por exemplo, Letizia (Lieberman 1997), WebWatcher (Joachims et al. 1997), PHOAKS (People Helping One Another Know Stuff) (Keller et al. 1997), Margin Notes (Rhodes 2000) e QuickStep (Middleton et al. 2001) são sistemas clássicos de recomendação de informação que inferem preferências de usuários a partir da observação do comportamento dos mesmos durante sua navegação. Middleton et al. (2004) têm incrementado as funcionalidades do sistema QuickStep com a definição e o uso de uma ontologia criada de modo implícito a partir de perfis de usuários. Ontologias podem oferecer uma conceitualização rica do domínio de trabalho de uma organização, representando os principais conceitos das atividades de trabalho. Esses relacionamentos podem representar informações isoladas tais como número do telefone de empregado, ou eles podem representar uma atividade como redação de um documento ou participação em uma conferência. Como no caso de aplicações de busca de informações, sistemas de recomendação de informações podem definir ontologia na tentativa de aprimorar os resultados de buscas. QuickStep classifica artigos de pesquisa científica de acordo com classes ontológicas e algoritmos de recomendação colaborativa. Inferências ontológicas são utilizadas para aprimorar o uso de perfis de usuários e conhecimento ontológico externo tem sido usado como um processamento inicial para o sistema de recomendação.

Para explorar e recomendar informações armazenadas em arquivos de documentação de projetos, alguns pesquisadores fazem uso de um sistema de recomendação especializado, o Hipikat (Cubranic \& Murphy 2003). Esse sistema define memórias de grupos de trabalhos de modo implícito a partir de informações de entrada para documentações de projeto como relatórios de falhas e características de programas, documentação de outros projetos e mensagens enviadas a fóruns de discussões. Com base nessas informações de grupo, Hipikat recomenda informações que podem ser úteis às tarefas que outros usuários estão executando. Assim, o desenvolvedor do projeto pode selecionar, a partir da memória de grupo apresentada, informações que possam auxiliar na tarefa em execução. Cubranic \& Murphy (2003) 
definiram, também para o Hipikat, relacionamentos entre informações de projetos utilizando inferências a partir de meta-informação das documentações de projeto. Essa idéia pretendia oferecer um conjunto mais completo de recomendações, pois projetos podem perder informações que podem ser recuperadas realizando engenharia reversa a partir de informações estruturadas de outros projetos. Assim, ligações inexistentes podem ser inferidas como informações contidas no projeto, e meta-informações disponíveis sobre essas informações podem, por exemplo, definir algumas dessas ligações. Outras informações podem ser implicitamente inferidas a partir do rastreamento da utilização do sistema e de arquivos de revisões.

Sharon et al. (2003) criaram um sistema de recomendação de informação suportado por um Web proxy e um agente de software. O agente recomenda páginas e define novos documentos com ligações para a página visitada de modo a revelar a popularidade relativa das páginas entre usuários de um mesmo grupo. As páginas anotadas são automaticamente comparadas com perfis de interesse de cada usuário. Os perfis de usuários são criados a partir do agente de software que, auxiliado por um Web proxy, rastreia os hábitos de navegação dos usuários para obter informações de comportamento dos usuários de modo implícito.

Também utilizando agentes de software, o sistema MEMOIR rastreia percursos de usuários e algumas outras interações com tecnologias hipertexto. Esse serviço utiliza conceitos de sistemas hipermídia abertos para permitir que usuários manipulem associações entre tipos diferentes de documentos de maneira flexível e independente (DeRoure et al. 2001).

Além das medidas implícitas de citação de informações e de informações navegadas e suas inferências, outro tipo de definição implícita de relevância é o tempo gasto na leitura ou na visita a documentos. Em um trabalho inicial com o sistema GroupLens, Resnick et al. (1994) utilizaram o tempo gasto na leitura de um artigo como uma opinião implícita sobre o mesmo. A partir da opinião de outros usuários, pesquisadores poderiam decidir sobre a leitura ou não de determinados artigos científicos recomendados. GroupLens ${ }^{4}$ é um projeto de investigação sobre coleta, filtragem, disseminação, relacionamento, colaboração e visualização de informações.

Alguns outros sistemas de recomendação estão disponibilizados na Web como, por exemplo, Amazon.com, MovieFinder.com, CDNow.com e Launch.com. Esses sistemas exploram tecnologias colaborativas de filtragem, após a autenticação de usuários, com detalhamento de interesses no contexto específico dos sítios em questão. Por esses motivos, esse tipo de sistema fornece suficiente precisão em seus domínios específicos de aplicação. Entretanto, o sucesso desses sistemas pode também ser levado a outros domínios de aplicação ou a experiências mais genéricas, pois os filtros colaborativos também calculam modelos preditivos baseados em aproximações heurísticas do comportamento humano.

A maioria dos sistemas de recomendação apresentados define grupos de usuários a partir da captura de características e comportamentos em um período curto de tempo. Por isso, esse tipo de sistema de recomendação pode causar falta de confiança nas recomendações sugeridas, uma vez que advém de pessoas pouco conhecidas. Motivada por essa razão, a

\footnotetext{
${ }^{4}$ http://www.cs.umn.edu/Research/GroupLens/index.html
} 
autora desta tese colaborou na definição de uma arquitetura e de um sistema de recomendação de informações na Web que define grupos de usuários a partir da declaração explícita de interesses em comum. Esse sistema, chamado WebMemex, utiliza ligações hipertexto semânticas criadas implicitamente entre o conteúdo de páginas Web navegadas por grupos de usuários explicitamente criados (Macedo et al. 2003). O sistema WebMemex será apresentado em detalhes nos próximos capítulos. O sistema WebMemex e os outros sistemas de recomendação apresentados nesta subseção têm como principal desvantagem a recomendação de informações imprecisas, uma vez que as recomendações são definidas de maneira implícita. Observa-se que se deve verificar o contexto de aplicação de um sistema de recomendação para se exigir participação explícita de usuários e assim tentar obter benefícios em termos de precisão. Já os sistemas apoiados por interações implícitas podem não ter o custo da sobrecarga do usuário, mas podem enfrentar problemas de precisão dos resultados.

\subsubsection{Aspectos de Privacidade e Convenções Sociais para Recomendação de In- formação}

O fato de sistemas de recomendação de informações estarem continuamente capturando e compartilhando atividades de usuários torna importante o tratamento de questões relacionadas com a privacidade e com convenções sociais. Em muitas situações, usuários podem querer ter suas informações preservadas.

Para tratar questões de privacidade, alguns sistemas de recomendação de informações fornecem aos usuários a oportunidade de especificar as funcionalidades que eles querem obter e as informações que desejam prover ao sistema. Na tentativa de preservar o espírito de colaboração, alguns sistemas de recomendação de informações iniciam suas atividades permitindo a captura e o compartilhamento de informações. Essa atitude somente é modificada pelo usuário através de sua sinalização explícita como, por exemplo, desmarcando algum campo da interface do sistema. Outra maneira de preservar a privacidade é permitir a participação de usuários anônimos.

Em relação a convenções sociais, um aspecto a ser considerado é o tratamento de reciprocidade. Observa-se que na sociedade moderna, quando uma pessoa tem uma dúvida, ela pergunta a pessoas que ela considera ter conhecimento no assunto. Se a pessoa se interessar em responder a questão, ela responderá e estabelecerá a reciprocidade. Alguns sistemas de recomendação de informação somente consideram o compartilhamento de informações entre participantes que indicam reciprocidade de intenção (Ribak et al. 2002). Essa atitude de tratamento de convenção social de reciprocidade auxilia na resolução de uma segunda questão de convenção, que ocorre quando há alterações no círculo de pessoas. Nesse tipo de situação, os velhos companheiros deveriam ainda ser capazes de ver informações que eles poderiam ver quando eram parte do círculo de contato? Outra dúvida ocorre em relação ao fato dos novos integrantes do círculo de compartilhamento de informações. Esses novos companheiros podem consultar informações compartilhadas na época em que eles não eram 
parte do grupo? As convenções adotadas para tratar esses aspectos de privacidade podem ser diferentemente aplicadas entre os diversos sistemas de recomendação de informação existentes.

O fato de usuários fazerem parte de diferentes círculos de relacionamentos provoca discussões em torno da privacidade de seus usuários em cada um dos círculos sociais. Grande parte dos sistemas de recomendação adotam a seguinte convenção para essa questão: sugestões de companheiros geralmente não devem ser incluídas no conteúdo retornado aos diferentes usuários de outros grupos. Esse tipo de atitude protege a privacidade quando cada usuário pode escolher de qual grupo deseja participar a cada momento.

Os aspectos de privacidade e de convenções sociais apresentados nesta seção apenas apresentaram um pouco da polêmica em torno de invasão de privacidade e de definições de convenções sociais. Esses assuntos são debatidos em diferentes áreas da computação como, por exemplo, computação ubíqua apresentada a seguir.

\subsection{Definição de Relacionamentos a partir de Informações Captura- das em Ambientes Ubíquos}

A demanda por interfaces mais naturais entre usuários e computadores motivou o desenvolvimento de uma área de pesquisa conhecida como computação ubíqua. Computação ubíqua propõe a integração de tecnologias de hardware e de software em ambientes tradicionais como residências e salas de aula, de maneira a auxiliar os seres humanos em suas atividades diárias sem interferir no modo como eles normalmente executariam essas tarefas (Weiser 1991).

Ambientes ubíquos de captura podem ser equipados com microfones, câmeras e outros tipos de dispositivos eletrônicos que capturam os diferentes fluxos de informação gerados. $\mathrm{O}$ momento entre o início da captura das atividades em desenvolvimento em ambientes ubíquos e o final é denominado sessão de captura. A sincronização e a criação de relacionamentos entre esses fluxos de informação são atividades que procuram facilitar a consulta das informações capturadas após o encerramento da sessão. Essas tarefas desafiadoras de definição de relacionamentos entre informações capturadas por meio de sincronização ou manipulação de conteúdo têm sido investigadas por pesquisadores conforme apresentado a seguir. O principal interesse da doutoranda nessa área advém das pesquisas de definição de relacionamento entre informações capturadas em ambientes ubíquos, já que a doutoranda aplicou suas pesquisas nesse tipo de ambiente e obteve resultados interessantes, conforme apresentado no Capítulo 6. 


\subsubsection{Relacionamento de Informações a partir da Sincronização da Captura de Experiências ao Vivo}

A sincronização de informações capturadas em ambientes ubíquos geralmente é realizada de acordo com a interação dos usuários com os dispositivos eletrônicos de captura e/ou utilizando marcações temporais. Esse tipo de atividade relaciona informações de acordo com a variável tempo e não por comparações de conteúdo ou estrutura, conforme apresentado para os sistemas das seções anteriores.

O eClass é um ambiente instrumentado - com lousa eletrônica, projetores, câmeras de vídeo e microfones - que automaticamente captura experiências ao vivo de salas de aula convencionais, sincroniza e gera hiperdocumentos que posteriormente são disponibilizados na Web. A sincronização automática dos dados capturados pelo ambiente eClass é temporal e baseada em alguns eventos como, por exemplo, navegação na Web e manuscritos na lousa eletrônica. O ambiente eClass tem sido utilizado por diversas turmas de estudantes do GATECH (Georgia Institute of Technology) e de outras universidades americanas com êxito (Abowd 1999). O ambiente eClass inspirou o desenvolvimento do ambiente iClass (Cattelan et al. 2003) no ICMC-USP sob a coordenação da professora Maria da Graça Campos Pimentel.

O sistema "Lecture Browser" é responsável pela captura de informações multimídia em salas de aula, bem como pela apresentação dessas informações como hiperdocumentos disponibilizados na Web. Esse ambiente provê aos estudantes a possibilidade de acesso remoto às experiências de sala de aula capturadas e sincronizadas, que podem ser estendidas com facilidades de busca de informação e reprodução de áudio. Segundo pesquisadores, essas funcionalidades auxiliam na compreensão do conteúdo da aula em contextos de ensino a distância (Mukhopadhya \& Smith 1999). A principal característica do Lecture Browser é a automatização do processo de autoria de hiperdocumentos a partir de eventos ao vivo. Porém, não há apoio a outras formas de autoria ou expansão de hiperdocumentos durante a visita dos mesmos. A infra-estrutura do projeto Lecture Browser é semelhante à do ambiente eClass: sala de aula equipada com tecnologias para captura de áudio, vídeo e slides. Porém, os elementos de mídia capturados são manualmente sincronizados, armazenados em uma base de dados e recuperados pelo usuário por meio de requisições pela Internet. Outra diferença do Lecture Browser e do eClass é que o primeiro não tem lousa eletrônica.

Dolphin é um sistema CSCW que suporta a captura de áudio e vídeo e a criação de interfaces de interação com lousas eletrônicas em encontros face-a-face ou distribuídos. Esse sistema tem o intuito de gerar automaticamente documentos, que podem ser colaborativamente editados após o encerramento da sessão (Streitz et al. 1994). Porém, esse sistema não sincroniza elementos de áudio e vídeo com os hiperdocumentos gerados durante a reunião.

Já no sistema Tivoli informações podem ser manipuladas durante conferências por meio de alguns tipos de interações realizadas em uma lousa eletrônica. O apoio à integração de informações capturadas com informações produzidas antes da sessão de captura permite que 
usuários importem informações textuais, imagens e informação hipermídia pré-preparada. Já a integração de informações produzidas depois da sessão é realizada com a captura de conteúdo a ser importado por um sistema hipermídia colaborativo (Haake et al. 1994).

O sistema "Authoring on the Fly" (AoF) fornece uma infra-estrutura de captura elaborada que enfatiza o apoio à captura, transmissão, sincronização e recuperação de apresentações ao vivo distribuídas (Müller \& Ottmann 2000). Para apresentação do material pré-preparado, o ambiente inclui gráficos de alta resolução e uma lousa eletrônica que permite ao professor editar interativamente textos e manipular partes do material. Após a captura das sessões, todo o material capturado é processado e são gerados automaticamente hiperdocumentos que permitem a reprodução das sessões, através do modelo de sincronização do AoF. O modelo de sincronização desse sistema facilita dentre outras coisas o acesso em granulosidade fina à informação capturada. Após a captura, é possível editar as sessões para corrigir erros de digitação ou eliminar trechos de áudio com problemas, através de um módulo de edição dos documentos gerados pelo AoF.

Chiu et al. (1999) apresentaram o sistema NoteLook que permite a captura, a definição de anotações no conteúdo capturado e a indexação de documentos resultantes da captura em salas de conferências. Em outra oportunidade, Chiu et al. (2000) apresentaram um algoritmo para definir similaridades entre imagens com o intuito de definir ligações hipermídia em interfaces metaforizadas como folhas de papel. Essa metáfora é reforçada pela disponibilização do sistema em computadores portáteis do tipo tablet. Ainda nesse contexto, o sistema Xlibris permitia a geração de ligações hipertexto dinamicamente por meio da captura de interações de usuários em dispositivos de leitura stand-alone (Price et al. 1998). O Xlibris implementa tecnologias hipertexto que permitiam a classificação e a organização de anotações, além da busca por informações relacionadas que estão armazenadas localmente.

Ushijima (2004) apresentou o sistema "KSU-FIS Lecture Recording System" que utiliza um conjunto de câmeras e microfones para capturar as atividades realizadas e as aulas conduzidas por professores de uma faculdade da universidade Kyushu Sangyo no Japão. As aulas capturadas são distribuídas na Web, mas com acesso restrito ao pessoal do campus devido a aspectos de segurança.

Outro tipo de sistema de computação ubíqua que enfatiza o relacionamento de informações capturadas através de eventos de sincronização são sistemas que manipulam o rastreamento de atividades. O projeto "Digital Family Portrait" fornece a membros de uma família contínuo acesso a um hipertexto que representa a soma de atividades realizadas em ambientes ubíquos por um ente da família (Mynatt et al. 2001). Em um contexto um pouco diferente, Chen (2003) construiu uma interface multimídia para apresentar o rastreamento de ações comunicativas em vídeo-conferências entre os participantes. Essa interface, quando utilizada em salas de aula, determina automaticamente se os estudantes estão falando, fazendo gestos ou movimentando-se em seus assentos. São também definidos, de forma automática, indicadores dessas atividades que são apresentados sobre informações de vídeo ao instrutor. Alguns outros cenários nos quais interações são utilizadas para sincronizar e apresentar 
as informações registradas a partir do rastreamento de atividades são: o rastreamento de percursos de pessoas em um ambiente com o intuito de identificá-las e localizá-las (Orr \& Abowd 2000), o encontro de objetos perdidos (Peters et al. 2001) e o registro de ações para apoiar a memória de curta duração (Tran \& Mynatt 2002) (Trevor et al. 2004).

Os sistemas de captura baseados na criação de relacionamentos por sincronização das informações capturadas apresentados foram investigados pela doutoranda com o intuito de estudar os modelos de dados subjacentes a esses sistemas com o objetivo de verificar como esses modelos apoiavam a recuperação da informação relacionada. Verificou-se que a maioria dos sistemas apresentava as marcações sobre fluxos de dados capturados como âncoras de ligações hipertexto à mídia em questão (Mukhopadhya \& Smith 1999) (Abowd 1999) (Müller \& Ottmann 2000). Alguns permitiam a inclusão de informação textual e a busca de conteúdo por meio de formulações de consultas (Pimentel et al. 2001b).

\subsubsection{Relacionamento de Informações a partir da Manipulação Textual de Infor- mações advindas da Captura de Experiências ao Vivo}

Além da captura de fluxos de dados de áudio e vídeo, ambientes ubíquos podem capturar outras atividades e converter as informações capturadas em informação textual. Utilizando essas informações textuais, pode-se definir relacionamentos de informações como apresentado a seguir para alguns sistemas.

Scholz et al. (2003) apresentaram o projeto de desenvolvimento de um ambiente ubíquo chamado iRoom, ${ }^{5}$ proposto para suportar reuniões de militares na Austrália. Esse ambiente, apoiado por uma infra-estrutura composta por um sistema multi-agente denominado Metaglue, permitirá o relacionamento de informações que podem ser utilizadas para caracterizar a situação de uma entidade considerada importante na interação entre um usuário e o ambiente. Esse tipo de informação foi denominada por Dey et al. (1999) como informação de contexto $^{6}$. Uma das possíveis aplicações desses relacionamentos definidos com informações de contexto será o apoio à procura por informação. Scholz et al. (2003) pretendem estender o iRoom com outras aplicações que coletem e apresentem informações. Esses pesquisadores querem, por exemplo, durante um encontro de planejamento de estratégias, que essa aplicação interconectada ao iRoom colete automaticamente informações relacionadas aos pontos discutidos pelos participantes da reunião sem que os mesmos diretamente iniciem um processo de busca. Os desenvolvedores do iRoom reconhecem que o principal problema para o desenvolvimento desse tipo de cenário é fazer o ambiente identificar quais são as atividades em desenvolvimento na sala de reunião e quais as informações que devem ser recuperadas. Scholz et al. (2003) sugeriram o uso de informações de contexto na tentativa de auxiliar a

\footnotetext{
${ }^{5}$ Scholz et al. (2003) relataram que o ambiente iRoom estava em fase inicial de desenvolvimento e que os trabalhos apresentados no artigo eram os protótipos inicias do projeto e a descrição de idéias para trabalhos futuros.

${ }^{6}$ Informação de contexto corresponde a qualquer informação que pode ser usada para caracterizar a situação de uma entidade considerada importante para a interação entre um usuário e uma aplicação. Contexto é tipicamente a localização, identidade e estado de pessoas, grupos ou objetos físicos.
} 
aplicação a buscar e a entender as informações capturadas. Os desenvolvedores do ambiente iRoom acreditam que mesmo explorando informações de contexto, uma das dificuldades do ambiente seria distinguir conversas informais de reuniões formais, principalmente porque esse tipo de atividade raramente segue uma estrutura linear.

Shipman et al. (2003) sugeriram mecanismos para definir relacionamentos entre slides e arquivos de áudio capturados em ambiente ubíquos. Os relacionamentos definidos não eram somente baseados em sincronização de captura, como no caso dos sistemas apresentados na subseção anterior, mas também com ligações definidas por meio de comparações textuais entre o conteúdo dos slides e o conteúdo das transcrições dos arquivos de áudio. Pesquisadores do projeto Lecture Browser já tinham proposto anteriormente esse tipo de abordagem para a definição de relacionamentos entre informações capturadas de acordo com o conteúdo extraído de slides (Mukhopadhya \& Smith 1999). Esses pesquisadores utilizaram um método de comparação de conteúdo HTML de slides com informações de vídeos que apresentaram a captura dos mesmos slides. Esse método utilizava mecanismos de segmentação de imagens de slides, destaque de regiões textuais, ampliação da imagem e conversão do conteúdo ampliado em elementos binários para finalmente comparar distâncias entre os elementos das imagens. A desvantagem desse método é que somente podia ser aplicado a slides puramente textuais.

Erol et al. (2003) propuseram um algoritmo que relaciona informações de arquivosfonte PowerPoint ${ }^{\mathrm{TM}}$ de slides. Esse algoritmo aplica análise de histogramas, comparações de cadeias de caracteres, análise de layout e comparações de linhas de perfis de usuários. Os pesquisadores consideraram esse algoritmo melhor que outros propostos na literatura, sendo que ele não restringe o tipo de imagens de slides a serem comparadas.

Chiu et al. (2000) propuseram uma maneira automática de definir ligações entre conteúdo de slides e vídeo utilizando comparações de imagens por meio de um algoritmo de Transformação Discreta de Co-senos (Discrete Cosine Transformation - DCT). Esse algoritmo considerava o conteúdo extraído dos vídeos das apresentações e cópias de handouts de slides para realizar comparações textuais.

Os trabalhos apresentados nesta subseção descrevem a utilização de informações de slides e de transcrição de arquivos de áudio para a definição de relacionamentos textuais de informação em ambientes de captura. Cada uma dessas pesquisas difere pela maneira como elas definem esses relacionamentos. Esse conjunto de trabalhos foi uma parte importante do levantamento de trabalhos relacionados, uma vez que o arcabouço proposto nesta tese manipula informações advindas de um ambiente ubíquo de captura de informações. Nesse trabalho, diferentemente do projeto iRoom, foi utilizada uma técnica de IR para definição de relacionamentos semânticos a partir da informação latente capturada. 


\subsection{Tecnologias Hipermídia para relacionar Experiências dos Mundos Real e Virtual}

Alguns pesquisadores têm investigado protótipos que combinam pesquisas de realidade virtual e hipermídia para organizar e manipular material digital e relacionamentos espaciais. Nesse sentido, pesquisadores procuram definir relacionamentos entre as informações dos mundos físico e digital. Esses relacionamentos algumas vezes são definidos por meio da adoção de metáforas.

Romero \& Correia (2003) apresentaram um modelo hipermídia que abstrai detalhes de ítens de informação do mundo real e provê uma interface para navegação e estruturação da informação em um mundo virtual. Esse modelo hipermídia é usado como um arcabouço para construir aplicações cientes de contexto que relacionam experiências do mundo real e virtual. Uma aplicação é considerada sensível a contexto ou ciente de contexto se ela utiliza informações de contexto para oferecer serviços e informações relevantes para usuários (Dey et al. 1999). Por isso, essas aplicações podem se adaptar ao local em que estão sendo utilizadas, ao conjunto de pessoas e objetos próximos, e também às mudanças deles ao longo do tempo. O arcabouço por Romero \& Correia também manipula diferentes tipos de elementos de mídia e define um esquema de apresentação que abstrai vários conceitos de navegação e de existência de ligações hipertexto. O modelo especifica uma estrutura base para os relacionamentos entre os espaços real ou virtual. Além disso, esse modelo fornece uma maneira de correlacionar objetos do mundo real e virtual com informações presentes em um grafo hipermídia.

Uma outra maneira para definir um ambiente ciente de contexto para aplicações que suportam a narração de história foi proposto por Weal et al. (2003). Esses pesquisadores definiram uma infra-estrutura de hardware e de software para capturar atividades de alunos fora da sala de aula, de modo que eles possam visitar essas experiências e refletir sobre elas em sala de aula. Essa infra-estrutura é composta por sensores eletrônicos para rastrear movimentos, microfones e uma variedade de computadores portáteis e servidores de grande porte. As informações coletadas são sincronizadas, apresentadas e adaptadas a ambientes de realidade virtual.

Grønbæk et al. (2002) abstrairam a noção de espaço, explorada pela comunidade de hipermídia em áreas de gerenciamento de informações espaciais, para localização geográfica. Grønbæk et al. (2002) denominaram essa abstração de hipermídia espacial como hipermídia geo-espacial e introduziram várias distinções conceituais. Esses pesquisadores discutem diferentes maneiras de compor espaços de trabalho (workspaces) abstratos e metafóricos com espaços de trabalho geo-espaciais. Em outra pesquisa, Grønbæk et al. (2003) apresentaram exemplos empíricos de como as pessoas costumam utilizar e organizar, no mundo real, materiais físicos de projeto como planos de projeto, modelos, amostras e rascunhos. Baseado nesse estudo empírico, eles identificaram um conjunto abstrato de ações a ser suportado pela hipermídia "física". Grønbæk et al. (2003) desenvolveram um protótipo para demons- 
trar como essas ações devem ser suportadas em escrivaninhas estendidas e em paredes dos ambientes de trabalhos de arquitetos no mundo virtual.

Sinclair et al. (2002) verificaram o uso, em hipermídia, de realidade estendida, ou seja, realidade composta de relacionamentos do mundo real com o mundo digital. Esses pesquisadores também exploraram possíveis modos de interação que incorporam funcionalidades de sistemas hipermídia abertos e uso de ligações hipertexto de acordo com informações de contexto. Nessa pesquisa, Sinclair et al. (2002) exploraram lugares comuns e metáforas do mundo real de fácil entendimento. Também concluíram que realidade estendida pode ser aprimorada adicionando sistemas hipermídia que forneçam informações de contexto na forma de âncoras e de ligações. A informação de contexto usada para selecionar as âncoras pode ser baseada em perfis de usuários ou em outras informações selecionadas dentro do sistema. Informações de contexto ou perfis de usuário estão sendo investigados em diversas áreas da computação, inclusive em hipermídia adaptativa.

Carter et al. (2004) propuseram métodos para auxiliar pessoas a enviarem e a receberem informações digitais de displays digitais públicos, e a modificarem e anotarem o conteúdo anteriormente enviado para criar modelos paralelos publicamente observáveis. Esses métodos suportam interações, anotações, extensões e publicações de conteúdo. Esse trabalho foi motivado pela observação de como as pessoas removem, modificam e estruturam documentos. Carter et al. (2004) apresentaram o projeto inicial de sua pesquisa nesse campo e algumas reações iniciais de usuários que conheceram o projeto. Os experimentos inicias de Carter et al. mostraram que o sistema implementado era útil mas que é crucial integrar, agregar e anotar conteúdo capturado em dispositivos móveis.

Pesquisadores de hipermídia têm trabalhado no desenvolvimento de aplicações que relacionam o mundo real ao mundo virtual. Esses pesquisadores têm utilizado principalmente informações de contexto para definir esses relacionamentos. Esse tipo de informação explicitamente fornece alguns tipos de relacionamentos como, por exemplo, o relacionamento direto entre as informações Who, Where, What, When, Why e How que formam as dimensões de contexto (Truong et al. 2001).

\subsection{Considerações Finais}

Sistemas de IR e sistemas de recomendação de informações objetivam facilitar a busca por informações relacionadas a consultas formuladas explicitamente por usuários ou por meio de informações obtidas implicitamente. Pesquisadores dessas áreas têm investigado mecanismos para definir relacionamentos entre informações que possam ser relevantes para seus usuários. Alguns pesquisadores que propõem a definição de relacionamentos de acordo com o conteúdo dos documentos, outros exploram a estrutura dos documentos, alguns sugerem a utilização de perfis de usuários enquanto outros exploram o uso de informações capturadas a partir da interação explicita ou implícita de usuários.

Ambientes ubíquos de captura têm como principal objetivo relacionar informações captu- 
radas a partir de experiências ao vivo para representar adequadamente as atividades registradas. Alguns desses ambientes são estendidos por mecanismos de definição de relacionamentos textuais entre informações para facilitar a busca de conteúdo relacionado.

Para relacionar o mundo real com o mundo digital, pesquisadores de hipermídia têm trabalhado no desenvolvimento de aplicações que utilizam informações de contexto para transferir características e comportamentos de objetos do mundo real para o virtual. Nesses exemplos, pode-se verificar a integração das áreas de Hipermídia e de Computação Ubíqua.

A definição de relacionamentos entre informações, seja pela sincronização de fluxos de dados capturados ou por meio da manipulação textual de informações, tem sido investigada e explorada por diferentes áreas da computação conforme apresentado neste capítulo. A pesquisa apresentada nesta tese pretende contribuir com resultados que objetivam suportar a definição de relacionamentos entre informações homogêneas. Por exemplo, quando pessoas integradas a ambientes ubíquos de salas de aula desejam estender o conteúdo do material apresentado, técnicas de IR podem auxiliar na busca por informações relacionadas em seus próprios repositórios como o sistema iRoom planeja fazer. De fato, a navegação na Web apoiada pela criação de ligações hipertexto pode auxiliar na busca de informações por meio da sugestão de páginas relacionadas a seus grupos de interesse. Nas duas situações, a utilização do arcabouço proposto nesta tese pode dar apoio a identificação automática de informações relacionadas sem exigir desvio do foco de atenção por parte do usuário da tarefa realizada. No próximo capítulo são apresentadas abordagens de IR que auxiliaram na definição de algumas classes e componentes do arcabouço proposto nesta tese. 


\section{Recuperação de Informação}

\subsection{Considerações Iniciais}

No final da década de 60 surgiram os primeiros catálogos bibliográficos on-line que em alguns minutos permitiam a recuperação de informações armazenadas. Para manusear informações, o usuário manipulava um ambiente de consulta utilizando um conjunto controlado de operações e linguagens pré-definidas. Naquela época os computadores tinham baixo poder de processamento sobre grandes quantidades de informações. Entre os anos de 1970 e 1980 , o tamanho das coleções de informações armazenadas e manipuladas pelos computadores cresceu de centenas para milhares de megabytes de informações. Finalmente, na década de 90, grande quantidade de informações estava disponível devido à popularização da Web.

Para acompanhar o crescimento do volume de informação disponível, indústrias trabalham no desenvolvimento de máquinas com maior capacidade de armazenamento e de processamento. Paralelamente, pesquisadores de diferentes áreas, inclusive Recuperação de Informação (Information Retrieval - IR) e Hipermídia, concentram esforços no desenvolvimento de mecanismos que promovam a recuperação, a integração estruturada das informações armazenadas e a apresentação das mesmas. A pesquisa apresentada nesta tese explorou técnicas de Recuperação de Informação para a integração de informações disponibilizadas em repositórios Web através da criação automática de ligações hipertexto. Neste capítulo são apresentados conceitos fundamentais de Recuperação de Informação com foco na representação e na busca de informações em documentos textuais. 


\subsection{Conceitos Básicos}

Recuperação de Informação (IR) é uma área dedicada a pesquisa de tecnologias para manipulação e recuperação de grandes coleções de informação em diferentes formatos de apresentação. Nessa área são investigadas formas de representação, de armazenamento, de organização e de acesso a ítens de informação de modo a permitir ao usuário fácil acesso à informação na qual ele está interessado (Baeza-Yates \& Ribeiro-Neto 1999). Usuários podem expressar a necessidade de certa informação especificando expressões denominadas consultas. Na maioria dos sistemas de IR, as tarefas de representação da coleção de documentos e de buscas de informação estão intimamente relacionadas, sendo que a forma de representar os documentos gera índices que são utilizados para a busca de informação. Assim a partir de consultas de usuários, sistemas de IR buscam documentos que possam satisfazer às necessidades de usuários especificadas pelas consultas.

Para manipular as coleções de documentos e para comparar as consultas aos documentos, sistemas de IR utilizam uma série de mecanismos como: análise textual; filtragem de informação por meio da extração de stopwords; técnicas de redução de palavras a seus radicais (stemming); técnicas de indexação como, por exemplo, arquivo invertido; modelos matemáticos e estatísticos para a representação de documentos, de consultas e a definição de coeficientes de similaridades; estruturas de categorização e de expansão de consultas por meio da utilização de, por exemplo, thesaurus e relevance feedback. Alguns desses mecanismos e modelos de representação de documentos e de consultas são apresentados neste capítulo.

\subsection{Modelos para Representação de Documentos}

O conteúdo de documentos textuais pode ser representado em um ambiente computacional por diferentes formas tais como vetores, grafos e árvores. As formas tradicionais de representação de documentos em IR são tratadas como métodos de indexação pois, para a representação de documentos, apenas algumas palavras-chave são armazenadas. Essas palavras são consideradas termos de indice da coleção representada. Termos que ocorrem freqüentemente como conjunções, preposições e artigos, denominados stopwords, são excluídos pois não são palavras que podem discriminar um documento. Existem sistemas de IR que, além de técnicas de extração de palavras, utilizam mecanismos que reduzem os termos dos documentos aos seus radicais (stemming). Alguns sistemas de IR representam tanto as formas completas dos termos quanto as formas reduzidas para flexibilizar a definição de consultas de usuários. A funcionalidade de busca avançada da ferramenta $\mathrm{MSN}^{1}$ da Microsoft possibilita a busca de termos reduzidos a seus radicais. A ferramenta de busca Google ${ }^{2}$ não utiliza stemming nem wildcards, segundo a equipe de desenvolvimento, eles adotaram essa

\footnotetext{
${ }^{1}$ http://search.msn.com/advanced.aspx

${ }^{2}$ http://www.google.com.br/intl/pt-BR/help/basics.html
} 
medida para apresentar resultados mais precisos. Portanto o Google busca exatamente o que está na caixa de procura.

Na primeira parte desta seção são apresentados os modelos clássicos de representação de documentos: modelo booleano, modelo vetorial e modelo probabilístico. Na segunda parte, são apresentados modelos estendidos para cada modelo clássico apresentado anteriormente.

\subsubsection{Modelos Clássicos}

\section{Terminologia}

Na apresentação dos modelos clássicos de representação de documentos em IR é utilizada a seguinte terminologia por muitos pesquisadores:

- $d_{j}$ representa um documento genérico de uma coleção de documentos;

- $q$ representa uma consulta de usuário;

- $t$ representa a quantidade de termos de índice da coleção de documentos;

- $k_{i}$ representa um termo de índice genérico;

- $K=\left\{k_{1}, \ldots, k_{t}\right\}$ representa o conjunto de todos os termos de índice da coleção;

- $w_{i, j}>=0$ representa o peso associado ao par termo de índice e documento $\left(k_{i}, d_{j}\right)$ e $w_{i, j}=0$ indica que o termo $k_{i}$ não pertence ao documento $d_{j}$. O valor do peso indica o grau de especificidade de cada termo que varia de documento para documento;

- $\vec{d}_{j}=\left\{w_{1, j}, w_{2, j}, \ldots, w_{t, j}\right\}$ é o índice da coleção, isto é, é o vetor de termos de índice do documento $d_{j}$;

- $g_{i}$ é uma função que retorna o peso associado ao termo de índice $k_{i}$ em qualquer vetor de t-dimensões, isto é, $g_{i}\left(\vec{d}_{j}\right)=w_{i, j}$.

\section{Modelo Booleano}

O modelo booleano representa documentos em IR com base na teoria dos conjuntos e na álgebra booleana. Assim cada documento é representado por um conjunto de termos de índice aos quais podem ser atribuídos apenas pesos binários, isto é, 1 se o termo de índice existir no conteúdo do documento que está sendo representado e 0 caso contrário.

Consultas booleanas são expressões booleanas especificadas por palavras-chave conectadas por alguns operadores lógicos (AND, OR e NOT). Durante o processamento da consulta, as palavras-chave são transformadas em valores binários a serem comparados com o conjunto representativo dos documentos. Uma consulta booleana convencional $\left(\vec{q}_{d n f}\right)$ é a forma normal disjuntiva (Disjunctive Normal Form - DNF) para a consulta $q$. Seja $\vec{q}_{c c}$ qualquer um dos componentes de $\vec{q}_{d n f}$, então a similaridade de um documento $d_{j}$ para a consulta $q$ pode ser expressa, segundo pesquisadores de IR, como: 


$$
\operatorname{sim}\left(d_{j}, q\right)= \begin{cases}1 & \text { se } \exists \vec{q}_{c c} \mid\left(\vec{q}_{c c} \in \vec{q}_{d n f}\right) \wedge\left(\forall k_{i}, g_{i}\left(\vec{d}_{j}\right)=g_{i}\left(\vec{q}_{c c}\right)\right) \\ 0 & \text { caso contrário }\end{cases}
$$

com $g_{i}$ sendo a função que retorna pesos com valores 0 ou 1 para cada termo de índice $k$ do vetor de dimensão $t$ que representa cada documento da coleção (Baeza-Yates \& RibeiroNeto 1999). Se o resultado da equação $\operatorname{sim}\left(d_{j}, q\right)$ for igual a 1 , o documento $d_{j}$ é considerado relevante à consulta de usuário, caso contrário o documento não é considerado relevante. Algumas limitações do modelo booleano são:

- a recuperação é baseada em decisão binária e, portanto, sem a definição de similaridade parcial. Esse fato indica que o modelo booleano é mais apropriado para a recuperação de dados do que para a recuperação de informação. Por exemplo, se for considerada a seguinte consulta " a AND b AND c AND d AND e", documentos que possuírem todas as palavras-chave da consulta menos a última não serão considerados. De forma similar, para uma consulta com " $a$ OR b OR c OR $d$ OR e", documentos que possuírem apenas um dos termos da consulta serão recuperados com a mesma relevância dos documentos que possuírem todos os termos da consulta;

- o modelo booleano clássico não ordena os resultados das buscas seguindo uma escala parcial. Os resultados são baseados em decisões binárias, isto é, 1 é resultado para documento relevante e 0 para documento considerado irrelevante;

- a tradução das necessidades de informação de usuários à expressão booleana é considerada complexa. Acredita-se que, por essa razão, as consultas booleanas formuladas por usuários geralmente possuem sintaxe simples. Esse fato ocasiona problemas de eficácia para sistemas de IR que utilizam esse modelo. A especificação de consultas booleanas é apresentada na próxima seção.

Apesar de suas desvantagens, o modelo booleano possui uma semântica precisa, com formalismo elegante baseado em conceitos matemáticos. Acredita-se que essas sejam as razões que justificam a utilização de modelos booleanos por alguns sistemas de IR como a aplicação para busca em bibliotecas digitais $\mathrm{NCSU}^{3}$ e o sistema $\operatorname{HotBot}^{4,5}$.

\section{Modelo Vetorial}

Motivados pelo fato de que a utilização de pesos binários não considera similaridades parciais, pesquisadores desenvolveram o modelo vetorial para a representação de documentos de coleções de informações para IR (Salton \& Lesk 1968). Nesse modelo, cada documento é representado por um vetor numérico no qual cada elemento representa um único termo ou um termo de índice de documento. A esses elementos são atribuídos pesos parciais os

\footnotetext{
${ }^{3}$ http://www.lib.ncsu.edu/

${ }^{4}$ http://www.searchengineshowdown.com/features/hotbot/review.html

${ }^{5} \mathrm{http}: / /$ www.hotbot.com
} 
quais indicam o grau de especificidade relativo de cada termo. Esses pesos são utilizados para calcular graus de similaridade entre consultas e documentos, e também para classificar os resultados.

Esquemas Clássicos de Atribuição de Pesos. Esquemas de atribuição de pesos a termos de índice de documentos procuram aprimorar o desempenho da recuperação de informação auxiliando na distinção dos termos que representem melhor o conteúdo dos documentos.

Em 1968, esquemas simples de atribuição de pesos a termos modelados em vetores foram introduzidos por Salton \& Lesk (1968). Esses esquemas normalmente representam termos de acordo com o número de vezes que eles ocorrem em um dado documento - o fator $t f$. Posteriormente em 1972, Jones introduziu um novo elemento aos esquemas de atribuição de pesos, o fator $i d f$, que desfavorece termos presentes na maioria dos documentos da coleção. Esse fator representa o inverso do número de ocorrências de um determinado termo na coleção de documentos (Jones 1972). Assim, idf varia inversamente com o número de documentos $n$ para o qual um termo está relacionado na coleção de $N$ documentos. Um valor típico para $i d f$ é $\log \left(\frac{N}{n}\right)$. Os mais conhecidos esquemas de atribuição de pesos exploram o par de medidas $t f$ e $i d f$ para cada termo de um documento. Em 1973, alguns pesquisadores em (Salton \& Yang 1973) discutiram a efetividade dessas medidas na recuperação de informação, como discutido a seguir.

Os melhores termos de índice para identificação de documentos são aqueles capazes de distinguir documentos individualmente da coleção de documentos. Isso implica que termos discriminantes devem ter alta freqüência no documento, $t f$, e baixa freqüência na coleção, $i d f$. Uma medida razoável de importância de termos pode ser obtida utilizando o produto da freqüência dos termos pela freqüência inversa dos termos $(t f \times i d f)$. Esquemas de atribuição baseados em $t f \times i d f$ sofrem críticas devido ao fato de não serem sustentados por propriedades teóricas, como no caso de esquemas de atribuição de pesos para modelos probabilísticos, os quais consideram as propriedades de relevância dos documentos.

Um terceiro fator de esquemas de atribuição de pesos é utilizado para controlar a existência de vetores de tamanhos diferentes na representação de documentos. Normalmente, documentos com poucas palavras tendem a ser representados por vetores pequenos e documentos longos tendem a ser apresentados em vetores com vários elementos. Segundo Salton \& Buckley, quando um conjunto grande de termos é utilizado para a representação de um documento é alta a chance desse documento ser considerado semelhante a outro documento ou consulta (Salton \& Buckley 1988). Além disso, os documentos mais extensos têm mais chances de serem recuperados que os documentos mais compactos. Portanto, deve-se cuidar para que o tamanho dos documentos não interfira no processo de recuperação. Assim é sugerido um fator de normalização a ser incorporado na fórmula $t f \times i d f$. Assumindo que $w$ represente o peso do termo $t$ calculado utilizando a fórmula original de $t f \times i d f$, o peso final normalizado pode ser definido como $\frac{w}{\sum_{i} w_{i}}$.

Alguns exemplos de esquemas de atribuição de pesos que utilizam combinações das me- 
didas $t f \times i d f$ são apresentados na Tabela 3.1. A segunda coluna da tabela é utilizada para atribuir pesos aos documentos e a terceira às consultas. Cada esquema é composto pela freqüência do termo $(t f)$, pela freqüência inversa $(i d f)$ e pela variável de normalização.

Tabela 3.1: Esquemas de atribuição de pesos

\begin{tabular}{|l||c|c|}
\hline \multicolumn{1}{|c||}{ Nome do Esquema } & \multicolumn{2}{c|}{$\begin{array}{c}\text { Esquemas de atribuição de pesos para: } \\
\text { documentos }\end{array}$} \\
\hline \hline $\begin{array}{l}\text { Esquema totalmente normali- } \\
\text { zado }\end{array}$ & $\frac{t f(i j) \cdot \log \left(\frac{N}{n_{i}}\right)}{\sqrt{\sum_{\text {vetor }}\left(t f(k j)^{2} \cdot \log \left(\frac{N}{n_{k}}\right)^{2}\right)}}$ & $\left(0,5+\left(\frac{0,5 \cdot t f(i j)}{\max t f(i j)}\right)\right) \cdot \log \left(\frac{N}{n_{i}}\right)$ \\
\hline Esquema probabilístico & $0,5+\left(\frac{0,5 \cdot t f(i j)}{\max t f(i j)}\right)$ & $\log \left(\frac{N-n_{i}}{n_{i}}\right)$ \\
\hline Esquema clássico $i d f$ & $\log \left(\frac{N}{n_{i}}\right)$ & $\log \left(\frac{N}{n_{i}}\right)$ \\
\hline $\begin{array}{l}\text { Esquema de independência } \\
\text { de termo binário }\end{array}$ & 1 & $\log \left(\frac{N-n_{i}}{n_{i}}\right)$ \\
\hline Esquema de peso padrão $t f$ & $\frac{t f(i j)}{\sqrt{\sum_{v e t o r} t f(k j)^{2}}}$ & $t f(i j)$ \\
\hline
\end{tabular}

No modelo vetorial, termos de índice são considerados mutuamente independentes e essa asserção implica em funções lineares de atribuição de pesos. Entretanto, o trabalho de van Rijsbergen (1977) define um modelo probabilístico que incorpora dependência entre termos de índice; resultados experimentais desse trabalho são apresentados em (Harper \& van Rijsbergen 1978). A dependência dos termos é derivada da distribuição de co-ocorrências em toda a coleção de documentos ou dos conjuntos de documentos relevantes ou não-relevantes, e conduz a uma função de atribuição de pesos não-linear.

Diferentes abordagens para calcular co-ocorrências entre termos durante o processo de recuperação de informações têm sido propostas. Raghavan \& Yu (1979) utilizam análises estatísticas para relacionar um conjunto de consultas com documentos relevantes e nãorelevantes, e assim estabelecer correlações positivas e negativas entre índices. Dessa maneira, esses pesquisadores pretendem resolver problemas de divisão por zero em cálculos de similaridades. Pôssas et al. (2002) definem um novo esquema de atribuição de pesos que utiliza técnicas de mineração de dados e regras associativas para atribuir pesos a termos de índice. Esquemas de atribuição de pesos podem também ser aplicados a modelos e consultas booleanas.

Cálculo de Similaridades. Para encontrar similaridades entre documentos e entre consultas e documentos, assume-se que os vetores unitários $v e c(i)$ e $\operatorname{vec}(j)$ são ortonormais ${ }^{6}$ e que os $t$ vetores unitários $v e c(i)$ formam uma base ortonormal de um espaço t-dimensional. Nesse espaço, as consultas e os documentos são representados como vetores com pesos. Assim, documentos e consultas (ou exclusivamente documentos) podem ser comparados pelo cálculo da distância (co-seno) entre os vetores representativos desses elementos. Esse cálculo de similaridade é normalmente representado por pesquisadores de IR (Salton \& Lesk 1968) como:

\footnotetext{
${ }^{6}$ Assume-se que os termos de índice ocorrem de uma forma independente dentro dos documentos.
} 


$$
\begin{aligned}
\operatorname{Sim}\left(d_{j}, q\right) & =\cos (\Theta) \\
& =\frac{\overrightarrow{d_{j}} \bullet \vec{q}}{\left|\overrightarrow{d_{j}}\right| \times|\vec{q}|} \\
& =\frac{\sum_{i=1}^{t} w_{i, j} \times w_{i, q}}{\sqrt{\sum_{i=1}^{t} w_{i, j}^{2} \times \sqrt{\sum_{i=1}^{t} w^{2} i, q}}}
\end{aligned}
$$

sendo $w_{i, j}>0$ sempre que $k_{i} \in d_{j}$ e $w_{i, q}>=0$ sempre que $k_{i} \in q$. Onde $w_{i, q}$ é o peso associado a cada termo da consulta, $\vec{q}=\left(w_{1, q}, w_{2, q}, \ldots, w_{t, q}\right)$ e $w_{i, j}$ de cada termo $k_{i}$ é associado um vetor unitário vec(i). Os cálculos de similaridade da equação 3.2 propiciam também a classificação de documentos de acordo com a similaridade obtida.

O fato do modelo vetorial permitir a classificação de documentos de acordo com o grau de similaridade incentiva sua utilização. Em termos de desempenho computacional, o modelo vetorial comporta-se de maneira linear em relação ao tamanho do vocabulário da coleção e ao número de documentos da coleção.

Um dos problemas é o cálculo de similaridade utilizando apenas comparações de palavras, já que palavras com um mesmo significado, mas com ortografias distintas, são consideradas diferentes. Esse problema pode ser tratado por técnicas de expansão de consultas e por técnicas de redução de dimensão, isto é, técnicas que procuram diminuir as chances de consultas e documentos referenciarem o mesmo conceito utilizando diferentes termos (Crestani 2000). As técnicas de expansão de consultas procuram associar termos sinônimos à consulta por meio da participação de usuários e dicionários de sinônimos. O sistema clássico de IR que utiliza o modelo vetorial é o sistema SMART (Salton 1971)

\section{Modelo Probabilístico}

O modelo probabilístico de recuperação foi proposto em 1960 por Maron \& Kuhns (Maron \& Kuhns 1960). A idéia básica desse modelo era classificar documentos em uma coleção, de acordo com sua probabilidade de ser relevante para a informação a ser buscada. Esse modelo sugere comparar a informação a ser buscada com cada documento para calcular a probabilidade de relevância entre eles. A informação a ser buscada deveria ser apresentada na forma de consulta.

Em 1977, Robertson analisou o modelo probabilístico e observou que um documento deveria ser recuperado se sua probabilidade de ser relevante for maior que a sua probabilidade de não ser relevante (Robertson 1977). Esse modelo indica que o principal objetivo de um sistema de IR é classificar informações textuais de acordo com suas probabilidades de relevância para consultas, dado que esse modelo sugere que há evidências disponíveis para estimar essas probabilidades. A fonte de evidência mais típica para IR é a distribuição estatística dos termos na coleção. Contudo existem outras fontes de evidência que podem ser exploradas, inclusive por Redes de Inferência que são modelos alternativos aos modelos probabilísticos. Redes de Inferência serão apresentadas a seguir.

O modelo probabilístico assume que, dada uma consulta, existe um conjunto-resposta 
ideal e o processo de busca está baseado na tentativa de encontrar as propriedades desse conjunto. O modelo probabilístico pressupõe que essas propriedades estejam relacionadas à semântica dos termos de índice dos documentos da coleção manipulada no processo. Como essas propriedades não são conhecidas no início da consulta, o modelo sugere um processo de suposições. Depois de algumas interações com usuário, o qual deve indicar os documentos pertinentes, as descrições probabilísticas do conjunto-resposta devem estar próximas às descrições do conjunto ideal.

O modelo probabilístico é baseado na estimativa das probabilidades que usuários têm de encontrar documentos relevantes à consulta. Dada uma consulta $q$, a probabilidade que o modelo assume para cada documento da coleção total de documentos $\left(d_{j}\right)$ é a probabilidade de usuários considerarem o documento $d_{j}$ relevante à consulta $q$ (Robertson 1977). Essa probabilidade é estimada como:

$$
\operatorname{sim}\left(d_{j}, q\right)=\frac{P\left(d_{j} \text { relevante-para } q\right)}{P\left(d_{j} \text { não-relevante-para } q\right)}
$$

Esse modelo assume que a probabilidade de relevância depende somente das representações de $q$ e dos documentos $d_{j}$. O conjunto-resposta ideal, $R$, deve conter os documentos relevantes previstos e, com isso, maximizar a probabilidade de relevância.

Uma das grandes vantagens do modelo probabilístico é que as estimativas de probabilidades podem ser utilizadas para a classificação dos documentos pertencentes ao conjunto de documentos relevantes. Entretanto, esse modelo tem problemas com relação à manipulação do processo inicial, devido ao fato de utilizar probabilidades imprecisas e não considerar a freqüência dos termos. O sistema INQUERY explora o modelo probabilístico para modelar as informações manipuladas (Callan et al. 1995). O INQUERY, criado pelo CIIR (Center for Intelligent Information Retrieval) da Universidade de Massachusetts, tem sido utilizado para apoiar buscas no Portal Web Oficial do governo federal americano ${ }^{7}$.

\subsubsection{Modelos Estendidos e Modelos Alternativos}

O surgimento de extensões e de novos modelos para representar documentos e consultas em sistemas de IR aconteceu devido ao fato de que os modelos clássicos apresentados têm marcantes vantagens e desvantagens quanto a sua utilização. Na tentativa de superar as desvantagens, o modelo booleano clássico foi estendido pelo Modelo Booleano Estendido e pelo Modelo de Conjuntos Difusos.

Já o modelo vetorial foi estendido por diversas propostas como, por exemplo, pelo Modelo Vetorial Generalizado, pela técnica de Análise da Semântica Latente (Latent Semantic Analysis - LSA) e pelas Redes Neurais Artificiais. O modelo probabilístico usa Redes Bayesianas de dois tipos para estender suas contribuições em IR: Redes de Inferência e Redes de Crença

\footnotetext{
${ }^{7}$ http://www.firstgov.gov/
} 
(Belief Network). A seguir é apresentado um modelo estendido ou alternativo para cada um dos modelos clássicos já apresentados.

\section{Booleano Estendido}

O modelo booleano clássico tem alguns problemas com relação à classificação de resultados devido ao fato deste apenas utilizar pesos binários para indicar a relevância dos termos em documentos. Motivados por esse problema, pesquisadores de IR propuseram um Modelo Booleano Estendido que suporta a definição de similaridade parcial por meio de atribuições de pesos aos documentos dentro de uma escala de 0 a 1 (Salton et al. 1983).

A proposta desse modelo está baseada na interpretação dos operadores de consultas conjuntivas e disjuntivas em termos de distâncias euclidianas ${ }^{8}$ em um espaço $t$-dimensional. Dessa abordagem pode-se extrair propriedades interessantes apesar de serem baseadas em cálculos um pouco mais complexos.

Dois anos após a proposta do modelo booleano estendido por Salton et al., alguns pesquisadores de IR utilizaram os operadores propostos para definir um sistemas de IR, o sistema RUBRIC (McCune et al. 1985). Atualmente a API de busca EGOTHOR ${ }^{9}$ também utiliza o modelo booleano estendido proposto por Salton et al..

\section{Redes de Inferência}

Redes de Inferência generalizam o modelo probabilístico tratando o processo de recuperação de informação como um processo de raciocínio baseado em evidências representadas em documentos (Turtle \& Croft 1991). Essas evidências devem ser utilizadas para estimar a probabilidade da informação buscada por usuário ser encontrada. Assim, redes de inferência são projetadas para incorporar diferentes fontes de evidência ao estimar a probabilidade de relevância de um documento específico para o usuário. Ao estimar probabilidades usando fontes de evidência, redes de inferências estendem o modelo probabilístico clássico.

Redes de inferência são formadas por grafos acíclicos dirigidos, nos quais os arcos entre os nós representam as condições probabilísticas de relevância e os nós representam documentos $\left(d_{i}\right)$, termos de índice $\left(k_{i}\right)$, consultas $(q)$ ou consultas extras $\left(q_{i}\right)$. Nós de consultas extras são utilizados para modelar consultas booleanas alternativas como, por exemplo, consultas expandidas a partir da consulta original $(q)$. Nesse caso, também é necessário outro nó extra (I) para suportar mais de uma consulta. Uma rede de inferência completa também inclui nós de conteúdo, de representação $\left(r_{j}\right)$ e de conceito $\left(c_{k}\right)$, os quais podem ser utilizados para representar termos ou informações específicas (por exemplo, datas e números) contidas em documentos ou consultas.

Uma abordagem simples para redes de inferência representa os elementos do grafo com valores booleanos, isto é, os valores de $d_{i}, k_{i}$ e $q$ podem assumir apenas 0 s ou $1 \mathrm{~s}$.

\footnotetext{
${ }^{8} \mathrm{O}$ cálculo da distância euclidiana para dois vetores $v_{i}$ e $u_{i}$ é $\sqrt{\left(v_{1}-u_{1}\right)^{2}+\left(v_{2}-u_{2}\right)^{2}+\ldots+\left(v_{t}-u_{t}\right)^{2}}$

${ }^{9} \mathrm{http}: / /$ www.egothor.org/
} 
Normalmente, redes de inferência utilizadas para recuperação de informação possuem alguns componentes pré-compilados e outros compilados em tempo de execução. Durante o pré-processamento, o processador extrai um conjunto de nós de representação de uma coleção de documentos e o armazena como conjunto de termos de índice. Durante o tempo de execução, quando a consulta do usuário está sendo transformada, um algoritmo utiliza o conteúdo dos nós para determinar a probabilidade que determinados documentos têm de serem relevantes à consulta. Documentos relevantes excedem um determinado valor que os classifica ao serem retornados ao usuário. Como já mencionado, o sistema INQUERY utiliza o modelo probabilístico para representar as informações manipuladas, especificamente uma rede de inferência (Callan et al. 1995).

\section{Análise da Semântica Latente}

A técnica de Análise da Semântica Latente (Latent Semantic Analysis - LSA), ou Indexação da Semântica Latente (Latent Semantic Indexing - LSI) ${ }^{10}$, provê mecanismos para a organização de informações textuais em estruturas semânticas as quais podem ser utilizadas para a recuperação de informações e para a navegação (Furnas et al. 1988).

A técnica de LSA procura superar problemas de comparações lexicais de termos ao considerar uma estrutura semântica latente implícita pela variabilidade das palavras. Para a técnica de LSA, a estrutura semântica é definida como a estrutura que representa a correlação de termos individuais nos documentos; nesse caso, a semântica refere-se ao fato de documentos poderem ser referenciados pelos seus próprios termos.

Em LSA, as descrições de documentos, de termos e de consultas são representadas pelo modelo vetorial. Técnicas algébricas e estatísticas são utilizadas para explorar a estrutura semântica latente implícita nos documentos. O modelo algébrico de Decomposição de Valores Singulares (Singular Value Decomposition - SVD) é adotado para representação da estrutura semântica manipulada pela técnica de LSA.

Decomposição de Valores Singulares. SVD representa termos, documentos e consultas como vetores em um espaço com dimensão reduzida. O co-seno dos pontos desse espaço indica a similaridade dos objetos representados. SVD é um modelo com representação explícita, ajustável e que pode ser manipulado através de computação (Furnas et al. 1988).

Para utilizar SVD no contexto de IR deve-se, primeiramente, definir e construir uma matriz $X$ com os documentos e os termos da coleção de documentos a ser manipulada. De acordo com SVD, essa matriz $X$ é retangular e pode ser decomposta em:

$$
X=T_{m} S_{m} D_{m}^{\prime}
$$

\footnotetext{
${ }^{10}$ Muitos pesquisadores utilizam LSA e LSI como sinônimos, mas outros apresentam LSI como uma técnica que utiliza LSA para indexação automática de documentos textuais (Deerwester et al. 1990).
} 
A equação 3.4 é denominada de Equação de Decomposição de Valores Singulares de $X$, e as matrizes $T, D$ e $S$ são as matrizes componentes com dimensão $m=$ min(número de termos, número de documentos). A matriz $T_{m}$ é composta pelos vetores singulares (autovetores) esquerdos de $X$, a matriz $D_{m}$ é composta pelos vetores singulares direitos de $X$ e a matriz $S_{m}$ é a matriz-diagonal de valores singulares (autovalores). Normalmente a matriz $X$, e conseqüentemente as matrizes $T_{m}, S_{m}$ e $D_{m}$, são de dimensões grandes e, por isso, difíceis de serem manipuladas. Analisando a matriz $S_{m}$, percebe-se que essa matriz possui células com valores próximos a zero que, segundo a teoria de SVD, podem ser desconsideradas para conservar os componentes linearmente independentes de $X$. Conseqüentemente, devese eliminar os respectivos termos em $T_{m}$ e em $D_{m}$. Dessa maneira, obtém-se um modelo reduzido com dimensão $k$ denominado $\hat{X}$. A partir de então, a matriz $\hat{X}$ é considerada para organizar a estrutura semântica e a aproximação das informações a serem recuperadas. A redução de dimensão da matriz $X$ para a matriz $\hat{X}$ diminui as chances de consultas e de documentos referenciarem o mesmo conceito utilizando diferentes termos. Contudo, essa redução pode provocar diferenças entre os valores das células da matriz original e os valores reconstruídos pelo SVD. Essas diferenças podem ocasionar erros. Na tentativa de reduzir esses prováveis erros, Korn et al. propuseram uma extensão ao modelo algébrico SVD - o SVDD (Korn et al. 1997).

Consultas. A técnica de LSA considerada uma consulta como mais um documento (pseudo-documento) da coleção de documentos indexados, isto é, mais um vetor-coluna da matriz $\hat{X}$. Como o vetor de consulta é calculado sobre valores da matriz $T_{k}$ componente da matriz $X$ aproximada, $\hat{X}$, então o vetor de consulta é considerado aproximado sendo representado por $\left(\hat{V}_{q}\right)$. $\left(\hat{V}_{q}\right)$ é composto pela freqüência dos termos de consulta de acordo com os termos de índice apresentados nas linhas da matriz $\hat{X}$. O vetor aproximado de consulta pode ser calculado da seguinte maneira:

$$
\hat{V}_{q}=T_{k} T_{k}^{\prime} V_{q}
$$

sendo $T_{k}^{\prime}$ a transposta de $T_{k}$.

O grau de similaridade entre $\hat{V}_{q}$ e os documentos pode ser calculado como sendo o co-seno do $\hat{V}_{q}$ por cada vetor-coluna da matriz $\hat{X}$.

Interpretação Geométrica. Interpretar geometricamente as matrizes de decomposição de SVD auxilia na construção da relação do modelo SVD para a definição de similaridades semânticas (Furnas et al. 1988). Comparações úteis podem ser feitas usando as linhas das matrizes $T$ e $D$, que são, respectivamente, vetores-índices para os correspondentes termos e documentos, apropriadamente relacionadas pela matriz diagonal $S$. Portanto ao considerar os vetores das matrizes $T_{k}$ e $D_{k}$ como coordenadas do espaço com dimensão "k" e a matriz $S_{k}$ como um prolongamento dos eixos ortogonais desse espaço, pode-se indicar a estrutura de similaridade de alguns pontos em direção a essas coordenadas.

Devido ao fato das matrizes $T, D$ e $S$ terem dimensões menores que a matriz $X$, seus vetores-linha formam um sistema de indexação eficiente para termos e objetos. Furnas et al. 
(1988) considera que esses termos de índice são importantes na eliminação de ruídos e de redundâncias inerentes da co-ocorrência de termos.

Para o modelo vetorial com comparações lexicais, o grau de similaridade entre dois documentos é calculado pelo co-seno dos documentos. Calcular essa similaridade, em LSA, para todos os pares de documentos da matriz reduzida, é equivalente a realizar a multiplicação de uma matriz $(\hat{X})$ pela sua transposta $\left(\hat{X}^{\prime}\right)$. De acordo com a decomposição SVD, esse cálculo é algebricamente equivalente a:

$$
\hat{X}^{\prime} \hat{X}=(D S)(D S)^{\prime}
$$

Assim, a comparação de um documento $i$ com um documento $j$ é calculada como sendo o co-seno das linhas $i$ e $j$ da matriz $D S$. Paralelamente, a comparação de um termo $i$ com um termo $j$ é realizada através do co-seno das linhas $i$ e $j$ da matriz $T S$ como:

$$
\hat{X} \hat{X}^{\prime}=(T S)(T S)^{\prime}
$$

Finalmente, a comparação de um termo $i$ e de um documento $j$ é realizada da seguinte forma:

$$
\hat{X}=\left(T S^{1 / 2}\right)\left(D S^{1 / 2}\right)
$$

Interpretação Gráfica. As operações definidas em (3.6), (3.7) e (3.8) podem ser representadas em um gráfico. Para facilitar a visualização gráfica do espaço de informação manipulado, deve-se representar o espaço gráfico com duas dimensões em vez de utilizar a dimensão do espaço reduzido com "k". Deve-se aproximar $X$ conservando somente os dois primeiros valores singulares de $S$ e as colunas correspondentes das matrizes $T$ e $D$. As coordenadas $T$ e $D$ posicionam respectivamente termos e documentos no espaço gráfico. O co-seno entre os pontos de termos e os de documentos fornece comparações interessantes para definir similaridades ao escalar os eixos do espaço com os termos da matriz-diagonal $S^{\frac{1}{2}}$.

Para a visualização completa da estrutura semântica latente, o vetor de consulta deve também ser apresentado graficamente. A consulta, considerada um pseudo-documento, deve ser apresentada no espaço SVD como o co-seno de seus termos com os outros pontos dos documentos. Deve-se calcular a partir de um novo documento $\hat{V}_{q}$ da matriz $\hat{X}$, uma nova linha $D_{q}$ na matriz $D$ :

$$
D_{q}=\hat{V}_{q}^{\prime} T S^{-1}
$$

Depois de um apropriado re-escalonamento dos eixos, o vetor de consulta é visualizado no centro dos pontos de termos. A maior contribuição da técnica de LSA é que consultas e documentos não precisam possuir termos em comum para serem considerados semelhantes. Caso o vetor de consulta e o vetor de um documento estejam próximos no espaço geométrico semântico, o documento é considerado similar à consulta. Entretanto, a técnica de LSA apresenta algumas desvantagens:

- alto custo computacional despendido em cálculos. O modelo algébrico SVD, manipu- 
lando matrizes esparsas, apresenta complexidade da ordem de $O(m n c)$, sendo $m$ e $n$ as dimensões da matriz de termos por documentos e $c$ o número de elementos diferentes de zero em cada linha da matriz.

- dificuldade para determinar a dimensão ideal do espaço conceitual reduzido (a matriz $\hat{X})$. Alguns pesquisadores usaram "tentativa e erro" para empiricamente determinar a dimensão ideal (Deerwester et al. 1990). Eles testaram $k$ variando de 50 a 150. Dumais utilizou $k$ variando de 200 a 350 nos experimentos da TREC-3, quando experimentava LSA com técnicas de expansão de consultas (Dumais 1995). Em outra oportunidade, Dumais e outros pesquisadores consideraram 100 dimensões na redução do espaço conceitual de um experimento com recuperação de informação em inglês e em francês (Dumais et al. 1996). Não existe, portanto, consenso sobre o número ideal de dimensões do espaço reduzido e, devido ao custo computacional do método, o SVD é impraticável para utilizar "tentativa e erro".

- problemas de escalablidade. Quando documentos são adicionados à coleção, os novos termos pertencentes a esses documentos não são diretamente considerados na comparação dos vetores. O número de termos não considerados cresce proporcionalmente ao número de documentos adicionados. Para que esses termos sejam considerados, uma nova execução de SVD torna-se necessária e o custo computacional de executá-la deve ser considerado. Contudo, se a coleção é estável, o SVD é executado uma única vez e o custo computacional é aceitável.

Pesquisadores têm proposto ajustes e extensões à técnica de LSA e ao modelo SVD a fim de aprimorá-los (Korn et al. 1997) (Ando 2000) (Ando \& Lee 2001) (Hoenkamp 2001). Inclusive alguns pesquisadores propõem a utilização da técnica de LSA estendida pelo modelo probabilístico para a classificação de informações textuais (Cohn \& Hofmann 2001). Dupret (2003) analisa as possibilidades da técnica de LSA prover mecanismos para compor sinônimos. Esse pesquisador propõe um método para palavras-chave de sinônimos considerando os fatores ortogonais explorados na matriz $S$, que dependem da consulta e da coleção manipuladas. LSA também tem sido utilizada em pesquisas de avaliação de usabilidade de interfaces de usuário (Soto 1999), especificação de consultas booleanas (Baek et al. 2000), classificação de informações textuais (Zelikovitz \& Hirsh 2001) e organização de imagens (Børner 2000).

Além da LSA, outros modelos alternativos para o modelo vetorial são o Modelo Vetorial Generalizado (Wong et al. 1985) e Redes Neurais Artificiais (McCulloch \& Pitts 1943). Em geral para a área de ciências da computação, redes neurais artificiais é uma abordagem computacional que apresenta um modelo matemático algébrico inspirado na estrutura neural de organismos inteligentes que adquirem conhecimento por meio de experiências. Para a área específica de recuperação de informação, redes neurais artificiais são modelos algébricos de recuperação de informação que representam consultas, termos de índices e documentos. Na tentativa de implementar os princípios de aprendizagem competitiva de redes neurais de 
maneira confiável, Kohonen (1982) definiu mapas ordenados globalmente com vários sensores de características em uma camada de rede neural, denominada Self-Organizing Map (SOM). Alguns pesquisadores têm proposto alternativas para reduzir a complexidade da SOM em relação ao número de comparações para assim tornar a SOM mais eficiente (Cuadros-Vargas et al. 2003).

\subsection{Consultas}

O processo básico de busca de informação a partir de consultas em sistemas de IR segue os seguintes passos: (1) o sistema de IR recebe uma consulta $q$ a ser comparada com o conjunto de documentos $d_{1}, d_{2}, d_{3}, \ldots, d n$ indexados previamente pelo sistema; (2) o sistema identifica a similaridade entre $q$ e os $n$ documentos e (3) o sistema de IR retorna uma listagem de documentos relevantes à consulta $q$ ordenada de acordo com o fator de similaridade. Esse fator de similaridade é geralmente calculado a partir de informações estatísticas associadas às propriedades de documentos como, por exemplo, a freqüência na qual os termos da consulta ocorrem no documento (freqüência do termo) ou o número de documentos que contêm os termos da consulta (freqüência inversa).

A busca de informações utilizando consultas de usuários é uma operação que poder ser imprecisa, pois nem sempre a consulta indica exatamente as necessidades do usuário. Esse tipo de problema geralmente acontece devido à dificuldade que o usuário tem de utilizar as linguagens ou tipos de consultas empregados pelos sistemas de IR. Pesquisadores indicam que consultas booleanas são difíceis de serem utilizadas por usuários novatos, mas elas são umas das mais utilizadas pelos sistemas de IR atuais na Web (Baeza-Yates \& Ribeiro-Neto 1999) (Kobayashi \& Takeda 2000).

Outra característica importante de consultas é que elas estão diretamente relacionadas ao modelo de representação de documentos utilizado pelo sistema de IR. Por exemplo, consultas sobre modelos baseados em classificação de índices são diferentes das consultas aplicadas sobre modelos de representação de documentos baseados na estrutura de organização das informações. No primeiro caso, as consultas são especificadas por palavras-chave e, no segundo caso, as consultas devem considerar elementos da estrutura do documento. Um exemplo de linguagem de consulta que manipula a estrutura dos documentos é a linguagem XQuery (2003) do W3C (World Wide Web Consortium ${ }^{11}$ ). XQuery utiliza funcionalidades XPath (1999) para manipular estruturas lógicas de documentos XML (Extensible Markup Language).

Nesta seção, são tratadas consultas textuais baseadas em palavras-chave (consultas especificadas por um único termo ou uma combinação de termos que identificam a informação a ser buscada) e algumas pesquisas sobre recuperação de informação baseada nas estruturas de documentos. Ainda nesta seção são apresentadas técnicas de expansão automática de consultas e índices de avaliação para sistemas de IR.

\footnotetext{
${ }^{11}$ http://www.w3c.org
} 


\subsubsection{Consultas Baseadas apenas em Palavras}

Esse tipo de consulta é composto por consultas especificadas pelo uso de uma única palavra, de várias palavras juntas ou de uma frase. Consultas formadas por várias palavras ou por uma frase são consideradas consultas baseadas em contexto.

\section{Consultas baseadas em apenas uma palavra}

Consultas baseadas em uma única palavra são consultas elementares para qualquer sistema de IR. Esse tipo de consulta é mais indicado para ser realizado sobre modelos de representação de documentos que consideram textos como um conjunto de palavras independentes. Entretanto, nesse tipo de abordagem surgem problemas para a busca por palavras compostas separadas por hífen.

Sistemas de IR que modelam palavras de maneira independente considerariam equivocadamente cada parte da palavra composta como uma nova palavra. Modelos de representação mais elaborados permitem especificar caracteres separadores como hífen que, em alguns casos, não separam palavras; outros consideram a divisão de palavras em letras.

O resultado de consultas baseadas em apenas uma palavra geralmente é um conjunto de documentos que contém pelo menos uma vez, o termo especificado na expressão de consulta. Alguns sistemas de IR destacam a palavra buscada em cada documento recuperado utilizando artifícios de formatação de textos (negrito, itálicos ou highlight).

\section{Consultas baseadas em contexto}

Muitos sistemas de IR complementam as consultas baseadas em uma única palavra com a habilidade de buscar palavras em um dado contexto, isto é, consultas especificadas pelo uso de várias palavras ou uma frase. Para esse tipo de consulta existem dois tipos diferentes de abordagens: consultas que consideram frases e consultas que consideram proximidades. Sistemas de IR que utilizam consultas baseadas em frases não permitem a recuperação de documentos que não apresentem as palavras na ordem em que estão na consulta. Por exemplo, se o usuário colocou os seguintes termos na consulta "Mosquito da Dengue", somente são retornados documentos que apresentam essa seqüência fixa de palavras. Entretanto, as consultas que consideram proximidades são mais flexíveis, sendo permitido que as palavras estejam no documento e um pouco distantes entre si. Por exemplo, nesse segundo caso para a mesma consulta, seriam recuperados documentos contendo a seguinte frase: "O mosquito que pode causar a doença da Dengue é ...".

É importante ressaltar que os modelos de representação não devem ser baseados apenas na divisão do conteúdo dos documentos em palavras, uma vez que palavras possuem significados contextualizados no conteúdo do documento no qual estão inseridas. Por isso, os modelos de representação devem considerar o conteúdo do documento como um todo, e não apenas as palavras como, por exemplo, faz o modelo vetorial. 


\subsubsection{Consultas Booleanas}

Consultas booleanas são consultas formadas pela combinação de palavras-chave ou frases por meio de operadores booleanos. Essa combinação pode ser especificada pela composição de operadores booleanos que podem ser formados a partir de resultados de outros operadores. Essa estrutura pode ser representada por uma árvore sintática na qual os operadores são os nós internos e as consultas básicas correspondem às folhas da árvore. Os operadores booleanos mais tradicionais são:

- OR - causa a recuperação do conjunto de documentos que atende a pelo menos uma das consultas básicas apresentadas na consulta booleana;

- AND - causa a recuperação do conjunto de documentos que satisfaz todas as consultas básicas apresentadas na consulta booleana;

- NOT - causa a recuperação do conjunto de documentos que satisfaz apenas as consultas básicas que não estão conectadas a esse operador.

Nos sistemas de IR que utilizam busca booleana clássica, não existe classificação de documentos baseada em comparações parciais das consultas com os documentos. Essa imparcialidade é decorrente do fato de que as respostas de comparações booleanas tradicionais são sempre verdadeiras (1) ou falsas (0). Para esse tipo de consulta, como para consultas baseadas apenas em palavras, pode-se também apresentar os resultados com destaque das palavras encontradas nas comparações com a consulta. Esse tipo de abordagem é interessante para possíveis reformulações.

Uma das desvantagens desse tipo de consulta é que os usuários consideram difícil manipular operadores booleanos (Greene et al. 1990). Visando minimizar esse problema, pesquisadores estenderam as consultas booleanas, com a criação de novos tipos de operadores e a definição de interfaces mais fáceis de serem utilizadas e mais flexíveis.

\subsubsection{Consultas em Linguagem Natural}

Linguagem natural é a linguagem usada por seres humanos para a comunicação. Em ciências da computação, linguagem natural refere-se a linguagem humana (inglês, português, espanhol, japonês, etc.) explorada na tentativa de comunicar-se com máquinas ${ }^{12}$. O termo linguagem natural usualmente refere-se a linguagem escrita, mas pode também ser utilizado para definir a linguagem falada.

Linguagem natural é um dos desafios de pesquisa mais complexo da Inteligência Artificial, devido à complexidade, irregularidade e diversidade de linguagens humanas e da semântica aplicada. Em computação, especificamente na área de IR, a linguagem natural pode ser utilizada para a especificação de consultas a sistemas de IR.

\footnotetext{
${ }^{12}$ http://dict.die.net/natural\%20language/
} 
Consultas formuladas em linguagem natural são consultas que combinam características de flexibilidade das consultas booleanas com operadores fuzzy com características de consultas intuitivas baseadas em contexto. Contudo a formulação desse tipo de consulta deve ser cuidadosa, sendo que não existe uma sintaxe pré-definida.

Esse tipo de consulta é flexível, pois permite a recuperação de todos os documentos que são parcialmente similares à consulta. Entretanto, consultas baseadas em linguagem natural são complexas de serem processadas, já que é necessária a realização de uma série de manipulações sobre as consultas antes de compará-las à coleção de documentos.

Os modelos de representação de documentos que utilizam esse tipo de consulta são modelos que consideram documentos e consultas como vetores de pesos. É interessante utilizar esse tipo de consulta com operações de expansão de consultas do tipo Relevance Feedback apresentadas a seguir.

Nos últimos anos desenvolvedores de software têm buscado incorporar processamento de linguagem natural como um dos requisitos de seus sistemas. Dessa maneira, eles estarão oferecendo facilidades de interação para os seus usuários, inclusive para a formulação de consultas. Alguns sistemas de IR que suportam processamento de linguagem natural são as aplicações comerciais Schwab (Mearian 2001) e NativeMinds (Johnson 2001).

\subsubsection{Consultas Baseadas na Estrutura dos Documentos}

Consultas baseadas apenas em palavras, consultas booleanas e consultas em linguagem natural estão preparadas exclusivamente para buscar informações sobre o conteúdo indexado, uma vez que desprezam a estrutura da informação manipulada. Contudo, o fato de documentos apresentarem uma estrutura textual pré-definida fornece características atrativas que podem ser exploradas durante a busca de informações. Essas informações adicionais podem ser utilizadas de diferentes maneiras, por exemplo para facilitar um entendimento intuitivo do documento como um todo, simplesmente verificando as estruturas principais que fazem parte do documento. Por exemplo, se a coleção manipulada é um conjunto de correspondências, com destinatário, remetente, data, assunto e corpo de texto, então uma consulta poderia ser feita buscando as correspondências com uma dada pessoa como remetente, e cujo assunto fosse "Recuperação de Informação".

Um benefício imediato do uso de informação estrutural para IR é o aumento do poder de expressividade durante a especificação da informação. Esse benefício é bastante importante quando se fala em grande quantidade de informações como na Web, que nos últimos anos tem incorporado documentos estruturados em sua coleção. Usando a estrutura da informação pode-se manipular informação textual de cada parte do documento e assim facilitar a navegação e a recuperação.

Consultas que consideram a estrutura dos documentos podem também fornecer funcionalidades de recursividade, isto é, o modelo de consulta aceita buscar informações em estruturas de maneira recursiva como, por exemplo, buscar informações em capítulos, seções e subseções desta tese. Consultas baseadas na estrutura de documentos podem ser classifi- 
cadas de acordo com os tipos principais de estruturas de documentos: estrutura padronizada (ex. correspondências e tabelas), estrutura hipertexto (nós, ligações hipertexto e âncoras) e estrutura hierárquica (livros, monografias, documentos HTML e documentos XML). Consultas sobre documentos com estrutura padronizada são um pouco restritivas em relação à utilização da estrutura em consultas, sendo que não existem regras pré-definidas de aninhamento e de repetições que possam ser utilizadas na formulação das consultas.

\section{Consultas em Estruturas Hipertexto}

Consultas em estruturas hipertexto são o paradigma atual predominante para buscas de informação na Web. Esse tipo de consulta geralmente combina a navegação pela estrutura, selecionando as ligações hipertexto, com buscas de conteúdo apoiadas pela formulação de consultas. Por exemplo, a ferramenta ScentTrails permite aos usuários a formulação de consultas, usando palavras-chave, que serão consideradas durante sua navegação para realçar âncoras do tema de interesse apresentado na consulta (Olston \& Chi 2003).

Alguns pesquisadores definiram formas de utilizar informações extraídas de relacionamentos entre páginas Web para buscar documentos (Brin \& Page 1998) (Kleinberg 1999) (Henzinger et al. 1999) (Kang \& Kim 2003). Esses pesquisadores sugerem que informações a cerca de ligações hipertexto e endereços de páginas Web podem auxiliar na busca de informações na Web. Medidas inicialmente definidas nesse sentido foram o número de páginas que referenciam cada página e o número de referências que uma página faz a outras páginas (Kleinberg 1999) (Kleinberg 2000). Um aprimoramento qualitativo dessas medidas sugere que não seja considerado apenas o número de páginas que referenciam uma determinada página, mas também as probabilidades de navegação de usuários em páginas Web, denominada PageRank (Henzinger et al. 1999). A aplicação Web Google ${ }^{13}$ utiliza informações da estrutura das ligações hipertexto na análise e busca dos documentos manipulados (Henzinger 2001).

Kang \& Kim (2003) sugerem a classificação das consultas e a seleção de documentos alvos da consulta, utilizando informações de conteúdo e de estrutura de páginas Web. Nesse esquema de classificação são utilizadas diferenças de distribuição de páginas, informação mútua dos relacionamentos e a taxa de utilização de âncoras textuais para definir categorias de consultas de usuários. Kang \& Kim (2003) aplicam diferentes algoritmos de classificação e busca na tentativa de obter resultados mais precisos. Para as consultas de busca por contexto, eles utilizam algoritmos que enfatizam a manipulação do conteúdo da informação. Já para a tarefa de busca por homepages e serviços, os algoritmos devem priorizar as informações sobre a estrutura das ligações hipertexto e de endereços de páginas Web.

Buscas em estruturas hierárquicas combinam estruturas padronizadas com estruturas hipertexto. Existem diferentes propostas de modelos hierárquicos que se adeqüam a consultas que exploram marcações textuais (tags), listas de referências e caminhos em árvores.

\footnotetext{
${ }^{13}$ http://www.google.com
} 


\section{Consultas em Estruturas Hierárquicas}

Hierarquias fornecem uma maneira de organizar, resumir e acessar informação. Documentos estruturados são documentos que incorporam a estrutura do documento na descrição do conteúdo. Alguns pesquisadores definem hierarquias de modo automático. Por exemplo, Lawrie \& Croft (2003) descrevem um método para automaticamente gerar hierarquias a partir de pequenas coleções textuais com o intuito de usá-las para resumir os documentos recuperados. Esses pesquisadores relatam que o principal desafio de criar hierarquias automáticas é selecionar os termos corretos que precisamente descreverão o conjunto de documentos para os usuários. Eles demonstraram que a utilização de termos de índice com mais alto peso atribuídos pelos esquemas TF e IDF podem não ser eficientes (Lawrie \& Croft 2003). Em muitos casos documentos estruturados são organizados hierarquicamente por meio do uso de linguagens de marcações como SGML (Standard Generalized Markup Language) ou XML.

XML. Documentos podem ser constituídos de conteúdo, de estrutura, de apresentação, de semântica, de metadados ${ }^{14}$ e de componentes de hipertexto. Por exemplo, documentos HTML geralmente são formados por conteúdo, estrutura, especificação de apresentação, metadados, um simples modelo de ligação hipertexto binário e unidirecional, e praticamente nenhuma informação semântica. A linguagem HTML é limitada para atender à demanda de aplicações hipermídia avançadas.

Para superar as limitações da linguagem HTML, o W3C definiu a linguagem XML apropriada à representação de dados, documentos e demais entidades, cuja essência fundamentase na capacidade de agregar informações (Bray et al. 1998).

Um documento XML representa, basicamente, duas dimensões de informação: o conteúdo propriamente dito e a estrutura organizacional do conteúdo. A Recomendação XML possibilitou a definição de especificações que representam as demais dimensões de informação de um documento. Existem muitas aplicações de XML reportadas na literatura. Uma importante aplicação é o intercâmbio de dados eletrônicos (Electronic Data Interchange - EDI) entre duas ou mais fontes de dados na Web. Um documento XML é uma seqüência de elementos, cada qual consistindo de conteúdo textual e/ou outros elementos, isto é, cada <endereco $>$ deve ter um </endereco $>$ associado e este deve estar apropriadamente aninhado. Um documento XML que tenha os pares de elementos propriamente aninhados é bem-formado. Os elementos em XML podem ser representados por objetos em base de dados orientadas a objetos ou relacionais. Por exemplo, um $<$ pessoa $>\ldots</$ pessoa $>$ corresponderia a um objeto pessoa ... . Elementos aninhados correspondem a campos de objetos, isto é, os elementos $<$ nome $>$, $<$ telefone $>$ e $<$ endereco $>$ em $<$ pessoa $>$ corresponderiam aos campos nome, telefone e endereco do objeto pessoa.

Dada a sua flexibilidade, XML facilita o intercâmbio de grande quantidade de informação na Web. Porém, a disponibilidade de grandes quantidades de documentos XML na Web implica em diversas questões técnicas que o padrão XML não considera como, por exemplo,

\footnotetext{
${ }^{14}$ Metadados são dados sobre outros dados. Por exemplo, livrarias têm como metadados: autor, título, assunto, editora e a localização física de cada livro.
} 
como as informações serão extraídas dos documentos XML?, como os documentos XML serão compartilhados, usando outros documentos XML ou consultas?, como as informações XML serão compartilhadas por comunidades, usando ontologias ou XMLSchemas?, como os XMLs de diferentes fontes de informação poderão ser integrados? Parte dessas questões são foco de estudo de pesquisadores de Banco de Dados e de IR, quando se trata principalmente de Web.

XML para IR. Extração de dados, transformação e integração são conhecidos problemas das áreas de Banco de Dados (BD) e IR para o caso da Web. As soluções em BD normalmente estão relacionadas com linguagens de consultas tanto relacionais (SQL) como orientada a objetos (OQL). Porém, essas linguagens de consultas não podem ser diretamente relacionadas com XML, porque informações em XML diferem de informações em banco de dados relacionais ou mesmo em banco de dados orientado a objetos. Documentos XML, contudo, são similares a outros modelos de dados estudados pelas comunidades de pesquisas: os modelos de dados semi-estruturados. Algumas pesquisas em linguagens de consulta têm sido projetadas e implementadas para documentos XML.

O consórcio W3C tem um grupo de trabalho de definição de linguagens de consulta XML (o XML Query Working Group) interessado em produzir um modelo de dados para documentos XML, um conjunto de operadores de consultas sobre esse modelo e uma linguagem de consulta baseada nesses operadores de consulta. Uma linguagem de consulta chamada XML-QL foi proposta ao W3C em 1998. XML-QL permite a formulação de consultas, que exploram algumas informações presentes em documentos XML e também algumas transformações que podem mapear elementos XML declarados em suas gramáticas e assim integrar diferentes fontes de informação (Deutsch et al. 1999). Fuhr \& Grojohann (2000) propuseram o XQIRL como extensão do XML-QL para os propósitos específicos de IR. XQIRL explorava um modelo lógico-probabilístico para manipular informações extraídas a partir de bases de dados relacionais. XQIRL foi remodelada como uma linguagem de consulta XML que incorpora conceitos de imprecisão manipulado pelo modelo probabilísticos tanto para consultas baseadas em estrutura como para consultas baseadas em conteúdo (Fuhr \& Grojohann 2004). Uma das funcionalidades mais interessantes da XQIRL é a possibilidade de recuperar apenas partes relevantes de documentos. Uma base de dados XIRQL pode conter várias classes de documentos com todos os documentos da classe em conformidade com o mesmo DTD. Ligações entre documentos também são suportadas pela nova versão da XIQRL, mas consultas XIRQL são ainda formuladas utilizando caminhos algébricos. Uma das desvantagens de utilização da XQIRL é o fato dela ainda não suportar XMLSchema.

Além do XML-QL, o grupo de linguagens de consulta XML do W3C definiu a linguagem XQuery (XQuery 2003) para atender os requisitos ${ }^{15}$ identificados por esse grupo para consultas a documentos XML. No ano de 2003, Carmel et al. (2003) sugeriram uma extensão para a linguagem de consulta XQuery. Essa extensão foi apoiada pelo modelo vetorial para busca e ordenação de documentos XML utilizando XQuery. Yu et al. (2003a) exploraram XQuery

\footnotetext{
${ }^{15}$ http://www.w3.org/TR/xquery-requirements/\#Requirements
} 
para manipular informações de um sistema de banco de dados XML nativo, o banco de dados Timber. Desse modo, esse sistema tornou-se capaz de manipular consultas estruturais XQuery, além de consultas textuais. A extensão proposta incorporou artifícios de IR como palavras-chave e condições não-booleanas na manipulação de XQuery. Outras pesquisadores utilizaram outros padrões XML como, por exemplo, o padrão XPath para percorrer árvores de dados representativas de documentos XML para a indexação de suas informações (Fuhr 2003).

Desconsiderando padrões W3C, Yu et al. (2003b) exploram álgebra TIX (Al-Khalifa et al. 2003) para buscas em documentos XML. Kotsakis (2002) propôs um método que utilizava expressões construídas a partir da captura de caminhos percorridos durante a navegação para definir os termos de índice para coleções XML e assim facilitar a busca de informações desejadas. Para esse fim, esse pesquisador combinou as estruturas hierárquicas de documentos XML com a estrutura de um arquivo-invertido. Shah et al. (2002) propuseram a inclusão de definições RDF, a partir de ontologias, para suprir a falta de informações semânticas em documentos XML.

Além das consultas já apresentadas, existem ainda consultas por padrões de comparação. Nas consultas por padrões de comparação, um padrão é definido como um conjunto de características sintáticas que precisam ocorrer em um segmento de texto para que o documento seja considerado e retornado ao usuário. Os principais tipos de padrão são strings, sub-strings, prefixos, sufixos, intervalos e expressões regulares. Consultas por padrões de comparação são geralmente utilizadas para extração de dados e de informações estatísticas.

A combinação de consultas que exploram a estrutura dos documentos com consultas baseadas em conteúdo tornam a consulta mais expressiva e podem trazer resultados que o uso exclusivo de uma das duas abordagens talvez não alcançasse. Segundo Baeza-Yates \& Ribeiro-Neto (1999), essa combinação pode aprimorar a qualidade da recuperação de informações em base de dados textuais.

A grande desvantagem da utilização de consultas baseadas na estrutura é que elas são dependentes do modelo textual. Outra desvantagem é que a estrutura de dados das informações pode ser mais complexa para manipular do que simplesmente o conteúdo. Por esses motivos um dos trabalhos de aplicação da abordagem proposta nesta tese utiliza um modelo vetorial de IR para armazenamento e manipulação do conteúdo e da estrutura de documentos XML.

\subsubsection{Expansão de Consultas}

Técnicas para expansão de consultas surgiram a partir de observações da dificuldade dos usuários em formular consultas e do fato de que os usuários sempre reformulavam a consulta original em uma tentativa de aprimorar os resultados obtidos. O processo de expansão de consultas envolve dois passos básicos para o sistema de IR: expansão da consulta com os novos termos e reformulação dos pesos dos termos da consulta expandida.

Expansão da consulta original consiste na interação com usuários e na utilização au- 
tomática de propriedades dos documentos recuperados para expandir a consulta original com o objetivo de torná-la mais efetiva. Na tentativa de aprimorar o desempenho de técnicas automáticas de expansão de consultas, Billerbeck \& Zobel (2003) quantificaram o desempenho de uma técnica de expansão de consultas e mostraram que o uso de parâmetros fixos para todas as consultas pode ser significamente aprimorado por meio de boas escolhas de parâmetros. Contudo esses pesquisadores não esclareceram como os parâmetros deveriam ser escolhidos. Billerbeck \& Zobel não identificaram uma maneira de fornecer dicas para realizar expansão de consultas. A seguir são apresentadas abordagens de expansão de consultas a partir de operação realizada com o auxílio de usuário e através de análises automáticas dos documentos recuperados ou de toda a coleção de documentos.

\section{Relevance Feedback}

Relevance feedback é um processo por meio do qual consultas podem ser seletivamente modificadas na tentativa de recuperar documentos mais relevantes de uma coleção de documentos (Rocchio 1971) (Baeza-Yates \& Ribeiro-Neto 1999). A consulta pode ser modificada com ajustes de pesos de termos da consulta, da inclusão de novos termos ou da combinação das duas abordagens. Essas abordagens de modificação da consulta original podem ser efetuadas via interação com usuários ou pela utilização automática de propriedades dos documentos recuperados.

O cálculo de relevance feedback de Rocchio (1971), apresentado na Equação 3.10, inclui à consulta inicial, após análise de relevância realizada por usuários, um conjunto de documentos relevantes. Os pesos dos vetores que modelam os documentos considerados relevantes são somados $\left(\vec{d}_{j}\right)$ e os vetores são normalizados em um novo vetor $\left(\left|D_{r}\right|\right)$ dividindo-se o vetorsoma de documentos relevantes pelo número de documentos relevantes. Um processo similar pode ser realizado para os documentos considerados irrelevantes. Os vetores resultantes podem ser modificados pela multiplicação de valores de ajuste $(\alpha, \beta$ e $\gamma)$. Na fórmula original de Rocchio, o valor de $\alpha$ é fixado em "1" (Baeza-Yates \& Ribeiro-Neto 1999) (Rocchio 1971). Finalmente, o vetor da consulta $(\vec{q})$ original deve ser modificado incluindo-se o novo vetor de documentos relevantes e subtraindo-se o novo vetor de documentos irrelevantes. Todo esse processo pode ser repetido por meio de múltiplas iterações até o usuário considerar satisfatório os resultados retornados.

$$
\vec{q}_{m}=\alpha \vec{q}+\frac{\beta}{\left|D_{r}\right|} \sum_{\forall \vec{d}_{j} \in D_{r}} \vec{d}_{j}-\frac{\gamma}{\left|D_{n-r}\right|} \sum_{\forall \vec{d}_{j} \in D_{n-r}} \vec{d}_{j}
$$

O trabalho de Ide (1971), baseado no trabalho de Rocchio, propõe a eliminação dos vetores normalizados $\left(\left|D_{r}\right|\right.$ e $\left.\left|D_{n-r}\right|\right)$ como apresentado na Equação 3.11. Ao eliminar esses vetores e fixar $\alpha=\beta=\gamma=1$, Ide propõe a utilização dos valores de cada elemento dos vetores de forma integral (Ide 1971). Na fórmula de Rocchio os vetores normalizados permitiam a utilização ponderada dos valores desses vetores. A fórmula de Rocchio é um pouco mais cara computacionalmente que a fórmula de Ide, mas ambas levam a resultados similares. 
Ide também experimenta a diminuição do valor de ajuste de $\gamma$, considerando apenas os documentos irrelevantes mais expressivos como apresentado na Equação 3.12. Algumas vezes, $\gamma$ pode ser considerado zero ocasionando uma estratégia de feedback totalmente positiva, isto é, baseada apenas no conjunto de documentos relevantes.

$$
\begin{gathered}
\vec{q}_{m}=\alpha \vec{q}+\beta \sum_{\forall \vec{d}_{j} \in D_{r}} \vec{d}_{j}-\gamma \sum_{\forall \vec{d}_{j} \in D_{n-r}} \vec{d}_{j} \\
\vec{q}_{m}=\alpha \vec{q}+\beta \sum_{\forall \vec{d}_{j} \in D_{r}} \vec{d}_{j}-\gamma \max _{\text {non-relevant }}\left(\vec{d}_{j}\right)
\end{gathered}
$$

Segundo Baeza-Yates \& Ribeiro-Neto (1999), as principais vantagens das técnicas de relevance feedback, apresentadas nas Equações 3.10, 3.11 e 3.12, são a simplicidade e os bons resultados. A simplicidade está relacionada ao fato de que os pesos dos termos modificados são calculados diretamente a partir do conjunto de documentos recuperados. Já os bons resultados estão relacionados ao fato de que o vetor modificado de consulta $\left(\vec{q}_{m}\right)$ procura refletir a consulta semântica pretendida. Porém, a grande desvantagem da utilização do método de relevance feedback é a dependência do julgamento de relevância por usuários. Uma solução que tem sido adotada para esse problema é a utilização automática de propriedades de documentos como informação de feedback (Xu \& Croft 1996) (Xu \& Croft 2000).

Harman realizou experimentos comparando o desempenho do método de relevance feedback para informações modeladas com o uso de vetores (modelo vetorial) e para informações representadas de acordo com propriedades do conjunto de documentos manipulado (modelo probabilístico) (Harman 1992). Harman concluiu que técnicas de relevance feedback são mais efetivas para informações representadas pelo modelo vetorial como, por exemplo, da técnica de LSA. Essa constatação motivou um dos trabalhos apresentados nesta tese.

\section{Expansão Automática de Consultas}

A estratégia de Relevance Feedback é apoiada pelo conhecimento semântico implícito dos usuários durante a análise de relevância dos documentos. Entretanto, essa análise pode ser auxiliada pelo próprio sistema de IR ao incorporar automaticamente termos para a expansão da consulta original. Para a realização dessa tarefa o sistema necessita implementar algoritmos que façam a identificação dos termos que estão relacionados aos termos da consulta. É nesse tipo de abordagem que os procedimentos de expansão automática de consultas estão apoiados. Existem expansões automáticas de consultas que analisam apenas os documentos recuperados enquanto outras analisam toda a coleção de documentos.

Análise Automática Local. Na estratégia local de expansão de consultas, os documentos recuperados para uma consulta $q$ são examinados no tempo de execução da consulta para determinar os termos que podem ser utilizados na expansão. Esse processo é similar ao processo de relevance feedback mas pode ser realizado sem a assistência de usuários ou com a participação parcial dos mesmos. As estratégias de análise local mais conhecidas 
são análise local baseada em categorias e análise local baseada em contexto. A primeira é formulada a partir da análise de documentos para identificar a correlação dos termos para a expansão da consulta, e a segunda ilustra as vantagens de combinar as duas técnicas. Alguns pesquisadores exploram análise local baseada em contexto na tentativa de aprimorar a efetividade de sistemas de IR (Robertson et al. 1992)(Xu \& Croft 1996) (Xu \& Croft 2000).

Análise Automática Global. Na abordagem de expansão de consulta utilizando análise global dos documentos, todos os documentos da coleção são utilizados para determinar uma estrutura global que define relacionamentos entre os termos. Essa estrutura global é normalmente representada por um sistema de organização de conhecimento, por exemplo taxonomias, ontologias e thesauri que são utilizados para expandir a consulta. Esses sistemas de organização de conhecimento têm como objetivo representar a estrutura semântica da informação e ser utilizado como uma estrutura auxiliar a indexação, a recuperação e como novas fontes de informações. Por exemplo, Xu \& Croft (1996) exploraram análise local e análise global, em termos de manipulação de co-ocorrência de termos, no sistema INQUERY para aprimorar o desempenho desse sistema.

Em IR, os pesquisadores geralmente usam thesauri para expansão de consultas, na tentativa de ajudar o usuário a expressar melhor suas idéias nas consultas formuladas. Há diversas definições para thesaurus na literatura e a maioria enfatiza o aspecto de definição de relacionamentos lexicais e a prioridade de manipulação de conceitos, em vez de palavras. Baeza-Yates \& Ribeiro-Neto (1999) definem thesaurus como sendo um esquema de classificação de palavras ou frases que ajuda a expressar as idéias em textos escritos.

Baeza-Yates \& Ribeiro-Neto (1999) classificam thesauri em thesaurus de similaridade e thesaurus estatístico. Um thesaurus de similaridade é normalmente formado por relacionamentos termo a termo para cada documento da coleção global manipulada. Esses relacionamentos são obtidos considerando que termos são conceitos em um espaço conceitual. Já thesaurus estatístico é baseado na co-ocorrência dos termos nos documentos. Gonzalez \& Lima (2003) subdividem thesauri de similaridade em sintáticos, baseados no cálculo de similaridade sintática ou em padrões léxico-sintáticos, e em semânticos, baseados na captura do conhecimento semântico lexical. Esses mesmos pesquisadores também classificam thesauri de acordo com:

- o grau de automatização da composição do thesaurus. Thesauri podem ser manuais, assumindo características de uma ontologia de abrangência geral e tipicamente semânticos, ou automáticos, geralmente estatísticos e de domínio específico.

- a abrangência das informações armazenadas. Um thesaurus pode ser de domínio específico, geralmente dependentes de corpus $^{16}$, ou genéricos.

- a composição de cada item lexical. Assim thesauri podem ser baseados em palavra, sendo cada termo uma palavra, ou baseados em sintagma, sendo cada termo um item

\footnotetext{
${ }^{16}$ Conjunto de documentos sobre um determinado assunto ou com uma finalidade comum.
} 
lexical composto por uma ou mais palavras.

- o idioma, os thesauri podem ser monolíngües, em um único idioma, ou multilíngües, que adotam dois ou mais idiomas.

Englobando as classes de thesaurus automático e de domínio específico, Chen et al. (2003) propuseram uma maneira de criar automaticamente thesauri de domínio específico para Web, apoiando-se nas informações da estrutura das ligações hipertexto do domínio. Primeiramente, um conjunto representativo de qualidade de sítios Web de um domínio específico é selecionado. Depois de filtrar as ligações hipertexto navegacionais desse conjunto, análises de ligações hipertexto são aplicadas para cada sítio Web para obter a estrutura do conteúdo por meio, por exemplo, de um grafo cujos nós representam as páginas Web que são os conceitos. Finalmente, o thesaurus é construído através da integração das estruturas dos sítios Web selecionados. Os resultados dos experimentos sobre a expansão automática de consultas usando o thesaurus proposto apresenta, segundo os pesquisadores, um aprimoramento de $20 \%$ na busca em termos de precisão (Chen et al. 2003).

O primeiro thesaurus organizado por tópicos foi criado pelo físico Peter Mark Roget e publicado em 1852 (Today in Literature 2003). Roget e outros pesquisadores descreveram o surgimento e desenvolvimento de sinônimos desde os estudos de Platão até o século XVII (Roget et al. 1958). Outros exemplos de thesaurus são: Macquarie Thesaurus (Bernard 1986), WordNet (Miller 1990), EuroWordNet (Peters et al. 1998), T-Lex (Gonzalez \& de Lima 2001), Merriam-Webster Online dictionary and thesaurus (Merriam-Webster Inc. 2004).

\subsection{Avaliação Clássica de Sistemas de IR}

Pesquisadores de IR têm devotado considerável atenção para questões de avaliação de sistemas de IR. Nesse sentido, medidas de avaliação e coleções de referências têm sido desenvolvidas.

\subsubsection{Coleções de Referência}

Para permitir a avaliação dos resultados obtidos com sistemas de IR, em termos de revocação (recall) e precisão (precision), todas as informações manipuladas em consultas e documentos precisam ser analisadas por especialistas conhecedores do conteúdo manipulado com o intuito de criar uma coleção de referência. Nessa análise, os especialistas indicam quais documentos, de toda a coleção de informação, podem ser considerados relevantes para cada consulta. Algumas das coleções de referência utilizadas pela comunidade científica de IR são CACM (Fox 1983), TREC (TREC 2004) e Cystic Fibrosis (Shaw et al. 1991).

A coleção de referência CACM tem importância histórica para a comunidade de IR e para pesquisadores de ciência da computação em geral, sendo que ela é composta por artigos publicados na Communications of the ACM de 1958 a 1979. CACM é uma grande coleção de informações com 3204 artigos estruturados e 52 consultas. 
TREC é uma coleção de referência recente que foi criada com o intuito de incentivar pesquisas de IR sobre grande quantidade de informação atualizada. Além da coleção de referência, os grupos organizadores da Text REtrieval Conference (TREC), Defense Advanced Research Projects Agency (DARPA) e National Institute of Standards and Technology (NIST), definem procedimentos de avaliação uniformes e um fórum anual para organizações interessadas em comparar resultados obtidos com o uso de sistemas de IR. O objetivo dessas conferências é incentivar a interação entre os grupos de pesquisadores nas empresas e no ambiente acadêmico. As TRECs são considerados importantes exercícios de avaliação de sistemas de IR, com muitos participantes de diversos países e grande variedade de técnicas propostas. Normalmente as coleções TREC são composta por coleções de documentos de diversas fontes de informação como, por exemplo, o Wall Street Journal, o Financial Times, o San Jose Mercury News, documentos do setor de Patentes dos EUA, além de artigos e resumos de suas próprias publicações ${ }^{17}$. Por exemplo para a TREC 2002, Soboroff \& Robertson (2003) construíram um conjunto de tópicos de pesquisa para a coleção de informações Reuters. Esses pesquisadores pretendiam medir a performance de sistemas de filtragem.

Cystic Fibrosis (CF) é uma coleção formada por 1239 documentos em inglês obtidos da base de dados MEDLINE da National Library of Medicine e por um conjunto de 100 consultas com indicações de suas relevâncias para cada documento da coleção (Shaw et al. 1991). As indicações de relevância de cada consulta para cada documento fazem parte da coleção e foram definidas por quatro usuários especialistas na área de fibrose cística (cystic fibrosis).

\subsubsection{Indice de Revocação}

Índice de revocação é definido como a fração de documentos relevantes que foram recuperados pelo sistema de IR. Esse índice indica o grau de exaustão de execução do sistema e o número de documentos recuperados que o usuário poderia querer. O índice de revocação é definido por:

$$
\text { IndiceDeRevocacao }=\frac{\mid \text { Rel } \cap \text { Ret } \mid}{\mid \text { Rel } \mid}
$$

As variáveis $R e l$ e Ret são, respectivamente, o conjunto de documentos relevantes recuperados e o conjunto total de documentos recuperados. O melhor índice de revocação é 1.0 (ou $100 \%$ ) e o pior 0.0 .

\subsubsection{Indice de Precisão}

Índice de precisão corresponde à fração de documentos recuperados que são relevantes. O índice de precisão mede a especificidade da busca e se todos os documentos recuperados são

\footnotetext{
${ }^{17}$ http://trec.nist.gov/data/docs_eng.html
} 
realmente relevantes. Esse índice é definido por:

$$
\text { IndiceDePrecisao }=\frac{\mid \text { Rel } \cap \text { Ret } \mid}{\mid \text { Ret } \mid}
$$

O melhor índice de precisão é 1.0 e o pior 0.0. O objetivo em IR é obter, simultaneamente, os melhores índices de precisão e de revocação. Esse objetivo é difícil de ser alcançado e, normalmente, os sistemas de IR com baixo índice de precisão possuem alto índice de revocação e vice-versa.

O cálculo dos índices de precisão e revocação demanda que um usuário, experiente no assunto pesquisado, indique que documentos são relevantes entre todos os recuperados.

Calcular a eficiência global de um sistema de IR é uma tarefa complicada. Normalmente as medidas de eficiência tendem a correlacionar os índices de precisão e de revocação, que geralmente são inversamente proporcionais. Uma possível solução seria criar uma medida que realizasse uma junção dos dois índices em vez de correlacioná-los. Alguns pesquisadores propõem novas medidas (Jin et al. 2001) e metodologias (Soboroff et al. 2001) para avaliar o desempenho de sistemas de IR.

Motivados pela vontade de eliminar a participação de usuários no processo de avaliação de sistemas de IR, Jin et al. (2001) propuseram uma função "meta-score" que considerada duas ou mais matrizes de termos por documentos geradas por diferentes esquemas de atribuição de pesos para automaticamente definir os índices da coleção. Esses pesquisadores utilizam SVD e distribuição condicional probabilística para calcular os resultados da função proposta. Jin et al. (2001) concluem que o procedimento automático de avaliação proposto é consistente com avaliações humanas e bom para avaliação de esquemas de atribuição de pesos.

Experimentos apresentados na TREC-8 mostraram que diferenças nas avaliações humanas para relevâncias durante a formação de coleções de referência não afetavam o desempenho medido para sistemas de IR. Apoiados por esses resultados, Soboroff et al. (2001) propuseram e descreveram os resultados iniciais da definição de uma nova metodologia de avaliação a qual substitui avaliações humanas de relevância pelo mapeamento randômico de documentos a tópicos (pseudo-relevância). Soboroff et al. (2001) afirmam que conseguiram resultados positivos com a metodologia proposta.

Embora os índices de revocação e de precisão tenham sido desenvolvidos para medir a eficiência dos algoritmos de IR, outros pesquisadores defendem a utilização desses índices para qualificar o desempenho combinada de usuário e sistema de IR (Nielsen 1990). Por exemplo, Swan \& Allan (1998) utilizam os índices de precisão e de revocação para comparar a usabilidade de diferentes interfaces de visualização.

\subsection{Considerações Finais}

Estruturas e características de hiperdocumentos podem ser exploradas para a busca, a navegação e a apresentação da informação manipulada por sistemas de IR. Nos últimos tempos, 
pesquisas da área de Recuperação de Informação têm expandido suas metas inicias (representação, indexação e busca de informação textual) devido ao desenvolvimento de sistemas de IR para Web, sendo que a Web é um ambiente com características bem distintas se comparadas aos sistemas clássicos de IR.

Apesar da comunidade de IR continuar investigando alternativas de representação e de indexação de informações, as atuais metas ou desafios de pesquisas de IR na Web incluem: arquitetura de sistemas, modelagem, classificação, categorização, filtragem de informação, linguagens, manipulação de informações multimídia, manipulação de páginas dinâmicas, manipulação de informações duplicadas, navegação, Intranet, interfaces de usuário e visualização de informação (Baeza-Yates \& Ribeiro-Neto 1999). Alguns trabalhos que exploram tais técnicas são apresentados no capítulo anterior.

O trabalho proposto nesta tese contribui com as atuais metas de pesquisa de Hipermídia ao especificar um arcabouço para apoio à criação automática de ligações hipertexto entre documentos. Neste capítulo foram apresentados conceitos fundamentais de IR com foco na representação e na busca de informações em documentos textuais. Vários desses conceitos foram explorados no contexto do trabalho proposto nesta tese como, por exemplo, técnicas de expansão de consulta, manipulação de documentos estruturados para IR e um dos modelos estendidos apresentado - a técnica de LSA. Portanto, tanto as abordagens de IR apresentadas, como os trabalhos sobre criação de relacionamentos apresentados no capítulo anterior, auxiliaram na análise de domínio e na definição de serviços de criação automática de ligações apresentados no próximo capítulo. 




\section{Análise do Domínio para Construção de Mecanismos de Criação Automática de Ligações Hipertexto}

\subsection{Considerações Iniciais}

Salton (1986) foi pioneiro na exploração de mecanismos de recuperação automática de informação textual para indexar coleções de documentos. Salton observou que a homogeneidade da informação é uma das características importantes para sistemas de recuperação de informação. Pesquisas recentes combinam técnicas tradicionais de recuperação de informação com conhecimentos abstraídos a partir da estrutura dos hiperdocumentos para aprimorar os resultados e as buscas realizadas por aplicações na Web (Henzinger et al. 1999) (Silva et al. 2000) (Ng et al. 2001) (Henzinger 2001).

O ambiente eClass, apresentado na Seção 2.4.1 do Capítulo 2, é um ambiente ubíquo de captura e acesso que automaticamente captura experiências ao vivo de salas de aula convencionais e gera hiperdocumentos que posteriormente são disponibilizados na Web. Já a CoWeb (Collaborative Website) é uma ferramenta computacional hipermídia que permite a autoria colaborativa de páginas Web sem que o usuário necessite de conhecimento prévio de quaisquer tecnologias relacionadas, como comunicação cliente-servidor, linguagens de marcação e de scripts (Guzdial 1999). A fim de facilitar a busca por material de conteúdo similar entre dois repositórios homogêneos e complementares em informações, foi reportado um serviço de criação manual de ligação hipertexto bi-direcional entre informações capturadas pelo eClass e páginas criadas na CoWeb quando esses dão suporte ao mesmo curso (Abowd et al. 1999). Assim, a informação capturada pelo eClass e a informação disponibilizada na CoWeb tratam 
do mesmo tema e são, no contexto desta tese, consideradas homogêneas.

Motivada pelo resultado do serviço manual de criação de ligações, a doutoranda iniciou uma análise de domínio sobre outras alternativas de integração de ambientes homogêneos como os ambientes eClass e CoWeb. Um dos requisitos levantados na época era a definição de um mecanismo automático que não sobrecarregasse os usuários. Nesse sentido, foi definido um serviço de criação automática de ligações hipertexto lexicais entre os mesmos ambientes, eClass e CoWeb (Pimentel et al. 2001b). Essa abordagem explorava a natural homogeneidade do conteúdo dos repositórios utilizando simples comparações lexicais de palavras, em vez de técnicas elaboradas de Recuperação de Informação. Porém, comparações lexicais podem omitir relacionamentos devido à existência de sinonímia ou criar relacionamentos imprecisos devido à ocorrência de polissemia.

A partir de pesquisas sobre técnicas de IR para indexação semântica, foi escolhida a técnica de Análise da Semântica Latente (Latent Semantic Analysis - LSA) para apoiar a definição de ligações hipertexto semânticas entre repositórios Web homogêneos e assim evitar problemas de dependência de vocabulário associados a técnicas baseadas em comparações lexicais (Macedo et al. 2001b). Posteriormente, esse trabalho foi estendido com a definição de um módulo que facilitava o armazenamento dos relacionamentos criados, inclusive possibilitando o uso de bibliotecas de ligações (Macedo et al. 2002b).

Para permitir a participação explícita de usuários no processo de definição de ligações hipertexto entre coleções similares, também foram definidos módulos de consulta e de retroalimentação (feedback) de usuários (Macedo et al. 2002a). Para todos os serviços mencionados, apenas o conteúdo textual dos documentos era considerado; mas um sistema de IR pode beneficiar-se do uso de informações de estrutura dos documentos (Brin \& Page 1998). Nesse sentido, foi definido também um serviço de criação de ligações entre documentos estruturados.

A cada extensão dos serviços citados, foram analisados os domínios em questão e especificadas infra-estruturas de software, módulos de programa e APIs (Application Programming Interfaces) para atender os requisitos advindos dos objetivos propostos. Esses componentes foram, ao final do trabalho da doutoranda, abstraídos no arcabouço proposto. Neste capítulo são apresentados os resultados obtidos em relação à análise do domínio para construção dos serviços de criação automática de ligações mencionados. As modelagens subjacentes aos serviços também são apresentadas.

\subsection{Criação Automática de Ligações Lexicais}

\subsubsection{Investigação do Domínio}

Com o intuito de beneficiar-se da natural homogeneidade existente entre informações tais como aquelas capturadas pelo eClass e as páginas disponibilizadas CoWeb para apoiar as atividades do mesmo curso, objetivava-se criar automaticamente ligações hipertexto entre 
as informações desses repositórios. Acreditava-se que esse trabalho poderia trazer benefícios ao sistema, sem sobrecarregar o usuário como acontecia no serviço manual (Abowd et al. 1999).

Para alcançar o objetivo proposto, foi definido como requisito utilizar simples comparações da estrutura lexical de palavras para identificar relacionamentos entre as informações armazenadas nos repositórios eClass e CoWeb. Esse requisito era apoiado pela seguinte hipótese: se as informações armazenadas nos repositórios homogêneos contiverem as mesmas palavras, elas, provavelmente, devem estar relacionadas. Para investigar essa hipótese, foi analisado um modelo implícito que as informações armazenadas nesses ambientes sugerem:

- O espaço de informações do eClass contém detalhes das informações que foram capturadas a partir de aulas presenciais. Essas informações incluem: os textos de cada slide (textos de slides pré-preparados e as transcrições de anotações manuais sobre os slides), anotações adicionadas pelos professor depois da aula, os endereços e os títulos de páginas Web visitadas durante a aula. Durante a captura de aulas tradicionais, todas as informações podem ser consideradas relevantes para o curso como um todo, visto que os apresentadores tendem a registrar em seus slides um resumo dos pontos mais importantes de cada aula.

- O espaço de informações CoWeb é composto por páginas criadas fora da aula presencial capturada. Em um curso típico suportado pela CoWeb, as páginas armazenadas no repositório podem ser classificadas em páginas: organizacionais (descrevem as atividades a serem realizadas durante o período do curso), pessoais (normalmente introduzem o professor e os alunos) e páginas de conteúdo (Guzdial 1999) (Macedo et al. 2001a). As páginas de conteúdo são criadas por estudantes e professores para conter matérias como questões a serem debatidas, resultados dos debates e outras tarefas a serem desenvolvidas durante o desenrolar do curso.

\subsubsection{Trabalho Realizado}

A partir da análise do domínio e da idéia de utilizar comparações lexicais para alcançar o objetivo proposto, foi definido um Serviço de Criação Automática de Ligações Lexicais (SCALL) entre os ambientes eClass e CoWeb (Pimentel et al. 2001b). O SCALL é um serviço que automaticamente define e cria ligações hipertexto entre as informações capturadas pelo eClass e os títulos das páginas CoWeb que suportam as atividades fora de sala de aula para o mesmo curso.

O intuito do trabalho foi explorar a homogeneidade dos espaços de informações utilizando simples comparação de palavras, em vez de técnicas elaboradas de recuperação de informação. Durante a implementação:

- dada uma página na CoWeb como entrada, o SCALL, baseando-se no título da página, 
procura por informações capturadas e armazenadas pelo eClass que sejam correspondentes ao título daquela página;

- utilizando como entrada as referências para aulas capturadas, o SCALL verifica se as informações textuais correspondentes àquela aula possuem o título de alguma página criada no repositório CoWeb;

- se a comparação de palavras verificar alguma informação textual do eClass igual a algum título de página CoWeb, uma ligação é criada entre os pontos relevantes da aula e da página CoWeb.

Na apresentação das ligações, páginas CoWeb são associadas a slides do eClass, e cada uma dessas páginas contém uma miniatura do slide ao qual ela está associada. Essa miniatura está associada a uma ligação hipertexto que leva ao slide original no repositório eClass.

Como implementado, o SCALL pode ser ativado automaticamente (a) quando páginas CoWeb são criadas ou editadas ou (b) se as informações capturadas pelo eClass são anotadas ou modificadas depois da aula ter sido capturada.

\subsubsection{Resultados}

O SCALL foi validado a partir da simulação de edição de páginas CoWeb do mesmo curso utilizado na criação manual de ligações apresentada em (Abowd et al. 1999). O curso tinha 18 aulas capturadas pelo ambiente eClass com 318 slides e 303 páginas disponibilizadas na CoWeb relativas às 18 aulas.

Um total de 112 ligações foi definido pelo serviço. Uma avaliação ad hoc, realizada com um dos instrutores do curso para todas as ligações criadas automaticamente, revelou que apenas 4 das 112 ligações eram totalmente irrelevantes. Esse valor apoiou a hipótese inicial de homogeneidade dos repositórios de informação, mas não avaliou completamente o serviço SCALL. Para uma avaliação mais ampla do serviço, seria importante calcular os índices de precisão e de revocação do SCALL, mas isso não foi possível devido à inexistência de uma coleção de referência.

Entre as 108 ligações relevantes ou parcialmente relevantes criadas, 73 continham informações discutidas colaborativamente no curso e 35 eram ligações para páginas pessoais. A Figura 4.2 apresenta o número de ligações criadas manualmente (preto) e as ligações lexicais criadas automaticamente (branco) para cada aula. O número de ligações apresentado no histograma em cinza é resultado do serviço de ligações descrito na próxima seção. Nessa figura pode-se perceber que o serviço de criação automática de ligação foi capaz de criar mais ligações que de criação manual, mas as duas últimas aulas não possuem ligações. Esse fato era esperado visto que a comparação lexical de strings é um método simples de recuperação de informação, uma vez que a diversidade de palavras pode omitir relacionamentos entre objetos (Pimentel et al. 2001b). 


\subsection{Criação Automática de Ligações Semânticas}

\subsubsection{Investigação do Domínio}

Simples comparações lexicais podem omitir relacionamentos entre termos devido à variabilidade de palavras para descrever um mesmo objeto (sinonímia), ou mesmo, definir relacionamentos equivocados devido à utilização de uma mesma palavra para nomear diferentes objetos (polissemia). Essas duas ocorrências lingüísticas podem atrapalhar a identificação de relacionamentos mesmo em repositórios homogêneos de informação.

Com o objetivo de definir ligações hipertexto entre informações homogêneas, evitando problemas de dependência de vocabulário associados a técnicas baseadas em comparações lexicais, foi estabelecido como requisito durante a análise do domínio a utilização de uma técnica de IR com esse intuito. O fato de pesquisadores de IR investigarem o gerenciamento e a recuperação de informações baseadas em conteúdo motivou a definição desse requisito. A definição de ligações hipertexto que conectam fragmentos de documentos semanticamente é uma pesquisa desafiadora para pesquisadores de hipermídia e, portanto, torna-se natural explorar técnicas de IR que definem a co-ocorrência de termos em documentos.

\subsubsection{Trabalho Realizado}

A partir do requisito levantado e de pesquisas sobre técnicas de IR para indexação semântica, foi escolhida a técnica de LSA (Latent Semantic Analysis) para apoiar a definição automática de ligações semânticas entre informações homogêneas. Para dar apoio à essa proposta, foram definidos uma infra-estrutura e um Serviço de Criação Automática de Ligações Semânticas (SCALS) (Macedo et al. 2001b).

\section{Infra-estrutura}

A Figura 4.1 ilustra a infra-estrutura proposta de abstração do processo de geração automática de ligações semânticas entre dois repositórios homogêneos na Web, $A$ e $B$.

O processamento implícito à infra-estrutura pode ser dividido nas seguintes fases, cujos números correspondem aos da figura:

1. Inicialmente, um robô de coleta de informações (crawler) coleta as informações dos repositórios $A$ e $B$, indicados por um usuário. Em seguida, esse robô envia as informações para um servidor que as indexará. O processo de indexação é realizado por meio da seleção de termos de índice (palavras-chave), a partir das informações enviadas pelo robô de coleta de informações. Após a seleção dos termos de índice, são calculadas a freqüência de cada termo para cada coleção e para cada documento separadamente. Esses valores de freqüência são utilizados para calcular os pesos dos termos de índice de acordo com os métodos de atribuição de pesos, apresentados no Capítulo 3. A indexação das informações dos repositórios corresponde à representação das informações 
das páginas Web por termos de índice (ver Figura 4.1 1(a) e 1(b)). Nessa fase, são utilizados arquivos-invertidos para o armazenamento dos diferentes termos e suas ocorrências. O mecanismo de indexação considera a natureza e o tamanho dos repositórios para essa infra-estrutura.

2. Os termos de índice resultantes do módulo 1(a) são associados aos repositórios com maior número de palavras. Essa atitude foi tomada na tentativa de indexar o maior número de palavras possíveis, uma vez que o repositório de menor tamanho deveria fornecer apenas alguns termos-chave utilizados como consulta. Esses índices são usados para gerar a matriz $X$ de termos por documentos da técnica de LSA, conforme apresentado no Capítulo 3.

3. Os termos de índice resultantes do módulo 1(b) são transformados no vetor-coluna de consulta, formando uma matriz cujas colunas representam os documentos do repositório.

4. A matriz $X$, produzida no passo 2, é decomposta nas matrizes componentes $T, S$ e $D$, conforme os conceitos de SVD, onde $T$ é a matriz de termos, $S$ é a matriz de valores singulares e $D$ é a matriz de documentos.

5. As matrizes $T, S$ e $D$ são reduzidas considerando k, conforme sugerido em (Furnas et al. 1988).

6. Cada consulta é considerada um pseudo-documento cujos termos similares são normalizados pela multiplicação do vetor-coluna de consulta pela matriz $T$ reduzida e pela matriz transposta de $T$ reduzida, para seu posterior relacionamento com a matriz $\hat{X}$ (apresentada no próximo passo).

7. A matriz $X$ reduzida $(\hat{X})$ é gerada pela multiplicação das matrizes $T, S$ e a matriz transposta de $D\left(D^{\prime}\right)$ também reduzidas.

8. A matriz semântica é finalmente gerada a partir da combinação das matrizes de $\hat{X}$ e dos vetores-coluna de consulta, através do cálculo do co-seno entre essas matrizes.

9. Dada a matriz semântica gerada no passo anterior, relacionamentos entre os repositórios são identificados considerando as células que têm o mais alto valor de similaridade. Relacionamentos semânticos dentro de um mesmo repositório podem ser identificados pelo cálculo do co-seno entre as colunas da matriz semântica para o caso do Repositório $A$.

\section{Implementação}

Uma instância da infra-estrutura foi implementada experimentada utilizando os repositórios CoWeb e eClass. Os detalhes de implementação são apresentados de acordo com cada módulo de processamento representado na infra-estrutura da Figura 4.1: 


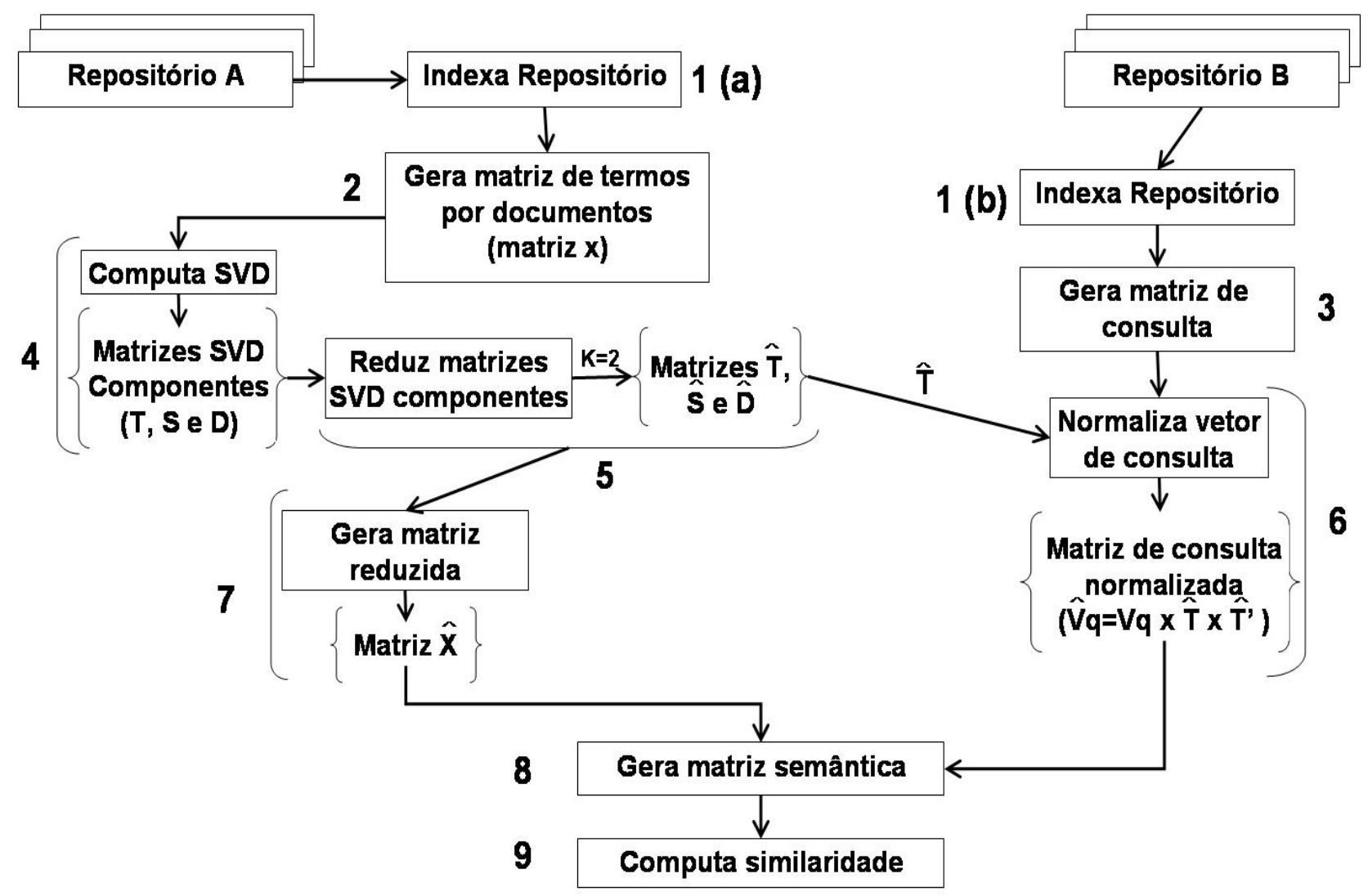

Figura 4.1: Infra-estrutura definida para ilustrar a geração automática de ligações baseadas nos conceitos de Análise da Semântica Latente (adaptada de (Macedo et al. 2001b))

1. (a) A indexação do repositório eClass foi realizada utilizando o mnoGoSearch (MnoGoSearch Group 2004) que é uma ferramenta de licença pública utilizada para coleta, indexação, armazenamento em banco de dados e busca das informações armazenadas. Para a utilização do mnoGoSearch alguns ajustes foram realizados como, por exemplo, adaptação do dicionário de stopwords com palavras utilizadas no contexto do repositório e modificação do código de indexação da ferramenta a fim de permitir extração de palavras a partir de páginas Web ativadas via JavaScript.

(b) Durante a indexação do repositório CoWeb somente foram considerados os títulos das páginas ${ }^{1}$. Acredita-se que títulos podem representar um resumo do conteúdo das páginas. Essa consideração permitiu uma pré-filtragem da informação coletada para o repositório que também foi indexada pela ferramenta mnoGoSearch.

2. O módulo "Gera matriz de termos por documentos" criou, a partir dos índices produzidos no módulo 1(a), a matriz $X$ de termos por documentos.

3. O módulo "Gera matriz de consulta" transformou os índices produzidos no módulo (b) em vetores de consulta formando com esses a matriz de consulta. Cada vetor de

\footnotetext{
${ }^{1}$ As informações do ambiente eClass foram integralmente coletadas na Web, mas somente os títulos das páginas CoWeb puderam ser obtidos.
} 
consulta representa uma coluna dessa matriz.

4. O módulo "Computa SVD", dada a matriz $X$ produzida em 2, executou SVD que gerou as matrizes componentes $T, S$ e $D$.

5. As matrizes $T, S$ e $D$ foram reduzidas considerando $\mathrm{k}=2$, de acordo com LSA.

6. No módulo "Normaliza vetor de consulta" durante o processamento da matriz de consulta gerada em 3, cada título da página CoWeb (coluna da matriz) é tratado como um pseudo-documento para SVD e é multiplicado pela matriz $T$ reduzida e pela matriz transposta de $T$ reduzida.

7. A matriz $X$ reduzida $(\hat{X})$ é gerada pela multiplicação das matrizes $T, S$ e $D^{\prime}$ reduzidas.

8. O módulo "Gera matriz semântica" define uma matriz semântica, através do cálculo do co-seno entre as matrizes obtidas com SVD e as colunas colunas da matriz de consulta.

9. O módulo "Computa similaridade", considerando 99\% de similaridade, identificou relacionamentos semânticos entre os repositórios.

Para a programação de todos os módulos foram utilizadas as linguagens de programação $\mathrm{C}++$ e OX. OX é uma linguagem de programação, desenvolvida na Oxford University, para manipulação de tipo de dados matriz.

Os módulos "Computa SVD", "Gera matriz semântica" e "Computa similaridade" podem ser reutilizados em outras implementações. Os módulos restantes necessitam de pequenos ajustes para se adaptarem a outras implementações. Esses módulos são específicos para os repositórios CoWeb e eClass e para os modelos de dados correspondentes a esses repositórios. Alguns problemas de ajustes para adaptação em outros repositórios eram as principais desvantagens desse serviço. Essa característica motivava a continuação dos trabalhos apresentados neste capítulo e que deram origem ao arcabouço proposto.

\subsubsection{Resultados}

O SCALS foi validado utilizando o mesmo contexto do serviço manual de criação de ligações (Abowd et al. 1999) e do serviço automática de criação de ligações lexicais (Pimentel et al. 2001b): um curso de graduação com 18 seminários com 318 slides capturados pelo eClass e apresentados por dois professores e seus alunos duas vezes por semana; e 303 páginas CoWeb criadas para apoiar as atividades do curso.

Foi realizado um experimento com o serviço SCALS para identificar relacionamentos semânticos entre os repositórios CoWeb e eClass. Nesse experimento foram realizados os passos apresentados em 4.3.2. Inicialmente foram criados a matriz $X$ com 1904 linhas (termos) e 616 colunas (agrupadas por 18 aulas capturadas) e os 303 vetores-consulta a partir dos títulos das páginas CoWeb. Em seguida, foi calculado o método SVD sobre a matriz $X$ e as matrizes resultantes desse processamento foram reduzidas, considerando $k=2$, e 
multiplicadas para gerar a matriz reduzida $X(\hat{X})$. Finalmente foi verificada a similaridade dos vetores-consulta extraídos da CoWeb com a matriz $\hat{X}$ pelo cálculo de co-seno. Apenas relacionamentos entre documentos e vetores-consulta com co-senos superiores a $99 \%$ foram considerados válidos para esse experimento.

No experimento de criação de ligações semânticas entre repositórios foram identificadas 789 ligações entre os repositórios eClass (com 18 aulas) e CoWeb (com 303 páginas) - uma média de 43,8 ligações por aula. A distribuição das ligações por aula pode ser visualizada na Figura 4.2. Nessa figura, a distribuição das ligações criadas por aulas pode ser comparada com a distribuição de ligações criadas para os experimentos realizados anteriormente com os repositório de informação da CoWeb e do eClass: (preto) ligações manuais de (Abowd et al. 1999) e (branco) ligações lexicais automáticas de (Pimentel et al. 2001b).



Figura 4.2: Ligações manuais (preto), ligações lexicais automáticas (branco) e ligações semânticas latentes automáticas (cinza), separadas nas 18 aulas de um curso de seminário capturado pelo eClass

O co-seno das colunas da matriz semântica resultou na identificação das ligações internas ao repositório eClass. O número médio de relacionamentos identificados entre as 18 aulas foi de 15 ligações por aula (com desvio padrão igual a 15). Esses valores, considerados altos, não surpreenderam os autores, já que as aulas correspondiam a um único tema extremamente relacionado.

Os resultados obtidos não foram avaliados, em termos do par de medidas clássica de avaliação de sistemas de IR, índice de revocação e índice de precisão, devido à inexistência de uma coleção de referência. Contudo, em termos quantitativos os resultados foram considerados bons, sendo que durante a indexação da CoWeb foram utilizados apenas os títulos das páginas como índices relevantes para o conteúdo das mesmas. 


\subsection{Criação Automática de Ligações Semânticas em Repositórios Abertos}

\subsubsection{Investigação do Domínio}

Procurando ampliar as contribuições do serviço SCALS, pretendia-se definir mecanismos de identificação de relacionamentos semânticos latentes inter e intra-repositórios Web explorando todo o conteúdo dos repositórios, em vez de apenas os títulos de documentos. Outra alternativa para ampliar as contribuições do SCALS seria permitir que os relacionamentos identificados pudessem ser usados por outras aplicações hipermídia ou não.

Um dos requisitos decorrentes dos objetivos propostos no trabalho era que repositórios Web deveriam ser integralmente indexados e relacionados. Para atender a esse requisito, a infra-estrutura inicialmente proposta deveria ser remodelada para coletar, indexar e definir o espaço semântico utilizando todo o conteúdo dos repositórios manipulados. Outro requisito era a possibilidade de criar ligações hipertexto em qualquer repositório Web sem ter de modificar os documentos, assim os relacionamentos identificados poderiam ser utilizados por outras aplicações hipermídia ou não.

\subsubsection{Trabalho Realizado}

Para atender os requisitos levantados na investigação domínio, a infra-estrutura definida anteriormente para o serviço SCALS foi remodelada e um módulo de armazenamento que interage com a biblioteca de ligações do serviço Web Linking Service (WLS) (Bulcão Neto et al. 2002) foi criado. O novo serviço implementado pela instanciação da nova infra-estrutura foi chamado Serviço Aberto de Criação Automática de Ligações Semânticas (SACALS) (Macedo et al. 2002b).

\section{O serviço WLS}

O serviço de ligações hipermídia WLS (Web Linking Service) visa, em ambiente Web, prover funcionalidades hipermídia a aplicações que desejem tornar-se hipermídia habilitadas, e possibilitar a integração com essas aplicações formando um ambiente computacional aberto baseado em padrões XML (Bulcão Neto 2001) (Bulcão Neto et al. 2002).

O WLS suporta: (a) separação explícita entre conteúdo e estrutura da informação, (b) ligações entre informações independentemente do conteúdo dos documentos que contêm a informação relacionada, (c) ligações que podem referenciar documentos em diferentes formatos, (d) bibliotecas próprias de ligações (privadas ou públicas), (e) ligações do tipo from e to para informações somente de leitura e (f) tipos de relacionamentos entre documentos.

Na fundamentação teórica para o projeto e a implementação do WLS, foram utilizadas abordagens da arquitetura de referência do Modelo Dexter (Halasz \& Schwartz 1994) e de sistemas hipermídia abertos (Open Hypermedia Systems - OHS) (Grønbæk \& Trigg 1994). 
Tabela 4.1: Mapeamento entre as classes do WLS e os objetos do SACALS (adaptada de (Macedo et al. 2002b))

\begin{tabular}{|c|c|}
\hline WLS & SACALS \\
\hline \hline Âncoras & Termos dos documentos (endereços de páginas Web) da matriz $X$ \\
\hline Nós & Referências aos documentos (endereços de páginas Web) da matriz $X$ \\
\hline Pontos Finais & Termos computados como extremidades de ligações semântica latente \\
\hline Ligações & Dois Pontos Finais que definem um relacionamento latente semântico \\
\hline Contexto & Coleção de ligações geradas automaticamente \\
\hline Semânticas & Pares de termos similares \\
\hline
\end{tabular}

Seguindo essas abordagens, o gerenciamento da rede de estruturas é de incumbência do WLS, enquanto que o armazenamento e a apresentação de documentos ficam sob responsabilidade das aplicações integradas ao WLS. Essa distribuição de tarefas segue o modelo navegacional do Protocolo Hipermídia Aberto (Open Hypermedia Protocol - OHP) (Grønbæk \& Trigg 1996).

Para a integração da biblioteca do WLS ao serviço de criação automática de ligações, foi necessária a realização de um mapeamento entre as classes do WLS (Contexto, Nó, Âncora, Ligação, Ponto Final e Semântica) e os conceitos manipulados pelo SACALS (endereço da página Web, limiar de similaridade, termos e relacionamentos com semântica latente). Esse mapeamento é apresentado na Tabela 4.1.

O processo de indexação é inicializado quando pelo menos uma URL de um repositório Web é fornecida ao sistema. Âncoras e Nós do WLS correspondem, respectivamente, aos termos dos documentos (URLs) e à referência ao documento (URL) que tem sido identificado como similar a outro documento. Os termos são obtidos a partir da matriz $T$ a qual foi obtida depois de aplicar SVD à matriz $X$. URLs são extraídas da matriz $D$ que é obtida após a aplicação de SVD à matriz X. Os Pontos Finais são equivalentes ao termos (mapeados em Âncoras).

Ligações são um conjunto de dois Pontos Finais identificados pelo serviço como relacionamentos semânticos latentes. Os relacionamentos semânticos entre os repositórios são identificados como as células que têm os maiores valores de similaridade, enquanto que relacionamentos internos são obtidos através do cálculo do co-seno entre as colunas da matriz semântica.

Contextos correspondem a toda a coleção de ligações geradas automaticamente pelo SACALS em um determinado tempo.

Semânticas corresponde a pares de termos similares. Esses pares podem ser automaticamente definidos pelo serviço e armazenados na biblioteca de ligações do WLS, independentemente dos documentos que continham a informação.

Em decorrência dos relacionamentos existentes entre as classes Âncoras, Pontos Finais e Ligações, o serviço de ligações do WLS fornece suporte a ligações multidirecionais (1-N) e à possibilidade de compartilhar uma Âncora entre vários Pontos Finais. A biblioteca externa de ligações definida pelo WLS suporta a criação efetiva de ligações. Essas funcionalidades 
também têm sido exploradas pelo serviço aberto de criação de ligações semânticas.

\section{Infra-estrutura}

A Figura 4.3 ilustra uma extensão da infra-estrutura apresentada na Figura 4.1. Essa nova infra-estrutura incorpora tecnologias de Hipermídia Aberta sobre os conceitos investigados e generaliza as contribuições da infra-estrutura anterior. O Nivel de linking é composto por parte da infra-estrutura definida anteriormente, uma vez que essa teve que ser remodelada para ilustrar a manipulação de todo o conteúdo de diferentes repositórios. Nesse nível, a infra-estrutura manipula componentes de conteúdo e de estrutura do serviço SACALS tais como nós e ligações hipertexto semânticas.

O Nivel de ancoragem contém métodos de chamada de procedimentos para ativar as funcionalidades da biblioteca de ligações WLS. Já o Nivel de armazenamento contém as tabelas de ligações manipuladas pelo WLS.

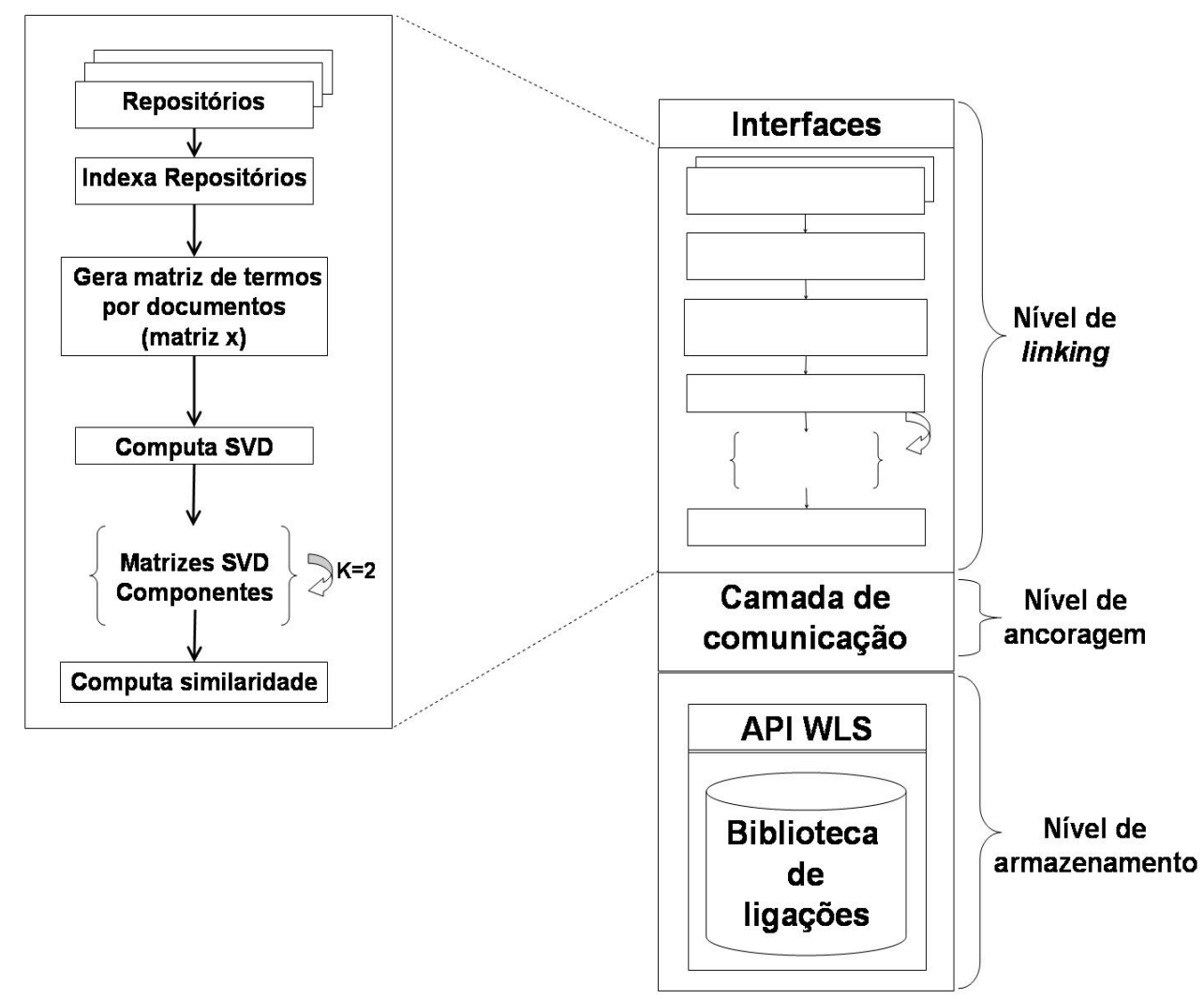

Figura 4.3: Infra-estrutura para ilustrar os módulos do serviço aberto de criação automática de ligações semânticas (adaptada de (Macedo et al. 2002b))

\section{Implementação}

Foi abstraído um algoritmo de uma das possibilidades de implementação da infra-estrutura para definição dos relacionamentos semânticos. Esse algoritmo é composto pelos módulos de processamento dos níveis de linking, de ancoragem e de armazenamento da infra-estrutura da 
Figura 4.3. Interfaces de apresentação não foram consideradas devido à sua dependência do tipo de serviço que está utilizando a infra-estrutura. Exemplos de interfaces do nível de apresentação de uma aplicação, criada para validar a infra-estrutura definida, são apresentados na Seção 4.4.3.

Os módulos de processamento, apresentados na Figura 4.3, foram implementados de acordo com o algoritmo a seguir. Durante todo o processo de implementação, foram utilizadas as linguagens de programação $\mathrm{C}++$ e a linguagem $\mathrm{OX}$ orientada a matrizes.



O procedimento OpenLatentSemanticLinking implementou, sem modificações, alguns dos módulos apresentados na Seção 4.3.2, e modificou o módulo "Indexa Repositórios()" que indexa diferentes URLs e não somente o repositório eClass. Foi definido um novo método, o "NovaLigacao()", no módulo "Computa similaridade". Esse método cria novas ligações semânticas, a partir de verificações do limiar de similaridade para as colunas da matriz semântica e solicita serviços da biblioteca de ligações WLS. Para atender essa solicitação, foi criado no nível de ancoragem um novo método, o "Armazena()", que armazena as ligações criadas pelo método "NovaLigacao()".

\subsubsection{Resultados}

Para experimentar a utilidade da infra-estrutura criada, foi construída uma aplicação, denominada LinkDigger Service². Essa aplicação permite: (a) a indexação e a identificação de relacionamentos semânticos entre, no máximo cinco repositórios ${ }^{3}$ Web, (b) a criação de ligações internas a um repositório, caso apenas uma URL seja informada à aplicação e (c) acesso aos resultados através de interfaces Web referenciando as páginas relacionadas pelo LinkDigger para os sítios indexados. As interfaces de apresentação do LinkDigger podem ser

\footnotetext{
${ }^{2}$ http://linkserver.icmc.usp.br/LSL/

${ }^{3} \mathrm{~A}$ quantidade de repositórios manipulados pelo LinkDigger foi definida aleatoriamente como 5. Ainda não foram testados os limites de processamento do serviço citado.
} 
visualizadas na Figura 4.4. A interface da Figura 4.4(a) é destinada à entrada de informações e a interface da Figura 4.4(b) tem como função a apresentação dos resultados. A interface de entrada de informações é composta por um formulário com campos para especificação das URLs a serem integradas, e a interface de apresentação de resultados apresenta as ligações criadas de forma hierárquica. Essa interface apresenta âncoras "No Title" quando a página Web manipulada não possui título. Existem outras interfaces do LinkDigger com textos explicativos sobre o serviço de criação de ligações.

\section{LINIKDIGGER}

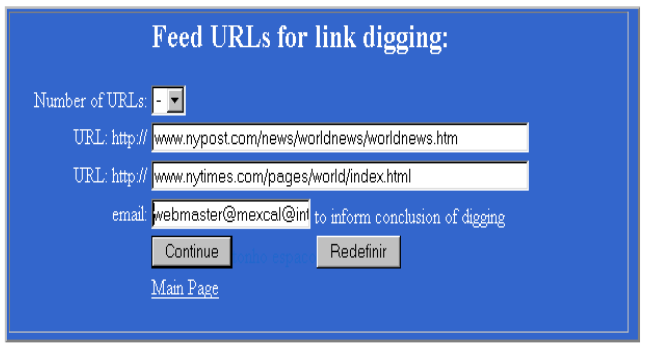

\section{LINIKDIGGER}

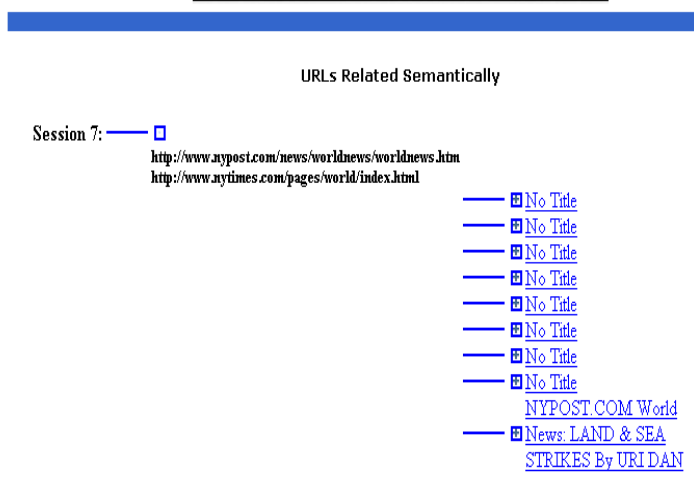

Figura 4.4: (a) Interface de ativação do LinkDigger e (b) Interface de resultados

Para executar o serviço, um usuário precisa realizar os seguintes passos: (1) selecionar o número de repositórios Web a serem relacionados semanticamente, (2) fornecer os endereços dos repositórios a serem relacionados, (3) disponibilizar um endereço de correio eletrônico para contato para o serviço avisar quando o processamento estiver finalizado e (4) ativar a execução do processamento. Para suportar a indexação e criação de ligações entre repositórios grandes, o serviço aberto de criação automática de ligações semânticas está sendo executado em background e por esse motivo é solicitado o correio eletrônico de contato.

No primeiro experimento, o LinkDigger relacionou páginas com notícias on-line dos seguintes jornais: The New York Times (NYT) e New York Post (NYP). O experimento considerou 25 páginas referentes a notícias internacionais publicadas no dia 13 de janeiro de 2002 naqueles jornais (16 notícias do jornal NYT e 9 do jornal NYP). O serviço identificou e criou 174 ligações semânticas latentes entre as 25 páginas dos jornais, uma média de 7 ligações por página. A página com o maior número de ligações, 14, foi a página inicial do NYT. Esse resultado era esperado sendo que essa página é uma página-índice para as notícias. Além disso, das 14 ligações criadas para essa página, 6 eram para páginas do NYP. Outro fato que chamou a atenção foi que a página principal do NYT foi relacionada aos dois jornais enquanto que a página principal do NYP foi relacionada exclusivamente a este jornal. Esse fato talvez possa ser explicado pelo fato do NYT ter um número maior de notícias além de uma maior variedade; embora, essa hipótese não tenha sido investigada.

Os resultados dos experimentos preliminares com o LinkDigger foram quantitativamente positivos, apesar do tamanho reduzido da coleção. Em análises ad hoc, foram encontrados problemas de precisão das ligações definidas. O serviço não foi avaliado em termos de precisão 
e de revocação devido à falta de uma coleção de referência, sendo que foram coletadas informações de utilidade pública na Web.

\subsection{Criação de Ligações com a Interação de Usuários}

\subsubsection{Investigação do Domínio}

Conforme discutido no Capítulo 3, para que sistemas de IR se adeqüem às necessidades dos usuários, podem ser utilizadas técnicas de expansão de consultas. Tais técnicas exploram a interação com usuários e a utilização automática de propriedades dos documentos.

Com o objetivo de adequar os serviços de criação automática de ligações às expectativas dos usuários e, assim, aprimorar a precisão desses serviços, foi investigado o método de relevance feedback, baseado na interação com usuários, para a expansão do conjunto de ligações relevantes geradas.

\subsubsection{Trabalho Realizado}

O serviço de criação de ligações criado para permitir a interação de usuários, com o intuito de atender suas expectativas e excluir relacionamentos irrelevantes, foi denominado Serviço de Criação de Ligações com a Interação de Usuários (SCLIU) (Macedo et al. 2002a)

A infra-estrutura, apresentada na Figura 4.5, ilustra o apoio à participação de usuários na definição de ligações entre repositórios Web. Essa infra-estrutura foi estendida a partir da infra-estrutura aberta, apresentada na Figura 4.3.

No Nivel de linking da infra-estrutura são definidas as ligações hipertexto entre os repositórios manipulados pelos serviços de criação de ligações e, após a apresentação aos usuários, essas ligações podem ser redefinidas nesse mesmo nível. As extensões nesse nível, devido à inclusão do módulo "Uso de relevance feedback", são suportadas pelo procedimento "RelevanceFeedback", detalhado a seguir.

No Nivel de apresentação, diferentes interfaces possibilitam a especificação de informações para a inicialização do serviço e a apresentação de resultados com possibilidade de interação de usuários.

A interface de apresentação de resultados mostra as informações advindas do Nível de armazenamento e permite que usuários indiquem, dentro do conjunto de ligações retornadas, as ligações que são relevantes. Essa última interface foi definida especialmente para o experimento da abordagem de relevance feedback.

O módulo de "Uso de relevance feedback" envolve dois passos básicos: expansão do conjunto de ligações hipertexto inicialmente gerado com novas ligações selecionadas por usuários e reformulação dos pesos dos termos dos documentos relacionados às ligações marcadas como relevantes. Para a implementação desse método, o procedimento "RelevanceFeedback" foi desenvolvido. 


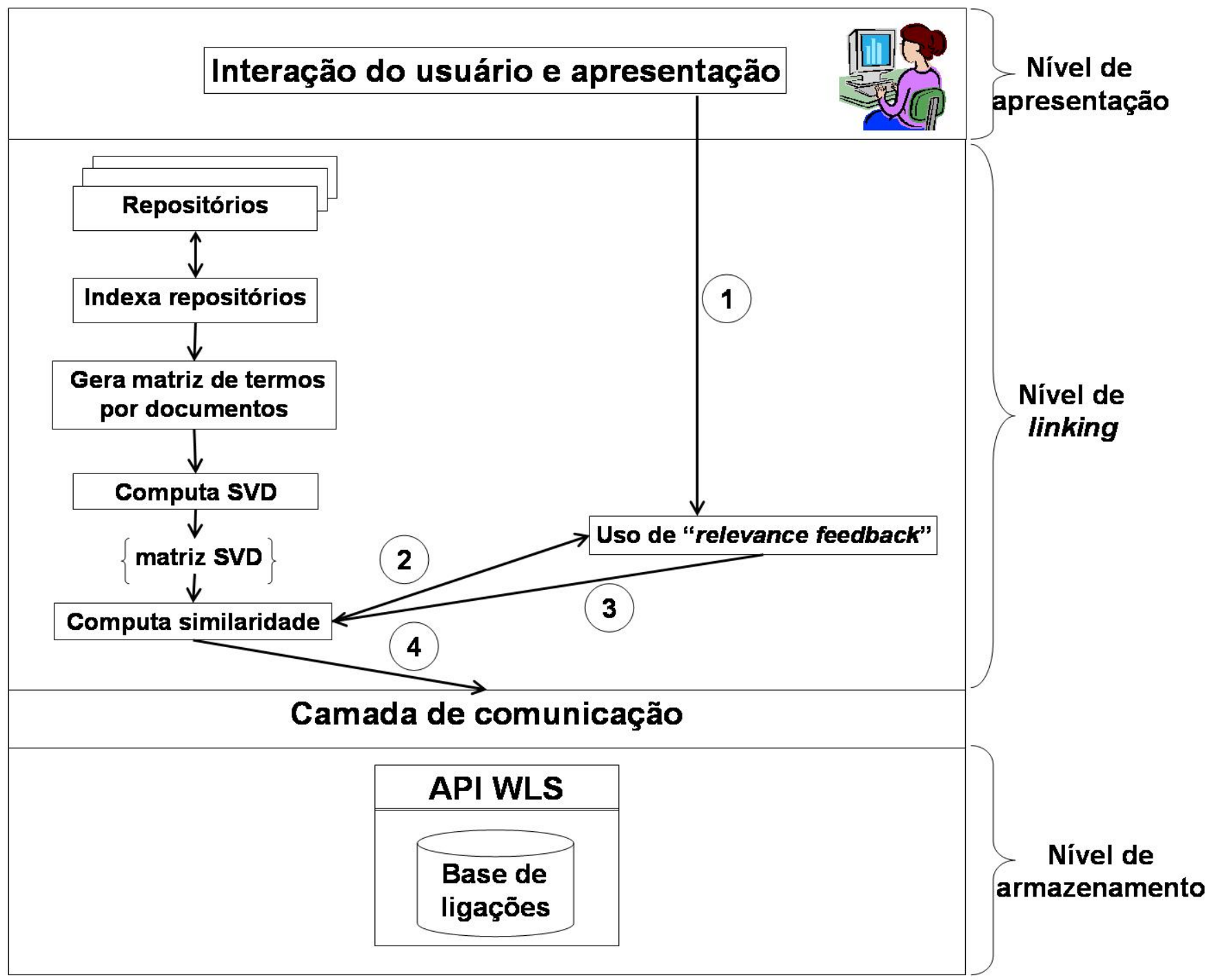

Figura 4.5: Infra-estrutura para geração de ligações semânticas entre repositórios Web com a participação do usuário por meio de relevance feedback (adaptada de (Macedo et al. 2002a))

Na Figura 4.5, o processamento (1) indica a interação de usuários no nível de apresentação para seleção das ligações a serem incluídas às ligações originais como se fossem novos termos de uma consulta. Em seguida, as informações armazenadas na matriz semântica são recalculadas incluindo as novas informações (processamento (2)) e, conseqüentemente, os pesos dos termos dos documentos que compreendem as ligações iniciais e as selecionadas por usuários são reformulados (processamento (3)).

Os métodos básicos do procedimento "RelevanceFeedback" são os seguintes:

- "CarregaMatriz()" - busca a matriz de similaridades semânticas gerada pelo procedimento OpenLatentSemanticLinking;

- "SomaVetores()" - soma todos os vetores de documentos relevantes, após sugestão dos usuários de quais ligações são relevantes. 
O procedimento a seguir mostra a implementação realizada para a extensão da infraestrutura.

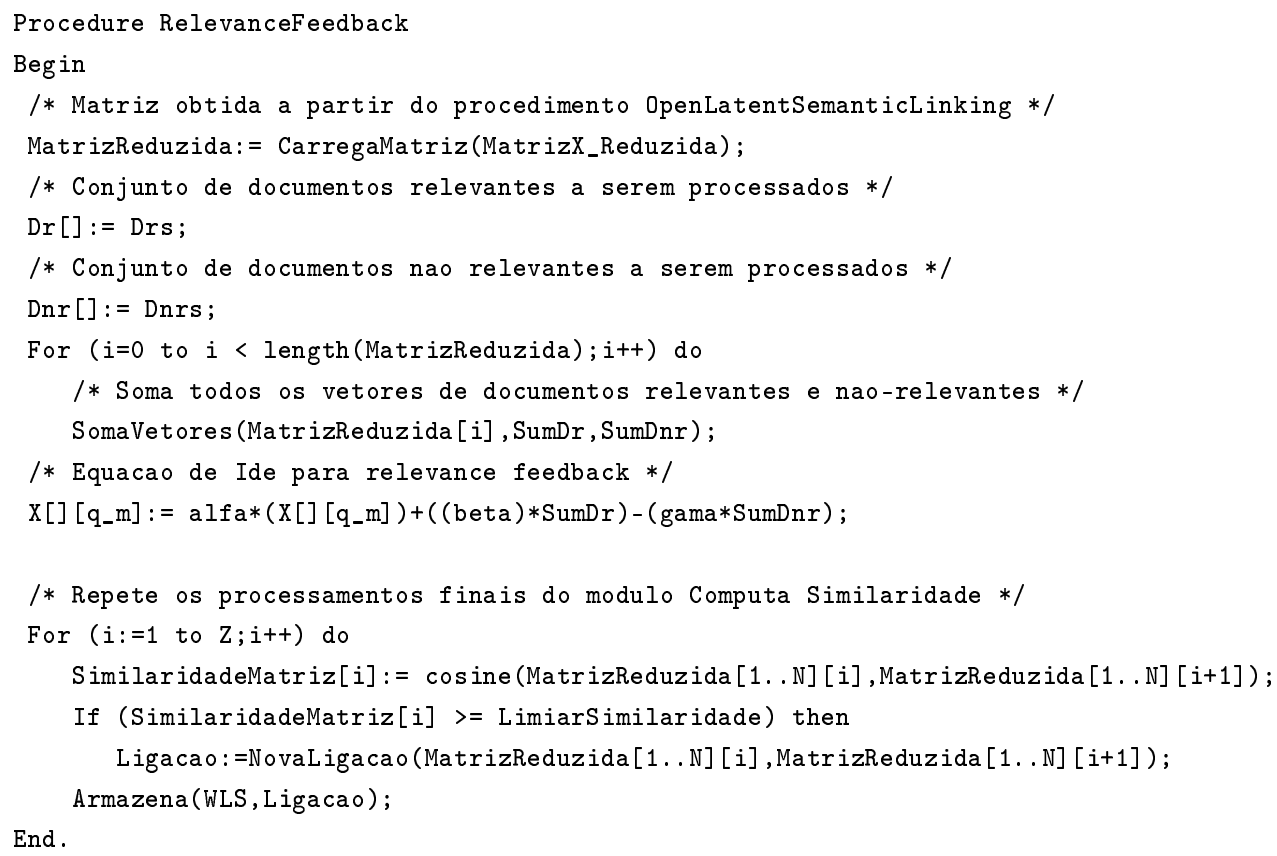

Para a codificação do procedimento "RelevanceFeedback" foi utilizada a equação de Ide, apresentada no Capítulo 3, com os seguintes valores para as variáveis de ajuste $\alpha=0,5$, $\beta=0,7$ e $\gamma=0,1$. Na equação de Ide, as consultas $\vec{q}$ foram consideradas como conjuntos de vetores de termos de um repositório a ser comparado com outros repositórios. Uma abordagem semelhante foi utilizada na modelagem dos repositórios com o uso da técnica de LSA. A diferença está no fato de que, para modelar os repositórios para gerar ligações usando LSA, todas as informações dos repositórios foram consideradas. No contexto de relevance feedback, apenas as informações componentes da matriz semântica, resultante de LSA, são alteradas na equação de Ide, sendo que essa matriz representa a estrutura semântica da coleção.

Para permitir diversas interações de usuários, indicadas por $m$, a equação de Ide foi ajustada, conforme apresentado na Equação 4.1.

$$
\vec{q}_{m+1}=\alpha \overrightarrow{q_{m}}+\beta \sum_{\forall \vec{d}_{j} \in D_{r}} \vec{d}_{j}-\gamma \sum_{\forall \vec{d}_{j} \in D_{n-r}} \vec{d}_{j}
$$

Devido ao fato do contexto manipulado ser composto por ligações hipertexto bi-direcionais, o vetor $\overrightarrow{q_{m}}$ da Equação 4.1 pode ser formado a partir de qualquer documento relacionado a cada uma das âncoras correspondentes às ligações semânticas geradas. Por esse motivo, na reconstrução da matriz semântica no procedimento "RelevanceFeedback", a equação de Ide foi aplicada duas vezes para cada ligação relevante considerada. Variou-se a âncora-origem de acordo com a direção que se desejava atender.

O serviço LinkDigger criado no experimento do serviço aberto de criação automática de ligações semânticas foi estendido para permitir que usuários participassem na definição 
de ligações entre repositórios Web (Camacho-Guerrero et al. 2002b). Os resultados desses experimentos são reportados a seguir.

\subsubsection{Resultados}

Para verificar a utilidade da infra-estrutura proposta, foi realizado um experimento com dois repositórios Web referentes a jornais on-line brasileiros para a criação automática de ligações semânticas mediante a participação de usuários nesse processo.

Os jornais manipulados foram a versão brasileira do jornal $\mathrm{CNN}^{4}$ e o jornal O Estado de São Paulo ${ }^{5}$ (OESP). Os sítios dos jornais OESP e CNN foram analisados na seção de Esportes. No contexto deste trabalho, a informação contida nesses repositórios, por serem de uma mesma categoria, é considerada homogênea.

Os repositórios homogêneos foram especificados como fontes de informação para o serviço LinkDigger no dia 20 de maio de 2002. O jornal OESP contava com 59 documentos na seção de Esportes. O jornal CNN possuía 15 documentos na mesma seção.

Com o objetivo de indexar esses dois jornais, o LinkDigger considerou um dicionário de stopwords em português com 169 palavras e diferentes atribuições de pesos às palavras localizadas no título e no corpo do documento. Após indexar os dois repositórios, gerar as ligações e apresentá-las, foram requeridas as participações de cinco usuários para a realização de relevance feedback sobre as informações geradas. Por meio da interface de apresentação de resultados do LinkDigger, os usuários indicaram se a ligação acompanhada pelo campo relevance era relevante ou não. Para realizar essa avaliação, foi solicitado aos usuários a leitura de cada par de documentos Web relacionado semanticamente pelo LinkDigger.

O experimento realizado no contexto apresentado resultou nas informações resumidas na Tabela 4.2. A coluna "Início" da Tabela 4.2 fornece a quantidade de ligações geradas pelo LinkDigger sem as interações de usuários. As demais colunas da tabela correspondem a informações geradas pelo LinkDigger após a interação de cada um dos cinco participantes do experimento (Usuário1 a Usuário5).

Os valores da linha (1) indicam as ligações marcadas como relevantes por cada usuário, a partir da análise das 44 ligações geradas inicialmente pelo LinkDigger. Os valores da linha (2) indicam as quantidades totais de ligações, relevantes e não-relevantes, geradas pelo LinkDigger, após as seleções das ligações consideradas relevantes por cada usuário e apresentadas na linha (1). A linha (3) apresenta as quantidades de ligações relevantes do total de ligações apresentadas na linha (2).

Na coluna "Início", os valores 44 e 8 nas linhas (2) e (3) correspondem às quantidades de ligações totais $(A)$ e ligações relevantes geradas $(R a)$ inicialmente pelo LinkDigger. Na linha (4) é apresentada a quantidade de ligações relevantes da coleção de referência $(R)$. Os índices de revocação e de precisão são calculados como $R e v=\frac{R a}{R}$ e $\operatorname{Prec}=\frac{R a}{A}$ e são apresentados, respectivamente, nas linhas (5) e (6) da tabela.

\footnotetext{
${ }^{4}$ http://www.cnn.com.br

${ }^{5}$ http://www.estadao.com.br
} 
Tabela 4.2: Informações obtidas a partir do experimento com LinkDigger considerando relevance feedback (adaptada de (Macedo et al. 2002a))

\begin{tabular}{|l||l|l|l|l|l|l|}
\hline Variáveis de avaliação & Início & Usuário1 & Usuário2 & Usuário3 & Usuário4 & Usuário5 \\
\hline $\begin{array}{l}\text { (1)Qtde de ligações mar- } \\
\text { cadas como relevantes } \\
\text { pelo usuário }\end{array}$ & 0 & 5 & 12 & 7 & 8 & 4 \\
\hline $\begin{array}{l}\text { (2)Qtde total de li- } \\
\text { gações geradas pelo } \\
\text { LinkDigger }(A)\end{array}$ & 44 & 37 & 12 & 16 & 12 & 9 \\
\hline $\begin{array}{l}\text { (3)Qtde de ligações } \\
\text { relevantes geradas pelo } \\
\text { LinkDigger }(R a)\end{array}$ & 8 & 5 & 7 & 6 & 7 & 2 \\
\hline $\begin{array}{l}\text { (4)Qtde de ligaç̃̃es rele- } \\
\text { vantes da coleção }(R)\end{array}$ & 27 & 27 & 27 & 27 & 27 & 27 \\
\hline $\begin{array}{l}\text { (5)Índice de precisão - } \\
R a / A(\%)\end{array}$ & 18,18 & 13,51 & 58,33 & 37,5 & 58,33 & 22,22 \\
\hline $\begin{array}{l}(6) \text { Índice de revocação - } \\
R a / R(\%)\end{array}$ & 29,63 & 18,51 & 25,92 & 22,22 & 25,92 & 7,40 \\
\hline
\end{tabular}

Analisando os resultados desse experimento, pode-se observar que, após a interação dos usuários através do método IR de relevance feedback, os índices de revocação e de precisão foram positivos para todos os usuários. O índice de precisão demonstra um ganho significativo após as interações de usuários, enquanto que o índice de revocação apresenta uma seqüência de pequenas quedas de valores se comparados ao contexto inicial de $29,63 \%$. Esses números demonstram a eficiência da abordagem investigada, uma vez que com um bom ganho de precisão, houve pouca geração de informação não-relevante.

Insatisfeito com os resultados da primeira interação, o quinto usuário realizou uma nova interação com o serviço LinkDigger e obteve $77,7 \%$ de índice de precisão e 25,9\% de índice de revocação. Esses valores sinalizam um aprimoramento de resultados a cada interação dos usuários com a coleção manipulada.

\subsection{Criação Automática de Ligações entre Documentos Estruturados}

\subsubsection{Investigação do Domínio}

As ligações hipertexto criadas para todos os serviços apresentados consideram apenas o conteúdo textual dos documentos manipulados. Contudo, o fato de documentos apresentarem uma estrutura textual pré-definida fornece características atrativas que podem ser exploradas durante a criação de ligações. Essas informações adicionais podem ser utilizadas de diferentes maneiras, por exemplo para permitir uma diferenciação de termos de índice definidos em partes específicas do documento.

O trabalho detalhado nesta seção objetivava definir relacionamentos entre documentos advindos de repositórios homogêneos, considerando a estrutura do documento manipulado, 
além do seu conteúdo. Para realização desse trabalho foi estabelecido como requisito inicial a manipulação de documentos XML.

\subsubsection{Trabalho Realizado}

Para atender o requisito levantado durante a investigação sobre a utilização de documentos estruturados, estendeu-se a infra-estrutura anteriormente definida (ver Figura 4.3) para o serviço SACALS e criou o Serviço de Criação Automática de Ligações entre Documentos Estruturados (SCALDE). A Figura 4.6 apresenta a infra-estrutura desenvolvida.



Figura 4.6: Infra-estrutura para geração de ligações semânticas entre documentos estruturados

A infra-estrutura que ilustra o processamento dos módulos implementados para o serviço SCALDE manipula as informações estruturais de documentos XML durante a definição de ligações entre repositórios Web, de acordo com a seqüência de processamentos (1), (2) e (3) da Figura 4.6.

No Nivel de apresentação são instanciadas interfaces que possibilitam a especificação de pesos a serem atribuídos ao elementos que compõem os documentos manipulados. Esse nível possibilita também a interação de usuários com os elementos estruturais dos documentos XML indexados separadamente e retornados a partir do nível de linking.

No Nivel de linking são definidas as ligações hipertexto entre os repositórios manipulados pelo serviço de criação de ligações. Nesse nível são separadas informações de conteúdo de informações de estrutura dos documentos. Enquanto o conteúdo é indexado e preparado para 
posterior utilização, os elementos que compõem a estrutura do documento são apresentados aos usuários no nível de apresentação. As extensões desse nível, devido à inclusão do módulo "Extrai estrutura XML", são suportadas pelo procedimento "StructuredDocumentsLinking", detalhado a seguir.

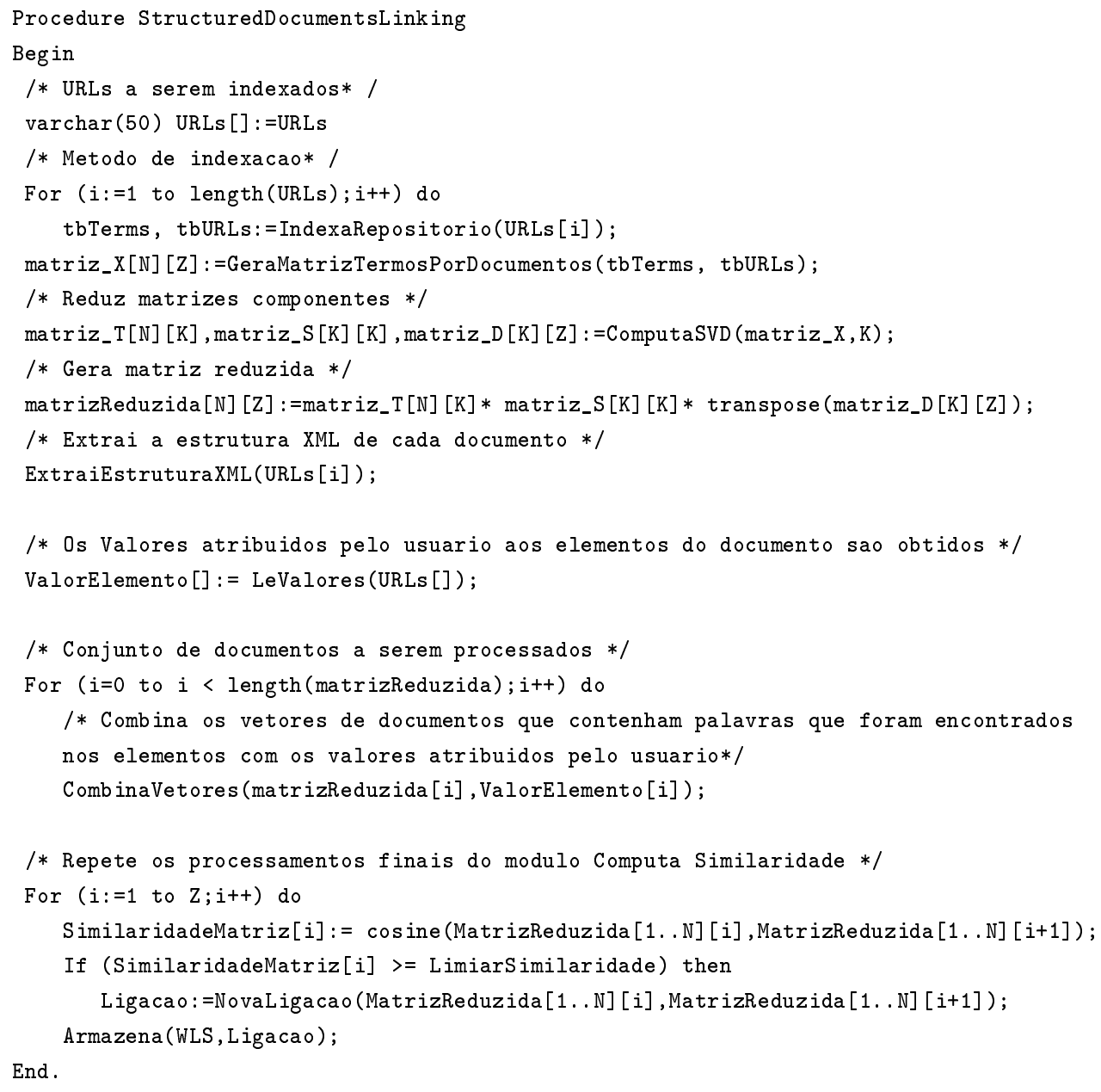

Na Figura 4.6, o processamento (1) indica o fluxo de documentos para a extração de suas informações estruturais. Em seguida, os elementos da estrutura dos documentos são apresentados aos usuários (processamento (2)) para serem atribuídos os valores correspondentes de importância para o conteúdo textual marcado pelos elementos da estrutura. Uma vez completado esse processo, as informações adicionadas pelos usuários são combinadas com as informações de conteúdo representadas na matriz semântica (processamento (3)), e conseqüentemente, os pesos dos termos dos documentos são reformulados. Finalmente, é calculada a similaridade entre os documentos.

\subsubsection{Resultados}

Para verificar a proposta de utilização de estruturas e de conteúdo de documentos XML durante a definição de ligações hipertexto, foi utilizada a coleção Lácio-Ref do Projeto LácioWeb $^{6}$. Lácio Web (LW) é um projeto com o objetivo de divulgar e disponibilizar livremente

\footnotetext{
${ }^{6}$ http://www.nilc.icmc.usp.br/lacioweb/
} 
na Web: (a) córpus do português brasileiro escrito contemporâneo, representando bancos de textos adequadamente compilados em um padrão que possibilite análises; e (b) ferramentas lingüístico-computacionais.

A coleção utilizada no experimento com o SCALDE é um córpus aberto e de referência do Projeto Lácio-Web, denominado Lácio-Ref, que é composto de textos em português brasileiro, tendo como característica serem escritos respeitando a norma culta. É um córpus não anotado com informações morfossintáticas, sintáticas ou de nível mais elevado, mas possui anotações da existência de elementos gráficos e cabeçalhos marcados com informações que podem ser interessantes para a indexação da coleção. Na preparação das amostras utilizadas pela doutoranda, a equipe do projeto Lácio-Web realizou as seguintes etapas:

- Primeiramente os pesquisadores compilaram a coleção — retiraram os textos da Internet e de CD-Rom e armazenaram em um diretório de modo que os documentos pudessem ser manipulados e formatados para o padrão TXT, respeitando o texto original.

- Para dar continuidade à preparação da coleção, os pesquisadores nomearam os arquivos utilizando informações a respeito do gênero do texto, meio de distribuição e algumas outras características para identificar apropriadamente os arquivos na construção de subcórpus de pesquisa.

- Finalmente esses pesquisadores anotaram os textos com um cabeçalho com as seguintes informações: (a) bibliográficas comuns (título, autoria, local e data de publicação, fonte, editor, língua), e (b) de catalogação (tamanho do arquivo, tipo de amostragem, tipo da autoria, sexo do(s) autor(es), e da tipologia de quatro categorias: domínios; gêneros; tipos textuais e meio de distribuição). Foi durante a catalogação dos textos que os pesquisadores do Lácio-Web utilizaram etiquetas XML.

A coleção Lácio-Ref foi submetida a uma nova versão do serviço LinkDigger que atendia os requisitos do serviço de criação automática de ligações entre documentos estruturados (ver processamento (1) da Figura 4.6). Foram processados 1179 documentos XML. Após um processamento inicial de extração da estrutura dos documentos, todas as marcações (tags) do documento foram apresentadas a um usuário que definiu valores de importância (peso) de cada marcação (processamento (2)). Ao indicar esses valores, usuários devem considerar a importância do conteúdo textual marcado por cada par de marcações. Essas instruções estão disponibilizadas na interface de acesso às estruturas dos documentos, conforme apresentado na Figura 4.7.

No experimento realizado, o usuário da coleção Lácio-Ref definiu valores de relevância para cada par de marcações como, por exemplo, title (3), autor(1), gênero(2), domínio geral (2), domínio especifico (2), entre outros.

Uma vez completado o processo de atribuição de pesos às informações de estruturas, os valores atribuídos às marcações são adicionados às informações armazenadas na matriz 
semântica de LSA (ver processamento (3) da Figura 4.6). Isso ocorre da seguinte maneira: é criado um vetor que contém as palavras localizadas em cada entidade com os respectivos valores atribuídos pelo usuário. Em seguida, as informações armazenadas na matriz semântica são recalculadas incluindo as novas informações. Finalmente, são calculadas as similaridades entre os documentos por meio do cálculo de co-seno e selecionados os valores a serem considerados na definição das ligações. No módulo de definição de ligações semânticas usando LSA foi estabelecido $k=350$ e limiar de similaridade $=90 \%$. Foram definidas 1630 ligações entre os 1179 documentos XML. A verificação qualitativa dessas ligações está em andamento. É interessante relatar que as ligações definidas acabaram categorizando os documentos manipulados, uma vez que a informação contida nos elementos dessa coleção representa características gerais dos documentos e não o conteúdo dos mesmos.



Figura 4.7: Interface de acesso às estruturas dos documentos

\subsection{Criação Configurável de Ligações}

\subsubsection{Investigação do Domínio}

Procurando suportar as diferentes abordagens de IR e de Hipermídia investigadas para os serviços criados, foram definidos uma infra-estrutura e um serviço de criação automática de ligações que são configurados para a criação de ligações entre repositórios Web (CamachoGuerrero et al. 2002a). Pretendia-se suportar diferentes combinações das abordagens exploradas na definição de ligações para atender de maneira mais satisfatória às necessidades e as expectativas de usuários. As combinações das abordagens são representadas pela combinação de parâmetros, assinalados antes do início do processamento. 


\subsubsection{Trabalho Realizado}

\section{Infra-estrutura}

A infra-estrutura do serviço configurável é apresentada na Figura 4.8 e detalhada a seguir.

No Nivel de linking, são definidas as ligações hipertexto entre os repositórios Web manipulados. Os parâmetros de configuração definidos nesse nível são numerados como (1), (2), (3), (4) e (5) na Figura 4.8 e, respectivamente:

(1) afetam a definição dos repositórios a serem manipulados e a definição dos parâmetros de indexação desses repositórios Web;

(2) são atribuídos à preparação dos termos a serem utilizados na criação de ligações semânticas. Diferentes versões e combinações de esquemas de atribuição de pesos podem ser consideradas;

(3) contextualizam a definição de ligações do tipo lexicais como, por exemplo, peso atribuído a cada termo comparado. É importante notar que os processos de geração automática de ligações lexicais e o processo de geração automática de ligações semânticas não são exclusivos;

(4) proporcionam interfaces para permitir a expansão da consulta original com os novos termos e a reformulação dos pesos dos termos da consulta expandida (relevance feedback);

(5) finalizam a definição das ligações semânticas. Nessa etapa, diferentes limiares de similaridades podem ser considerados, para determinar as ligações a serem armazenadas. Caso sejam atribuídos pesos aos termos comparados pelo módulo "Gera ligações lexicais", pode ser desejável a utilização de parâmetros que especifiquem graus de similaridades.

O módulo "Gera ligações lexicais" permite a definição de ligações lexicais, explorando apenas comparações de palavras como no SCALL. É possível que outros módulos de geração de diferentes tipos de ligações sejam adicionados à infra-estrutura, demonstrando a propriedade de estensibilidade da infra-estrutura configurável. Outro módulo implementado foi o módulo "Calcula peso", que explora diferentes esquemas de atribuição de pesos para a definição de ligações semânticas.

A comunicação entre os níveis de linking e de armazenamento é suportada por chamadas de funções à API (Application Programming Interface) do WLS (Bulcão Neto et al. 2002) ou por simples comandos de inserção em tabelas de banco de dados. Essas funcionalidades estão disponíveis na camada de apresentação.

No Nivel de apresentação, interfaces possibilitam (a) a especificação dos parâmetros configuráveis (habilita o fornecimento das informações necessárias às funcionalidades e às técnicas implementadas nos módulos do nível de linking) e (b) a apresentação de resultados (mostra as informações advindas do Nivel de armazenamento, e os parâmetros especificados). 


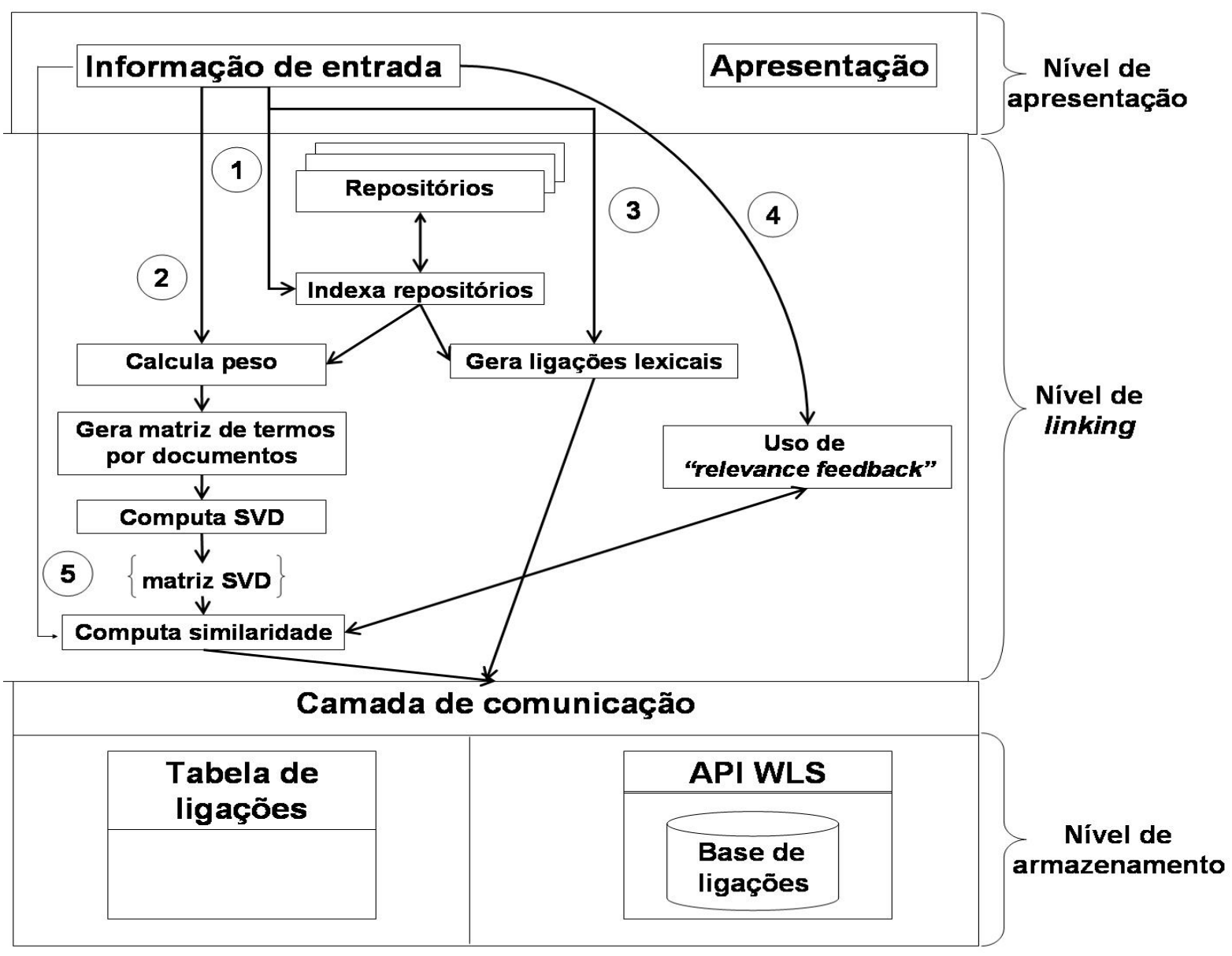

Figura 4.8: Infra-estrutura configurável para a geração automática de ligações Web

\section{Implementação}

Para a implementação dos módulos da infra-estrutura configurável, apresentados na Figura 4.8, o algoritmo codificado em "FlexibleServiceLinking", apresentado a seguir, foi desenvolvido.

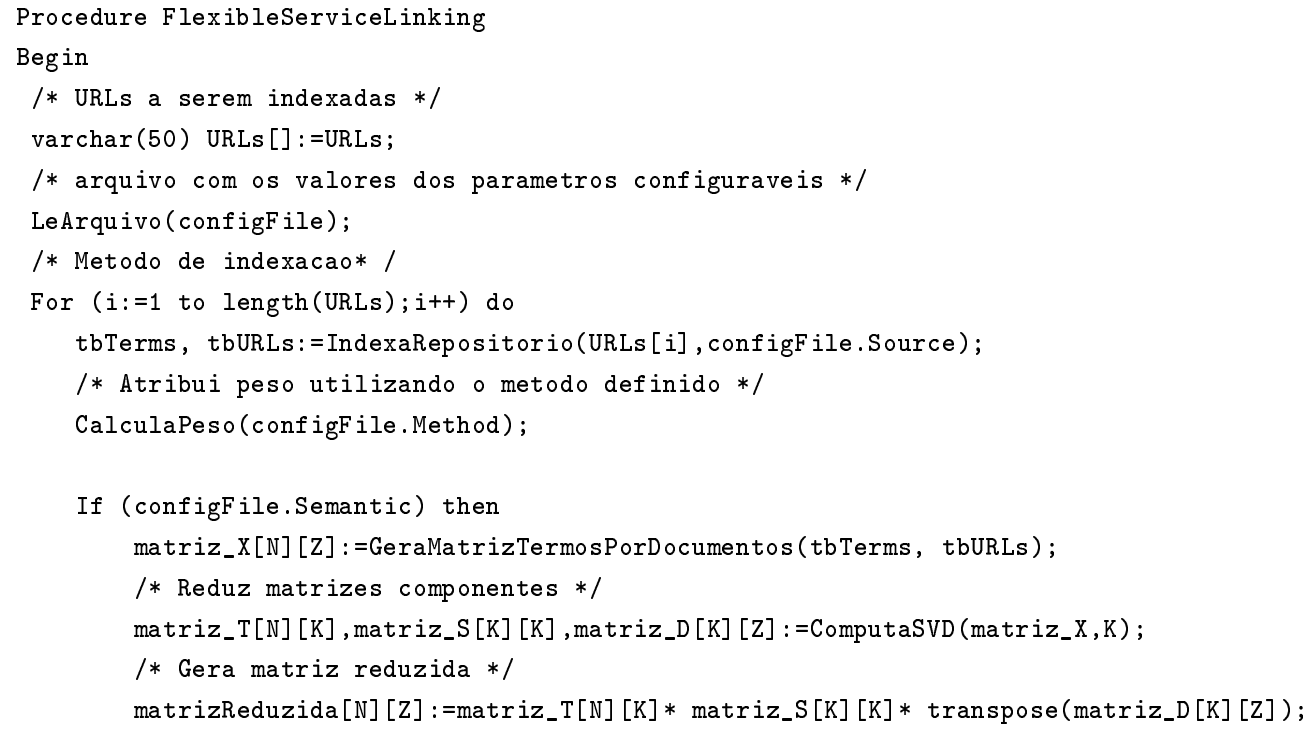




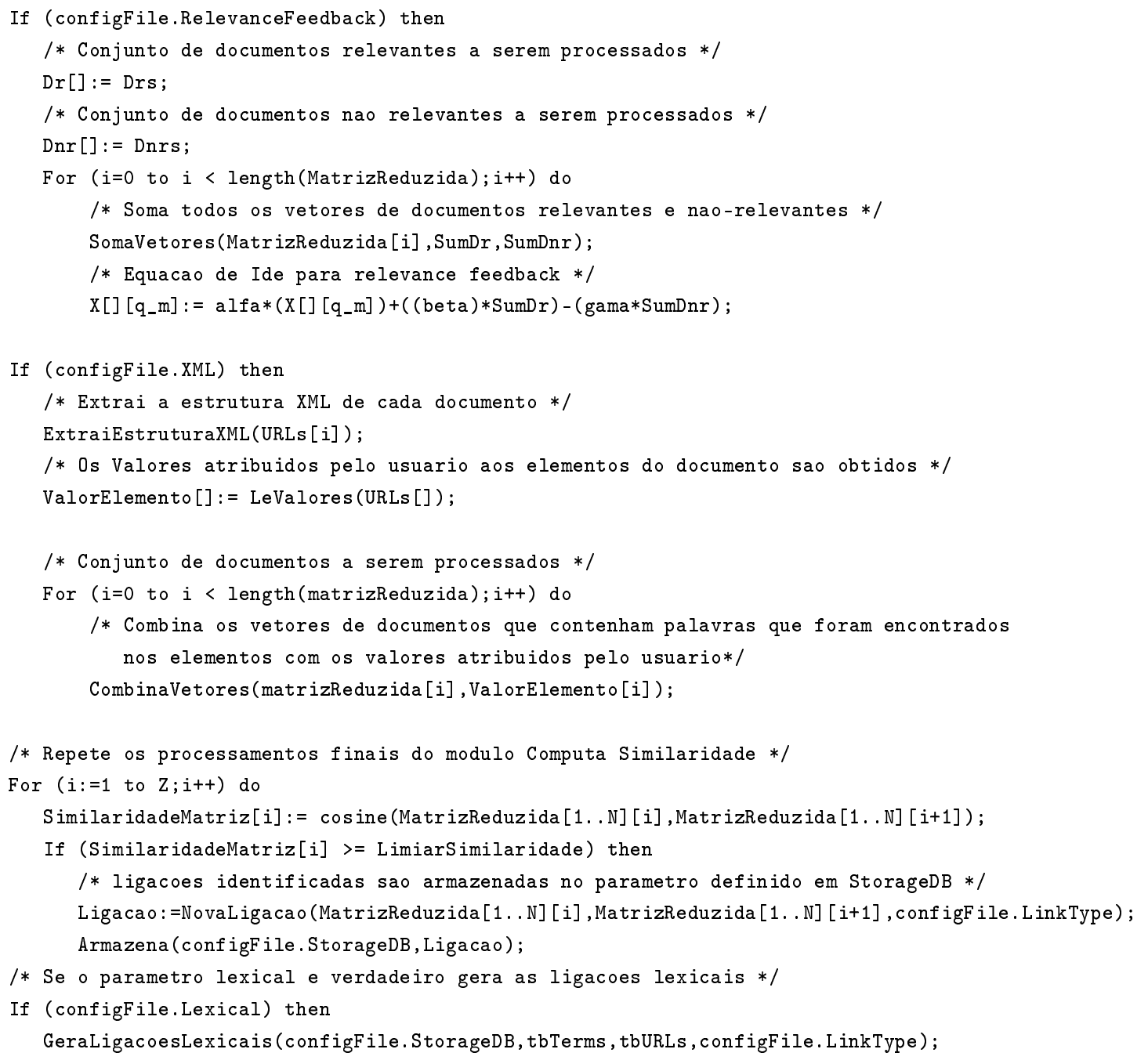

End.

O procedimento executa os seguintes métodos:

- "LeArquivo()" - lê os parâmetros de configuração inseridos pelo usuário;

- "IndexaRepositorio()" - indexa cada repositório Web. Esses repositórios são indexados separadamente e armazenados no banco de dados;

- "CalculaPeso()" - atribui pesos a termos utilizando o esquema de atribuição selecionado;

- "GeraMatrizTermosPorDocumentos()" - gera, considerando as tabelas e os termos de índice gerados a partir dos repositórios, a matriz de termos por documentos $X$;

- "ComputaSVD()" - dada a matriz X gerada e o valor $k$ de redução, executa o análise de SVD gerando as matrizes componentes $T, S$ e $D$ e a dimensão reduzida dessas matrizes de acordo com $k$;

- "SomaVetores()" - soma todos os vetores de documentos relevantes, após sugestão dos usuários de quais são relevantes ou não; 
- "ExtraiEstruturaXML()"- extrai a estrutura dos documentos para serem apresentadas a usuários;

- "LeValores()" - lê os valores atribuídos pelos usuários aos elementos que compõem os documentos;

- "CombinaVetores()" - as informações adicionadas pelos usuários são combinadas com as informações armazenadas na matriz semântica;

- "SimilaridadeMatriz()" - utiliza o limiar de similaridade, selecionado na configuração, para gerar a matriz de relevância semântica a qual é usada para identificar o relacionamento entre os repositórios;

- "Armazena()" - faz requisições ao serviço de armazenamento o qual gera e armazena as ligações no WLS ou na tabela de ligações do LinkDigger;

- "GeraLigacoesLexicais()" - dada as tabelas de termos e de documentos, gera ligações entre os repositórios comparando palavras contidas em cada documento. Essas ligações são armazenados no WLS ou na tabela de ligações do LinkDigger.



Figura 4.9: Interface do LinkDigger para configuração dos parâmetros

A infra-estrutura configurável foi implementada como extensão do LinkDigger (CamachoGuerrero et al. 2002b) para suportar a configuração de parâmetros a serem explorados durante a criação e a apresentação das ligações identificadas e criadas pelo serviço. Os parâmetros de configuração que podem ser habilitados na extensão do LinkDigger, apresentados na Figura 4.9, são: (a) banco de dados utilizado na indexação (nome do servidor, 
nome do usuário, senha, porta de conexão e nome da base de dados); (b) tipo de repositório de informação a ser manipulado (sítios na Web, arquivos, banco de dados e documentos XML); (c) mecanismos de pré-processamento textual (dicionários de stopwords, idioma, afixos/prefixos); (d) tipo de armazenamento das ligações (biblioteca de ligações WLS, tabela interna ou banco de dados que armazena documentos XML); (e) direção das ligações a serem criadas (intra-repositórios e inter-repositórios); (f) tipo de ligações a serem criadas (lexicais ou semânticas); (g) esquema de atribuição de pesos a ser utilizado; (h) limiar de similaridade e (i) apresentação das ligações criadas (ligações em páginas-índices, roteiros guiados e expansão da consulta).

\subsection{Limitações dos Serviços de Criação Automática de Ligações}

As limitações dos serviços apresentados neste capítulo referem-se diretamente às limitações dos artefatos utilizados. Algumas dessas limitações já foram mencionadas no capítulo anterior em relação à técnica de LSA, mas são detalhadas a seguir especificamente para os serviços apresentados:

- alto custo computacional despendido em cálculos. O modelo algébrico SVD, manipulando matrizes esparsas, apresenta complexidade da ordem de $O(m n c)$, sendo $m$ e $n$ as dimensões da matriz de termos por documentos e $c$ o número de elementos diferentes de zero em cada linha da matriz. Essa limitação é enfrentada pelos métodos de definição de relacionamentos semânticos dos módulos da infra-estrutura da Figura 4.8. Essa limitação advém do uso da técnica de LSA;

- dificuldade para determinar a dimensão ideal do espaço conceitual reduzido (a matriz $\hat{X})$. Alguns pesquisadores usaram "tentativa e erro" para empiricamente determinar a dimensão ideal (Deerwester et al. 1990). Essa dificuldade de encontrar o valor de $k$ também é decorrente do uso da técnica de LSA;

- problemas de extensão da informação manipulada. O problema de extensão ou escalabilidade ocorre quando a quantidade de informação de cada repositório cresce. Este problema é decorrente do fato de que o modelo de proximidade utilizado para representar cada repositório - LSA - manipula co-seno entre vetores que representam documentos para definir as relações semânticas. Sabe-se que se um documento for incluído nos repositórios indexados, não aconteceriam perdas significativas na comparação desse documento com a estrutura semântica definida. O documento seria manipulado como uma consulta a ser comparada com os documentos já relacionados. Entretanto, a partir do segundo documento começariam a surgir perdas de precisão. Com o crescimento da quantidade de documentos incluídos nos repositórios, torna-se imprescindível saber o grau evolutivo das perdas para determinar o limite aceitável de perda. Quando esse limite for excedido, é necessário realizar quase todo o processo de 
criação de ligações novamente, com exceção apenas da coleta. Essa limitação também é decorrente da técnica de LSA;

- incerteza do nivel de precisão dos serviços criados. Está sendo bastante complicado avaliar a performance dos serviços de ligações criados, desde que não foram encontradas coleções de referência para comparação e avaliação de desempenho de sistemas desse domínio. As avaliações ad hoc das ligações criadas pelos serviços também são tarefas complicadas, uma vez que cada indivíduo tem um particular entendimento de ligação "boa" ou "ruim". Talvez esta seja a principal razão da inexistência de métodos automáticos para a avaliação de ligações. A avaliação de ligações torna-se ainda mais difícil quando essas ligações são definidas a partir da semântica latente, uma vez que os relacionamentos dependem do contexto onde as ligações estão sendo utilizadas;

- identificação de relacionamentos explorando apenas técnicas de IR. É bastante limitada a variabilidade de mecanismos de identificação de ligações pelos serviços de criação automática de ligações. Atualmente utiliza-se apenas comparações lexicais, comparações estruturais e comparações considerando a semântica latente da informação. Dicionários de sinônimos e outras técnicas de identificação de relacionamentos textuais poderiam ampliar a oportunidade de identificar informações similares;

- pouca interação com usuários. A permissão de participação de usuários apenas através da formulação de consultas e do método de relevance feedback é uma limitação decorrente da utilização isolada de técnicas de IR. Relacionamentos dessa pesquisa com outras área podem suprir essa limitação.

\subsection{Considerações Finais}

Os serviços criados suportam a integração automática das informações dos repositórios manipulados. Essa integração tem sido apresentada por ligações hipertexto, semânticas e lexicais, criadas entre documentos Web visando auxiliar a busca de informações similares em diferentes repositórios.

O primeiro serviço de comparações lexicais (SCALL) possuía algumas desvantagens de utilização como falta de exaustão devido às simples comparações lexicais de palavras que podem omitir relacionamentos implícitos e gerar relacionamentos equivocados. O segundo serviço - SCALS - foi criado com a idéia de complementar as ligações lexicais já definidas através da identificação e criação de ligações semânticas. O SCALS identificou um grande número de ligações, mas restringiu o tipo de repositório em que o serviço poderia trabalhar somente repositórios onde o serviço poderia ter a permissão de escrita nos documentos. Para esse serviço foi definida uma modelagem que sistematizou o processo de geração automática de ligações entre dois repositórios Web homogêneos especiais.

O serviço SACALS foi uma evolução do SCALS, uma vez que aprimorou a contribuição da utilização de semântica com as facilidades de Hipermídia Aberta, permitindo a criação 
de ligações para qualquer repositório Web. Para esse serviço foi estendida a modelagem definida anteriormente. A nova modelagem permitiu a apresentação do processo de geração, armazenamento e apresentação de ligações criadas automaticamente para qualquer repositório Web.

No sentido de adequar os serviços de criação automática de ligações às expectativas dos usuários e, assim, aprimorar a precisão desses serviços, foi investigado o método de relevance feedback, baseado na interação com o usuário, para a expansão do conjunto de ligações relevantes geradas. Essa investigação deu origem a uma infra-estrutura e o serviço SCLIU que ilustram o apoio à participação de usuários na definição de ligações entre repositórios Web.

As ligações hipertexto criadas para todos os serviços consideram apenas o conteúdo textual dos documentos manipulados. Porém, o fato de documentos apresentarem uma estrutura textual pré-definida fornece características atrativas que podem ser exploradas durante a criação de ligações. Com o objetivo de definir relacionamentos entre documentos advindos de repositórios homogêneos, considerando a estrutura do documento manipulado, além do seu conteúdo, foi criado o serviço de criação automática de ligações entre documentos estruturados (SCALDE).

A cada extensão dos serviços de criação de ligações, os módulos das infra-estruturas (mapeados nos procedimentos) e as APIs desses serviços foram definidos respectivamente como classes e métodos os quais posteriormente foram utilizadas na definição do arcabouço proposto. Foram também identificados pontos de flexibilização do domínio de aplicações de criação automática de ligações. Por exemplo, nos serviços apresentados pode-se notar a variabilidade de tipos de repositórios para armazenamento das informações relacionadas ao processo de criação de ligações. Devido à complexidade de manipular diversos repositórios de armazenamento, uma classe denominada Armazenamento foi criada para incluir os processos e os módulos que essa flexibilização requisita.

Agregando as funcionalidades dos diferentes serviços criados foi definido um serviço para criação configurável de ligações. Assim, pretendia-se suportar diferentes combinações das abordagens exploradas na definição de ligações para atender às necessidades e expectativas de usuários.

Os serviços apresentados neste capítulo correspondem à etapa de análise de domínio e aplicação de tecnologias Hipermídia e de Recuperação de Informação para a criação de ligações entre documentos Web. Na continuidade deste trabalho, foram pesquisadas maneiras de incorporar os serviços de ligações criados como um componente de definição de ligações em outros sistemas. Para transformar esses serviços em um componente, foram necessárias abstrações das funcionalidades dos serviços e definições de novas interfaces entre os módulos dos serviços.

Para facilitar a reutilização dos componentes de software desenvolvidos para os serviços apresentados, foi definido o arcabouço CARe (Criação Automática de Relacionamentos), que oferece um conjunto de componentes ou classes que podem ser combinados e reutilizados 
com o intuito de definir automaticamente relacionamentos entre informações homogêneas. No próximo capítulo é apresentado o arcabouço CARe com suas classes, atributos, métodos e relacionamentos. 


\section{Arcabouço para Criação Automática de Ligações Hipertexto entre Informações Homogêneas}

\subsection{Considerações Iniciais}

Em Engenharia de Software utiliza-se o conceito de arcabouço, do inglês framework, para designar a tecnologia que oferece aos desenvolvedores de aplicações uma maneira poderosa de aumentar a reutilização de componentes de software, sendo que inúmeras aplicações distintas podem ser criadas por meio de sua instanciação. Johnson \& Foote (1988) relatam que o processo de instanciação de arcabouços é complexo e geralmente exige conhecimento técnico da construção do arcabouço. Arcabouços devem ser formados por componentes fixos e componentes de flexibilização (Johnson 1997). Pontos fixos (frozen spots) devem refletir o comportamento comum do domínio e pontos de flexibilização (hot spots) devem refletir o que muda no domínio de uma aplicação para outra. Pontos fixos constituem o núcleo do arcabouço, que é formado por partes de código que chamam pontos de flexibilização fornecidos pelo desenvolvedor da aplicação em questão. Pontos fixos são as partes constantes em cada instância do arcabouço.

Nesta tese usa-se o termo arcabouço para designar um conjunto de classes abstratas e mecanismos de colaboração entre as instâncias dessas classes. Segundo Johnson (1997), arcabouço é a representação de um projeto orientado a objetos que geralmente é implementado em linguagens de programação orientadas a objetos e tem como objetivo reduzir o custo de desenvolvimento de aplicações. Além de permitir reutilização, arcabouços podem facilitar a captura da essência de padrões de projeto com o objetivo de aumentar a qualidade e a produtividade do desenvolvimento de aplicações (Gamma et al. 1997).

A dificuldade em construir e utilizar arcabouços é um dos inibidores de sua utilização. 
Existem diferentes técnicas que propõem passos para a construção de arcabouços. Para a instanciação de um arcabouço deve-se contar com uma boa documentação de sua hierarquia de classes, código fonte, classes abstratas, métodos e exemplos concretos de aplicações que dele farão uso. Além de toda a documentação, é interessante oferecer treinamento e tutoriais especializados aos desenvolvedores de aplicações que pretendam utilizar o arcabouço provido (Johnson 1997).

O uso do conceito de arcabouço, na modelagem de componentes do processo de criação automática de ligações hipertexto em repositórios de conteúdo homogêneo, provê estruturas de projeto e de código a serem reutilizadas por aplicações que tenham o mesmo objetivo. $\mathrm{O}$ arcabouço CARe (Criação Automática de Relacionamentos) é representado por um conjunto de classes, métodos e relacionamentos que dão apoio a tarefas de coleta de informações, pré-processamento textual, geração de índices, relacionamento de documentos, armazenamento, acesso e interações de usuários para o domínio de aplicações com interesse na criação automática de relacionamentos. O uso do conceito de arcabouço demandou a definição de estruturas de projeto (classes, métodos, relacionamentos e diagramas) e a implementação de classes e métodos a serem reutilizados por aplicações que tenham o mesmo objetivo. A seguir é apresentado o arcabouço proposto para criação automática de relacionamentos entre informações advindas de repositórios homogêneos.

\subsection{Identificação de Pontos Fixos e de Flexibilização}

Para a criação do arcabouço proposto, a primeira atividade desenvolvida foi a análise de domínio para criação automática de ligações hipertexto. Durante essa análise, alguns requisitos do domínio foram identificados e utilizados para a criação iterativa dos componentes de software do arcabouço apresentado neste capítulo.

Depois de cada extensão dos serviços apresentados no capítulo anterior, os módulos de programa foram formalizados como APIs (Application Programming Interfaces) com o intuito de suportar o intercâmbio de funcionalidades. Por meio desse processo iterativo e evolucionário, esses módulos foram generalizados e convertidos nas classes e nos métodos do arcabouço proposto. Dessa maneira, foram identificados os componentes de software que poderiam ser reutilizados por outros sistemas.

Durante a definição dos componentes reutilizáveis do arcabouço, pontos fixos e pontos de flexibilização foram identificados. Esses pontos estão associados a funcionalidades do domínio. Algumas dessas funcionalidades como a coleta de informações, a criação de relacionamentos e a apresentação desses relacionamentos devem estar presentes em qualquer aplicação interessada em utilizar os componentes do arcabouço proposto. Embora essas funcionalidades devam ser sempre consideradas por aplicações que desejam reutilizar o arcabouço, elas fazem parte de classes com métodos flexíveis. Por exemplo, durante a criação de relacionamentos, desenvolvedores de software são capazes de configurar alguns parâmetros utilizados pela técnica de LSA. Todas as classes do arcabouço proposto são consideradas 
pontos de flexibilização. Esses pontos objetivam ampliar as chances do arcabouço atender as necessidades de um grande volume de aplicações interessadas no domínio de definição de relacionamentos entre informação textual.

\subsection{Terminologia}

Para o projeto inicial das estruturas de projeto do arcabouço CARe, foi definido um conjunto de termos e seus significados que envolvem a abstração do arcabouço em um diagrama de classes apresentado a seguir. Na apresentação do arcabouço proposto é utilizada a seguinte terminologia para a descrição da hierarquia de classes:

- $C$ representa a classe controladora "CARe", que está relacionada com as seguintes classes: $c i, p p, i r, o c$, ar e ac. A classe $i r$ pode ser especializada nas subclasses $r s$ e $r l$. "CARe" é na verdade o nome do arcabouço.

- ci representa a classe "ColetaInformacao", que possui métodos para realizar a coleta das informações a serem relacionadas;

- $p p$ representa a classe "Pré-processamento", que é formada por um conjunto de métodos que realizam funções de pré-processamento de informações textuais;

- ir representa a classe "IdentificacaoRelacionamento", que identifica os relacionamentos entre informações a partir do espaço semântico definido na subclasse "RelacaoSemantica" $(r s)$ ou simplesmente pela comparação lexical dos termos a partir da subclasse "RelacaoLexical" $(r l)$;

- oc representa a classe "OperacaoConsulta", que apóia as formulações de consulta e ao método relevance feedback;

- ar representa a classe "Armazenamento" que manipula chamadas de funções de pacotes que armazenam os relacionamentos identificados;

- ac representa a classe "Acesso", que suporta o acesso às informações similares relacionadas.

Os termos wView e iView são utilizados para representar pacotes compostos por aplicações de visualização de informações que podem ser instanciadas a partir da classe "Acesso". Já os termos XML, MySql e WLS são utilizados para representar pacotes de funções de armazenamento de ligações relacionados à classe "Armazenamento". Finalmente, o termo mnoGoSearch refere-se a um pacote relacionado a classe "Coleta de Informações".

Cada uma das classes de composição da classe controladora é formada pelos seguintes artefatos $E_{i}, r_{i}, a t_{i}, m_{i} e S_{i}$ obedecendo a seguinte terminologia:

- $E_{i}$ representa as informações de entrada para uma determinada classe $i$, sendo que $i=\{I \mid I \in C\}$ 
- $r_{i}$ representa um conjunto de requisitos da classe $i$, sendo que $i=\{I \mid I \in C\}$;

- $a t_{i}$ representa um conjunto de atributos da classe $i$, sendo que $i=\{I \mid I \in C\}$;

- $m_{i}$ o conjunto de métodos que compõem a classe $i$, sendo que $i=\{I \mid I \in C\}$;

- $S_{i}$ representa as informações de saída de uma determinada classe $i$, sendo que $i=$ $\{I \mid I \in C\}$. Cabe mencionar que o conjunto de saída de uma classe pode ser o conjunto de entrada de uma outra.

\subsection{Diagrama de Classes}

O projeto do arcabouço proposto tem como objetivo definir uma arquitetura com componentes de software (ou bibliotecas de classes) que possam ser reutilizados em outros projetos de desenvolvimento de aplicações com o intuito de criar ligações hipertexto entre informações homogêneas. Por esse motivo, esse arcabouço deve possuir estrutura flexível de software, de modo a incorporar os pontos de flexibilização e os pontos fixos já definidos.

Para representar a hierarquia de classes, as classes e os relacionamentos entre elas no arcabouço proposto, foi definido um diagrama de classes, ilustrado na Figura 5.1. Esse diagrama representa o arcabouço como um conjunto de classes abstratas e mecanismos de colaboração entre as instâncias dessas classes.

Na definição do arcabouço foram utilizadas as infra-estruturas definidas na análise do domínio apresentada no capítulo anterior. Alguns dos processos definidos nessas infra-estruturas podem ser diretamente identificados no diagrama de classes, outros foram agrupados em uma classe que identifica seu comportamento. Por exemplo, o processo "Computa Similaridade" foi diretamente abstraído como a classe "IdentificacaoRelcionamentos".

O diagrama de classes é composto pelas seguintes classes: classe controladora (CARe $C$ ), classe de coleta de informações (ColetaInformacao - ci), classe de pré-processamento (Pré-processamento - pp), classe de identificação de relacionamento (IdentificacaoRelacionamento - ir), classe de definição de relacionamentos lexicais (RelacaoLexical $-r l$ ), classe de definição de relacionamentos semânticos (RelacaoSemantica - rs), classe de armazenamento (Armazenamento - ar), classe de manipulação de consulta e relevance feedback - OperacaoConsulta $o c$ ) e classe para acesso às informações similares relacionadas (Acesso - ac). Cada uma dessas classes é composta por métodos, atributos, informações de entrada e de saída que são apresentadas a seguir. As classes são detalhada nas próximas subseções.

Além das classes e métodos existentes no diagrama de classes da Figura 5.1, existem pacotes que são dependentes das classes relacionadas a eles no diagrama. São eles wView, iView, mnoGSearch, XML, MySql e WLS.

No diagrama de classes apresentado na Figura 5.1, relacionamentos entre as classes componentes ilustram a associação entre as classes e a comunicação entre os métodos definidos nas classes. Esses relacionamentos são representados por setas continuas. Por exemplo, na 




Figura 5.1: Diagrama de Classes do arcabouço CARe para apoio à criação automática de ligações entre repositórios homogêneos de informações 
classe "Acesso" (ac) a conectividade com as classes principais do arcabouço podem ser interpretadas como, (1) atendimento da consulta gerada pela classe "OperacaoConsulta" (oc), (2) envio de informação a ser relacionada, e (3) requisição à classe "Armazena" (ar) para obtenção de relacionamentos armazenados. Já na classe "IdentificacaoRelacionamento" (ir) o relacionamento "identifica", representa a ativação do processo de ligações da informação coletada ou pré-processada pelos respectivos métodos. Já as setas pontilhadas representam dependência da classe com sistemas externos, como é o caso da classe ar quando utiliza a biblioteca de ligações do WLS. O outro tipo de seta representa especializações de classes como, por exemplo, a classe ir que é uma generalização das sublasses $r s$ e $r l$.

\subsection{Descrição das Classes}

O arcabouço proposto possui as classes com métodos e atributos que devem ser sobrepostos ou instanciados nas subclasses da aplicação. Esses métodos, atributos, informações de entrada e informações de saída são apresentados a seguir em detalhes para cada classe que compõe o arcabouço CARe.

\subsubsection{Coleta de Informação}

A classe "ColetaInformacao" (ci) extrai a informação dos repositórios e gera um conjunto de palavras para representar cada documento da coleção. Essas palavras são enviadas como parâmetro de entrada $\left(E_{i}\right)$ à classe "Pré-processamento" $(p p)$ apresentada na próxima seção.

A classe $c i$ possui alguns pontos fixos como, por exemplo, o método de "Coleta()" apresentado a seguir; porém essa classe contém vários pontos de flexibilização como o método que permite a escolha do pacote "mnoGoSearch()" ou "LDCrawler()" para a coleta de informações.

Para a instanciação da classe' $c i$, informações de entrada $\left(E_{i}\right)$ como endereços dos repositórios a serem manipulados, pontos de flexibilização como, por exemplo, o robô de busca a ser utilizado, e alguns requisitos como homogeneidade da coleção e organização da informação como hierarquia de diretórios são necessárias. As informações de saída $\left(S_{i}\right)$ dessa classe são diretamente utilizadas pela classe $p p$. As informações de saída são um conjunto de palavras-chave (bag of words) e a estrutura dos documentos manipulados, caso esse ponto de flexibilização esteja sendo instanciado.

Na definição dessa classe foram utilizados sistemas externos que auxiliam na coleta e manipulação dos documentos. Os sistemas utilizados, representados como pacotes mnoGoSearch e XML, auxiliam na coleta, extração de palavras e separação de conteúdo e estrutura dos documentos.

Os pré-requisitos para instanciação dessa classes são homogeneidade da informação e organização hierárquica da informação. Os artefatos que formam a classe $c i$ são descritos a seguir. 
- Informação de entrada $\left(E_{c i}\right)$ : endereço ou lista de endereços dos repositórios a serem relacionados.

- Atributos: $a t_{i}=\{I \mid I \in(a, b, c)\}$, sendo

$a=$ tipoRepositorio: o tipo de repositório de informação a ser manipulado, isto é, sítios Web, arquivos ou banco de dados. Atualmente essa classe aceita somente os seguintes valores para esse atributo: web $\vee$ arq $\vee b d$. $\mathrm{O}$ valor $w e b$ deve conter uma URL, o valor arq deve conter o nome de um arquivo e o valor $b d$ deve ser o endereço de um banco de dados;

$b=($ nomeservidor $\wedge$ usuario $\wedge$ senha $\wedge$ porta $):$ repositório a ser coletado;

$c=($ ar Local $\vee$ arEstrutura): artifícios de coleta podem estar disponíveis para coletar apenas informações de conteúdo (arLocal) e/ou informações de estrutura (arEstrutura).

- Métodos disponibilizados:

$m_{i}=\{I \mid I \in($ mnoGoSearch (), LDCrawler (), ExtraiEstruturaXML(), Coleta ()$)\}$, sendo

mnoGoSearch(): método que lê a informação de entrada $\left(E_{c i}\right)$ para $v[a]=(w e b)$ e chama a ferramenta mnoGoSearch (MnoGoSearch Group 2004) para rastrear páginas Web a serem manipuladas e fazer a extrair palavras de cada unidade de informação que compõem a coleção. Esse método é uma instanciação de classes do sistema externo mnoGoSearch;

$L D C r a w l e r()$ : método que lê a informação de entrada $\left(E_{c i}\right)$ para $v[a]=(\operatorname{arqoubd}) \mathrm{e}$ chama o robô de coleta de páginas da ferramenta LinkDigger, ambos desenvolvidos no contexto do trabalho proposto. Esse método também faz a extração de palavras de cada unidade de informação que compõem a coleção;

ExtraiEstruturaX $M L()$ : método que lê a informação de entrada $\left(E_{c i}\right)$ para $v[c]=$ (arEstrutura) e armazena apropriadamente a estrutura de um documento estruturado coletado. Esse método é uma instanciação de classes do pacote XML;

Coleta(): método principal da classe que seleciona e executa os métodos descritos acima para coleta.

- Informação de saída $\left(S_{c i}\right)$ : conjunto de palavras extraídas (bag of words) dos repositórios com o número de vezes que cada palavra apareceu no documento $V_{p}$. A localização da palavra dentro do documento influi diretamente no valor adicionado a $V_{p}$. A estrutura extraída dos documentos é armazenada no repositório correspondente para sua posterior utilização.

A classe "ColetaInformação" implementa, através do método "Coleta", parte do módulo "Indexa repositórios" da infra-estrutura apresentada no capítulo anterior, especificamente na 
Figura 4.8. Os métodos de indexação, outra parte do módulo "Indexa repositórios", foram abstraídos na classe apresentada a seguir.

\subsubsection{Pré-processamento da Informação}

A classe de pré-processamento da informação $(p p)$ cria um subconjunto de palavras que é representativo da coleção manipulada. Uma vez obtido esse subconjunto, são atribuídos pesos às palavras para a definição de índices da coleção. Nessa classe também foram implementados métodos para tratamento de consultas e pré-processamento de palavras como, por exemplo, métodos de eliminação de stopwords e métodos de stemming. Pode-se dizer que esta classe processa a informação obtida pela classe "ColetaInformacao".

Os pré-requisitos para instanciação dessa classes são homogeneidade da informação, organização hierárquica da informação e lista de relevância das palavras para os documentos.

- Informação de entrada $\left(E_{p p}\right)$ : conjunto de palavras extraídas dos repositórios ou de consultas formuladas por usuários com os valores de $\hat{V}_{q}$ da equação 3.5 de consulta da técnica de LSA apresentada no Capítulo 3.

- Atributos: $a t_{i}=\{I \mid I \in(a, b, c)\}$, sendo

$a=($ afixos $\wedge$ stemming $\wedge$ stopwords $\wedge$ prefixos $\wedge$ podaInf $\wedge$ podaSup $\wedge$ minPalavras): artifícios de pré-processamento de texto;

$b=$ metodoPeso: o método a ser utilizado no cálculo e atribuição dos pesos às palavras indexadas. Foram implementados três métodos de atribuição de pesos e podem ser selecionados com os valores: 1, 2 ou 3. Esses métodos foram descritos no Capítulo 3;

$c=$ idioma: o idioma a ser considerado pelo processo de pré-processamento. Três idiomas são suportados: inglês, espanhol e português (in, es e pt).

- Métodos disponibilizados:

$m_{i}=\{I \mid I \in($ RemoveStopwords(), AplicaStemming(), RemoveDocumentos(), RemovePalavras(), IndexaRepositorio(), PodaVetores(), CalculaPeso(), CombinaPeso(), NormalizaVetorConsulta()\}, sendo

RemoveStopwords(): método que remove do conjunto de palavras artigos, preposições, conjunções, pronomes, etc. As stopwords não conseguem representar efetivamente um documento;

AplicaStemming(): método que verifica se cada palavra está no plural, conjugada ou no gerúndio e, em seguida, extrai apenas o radical da palavra;

RemoveDocumentos(): método que realiza a pré-seleção de documentos tendo como critério o número de palavras dos documentos. O mínimo de palavras que um documento deve ter é configurável e instanciado em uma variável; 
RemovePalavras(): método que elimina do conjunto inicial as palavras cujo peso extrapola os limiares máximo e mínimo obtidos no método de poda apresentado a seguir;

PodaVetores(): método que calcula os valores que delimitam o conjunto de palavras que representam claramente a coleção de informação. Palavras cujo peso é menor ao limite inferior podem ser consideradas próprias do ambiente. Por outro lado, palavras com peso que superam o limite superior podem-se consideradas nãorepresentativas do documento;

CalculaPeso(): método que atribui peso às palavras dos documentos;

CombinaPeso(): método que adiciona o valor dado por usuários a elementos da estrutura de documentos;

NormalizaVetorConsulta(): método que transforma os valores de freqüência do vetor que representa a consulta em valores normalizados com a matriz semântica;

IndexaRepositorio(): método principal da classe que diferencia os termos de acordo com valor de metodoPeso que indica um dos diferentes métodos de atribuição de pesos apresentados no capítulo anterior;

- Informação de saída $\left(S_{p p}\right)$ : conjunto de índices que representam as palavras extraídas dos repositórios.

Essa classe, agrupa métodos referentes ao tratamento de palavras e representa parte do módulo "Indexa repositórios" da infra-estrutura apresentada na Figura 4.8.

\subsubsection{Identificação de Relacionamentos}

Dado os índices gerados pela classe $p p$, a classe de "IdentificacaoRelacionamento" (ir) compara conteúdos de documentos e relaciona aqueles com valores de similaridade altos. Relacionamentos semânticos e/ou lexicais podem ser identificados dependendo da subclasse a ser instanciada. Similaridades são identificadas através do cálculo do co-seno ou da distância euclidiana entre as colunas da matriz.

Pré-requisitos da informação de entrada são termos de índice contendo valores que representam a importância de cada palavra dentro do documento.

- Informação de entrada $\left(E_{i r}\right)$ : termos de indice que representam os documentos a serem relacionados. Esses índices podem ser pré-processados em $p p$, antes de iniciar a identificação.

- Atributos: $a t_{i}=\{I \mid I \in(a, b, c, d, e)\}$, sendo

$a=$ direcao: direção das ligações. Podem ser criadas ligações entre documentos do mesmo repositório (intra) ou entre informações contidas em diferentes repositórios (inter); 
$b=$ tipo: tipo das ligações a serem criadas. Esse atributo permite a instanciação de classes especializadas que identificam relacionamento semântico ou lexical. A classe "RelacaoSemantica", apresentada a seguir, é uma especialização da classe "IdentificaRelacionamento". "RelacaoSemantica" identifica relacionamentos de tipo semântico através da técnica de LSA. Outra especialização implementada é classe "RelacaoLexical", que realiza simples comparações lexicais para definir relacionamentos.

$c=$ metodo: seleciona o método de cálculo de aproximação de vetores. Foram implementados dois métodos de aproximação de vetores: um método que usa co-seno e outro que usa distancia euclidiana;

$d=\operatorname{simMax}$ : limiar máximo de similaridade (valores entre 0 e 1);

$e=\operatorname{simMin}$ : limiar mínimo de similaridade (valores entre 0 e 1).

- Métodos disponibilizados:

$m_{i}=\{I \mid I \in($ ComputaSimilaridade(), NovaLigacao(), CriaEspaco(), cosine(), distancia (), Identifica ()$)\}$, sendo

ComputaSimilaridade(): método que calcula o co-seno ou a distância euclidiana entre dois vetores cujo valor resultante representa o grau de aproximação entre eles. Esses vetores podem representar documentos e consultas.

NovaLigacao(): método que define relacionamentos entre duas unidades de informação.

CriaEspaco(): método que prepara o espaço de informação para a identificação de relacionamentos. Esse método seleciona o tipo de relacionamento a ser definido (semântico ou lexical);

cosine(): método que computa o co-seno entre dois vetores da matriz que representa a coleção de informação. São obtidos valores entre 0 e 1 que representam a aproximação dos vetores em um espaço gráfico, onde 1 representa a vetores sobrepostos (documentos similares) e 0 vetores distantes (documentos distintos);

distancia(): método alternativo para cálculo de aproximação de vetores. O valor retornado por esse método representa a distância euclidiana entre os documentos comparados;

Identifica(): método principal da classe que seleciona e executa os métodos para identificação de relacionamentos e armazena os relacionamentos identificados.

- Informação de saída $\left(S_{i r}\right)$ : conjunto de relacionamentos entre documentos.

$\mathrm{Na}$ infra-estrutura apresentada no capítulo anterior na Figura 4.8, os módulos "Computa similaridade" e "Gera ligações lexicais" realizavam a identificação de relacionamentos entre 
documentos. Dado que o comportamento dos dois módulo é similar, a classe "IdentificaRelacionamento" generaliza esses dois módulos. A seguir são apresentadas as classes específicas para cada tipo de relacionamento suportado pelo CARe.

\subsubsection{Relação Semântica}

A classe de "RelacaoSemantica" ( $r s$ ), especialização da classe "IdentificaRelacionamento", aplica sobre as informações coletadas e pré-processadas a técnica de LSA para obter a estrutura semântica que representa a coleção de informações manipulada. $O$ valor de redução $(k)$ é previamente definido e atribuído a uma das variáveis.

Os pré-requisitos para instanciação dessa classe são peso_indices e rela_indice_doc. Os atributos de limiar de similaridade são herdados da classe de identificação de relacionamento $($ ir $)$.

- Informação de entrada $\left(E_{r s}\right)$ : conjunto de ndices que representam as palavras extraídas dos repositórios.

- Atributos: $a t_{i}=\{I \mid I \in(a)\}$, sendo

$a=k$ : valor de redução das matrizes.

- Métodos disponibilizados:

$m[i]=\{I \mid I \in($ GeraMatrizTermosPorDocumentos(),ComputaSVD(),

GeraMatrizReduzida(), CriaEspaco(), GeraLigacoesSemanticas())\}, sendo

GeraMatrizTermosPorDocumentos(): método que cria um arquivo-matriz para cada repositório definido que representa a correlação entre termos e documentos e o peso que foi atribuído a cada termo dentro desse documento;

ComputaSVD(): método que recebe a matriz obtida pelo método anterior e extrai as matrizes componentes através do método SVD. O SVD (Singular Value Decomposition) é um modelo de análise para generalização em um espaço onde termos (palavras) e documentos são manipulados como vetores;

GeraMatrizReduzida(): método que gera as matrizes componentes reduzidas considerando $k$. Com essa redução pretende-se eliminar informações não-representativas da coleção;

CriaEspaco(): método que gera uma matriz que representa um espaço semântico onde os documentos são contidos. Essa matriz e obtida através da multiplicação das matrizes componentes reduzidas;

GeraLigacoesSemanticas(): método principal da classe que ativa o processo de relacionamento semântico.

- Informação de saída $\left(S_{r s}\right)$ : espaço semântico deve representar documentos e palavras com valores que identifiquem cada documento na coleção. 


\subsubsection{Relação Lexical}

A classe de "RelacaoLexical" $(r l)$ realiza simples comparações lexicais de palavras para a identificação de relacionamentos lexicais entre os repositórios de informação manipulados. Essa classe também é uma especialização da classe "IdentificaRelacionamento".

Os pré-requisitos para instanciação dessa classes são peso_indices e rela_indice_doc.

- Informação de entrada $\left(E_{r l}\right)$ : conjunto de indices que representam as palavras extraídas dos repositórios.

- Atributos: $a t_{i}=\{I \mid I \in(a)\}$, sendo

$a=$ vazio: os atributos utilizados nessa classe são herdados da classe $i r$.

- Métodos disponibilizados:

$m[i]=\{I \mid I \in($ CriaEspaco(), GeraLigacoesLexicais ()$)\}$, sendo

CriaEspaco(): método que gera uma matriz que representa um espaço onde os documentos estão contidos;

GeraLigacoesLexicais(): método principal da classe que ativa o processo de relacionamento entre documentos comparando seus termos.

- Informação de saída $\left(S_{r l}\right)$ : espaço lexical que representa documentos e palavras com valores que identificam a importância de cada documento na coleção.

\subsubsection{Armazenamento}

A classe "Armazenamento" (ar) é composta por pacotes que auxiliam o armazenamento das ligações identificadas. Tais subclasses instanciam os repositórios de armazenamento de ligações: o WLS, um repositório para armazenamento de arquivos XML e um BD MySQL. Outros pacotes de armazenamento podem ser incluídos.

Os pré-requisitos da informação de entrada são: tupla contendo informação dos documentos a serem armazenados, tipo de ligação identificada, direção do relacionamento e grau de similaridade.

- Informação de entrada $\left(E_{a r}\right)$ : conjunto de relacionamentos

- Atributos: $a t_{i}=\{I \mid I \in(a, b)\}$, sendo

$a=$ tipo: tipo de armazenamento das ligações. Atualmente, são utilizados os sistemas externos de manipulação e armazenamento de informação, representados no diagrama de classes como pacotes WLS, XML e MySQL;

$b=($ nomeServidor, porta, usuario, senha): artifícios de armazenamento.

- Métodos disponibilizados:

$m[i]=\{I \mid I \in($ Conecta (), Insere (), Atualiza (), Remove (), Armazena ()$)\}$, sendo 
Conecta(): método que autentica a conexão ao repositório de informações selecionado; Insere(): método que insere informações no repositório de armazenamento;

Atualiza(): método que atualiza informações do repositório de armazenamento; Remove(): método que remove as informações do repositório de armazenamento; Armazena(): método principal da classe encarregado de ativar os artefatos necessários para o armazenamento e recuperação da informação relacionada.

- Informação de saída $\left(S_{a r}\right)$ : endereço do repositório onde foram armazenadas as ligações.

- Pacotes:

- WLS: pacote de funções de armazenamento de relacionamentos definidos na biblioteca de ligações WLS;

- XML: pacote que contém métodos de armazenamento para bancos de dados XML;

- MySQL: pacote que fornece mecanismos de criação, inserção, atualização e consulta a bancos de dados.

A classe aqui detalhada representa a "Camada de comunicação" entre o nível de linking e o nível de armazenamento ilustrados na Figura 4.8. No nível de armazenamento da mesma infra-estrutura é possível instanciar diferentes pacotes de armazenamento.

\subsubsection{Acesso}

A classe "Acesso" (ac) é composta por métodos que auxiliam na apresentação das ligações identificadas e nas interfaces de comunicação entre os diferentes sistemas que instanciam o arcabouço CARe. Podem ser utilizados sistemas externos que auxiliem na apresentação das informações identificadas. Atualmente, dois sistemas de apresentação estão sendo utilizados, a iView e a wView.

- Informação de entrada $\left(E_{a c}\right)$ : conjunto de requisições.

- Atributos: $a t_{i}=\{I \mid I \in(a, b, c)\}$, sendo

$a=$ tipoEntrada: recebe o tipo de entrada de informações a serem apresentadas. Atualmente pode-se utilizar Vetor e BD;

$b=$ tipoSaida: recebe o tipo de saída de apresentação da informação. Atualmente são os pacotes iView,wView, páginas HTML ou vetores. Esses dois últimos tipos têm sido utilizados nos serviços apresentados anteriormente;

$c=$ contexto: recebe o contexto da ligação. Contexto, refere-se ao nome dado pelo serviço ao tipo de informação manipulada.

- Métodos disponibilizados:

$m[i]=\{I \mid I \in($ CriaInterface (), ranking (), CriaHtml ()$)\}$. 
CriaInterface(): método que define o conteúdo do documento de saída e a interface de apresentação da informação de saída;

ranking(): método que classifica os elementos a serem apresentados;

CriaHtml(): método que gera HTML para apresentar os pares de âncoras.

- Informação de saída $\left(S_{a c}\right)$ : interface de acesso para apresentação das ligações criadas (ligações criadas, páginas-índices, roteiros-guiado, iView e wView) ou vetores que retornam relacionamentos.

- Pacotes:

- iView: aplicação que usa um documento XML com a informação a ser apresentada e um documento com o layout de saída da apresentação;

- wView: aplicação que usa o esquema do repositório ou diagrama de classes onde são armazenados as ligações.

A classe de "Acesso" (ac) engloba o nível de apresentação da infra-estrutura da Figura 4.8 e implementa serviços de comunicação para o intercâmbio de informação com outros sistemas. Essa classe é de grande importância na integração e declaração dos serviços apresentados no próximo capítulo. Por esses motivos a classe "Acesso" é considerada um ponto fixo do arcabouço aqui proposto.

\subsubsection{Operação de Consulta}

A classe "OperacaoConsulta" (oc) é definida como ponto de flexibilização do arcabouço, pois sua instanciação só é necessária para sistemas que implementam funcionalidades específicas. Essa classe faz parte do nível de apresentação da infra-estrutura ilustrada na Figura 4.8 e implementa o módulo "Uso de relevance feedback" dessa mesma infra-estrutura.

- Informação de entrada $\left(E_{o c}\right)$ : conjunto de palavras, documentos ou repositórios que representam a consulta.

- Atributos: $a t_{i}=\{I \mid I \in(a)\}$, sendo

$a=$ query: esse atributo recebe a consulta do tipo string enviada à aplicação.

- Métodos disponibilizados:

$m[i]=\{I \mid I \in($ GeraVetorConsulta (), Consulta (), feedback ()$)\}$.

GeraVetorConsulta(): método que cria o vetor de consulta query a partir da informação de entrada $E_{o c}$;

Consulta(): método principal da classe. Esse método transforma a consulta em um vetor que é considerado como mais um documento (pseudo-documento) da coleção de documentos indexados, isto é, mais um vetor-coluna da matriz que representa o 
espaço semântico. Esse método utiliza instâncias das classes Pré-processamento, IdentificacaoRelacionamento e Acesso;

feedback(): método que envolve dois passos básicos: expansão da consulta original com os novos termos e reformulação dos pesos dos termos da consulta expandida. Para a utilização de expansão de consulta por sistemas de criação automática de ligações, foi definida uma especialização da classe consulta que realiza as operações próprias dessa funcionalidade.

- Informação de saída $\left(S_{o c}\right)$ : conjunto de documentos relevantes à consulta.

\subsubsection{RelevanceFeedback}

A classe "RelevanceFeedback" é uma subclasse especializada da classe "OperacaoConsulta" (oc). Essa classe é responsável pela soma dos vetores da matriz dos documentos do repositório e do vetor de consulta formado a partir do feedback de usuários.

- Informação de entrada: a matriz de documentos do repositório a ser relacionado e o vetor de consulta formado a partir do feedback de usuários.

- Métodos disponibilizados: $m[i]=\{I \mid I \in($ SomaVetores ()$)\}$.

SomaVetores(): método que utiliza a função de $\hat{V}_{q}$ da equação 3.5 de consulta da técnica de LSA, apresentada no Capítulo 3, para reformular os valores de similaridade entre os documentos.

- Informação de saída: matriz reformulada.

As classes "ColetaInformacao", "Pré-processamento", "Armazenamento", "IdentificaRelacionamento" e suas respectivas especializações foram implementadas utilizando as linguagens de programação orientadas a objetos $\mathrm{C}++$ e OX. OX é uma linguagem de programação, desenvolvida na Oxford University, para manipulação de matrizes. Já as outras classes do arcabouço, "OperacaoConsulta" e "Acesso", foram desenvolvidas utilizando a linguagem orientada a objetos Java, uma vez que essa linguagem facilita a conectividade com sistemas externos desenvolvidos em outras plataformas. A classe "Acesso" também explora essa vantagem, sendo que ela foi desenvolvida para suportar a comunicação entre aplicações que utilizam o serviço de criação automática de ligações e as classes CARe que auxiliam na identificação de relacionamentos. No próximo capítulo são apresentados casos de uso do arcabouço aqui proposto e detalhada as instanciações das classes envolvidas para esses serviços.

\subsection{Considerações Finais}

Na tentativa de padronizar e definir arquiteturas para sistemas e para documentos hipermídia, foram propostos, respectivamente, na literatura modelos como o Dexter (Halasz \& 
Schwartz 1994) e o MCA (Modelo de Contextos Aninhados) (Soares et al. 2000), que estruturam sistemas hipermídia para torná-los mais flexíveis. Além disso, existem modelos, métodos e metodologias propostos para o acompanhamento do processo de desenvolvimento de hiperdocumentos como, por exemplo, o modelo HDM (Hypertext Design Model) (Garzotto et al. 1993), o método OOHDM (Oject-Oriented Hypermedia Design Method) (Schwabe et al. 1996) e a metodologia RMM (Relationship Management Methodology) (Isakowitz et al. 1995). Alguns esforços têm sido despendidos para a definição de arcabouços que facilitem a reutilização de funcionalidade específicas para sistemas hipermídia. Rao \& Turoff (1990) propuseram um arcabouço semântico para tratamento exclusivo de tarefas de projetos de interfaces e o relacionamento entre elas. Esse arcabouço teórico generaliza os componentes hipertexto em seis diferentes tipos de nós e doze diferentes tipos de ligações, mas não oferece nenhum tipo de apoio à reutilização de seus componentes.

Por outro lado, para sistemas de recuperação de informações existem diversas propostas de arcabouços. Por exemplo, o $\operatorname{IRF}^{1}$ (Information Retrieval Framework) é um arcabouço GNU (General Public License) para aplicações de recuperação de informação. IRF possui coleções textuais para a realização de experimentos e uma aplicação IR (SampleApp) construída a partir da instanciação das classes desse arcabouço. O IRF, a aplicação "SampleApp" e as coleções textuais foram criados pelo grupo de Recuperação da Divisão de Acesso de Informações do NIST (National Institute of Standards and Technology).

IRF surgiu a partir de uma abstração do pacote de aplicações IR do ZPRISE ${ }^{2}$ (Z39 UNIX/PRototype Indexing and Search Engines) com o intuito de torná-lo mais portável, extensível e de servir melhor aos pesquisadores do NIST que estavam tendo crescente interesse em IR para vários tipos de mídia. As principais classes do IRF são as classes IrfConverter, IrfIndexer, IrfUpdatingIndexer, IrfRetriever e IrfPresenter. IrfConverter é uma classe abstrata composta por métodos de conversão de documentos em unidades de informação que podem ser indexadas. IrfIndexer é a classe responsável pela atribuição de índices a documentos para representá-los. Essa classe é especializada em duas subclasses as quais representam diferentes tipos de índices baseados em comparação de palavras-chave e na medida IDF. Já IrfUpdatingIndexer é uma classe abstrata que permite a reformulação dos valores de índices. Essa classe é semelhante à classe oc do arcabouço CARe. IrfRetriever manipula a pontuação de relevância dos documentos. IRF suporta tipos de recuperação de documentos: $\max$ (retorna os valores mais altos), mim (retorna os valores mais baixos e diferentes de zero) e lin (retorna os valores da média). Uma vez criado o conjunto resposta pela classe IrfRetriever, documentos da coleção podem ser apresentados pela classe IrfPresenter. SampleApp apresenta documentos HTML textuais padronizados que destacam os termos encontrados a partir da consulta.

Os autores do IRF admitem que o arcabouço possui várias limitações como, por exemplo, problemas qualitativos nos métodos de indexação, a necessidade da definição de novos ele-

\footnotetext{
${ }^{1}$ http://www.itl.nist.gov/iaui/894.02/projects/irf

${ }^{2}$ http://www-nlpir.nist.gov/works/papers/zp2/zp2.html
} 
mentos de dados a cada inclusão de novos tipos de dados, armazenamento não persistente e manipulação apenas de textos em um formato específico. Ao comparar o IRF ao arcabouço CARe proposto, pode-se perceber que o primeiro possui apenas algumas das classes do CARe, principalmente porque ele foi desenvolvido especificamente para aplicações de IR. O CARe, desenvolvido para permitir a criação de ligações hipertexto, possui classes específicas para suportar essas funcionalidades e também todas as classes do IRF para realizar recuperação de informação a partir de consultas. Inclusive, o CARe possui classes baseadas em técnicas de IR não existentes no IRF, como a técnica de LSA e o método de relevance feedback, que podem ser muito úteis para aplicações de IR. Além do IRF, existem outros arcabouços para aplicações que suportam a recuperação (Terrier IR Group - Glasgow 2004) e a visualização (Eidenberger \& Breiteneder 2003) de informações em sistemas IR; mas nenhum agrega funcionalidades de hipertexto e de recuperação de informações simultaneamente.

No próximo capítulo, são apresentados dois experimentos de instanciação do CARE. Primeiramente é apresentado o WebMemex, que é um serviço que utiliza as classes de identificação de relacionamento e de armazenamento para compartilhar informações navegadas por grupos de usuários na Web. Em seguida, é apresentada a utilização de algumas outras classes do arcabouço CARe em um ambiente de captura ubíqua, o iClass. 


\section{Casos de Uso do Arcabouço para Criação Automática de Ligações Hipertexto}

\subsection{Considerações Iniciais}

Após a investigação, a especificação e a implementação das classes do arcabouço CARe, se fez necessária a verificação da possibilidade de sua utilização. Essa verificação ocorreu através da reutilização das classes do CARe em aplicações de diferentes domínios de modo a fornecer funcionalidades antes não suportadas pelos mesmos.

Uma instanciação se deu com a extensão de um sistema CSCW do tipo Sistema de Recomendação de Informações, o WebMemex. Nesse contexto, métodos e atributos das classes de coleta, de pré-processamento, de definição de relacionamentos, de consulta, de acesso e de armazenamento de ligações foram acoplados ao sistema. Esse sistema captura páginas navegadas na Web por grupos de usuários explicitamente formados para compartilhar informações (Macedo et al. 2003).

Outra instanciação se deu no contexto de um ambiente de captura automática de experiências em sala de aula, o ambiente iClass. Foram estudadas maneiras de se utilizar os componentes do arcabouço para fornecer sugestões de informações capturadas e relacionadas à atividade em andamento (Macedo et al. 2004a). Neste caso o objetivo era a definição de relacionamentos entre informações capturadas. Nesse trabalho, foram utilizadas as classes de coleta de informações, de pré-processamento, de definição de relacionamentos semânticos e lexicais, de armazenamento, de consultas e de acesso do arcabouço CARe. Combinações diferentes dessas classes foram necessárias nas distintas fases de aplicações de captura automática de atividades ao vivo.

Neste capítulo são apresentados esses dois casos de uso do arcabouço CARe: para re- 
comendação de informações com conteúdo similar durante a navegação de grupos colaborativos na Web e durante a captura automática de experiências em sala de aula.

\subsection{Criação Automática de Ligações Compartilhadas para Navegação na Web}

\subsubsection{Investigação do Contexto de Sistemas de Recomendação de Informações}

Sistemas típicos de recomendação de informações fornecem sugestões a usuários por meio de agregações ou comparações eficientes entre informações providas por diferentes pessoas (Recommender Systems Site 1999). Alguns pesquisadores acreditam que seres humanos são melhores reconhecendo a informação desejada do que manipulando palavras-chave como entrada para mecanismos de busca (Middleton et al. 2001).

O sistema CSCW de recomendação de informações WebMemex captura páginas navegadas na Web por grupos de usuários explicitamente formados para compartilhar informações. Uma maneira de oferecer recomendações a usuários pode ser definida com o uso das funcionalidades dos serviços de criação automática de ligações apresentados no Capítulo 4. Com esse intuito, foram reutilizadas algumas classes do arcabouço CARe. Os resultados da instanciação das classes CARe utilizadas e a experimentação da aplicação resultantes dessa instanciação são apresentados a seguir ${ }^{1}$.

\subsubsection{Instanciação do Arcabouço CARe para um Sistema CSCW}

Antes de reutilizar as classes do CARe, o WebMemex coletava apenas meta-informações de páginas HTML e comparava lexicamente o conteúdo dessas informações para fornecer recomendações aos seus grupos de usuários. Esse tipo de atitude implicava na geração de poucas recomendações. Com o intuito de ampliar o número de recomendações utilizando a semântica das informações coletadas, optou-se pela integração dos componentes do arcabouço CARe a esse sistema CSCW. Assim, todo o conteúdo de diferentes tipos de documentos Web visitados poderia ser coletado para a criação de ligações lexicais e semânticas, e os relacionamentos obtidos poderiam ser armazenados em uma biblioteca de ligações a qual, inclusive, poderia ser explorada por outras aplicações. Para alcançar esses objetivos, os módulos do arcabouço CARe correspondentes às classes de coleta de informações, de préprocessamento, de definição de relacionamentos, de consulta, de acesso e de armazenamento de ligações foram acopladas ao WebMemex (Macedo et al. 2003). Os componentes de software definidos a partir das classes CARe e o protótipo implementado são detalhados a seguir.

\footnotetext{
${ }^{1} \mathrm{O}$ trabalho reportado nesta seção contou com a participação de um aluno de doutorado do Georgia Tech Institute e um aluno de mestrado do ICMC-USP.
} 


\section{Componentes definidos a partir das Classes CARe}

A infra-estrutura da Figura 6.1 ilustra os seguintes componentes do sistema WebMemex:

- "Capture Component" é o componente de coleta e preparação de informações para a aplicação. Conforme apresentado na Figura 6.1, esse componente incorpora os métodos das classes de coleta de informações $(c i)$ e de pré-processamento $(p p)$ do arcabouço CARe. Essas novas classes permitem a coleta de diferentes tipos de documentos Web e a indexação de todo o conteúdo manipulado.

- "Linking Component" é o componente de criação de ligações da aplicação. Esse componente é composto pelas classes de identificação de relacionamentos (ir) e operações de consulta $(o c)$ do arcabouço CARe, conforme apresentado na Figura 6.1. Os módulos da versão original de comparação lexical e de indexação foram substituídos. A classe de identificação de relacionamentos $(i r)$, especificamente a classe de relacionamentos semânticos $(r s)$, foi reutilizada pelo WebMemex para identificar páginas relacionadas a serem sugeridas como recomendações aos usuários, enquanto estiverem navegando na Web. A classe de consulta $(o c)$ foi integrada ao WebMemex para capturar o conteúdo da página navegada e realizar uma consulta sobre as páginas da matriz semântica da classe rs. O conteúdo das páginas utilizadas como consultas é anexado à matriz de LSA para futuros processamentos de SVD. É importante mencionar que, de tempos em tempos, os métodos da classe $r s$ devem ser executados para não permitir a inclusão de muitos ruídos nos cálculos de similaridades semânticas.

- "Storage Component" é o componente de armazenamento da aplicação. Esse componente é uma classe direta do arcabouço CARe que foi instanciada pela aplicação WebMemex. O antigo módulo de armazenamento do WebMemex foi sobreposto pela classe de armazenamento (ar). No WebMemex, a classe ar instancia o pacote WLS. A interação do WebMemex com o WLS, via a classe ar, permitiu que os relacionamentos identificados pela classe ir fossem armazenados na biblioteca do WLS, conforme Figura $6.1(\mathrm{~g})$.

- "Access Component" é o componente de acesso da aplicação. Conforme apresentado na Figura 6.1, esse componente incorpora os métodos da classe de acesso (ac) do CARe que permitiu a interação do WLS na classe ar com as interfaces de usuários do sistema WebMemex. No contexto desse trabalho com o WebMemex, foi definida uma infraestrutura de apoio a essas funcionalidades e o protótipo do sistema de recomendação WebMemex baseado nessa arquitetura.

Componente de Autenticação de Usuários

O sistema WebMemex recomenda páginas Web para grupos de usuários. Para identificar usuários e grupos, esse sistema apóia-se em um navegador Web que deve estabelecer 
conexões com o servidor proxy do WebMemex para monitoramento de requisições HTTP na Web (ver Figura 6.1a e 6.1c). O servidor proxy mantém: (a) uma lista de endereços a serem monitorados, (b) o ID do usuário em um determinado endereço IP (se o usuário está conectado ou não; e se o usuário ainda não foi autenticado) e (c) a última vez que houve alguma atividade a partir daquela máquina (ver Figura 6.1b). Caso um usuário esteja ausente por um longo período de tempo, é requerida uma nova autenticação desse usuário no WebMemex. Enquanto o ID do usuário estiver nulo, o servidor proxy apresenta para o usuário somente a página de autenticação de usuários ou a página de ajuda.

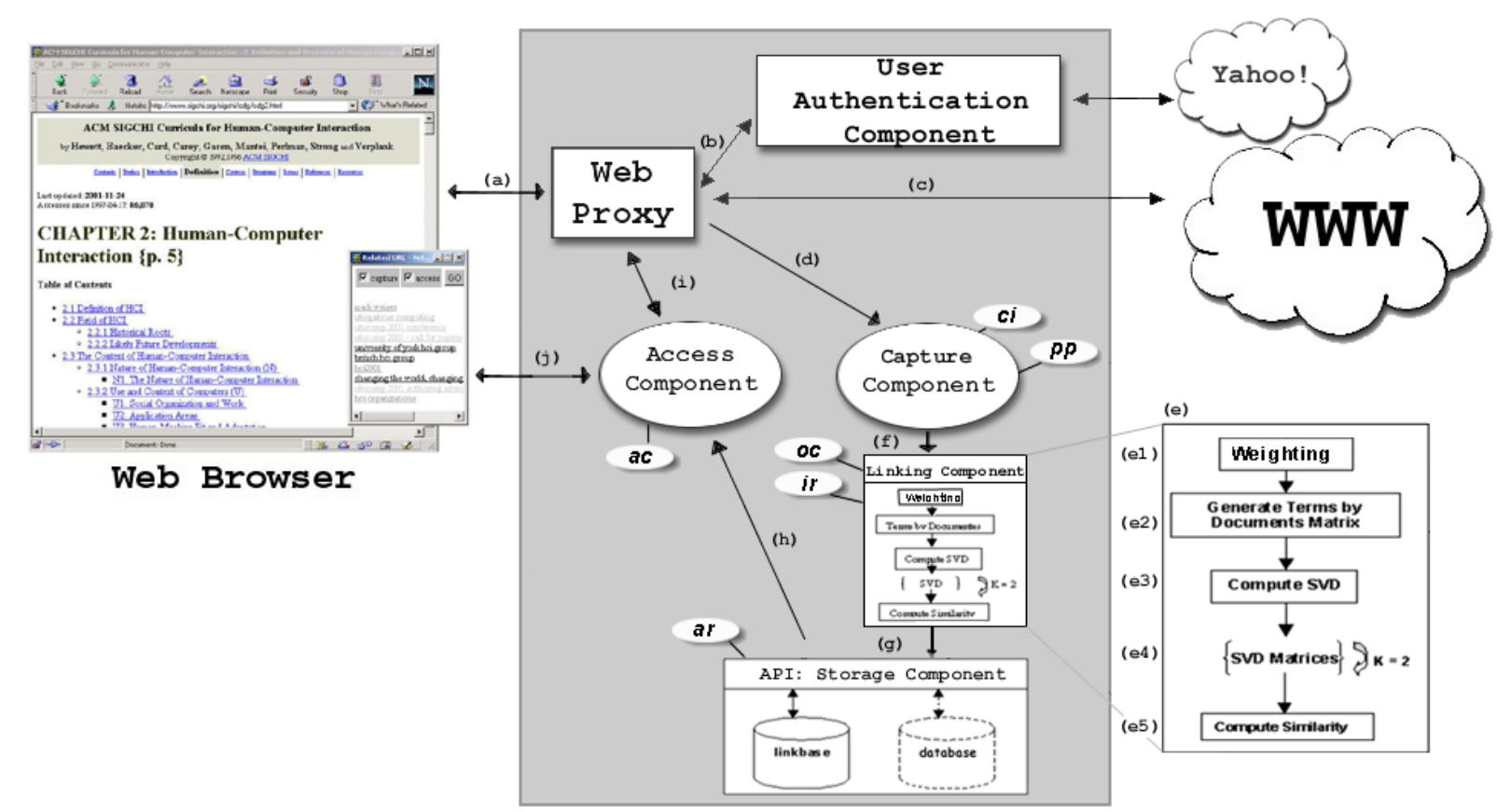

WebMemex Server

Figura 6.1: Infra-estrutura do WebMemex: (a) comunicação entre o servidor proxy na Web e um navegador-cliente, (b) manutenção de autenticação de usuários, (c) comunicação para cada requisição HTTP, (d) inicialização do componente de captura (composto pelas classes $c i$ e $p p$ do arcabouço CARe), (e) processamento do componente de criação de ligações, (f) componente de criação de ligações (classes ir e oc do CARe), (g) componente de armazenamento (classe ar do CARe), (h) inicialização do componente de acesso (classe ac do CARe), (i) lista de páginas Web similares aos documentos, (j) fluxo de execução de acesso (thread) para apresentar recomendações (adaptada de (Macedo et al. 2003))

\section{Componente de Captura}

O serviço WebMemex é também apoiado por um servidor proxy estendido para capturar atividades de navegação. Quando uma informação é requerida, o servidor proxy recupera a informação e imediatamente devolve-a para o cliente requerente (ver Figura 6.1a). Se esse usuário permitir a captura das informações navegadas por ele, então o documento recuperado é transferido para o componente de captura (ver Figura 6.1d).

Na primeira versão do componente de captura, o servidor proxy manipulava somente arquivos-texto ou HTML retornados pelo navegador Web. Documentos HTML podiam ser 
processados considerando apenas as meta-informações adicionais para a definição de ligações hipertexto. Atualmente, esse componente instancia as classes de coleta de informações e de pré-processamento do arcabouço CARe para permitir a coleta e o tratamento de outros tipos de documentos.

Quando um documento é carregado no navegador Web, o componente de captura registra (a) as visitas dos usuários, identificando-as com a URL; (b) o horário que a página foi visitada; (c) o endereço IP da máquina do navegador; e (d) os IDs dos usuários em atividade. Essas informações são necessárias para inicializar o processamento dos módulos do componente de criação de ligações, apresentados na Figura 6.1f.

As ligações criadas entre as páginas Web visitadas são enviadas para o componente de armazenamento. Quando usuários visitam páginas relacionadas pelo WebMemex, o componente de acesso recupera as ligações desse componente de armazenamento.

\section{Componente de Criação de Ligações}

Utilizando informações enviadas pelo componente de captura, o processo de cálculo de pesos das palavras-chave das páginas Web é inicializado no componente de criação de ligações desse componente. A Figura 6.1e ilustra todos os módulos do componente de criação de ligações da infra-estrutura do WebMemex, que automaticamente gera ligações hipertexto entre páginas Web navegadas por usuários. Essas páginas foram capturadas e indexadas pelo componente de captura. O componente de criação de ligações define as ligações hipertexto entre as páginas indexadas de acordo com a técnica de LSA (Furnas et al. 1988) a qual é implementada nos métodos da classe $r s$.

Os módulos do componente de criação de ligações podem ser visualizados a partir da Figura 6.1e. Esses módulos não são detalhados nesta seção, uma vez que foram descritos, em detalhes no Capítulo 4.

\section{Componente de Armazenamento}

Ligações definidas pelo componente de criação de ligações podem ser armazenadas em base de dados ou em bibliotecas de ligações hipermídia as quais são pacotes da classe ar instanciadas pelo WebMemex. O protótipo implementado do WebMemex utiliza a biblioteca de ligações do pacote WLS da classe ar que oferece algumas facilidades não oferecidas por base de dados tradicionais. Devido a essa instanciação, as operações da biblioteca de ligações podem ser reutilizadas pelo protótipo do WebMemex, reduzindo os esforços de autoria. A classe de armazenamento ar e a biblioteca de ligações do WLS já foram detalhadas.

Além das tabelas da biblioteca de ligações WLS, o componente de armazenamento manipula algumas tabelas adicionais, durante a definição de termos de índice, para gerenciar URLs, por exemplo, a lista de stopwords, a tabela de pesos dos termos de índice, e a lista de usuários e grupos. A tabela de relacionamentos entre usuários e grupos com as URLs visitadas é atualizada sempre que novas URLs são capturadas pelo WebMemex. O componente 
de acesso obtém as ligações criadas, a partir dessa tabela pela comparação de ID de usuários e grupos.

Componente de Acesso

O servidor WebMemex separa a manutenção dos componentes de captura, de criação de ligações, de armazenamento e de acesso à medida que o sistema captura as visitas, para não atrapalhar as atividades de navegação na Web, e sugere informações relacionadas à informação navegada. Quando o conteúdo de uma página Web está sendo capturado e conseqüentemente relacionado e armazenado, o servidor proxy do WebMemex cria um fluxo de execução do componente de acesso para consultar recomendações criadas e armazenadas pelo WebMemex, como na Figura 6.1i.

Quando usuários visitam páginas Web pela primeira vez e sua captura está habilitada, os processos de criação de ligações e de armazenamento devem esperar sua chamada, em determinado período, isto é, os processos de visita e de captura são paralelos - enquanto que os processos de criação de ligações e de armazenamento são executados seqüencialmente em um determinado momento depois da captura e repetido periodicamente. Portanto, para que páginas visitadas pela primeira vez sejam relacionadas com outras páginas armazenadas na biblioteca de ligações ou na base de dados, é necessário esperar a próxima chamada e execução do processo de criação de ligações. Uma vez que os relacionamentos são definidos e armazenados, o componente de armazenamento provê ao componente de acesso uma lista de páginas Web semelhantes ao documento visitado (ver Figura 6.1h). O componente de acesso dá formato a esses endereços para serem recomendados aos usuários do WebMemex que estão navegando em páginas relacionadas. Essas recomendações são apresentadas em uma janela do tipo pop-up, como pode ser visto na Figura 6.1j.

\section{Implementação}

Para desenvolver um protótipo do WebMemex, foi necessário considerar características e restrições de navegadores Web que iriam suportar as funcionalidades de captura e de acesso do sistema. Uma característica de acesso suportada é a execução de buscas pessoais em históricos de navegação. Dessa maneira, usuários podem revisitar caminhos prévios de navegações. Nesta seção são detalhadas as implementações das funcionalidades de recomendação assíncrona do WebMemex. O WebMemex utiliza experiências prévias na Web para aprimorar sessões de navegação de usuários com sugestões de URLs relacionadas.

\section{Utilização do WebMemex}

Para utilizar o WebMemex pela primeira vez, um usuário precisa configurar seu navegador Web para que ele se comunique com o servidor proxy do WebMemex, sendo que esse servidor capturará os históricos de navegação na Web desse usuário (ver Figura 6.2a). Quando usuários iniciam uma sessão de navegação (ver Figura 6.2b), o navegador automaticamente 
carrega a interface de conexão (ver Figura 6.2c). Uma vez que o usuário esteja autenticado, o navegador Web estará estendido pelas funcionalidades do WebMemex e por isso ele poderá capturar e sugerir URLs, a partir do histórico de navegação na Web dos usuários e seus grupos. As URLs sugeridas são apresentadas em uma pequena janela pop-up ao lado do navegador Web (ver Figura 6.2d).

\section{Manutenção de Autenticação de Usuários}

O protótipo do WebMemex utiliza as funcionalidades de autenticação de usuários do serviço "Yahoo! Messenger". Antes de iniciar o uso do WebMemex, usuários definem identificadores e senhas nesse serviço. Quando usuários se conectam, o WebMemex confirma essas informações chamando funções do Yahoo! As funcionalidades de mensagens instantâneas do "Yahoo! Messenger" não precisam ser executadas, nem instaladas no navegador-cliente. Contudo, usuários devem ter contas no Yahoo!, porque assim o sistema "Yahoo! Messenger" pode verificar a combinação correta do ID e da senha.

(a)

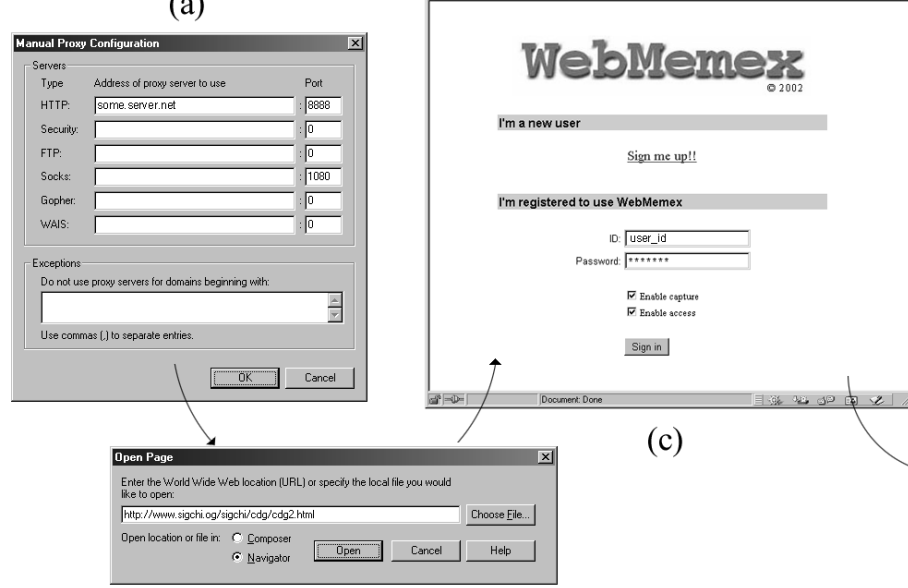

(b)

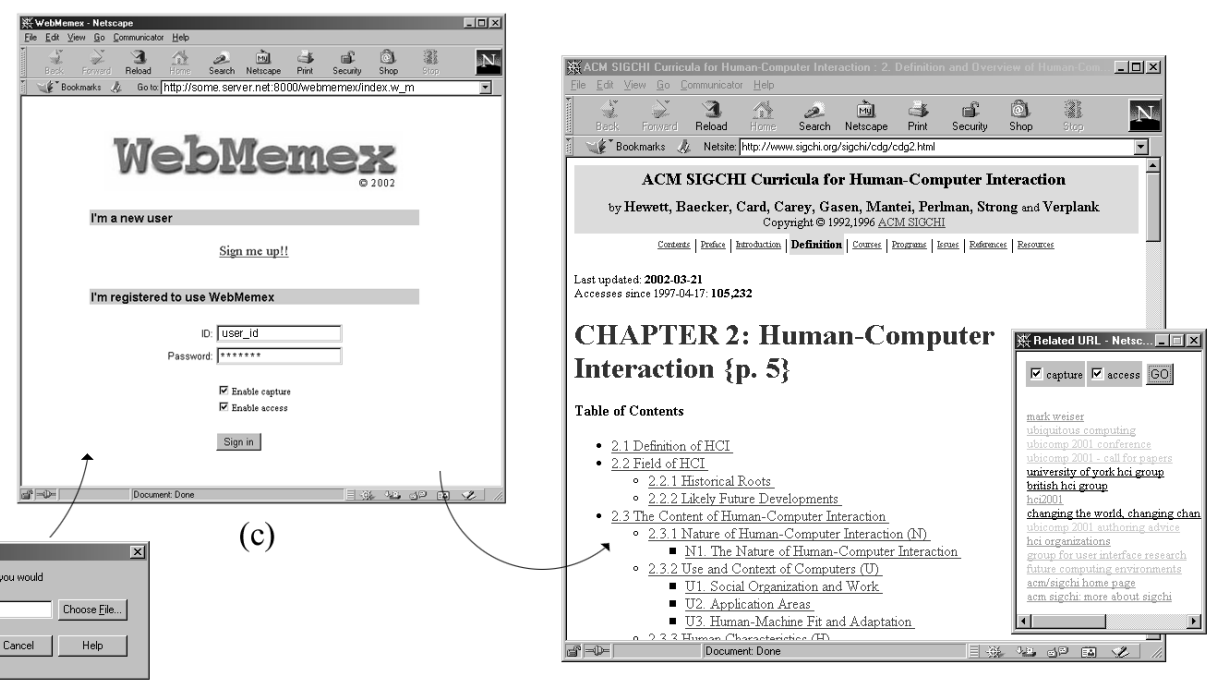

(d)

Figura 6.2: O protótipo do WebMemex. Interfaces de usuários para: (a) configuração do servidor proxy do WebMemex, (b) inicialização da sessão de navegação, (c) autenticação de usuários, (d) apresentação dos endereços de páginas Web relacionadas (adaptado de (Macedo et al. 2003))

Além da utilização das funcionalidades de manutenção de ID de usuários e senhas, a decisão de utilizar as funcionalidades do Yahoo! aconteceu devido ao fato de que esse serviço armazena listas de amigos. Essas listas permitem ao sistema WebMemex determinar com quem cada usuário quer compartilhar seus históricos de navegação na Web.

O componente de autenticação de usuários é implementado em Java. Esse componente verificava o nome do usuário e sua senha para utilizá-los na comunicação com o servidor do "Yahoo! Messenger". Através de uma conexão HTTP com o servidor Yahoo!, se o nome de usuário e a senha corretos são fornecidos, uma lista de amigos que estão conectados é obtida pelo componente de autenticação. 
Em uma versão mais recente do WebMemex, o sistema tem um serviço proprietário de autenticação de usuários e manutenção de listas de amigos. A nova versão do WebMemex e suas principais extensões e mudanças são apresentadas na próxima seção.

\section{Captura Constante de Páginas Web}

Para capturar históricos de navegação na Web, o WebMemex precisa monitorar e registrar constantemente as páginas Web visitadas por cada um de seus usuários. Inicialmente, foi explorada a implementação de listeners para navegadores tradicionais; entretanto, esse método não foi satisfatório, sendo que soluções baseadas em clientes são dependentes de plataforma. Em algumas situações, usuários podem trabalhar em mais de uma máquina com diferentes plataformas. Por esse motivo, foi explorada a habilidade de navegadores Web de se comunicar com proxies HTTP. Nos navegadores existentes, usuários podem facilmente especificar o endereço de um servidor proxy, como apresentado na Figura 6.2a. Assim quando usuários iniciam a navegação na Web, seus navegadores se comunicam com o servidor proxy, que verifica se o usuário está registrado para, em seguida, permitir o uso do serviço. O servidor proxy do WebMemex permite que históricos de páginas visitadas possam ser acessíveis de qualquer computador em rede, independentemente da máquina na qual as páginas foram inicialmente visitadas. Usuários do WebMemex precisam somente informar ao sistema os seus ID e às suas senhas para assim ter em acesso as informações capturadas e relacionadas (ver Figura 6.2c).

O servidor proxy do WebMemex é uma aplicação escrita em Java para bloquear requisições HTTP até usuários se conectarem, com sucesso, ao sistema. Esse servidor ativa os componentes de sua infra-estrutura à medida que usuários visitam páginas Web. O componente de captura é um processo Java que registra cada página que o usuário visita. Esse processo caracteriza a página visitada com o tempo inicial da visita e o ID do usuário, antes de passar o endereço da página ao componente de criação de ligações. O componente de captura também instancia métodos das classes ci e $p p$ do CARe.

Criação de Ligações entre Páginas Web

A Figura 6.1e apresenta uma instância do componente de criação de ligações explorado no protótipo do WebMemex. O módulo "Compute Similarity" utiliza um limiar de similaridade para filtrar as informações e gerar a matriz semântica de relevância. Essa matriz é utilizada para identificar os relacionamentos semânticos entre os documentos navegados. No protótipo do WebMemex, foi utilizado, após algumas experimentações, um limiar de similaridade de $85 \%$.

Devido ao fato da computação envolvida no processamento de LSA ser bastante cara, as matrizes são processadas periodicamente, por exemplo, uma vez ao dia. Durante a fase de acesso, as palavras-chave utilizadas como termos de índice da página visitada são utilizadas como consultas na matriz semântica, através da instanciação da classe de operação de consultas (oc) do CARe. A matriz-coluna de consulta é considerada sobre todas as navegações 
executadas até o último processamento da matriz semântica; as navegações mais recentes são incluídas no próximo processamento da matriz semântica.

Depois da definição de ligações no último módulo do componente de criação de ligações, as ligações são armazenadas na biblioteca de ligações WLS, através da instanciação da classe ar que mantém e provê informações ao componente de acesso do WebMemex.

As classes do componente de criação de ligações estão utilizando uma linguagem de programação orientada a matrizes, OX, estendida com código $\mathrm{C}++$.

Acesso a Páginas Web Recomendadas

Ligações Hipertexto são utilizadas para apresentar sugestões aos usuários. Elas são apresentadas em uma janela pop-up, como apresentado na Figura 6.3, quando usuários navegam na Web. Para cada página navegada na Web, o WebMemex relaciona essa página com páginas visitadas pelo próprio usuário e seus amigos.

O componente de acesso é um processo Java independente que se comunica com a biblioteca de ligações WLS para recuperar a lista de páginas Web relevantes as páginas Web visitadas. Esse componente prepara a lista de URLs relacionadas em uma interface HTML, como a interface apresentada na Figura 6.1h.

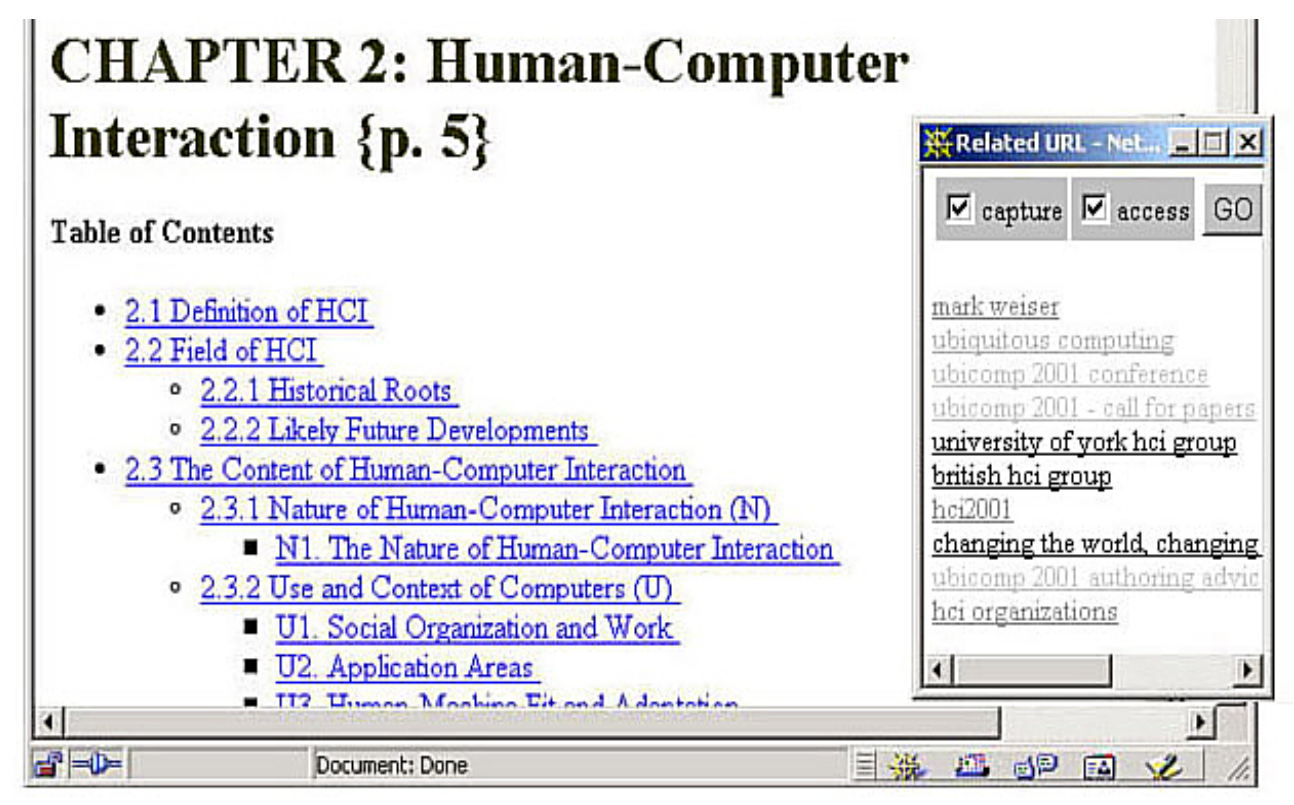

Figura 6.3: As ligações para as páginas Web sugeridas são apresentadas em uma pequena janela em primeiro plano - diferentes cores são utilizadas para indicar vários níveis de relevância. Nessa interface, usuários habilitam e desabilitam os componentes de captura e de acesso (adaptada (Macedo et al. 2003))

\subsubsection{Experimentação do Sistema CSCW Instanciado}

Nesta seção são apresentados dois experimentos com protótipo do WebMemex e as extensões realizadas para esse sistema após as avaliações dos experimentos. A seção está divida em 
três subseções: a primeira subseção apresenta a utilização do WebMemex entre um grupo de quatro pessoas, no Georgia Institute of Technology (GATECH), em Atlanta nos Estados Unidos, a segunda descreve as experiências da utilização do WebMemex por um grupo de quatro pessoas, na Universidade de São Paulo (USP), em São Carlos no Brasil, e a terceira subseção apresenta o WebMemex estendido.

O primeiro experimento foi conduzido entre um grupo de quatro amigos, todos estudantes de pós-graduação do GATECH. Essas pessoas forneceram seus históricos de navegação na Web do mês de janeiro de 2003. Esses históricos incluíam páginas Web relativas a equipamento de computação, programas de computador, sítios de comércio eletrônico, bancos on-line, informações sobre estágios de verão, notícias e informações sobre atrações turísticas.

O segundo grupo era composto por três estudantes de pós-graduação e um professor. Esse grupo foi considerado um grupo homogêneo, pois era formado por pessoas que colaboravam no Grupo de Pesquisa no ICMC da USP de São Carlos. Durante o intervalo de um mês, eles pesquisaram informações relativas a ontologias, abordagens XML, serviços Web, agentes, Java, sistemas para apresentação de vídeos, equipamentos e programas de computação, bancos on-line, comentários esportivos e atrações turísticas.

Tabela 6.1: Características dos dois experimentos com o WebMemex

\begin{tabular}{|l||c|c|}
\hline \multicolumn{1}{|c||}{ Características Gerais } & \multicolumn{2}{c|}{ Experimentos } \\
\hline \hline Qtde de páginas Web & 1 & 2 \\
\hline Qtde de usuários & 2556 & 2555 \\
\hline Média de páginas por usuário & 4 & 4 \\
\hline Qtde de páginas Web depois do filtro & 639 & 638.7 \\
\hline Média de páginas por usuário & 454 & 106 \\
\hline Qtde de termos distintos & 113.5 & 26.5 \\
\hline Qtde de stopwords & 13376 & 2466 \\
\hline Qtde de ligações hipertexto criadas & 562 & 1180 \\
\hline
\end{tabular}

\section{Primeiro Experimento}

No primeiro experimento, um conjunto de 2556 páginas Web foi capturado a partir do histórico de navegação dos quatro participantes desse experimento, uma média de 639 páginas Web de cada pessoa, conforme apresentado na Tabela 6.1. Essas páginas Web eram relativas a vários tópicos incluindo equipamentos e programas de computação, sítios de comércio eletrônico, bancos on-line, estágios, notícias e atrações turísticas. Entretanto, uma análise manual de cada página revelou que várias páginas visitadas eram arquivos de imagens, arquivos PDF ou arquivos textuais com imagens. Até aquele momento, o componente de criação de ligações não manipulava arquivos PDF. Portanto, o primeiro passo no experimento foi incluir, no arquivo de configuração do serviço de ligações, um filtro para ignorar esses tipos de arquivos. Também foi requerido pelo menos dez palavras em um documento antes 
dele ser considerado um documento útil para o experimento. A partir da análise manual, foi definido e incluído no WebMemex um filtro que automaticamente procurava arquivos-texto e arquivos HTML. Depois da etapa de filtragem, 454 páginas Web foram indexadas.

O processo de indexação sobre as 454 páginas Web gerou uma matriz de 454 colunas e 13376 linhas a ser manipulada pela técnica de LSA. Ao final do processo de criação de ligações, 71 ligações hipertexto tinham sido definidas para o primeiro experimento.

Analisando informações da Tabela 6.2, a utilidade das recomendações do WebMemex pode ser numericamente verificada para cada usuário. Por exemplo, o Usuário1 recebeu 53 páginas Web como recomendação. Manipulando o histórico de navegação desse usuário, 37 recomendações foram criadas a partir dele para os outros usuários do grupo. Contudo, o Usuário2 forneceu 19 páginas para recomendação e recebeu apenas 12 recomendações. Portanto, pode-se perceber que o WebMemex foi numericamente mais útil para o Usuário1.

Tabela 6.2: Informações do primeiro experimento com o WebMemex: (a) número de páginas Web recomendadas pelo sistema para cada usuário e (b) número de recomendações criadas para outros usuários a partir das páginas navegadas pelo usuário em questão

\begin{tabular}{|c||c|c|}
\hline & $(\mathrm{a})$ & $(\mathrm{b})$ \\
\hline \hline Usuário1 & 53 & 37 \\
\hline Usuário2 & 12 & 19 \\
\hline Usuário3 & 5 & 9 \\
\hline Usuário4 & 1 & 6 \\
\hline
\end{tabular}

Nesse experimento, 48 recomendações vieram do mesmo histórico de navegação e 23 recomendações vieram de diferentes históricos de navegação. As 23 recomendações equivalem a quase um terço do número total de ligações, demonstrando assim o valor potencial de se ter acesso a informações de outras pessoas do grupo.

Uma análise qualitativa do primeiro experimento revelou algumas informações. A análise manual das 71 ligações hipertexto geradas pelo WebMemex como recomendações indicou que $44(62 \%)$ ligações hipertexto eram realmente relacionadas a páginas Web às quais foram ancoradas.

\section{Segundo Experimento}

Um conjunto de 2555 páginas Web foi capturado durante a navegação dos quatro usuários no segundo experimento, uma média de 639 páginas Web por pessoa (ver Tabela 6.1). As 2555 páginas continham os temas de pesquisa citados anteriormente: ontologias, XML, serviços Web, agentes, Java, sistemas para apresentação de vídeos, equipamentos e programas de computação, bancos on-line, comentários esportivos e atrações turísticas.

Para esse experimento foi realizada uma análise manual das páginas navegadas e foi definido um filtro e um limiar numérico para ignorar os mesmos tipos de arquivos eliminados no primeiro experimento. Essa análise é realizadas pela classe $p p$ do arcabouço. Depois da etapa de aplicação do filtro, 106 páginas Web foram indexadas como apresentado na Tabela 6.1 . 
O processo de indexação resultou em uma matriz com 2466 termos distintos (linhas) e 106 documentos (colunas). Os módulos do componente de criação de ligações manipularam essa matriz e criaram 154 ligações hipertexto. Esses relacionamentos equivalem a recomendações do WebMemex entre os participantes do segundo grupo; o número de ligações criadas para cada usuário é indicado na Tabela 6.3. O alto número de ligações criadas pode estar relacionado ao fato do escopo de navegação desse grupo ser mais homogêneo do que do primeiro grupo.

Tabela 6.3: Informações do segundo experimento com o WebMemex: (a) número de páginas Web recomendadas pelo sistema para cada usuário e (b) número de recomendações criadas para outros usuários a partir das páginas navegadas pelo usuário em questão

\begin{tabular}{|c||c|c|}
\hline & (a) & (b) \\
\hline \hline Usuário1 & 30 & 135 \\
\hline Usuário2 & 10 & 16 \\
\hline Usuário3 & 4 & 5 \\
\hline Usuário4 & 1 & 2 \\
\hline
\end{tabular}

Para o segundo experimento não foi possível realizar uma análise qualitativa das ligações criadas, mas algumas observações puderam ser realizadas. Existe um grande número de páginas Web visitadas por mais de um participante desse experimento. Conseqüentemente, quando as recomendações foram computadas, ligações hipertexto para a mesma âncora tinham múltiplos pontos-finais (algumas vezes, incluindo a navegação do mesmo usuário). Isso sugere que, no WebMemex, mesmo que usuários não tenham previamente visto uma página relacionada, históricos Web de outros usuários podem apresentá-la.

\section{Nova Versão do WebMemex}

Nos dois experimentos realizados, os participantes identificaram alguns problemas e limitações no uso do WebMemex. Portanto, a partir desse trabalho, foram definidas e reimplementadas algumas funcionalidades do WebMemex, com o intuito de facilitar a interação de usuários com o sistema.

Na nova versão, usuários podem recomendar explicitamente a membros dos seus grupos, endereços de páginas Web visitadas. Além isso, usuários do WebMemex podem criar grupos privados e públicos. Para os grupos privados, existe controle de inscrição; para usuários ingressarem nesses grupos, é necessária a autorização do criador do grupo. Já nos grupos públicos, a adesão de usuários é livre. Além disso, os usuários também podem indicar se desejam receber e enviar informações para um grupo específico ou para todos os seus grupos. As novas funcionalidades de grupos só puderam ser implementadas, devido ao fato de que a nova versão do WebMemex tem serviços próprios de controle de grupos. A dependência do "Yahoo! Messenger" limitava o uso do sistema.

Além das funcionalidades de apoio a grupos, as funções de captura e de acesso foram aprimoradas na versão mais recente do WebMemex. A função de captura ativa o servidor proxy 
para capturar as páginas navegadas, e a função de acesso ativa o módulo de recomendação que mostra a lista de endereços de páginas relacionadas à página visitada. Na nova versão do WebMemex, essas funcionalidades são independentes. Usuários podem navegar sem que o servidor proxy capture a navegação, mas eles ainda recebem recomendações de páginas similares à página visitada, e páginas podem ser enviadas ao proxy para serem capturadas mesmo com o módulo de recomendação desativado. Outra funcionalidade adicionada ao WebMemex foi a capacidade de manipular outros tipos de arquivos como, por exemplo, arquivos PDF. Anteriormente, o WebMemex indexava apenas arquivos-texto e arquivos HTML.

A versão mais recente do WebMemex tem sido utilizada no ICMC-USP por 13 alunos de pós-graduação e 3 professores, distribuídos em 5 grupos. Em dois meses, o WebMemex capturou 4925 páginas Web navegadas (1941 URLs diferentes) e recomendou nesse período 14 páginas Web de maneira manual (usuários indicam explicitamente a URL) e 1029 páginas Web foram recomendadas automaticamente, usando o serviço de criação de ligações. Atualmente, o WebMemex está sendo instrumentado com funcionalidades de captura de interações de usuários para verificar o uso das recomendações do sistema, assim como informações de contexto e perfis de usuários.

\subsection{Criação Automática de Ligações entre Informações Capturadas em Ambientes Ubíquos de Captura e Acesso}

\subsubsection{Investigação do Contexto de Sistemas de Captura e Acesso}

Um dos temas de pesquisa em computação ubíqua é o desenvolvimento de aplicações de captura e acesso. Essas aplicações suportam sessões de captura para registrar experiências diárias, ricas em informação, e disponibilizar o conteúdo capturado utilizando, por exemplo, hiperdocumentos, que podem ser visualizados por usuários após o encerramento da sessão de captura (Abowd et al. 2000) (Pimentel et al. 2000). Algumas aplicações de captura e acesso são construídas para apoio a reuniões (TeamSpace (Richter et al. 2001) e NoteLook (Chiu et al. 2000)) e ambientes educacionais (sistema para gerenciamento automático de câmeras em ambientes de sala de aula (Liu et al. 2001), eClass (Abowd 1999) e Cornell Lecture Browser (Mukhopadhya \& Smith 1999)).

Abowd e outros pesquisadores relatam que uma das características mais importantes para aplicações de captura e acesso é o grau de automatização fornecido. Esses pesquisadores sugerem que o apoio às atividades de captura e acesso deve ser distribuído em quatro fases (Abowd et al. 1996): (i) pré-produção: preparação da sessão; (ii) captura ao vivo: captura de fluxos de dados relevantes; (iii) pós-produção: integração dos dados capturados para gerar hiperdocumentos; (iv) acesso: apresentação dos hiperdocumentos aos usuários. As fases de pré-produção, captura ao vivo e acesso ocorrem, respectivamente, antes, durante e depois de uma sessão de captura. A fase de pós-produção também acontece depois de uma experiência ao vivo. 
Pimentel et al. (2001a) observam que em virtude da informação apresentada em sessões de captura ser usualmente relacionada com informações capturadas em sessões anteriores e também com outros documentos, existe uma demanda por operações que permitem o relacionamento manual e automático de documentos relacionados antes e depois da ocorrência de uma sessão de captura.

No contexto de um ambiente de captura e acesso de experiências em sala de aula, o iClass (Cattelan et al. 2003), foram estudadas maneiras de se utilizar as classes do arcabouço CARe para fornecer sugestões de informações já capturadas ao relacionar essas informações à atividade em andamento (Macedo et al. 2004a) (Macedo et al. 2004b). Nesse trabalho foram utilizadas todas as classes do arcabouço proposto: coleta de informações $(c i)$, identificação de relacionamentos $(i r)$, definição de relacionamentos semânticos $(r s)$, definição de relacionamentos lexicais $(r l)$, armazenamento $(a r)$, consultas $(a r)$ e acesso $(a c)$. Nesta seção são apresentados os resultados da instanciação dessas classes com o intuito de sugerir informações para auxiliar a autoria de hiperdocumentos antes, durante e depois de sessões de captura, isto é, em todos aqueles momentos em que o usuário está concentrando sua atenção no conteúdo da informação manipulada. São propostas alternativas de interação suportadas por operações de busca, a serem oferecidas para a identificação de ligações ${ }^{2}$.

Considerando o domínio de computação ubíqua, diferentes alternativas de interação devem ser oferecidas aos usuários, dependendo do estilo de interface explorado para a captura. No trabalho apresentado a seguir, reconhecimento de voz e de escrita realizados durante a captura, podem automaticamente ativar a criação de ligações hipertexto. Formulações de consultas e navegações na Web são outras alternativas de interação que podem auxiliar na definição de ligações, antes e depois de uma sessão de captura.

\subsubsection{Instanciação do Arcabouço CARe para um Sistema Ubíquo de Captura e Acesso}

\section{Composição de Classes CARe para as Fases de Captura e Acesso}

A Figura 6.4 apresenta uma arquitetura composta por aplicação reutilizando as classes do arcabouço CARe nas diferentes fases de aplicações de captura e acesso. A fase de préprodução é apoiada pela ferramenta AutorE, que permite a preparação manual de sessões, por exemplo, por meio da criação de sessões e da associação de metadados e de slides prépreparados (Pimentel et al. 2003) (ver Figura 6.4(a)).

A fase de captura é suportada pelo sistema iClass ${ }^{3}$. Esse sistema de captura de sessões ao vivo foi construído para registrar informação produzidas durante uma sessão, incluindo anotações eletrônicas feitas sobre slides pré-preparados apresentados em uma lousa eletrônica, fluxos de dados de áudio capturados a partir de microfones, e endereços de páginas Web

\footnotetext{
${ }^{2} \mathrm{O}$ trabalho reportado nesta seção contou com o apoio de alunos de mestrados e bolsistas DTI quanto à implementação e a integração das aplicações.

${ }^{3}$ iClass foi inspirado no sistema eClass; ver Capítulo 2 ou (Abowd 1999).
} 


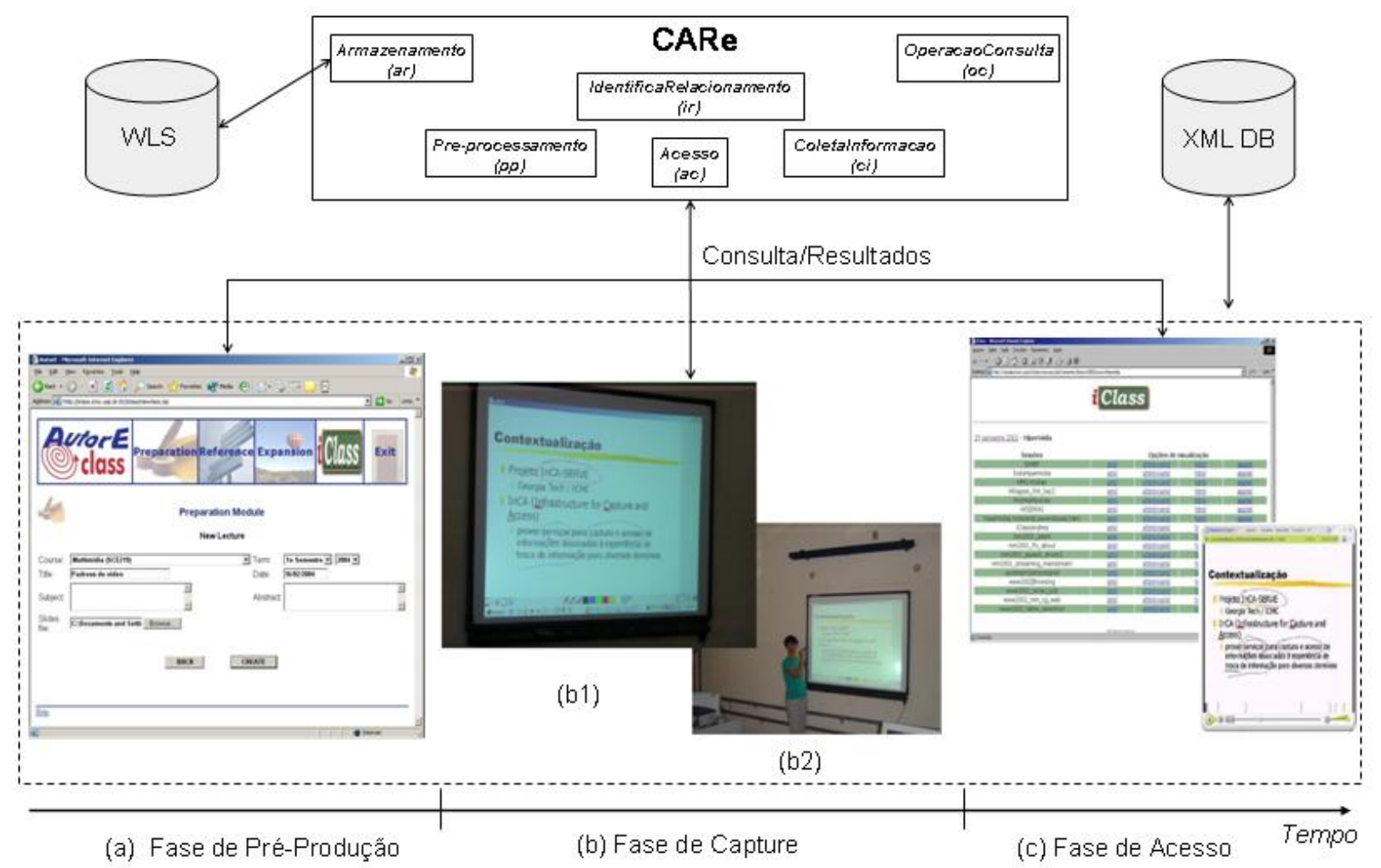

Figura 6.4: Combinações das classes do arcabouço CARe são integradas em todas as fases de uma aplicação de captura e acesso

visitadas durante a sessão (ver Figura 6.4(b)). A mesma arquitetura ilustra, na fase de acesso, que um usuário pode manualmente estender a informação capturada com anotações e ligações hipertexto (ver os manuscritos na Figura 6.4(c)). As informações das fases de pré-produção, captura e de acesso são armazenadas em uma base de dados XML (ver Figura 6.4).

O trabalho descrito nas subseções seguintes explora voz, escrita digital e a extração transparente do texto original de slides pré-preparados como alternativas de ativação da identificação de ligações entre hiperdocumentos produzidos na fase de captura, quando usuários estão interagindo com equipamentos computacionais ubíquos como, por exemplo, uma lousa eletrônica (ver Figura 6.4(b)). Entretanto, considerando que, em muitos casos, usuários estarão utilizando computadores desktop tradicionais, a criação automática de ligações nas fases de pré-produção e de acesso também deve ser suportada. Além disso, considerando que quando um usuário estiver utilizando o sistema em qualquer uma das fases ele terá o foco de atenção na informação manipulada, o trabalho apresentado permite que esses usuários decidam quais ligações sugeridas por um componente de criação de ligações acoplado no iClass eles querem anexar aos seus documentos. Esse componente de criação de ligações instancia diferentes classes do arcabouço CARe para as diferentes fases da aplicação de captura e acesso. 


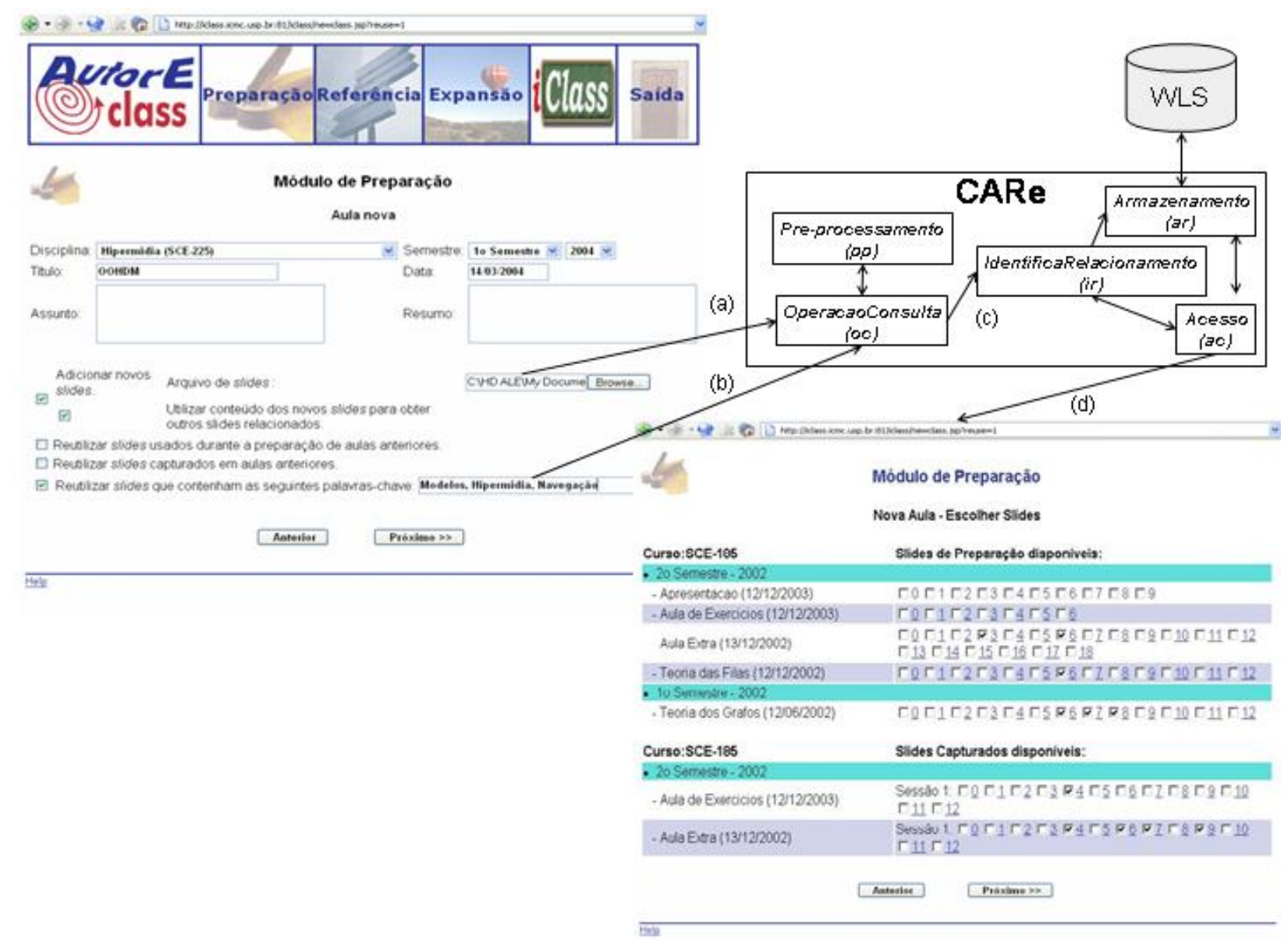

Figura 6.5: Criação de ligações hipertexto na fase de pré-produção permite a reutilização de informações através de sugestões de material do repositório manipulado, enquanto os autores preparam nova sessões. (a) Um vetor de consulta é criado com informações automaticamente extraídas de slides e metadados de sessões (título da sessão, por exemplo). (b) $\mathrm{O}$ vetor de consulta pode ser expandido com palavras-chave fornecidas por usuários. (c) O vetor de consulta é enviado à classe $i r$. (d) As ligações resultantes são apresentadas como recomendações na interface de preparação

\section{Criação de Ligações Hipertexto na Fase de Pré-Produção}

A fase de pré-produção é a etapa de preparação da sessão. Diferentes aplicações gerenciam a preparação de material a ser explorado em sessões ao vivo. A arquitetura apresentada permite que o gerenciamento desse alto nível de abstração seja realizado com a utilização de um sistema de autoria, denominado AutorE, como apresentado na Figura 6.4(a).

O sistema AutorE implementa funcionalidades para apoiar o processo de autoria de informações no sentido de prover funções de preparação, reutilização, extensão e referência de material didático (Pimentel et al. 2003). Esse sistema disponibiliza essas funções para o sistema de captura iClass, utilizando documentos XML. Para cada função, o AutorE possui um módulo específico. Utilizando o módulo de preparação, usuários podem preparar uma nova sessão para captura reutilizando material de outras sessões ou adicionando novo material (slides pré-preparados). Na Figura 6.5, a interface Web superior é uma interface típica do módulo de preparação de apresentações. 
Para permitir que um usuário, ao preparar uma sessão, receba sugestões de material relacionado apresentado em outras sessões, o módulo de preparação da ferramenta AutorE foi estendido pelas classes de consultas $(o c)$, de pré-processamento $(p p)$, de identificação de relacionamento $(i r)$, de armazenamento $(a r)$ e a de acesso $(a c)$ do arcabouço CARe, conforme apresentado na Figura 6.5.

A classe $o c$ permite a formulação de consultas que ativam o processamento da classe de identificação de relacionamentos $(i r)$. Essas consultas podem ser formuladas de duas maneiras: (i) o vetor de consulta é criado com informações automaticamente extraídas de slides e metadados de sessões (Figura 6.5(a)) e (ii) o vetor de consulta é expandido com palavras-chave fornecidas por usuários (Figura 6.5(b)). Uma vez gerado o vetor de consulta, ele é enviado à classe $p p$ que realiza o pré-processamento do conteúdo e envia o vetor com um conjunto de palavras-chave à classe $i r$.

A classe ir identifica o atributo tipo para saber qual das subclasses rs ou $r l$ deverá ser instanciada (Figura 6.5(c)). Depois de instanciada a classe correta, o vetor consulta é processado pelos métodos específicos de cada classe que identificam documentos semanticamente ou lexicamente relacionados ao vetor. Os resultados da definição de ligações são enviados à classe de armazenamento (ar), a qual é acessada pela classe de acesso (ac) para retornar os resultados aos usuários (ver Figura 6.5(d)). Dependo da seleção de atributos dessa classe, os resultados podem ser apresentados em interfaces da própria aplicação ou utilizar os pacotes iView (Oshiro 2003) e wView (Andrade 2004) da classe ac. Na versão atual da aplicação de captura e acesso iClass e AutorE, a biblioteca de ligações WLS tem sido utilizada para armazenamento dos relacionamentos de conteúdo de sessões identificados em todas as fases de aplicações de captura e acesso.

O resultado do processamento descrito é uma lista de âncoras para páginas que correspondem a outras sessões com conteúdo similar à sessão em preparação. As sugestões são apresentadas na parte inferior da interface original do AutorE, como apresentado na Figura 6.5. É importante observar que qualquer outra aplicação de autoria pode ser utilizada na fase de pré-produção, desde que ela envie um vetor de consulta à classe $o c$.

\section{Criação de Ligações Hipertexto na Fase de Captura}

A fase de captura, apresentada na Figura 6.4(b), mostra uma sessão ao vivo acontecendo com o apoio do sistema iClass: os slides pré-preparados são apresentados em uma lousa eletrônica via um applet Java (ver Figura 6.4(b1)); o apresentador pode escrever sobre os slides (ver Figura 6.4(b2)) e pode usar um microfone para capturar fluxos de áudio durante toda a sessão. Todas essas funcionalidade são provenientes dos componentes de captura (lousa eletrônica, vídeo, áudio, chat, weblog, etc) da ferramenta xINCA (Cattelan et al. 2003). xINCA (eXtended INfrastructure for Capture and Access Applications) é uma ferramenta que permite a combinação de componentes de software para aplicações de captura e acesso, pois muitas dessas aplicações utilizam funcionalidade recorrentes. Um exemplo típico ocorre no domínio educacional: muitas das aplicações desenvolvidas precisam controlar interações 
na lousa eletrônica.

Para a identificação de relacionamentos durante a fase de captura, as classes CARe de operação de consultas $(o c)$, de identificação de relacionamentos $(i r)$, de armazenamento (ar) e de acesso $(a c)$ devem ser instanciadas pela aplicação de captura e acesso iClass, conforme indicado na Figura 6.6.

Primeiramente, a aplicação iClass pré-processa as informações e compõe um vetor de consulta com informações provenientes de alguns componentes xINCA e, em seguida, envia esse vetor para a classe oc. Textos extraídos de slides apresentados durante a sessão são utilizados de maneira transparente para compor o vetor de consulta. Contudo, considerando a ubiqüidade do ambiente, é importante que informações advindas de anotações e de fluxos de áudio possam ser fornecidas como interações alternativas para a definição do vetor de consulta.

Para reconhecer de modo on-line caracteres de manuscritos, foi desenvolvida, no contexto de um trabalho de mestrado do grupo do qual a doutoranda participa, a API jInk, a qual explora o método proposto por Chan \& Yeung (1998). jInk provê uma interface gráfica a ser utilizada por usuários interessados em ajustar os modelos de caracteres ao seu próprio estilo de escrita, e assim obter mais precisão do reconhecedor. A API jInk foi incorporada ao sistema iClass de maneira estendida, sendo que além de dígitos e letras, jInk pode reconhecer símbolos e gestos. Gestos podem ser utilizados para ativar algumas operações da aplicação. Gestos ainda não foram explorados na criação de ligações, mas anotações escritas podem. Contudo, para a ativação do processamento de criação de ligações, pode-se utilizar voz. O reconhecimento de voz é realizado pelo programa ViaVoice ${ }^{\mathrm{TM}}$ explorando a implementação da API Java Speech (JSAPI) (Microsystems 1998) da IBM.

Assim, um usuário pode utilizar comando de voz para ativar a composição de um vetor de consulta com informações extraídas dos componentes xINCA. Após o comando de ativação, a consulta é enviada à classe oc. Essa ativação pode também ser realizada via um botão na interface de captura da lousa eletrônica.

A classe $o c$ envia o vetor de consulta para a classe de identificação de relacionamentos ic que processa as informações necessária para identificar e definir relacionamentos latentes semânticos e relacionamentos lexicais. Esses relacionamentos são armazenados pela classe de armazenamento ar na biblioteca de ligações do WLS. Assim que o componente de acesso da aplicação iClass ativar a classe de acesso $a c$, essa classe se comunicará com a classe ar que retornará os relacionamentos identificados.

A grande motivação do processamento apresentado é a definição de ligações hipertexto entre documentos capturados em tempo de execução. Essas ligações são apresentadas como recomendações em uma pequena janela em primeiro plano sobre o applet de captura, como apresentado na Figura 6.6. Na janela de recomendações existem campos de formulário eletrônico para que usuários possam indicar se uma dada ligação deve ou não ser adicionada como anotação ao documento. Somente as ligações selecionadas serão parte do documento correspondente à sessão que está sendo capturada. 


\section{Criação de Ligações Hipertexto na Fase de Acesso}

Ao final da sessão de captura, a informação XML correspondente à sessão é utilizada para gerar diferentes versões de hiperdocumentos a serem visitados por usuários interessados em rever o conteúdo capturado. Uma interface Web, como a da Figura 6.7, apresenta uma estrutura hierárquica de anos e semestres, que permite acesso a uma lista de sessões correspondentes que podem ser visitadas explorando diferentes formatos de documentos (Figura 6.7, parte inferior da figura). Por exemplo, as sessões podem estar associadas a aulas de cursos ou a reuniões de projetos.

Entre os formatos suportados para apresentação da informação capturada na forma de hiperdocumentos na atual versão do iClass estão: HTML (HyperText Markup Language), xHTML (Extensible HyperText Markup Language), SMIL (Synchronized Multimedia Integration Language) (Synchronized Multimedia Working Group 2004) e um applet que apresenta a sessão por meio de animações sincronizadas das anotações eletrônicas correspondentes com o áudio. Enquanto estiver interagindo com essas interfaces, usuários podem receber re-



Figura 6.6: Criação de ligações na fase de captura. Anotações eletrônicas capturadas a partir do componente de captura da lousa eletrônica são utilizadas para compor um vetor de consulta juntamente com textos extraídos automaticamente de slides pré-preparados. A ativação da consulta é realizadas por comandos de voz. As recomendações resultantes são apresentadas em uma janela em primeiro plano 


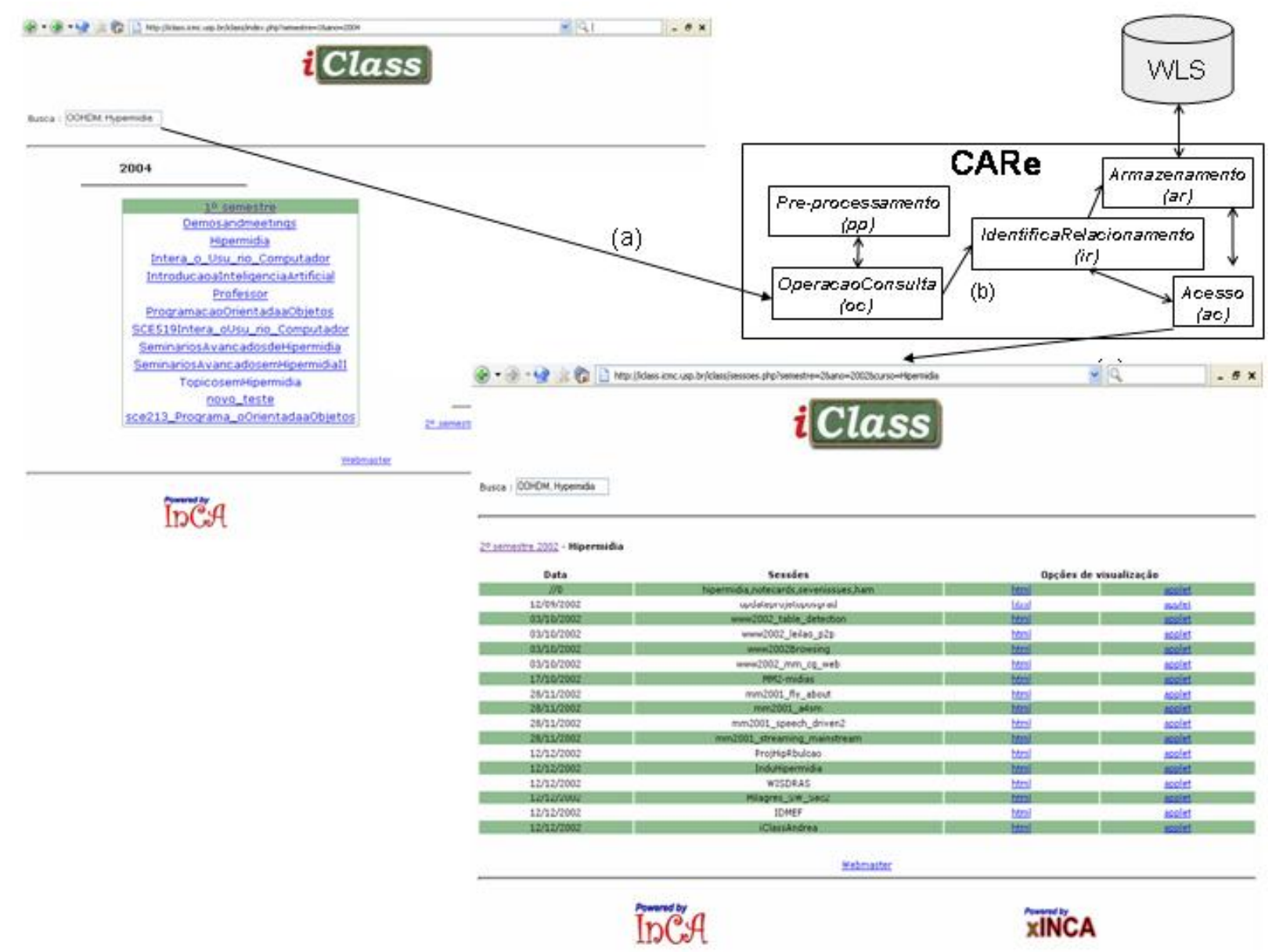

Figura 6.7: Criação de ligações hipertexto na fase de acesso: (a) palavras-chave são fornecidas por usuários para serem utilizadas como um vetor de consulta; (b) o vetor de consulta é enviado à classe ir; (c) ligações semânticas são definidas entre o vetor de consulta e o material capturado. As ligações definidas são apresentadas na interface de acesso

comendações criadas automaticamente, ou podem fazer consultas explícitas que podem ser utilizadas para formar um vetor de consulta à classe $i r$.

A Figura 6.7(a) indica que usuários são capazes de fornecer palavras-chave para compor um vetor de consulta a ser enviado para a classe oc reutilizada a partir do arcabouço CARe. Uma vez criado o vetor de consulta, ele é enviado à classe de identificação de relacinamentos ir (Figura 6.7(b)). O vetor é processado pela classe e os relacionamentos identificados são armazenados com o auxílio da classe (ar) na biblioteca de ligações do WLS. Em seguida, a classe de acesso $(a c)$ requisita os resultados e enviá-os à interface de apresentação (Figura 6.7(c)).

\section{Aspectos de Privacidade}

O fato de aplicações de captura e acesso estarem continuamente capturando e compartilhando informações implica em importantes questões relacionadas à privacidade. Em algumas situações, usuários podem querer ter seu material preservado. Por isso, foi definida uma maneira de permitir que usuários do iClass especifiquem se eles querem que seu material seja utilizado para definir ligações e recomendações para outras pessoas. 
Na fase de pré-produção, usuários podem indicar ao sistema para não criar ligações com o material utilizado para produzir os documentos correspondentes àquela sessão em todas as fases. Com o intuito de preservar o espírito de compartilhamento, a opção padrão é permitir o compartilhamento da informação produzida em todas as fases.

\subsection{Considerações Finais}

Nas duas experimentações resultantes da instanciação das classes do CARe, pôde-se verificar que os componentes do arcabouço puderam ser reutilizados e integrados a outros sistemas de modo a fornecer funcionalidades de criação automática de ligações, antes não suportadas pelos mesmos.

Nas experimentações apresentadas todas as classes foram utilizadas. A realização de uma experimentação do CARe para o serviço LinkDigger, criado durante a especificação do arcabouço, não utilizaria a classe de consulta op. Isso ocorreria porque o LinkDigger relaciona todo o conteúdo dos repositórios. Na verdade, as únicas classes que acredita-se necessárias em todas as aplicações são os pontos fixos apresentados no capítulo anterior.

Os resultados satisfatórios das duas experiências de aplicação do CARe foram detalhados neste capítulo e fundamentam a oportunidade da continuação da pesquisa aqui reportada. No próximo capítulo são apresentadas as conclusões sobre as pesquisas e propostas desta tese e os trabalhos futuros que podem ser realizados a partir dos resultados aqui reportados. 


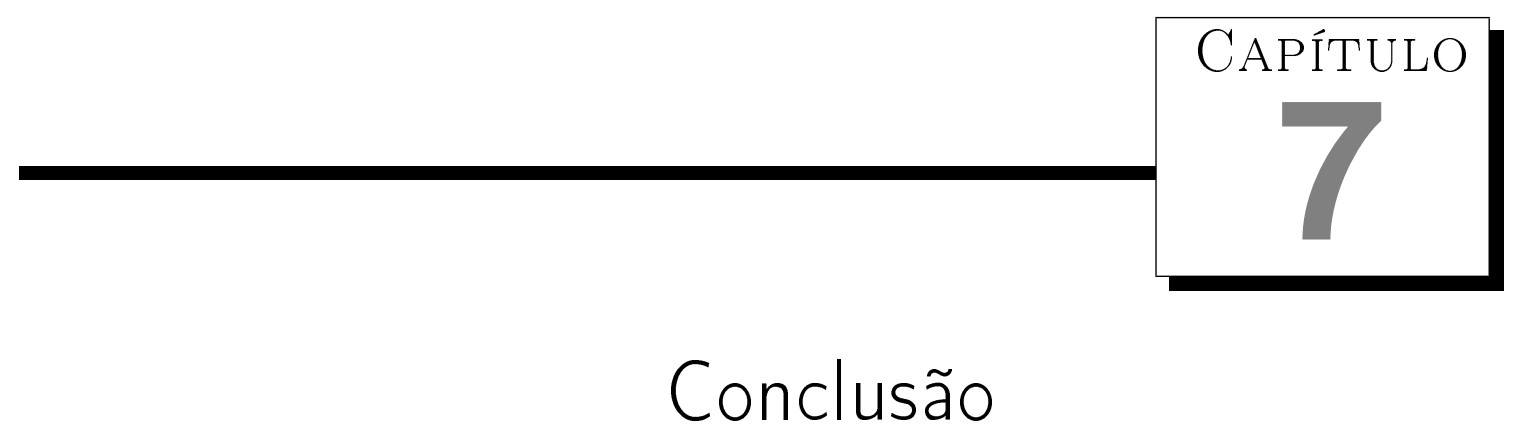

Nesta tese, foram apresentados trabalhos que exploram a definição de relacionamentos entre informações homogêneas e que envolvem pesquisas de Hipermídia, Recuperação de Informação, Sistemas CSCW Recomendação de Informações e Ambientes de Captura Ubíqua e tecnologias Web. Tais trabalhos fundamentam a pesquisa descrita nesta tese como investigações que auxiliam usuários na busca por informações similares, cujos relacionamentos podem ser apresentados como ligações hipertexto, criadas a partir da sincronização de informações capturadas, ou pela análise textual e estrutural das mesmas. Nesse mesmo domínio, foi proposto um arcabouço para apoiar a criação de ligações hipertexto a partir da exploração de diferentes tecnologias advindas de diferentes áreas, ao combinar um conjunto de classes e assim, definir diferentes tipos de sistemas hipermídia. Dessa maneira, o arcabouço proposto contribuiu com a evolução do estado da arte para sistemas hipermídia.

\subsection{Resumo do Trabalho Realizado}

Motivada pelo resultado de um serviço manual de criação de ligações entre repositórios homogêneos (Abowd et al. 1999), a doutoranda iniciou uma análise de domínio sobre outras alternativas de integração de ambientes homogêneos como os ambientes eClass e CoWeb. Um dos requisitos levantados na época era a definição de um mecanismo automático de criação de ligações para não sobrecarregar os usuários. Nesse sentido, foi definido um serviço de criação automática de ligações hipertexto lexicais entre os repositórios de informações gerados pelas aplicações eClass e CoWeb (Pimentel et al. 2001b). Essa abordagem explorava a natural homogeneidade do conteúdo dos repositórios, quando correspondiam a informações de um mesmo curso, utilizando apenas comparações lexicais de palavras, em vez de técnicas elaboradas de IR. Porém, comparações lexicais podem omitir relacionamentos devido à existência 
de sinonímia e de polissemia.

A partir de pesquisas sobre técnicas de IR para indexação semântica, foi escolhida a técnica de Análise da Semântica Latente (Latent Semantic Analysis - LSA) para apoiar a definição de ligações hipertexto semânticas entre repositórios Web contendo informações homogêneas e, assim, evitar problemas de dependência de vocabulário associados à técnicas baseadas em comparações lexicais (Macedo et al. 2001b). Posteriormente, esse trabalho foi estendido com a definição de módulos que facilitavam o armazenamento dos relacionamentos criados, inclusive permitindo o uso de bibliotecas de ligações (Macedo et al. 2002b).

Para permitir a participação explícita de usuários no processo de definição de ligações hipertexto entre coleções similares, também foram definidos módulos de consulta e de retroalimentação (feedback) de usuários (Macedo et al. 2002a). A cada extensão dos serviços de criação de ligações hipertexto, os módulos criados eram definidos como APIs (Application Programming Interfaces) para facilitar o intercâmbio de funcionalidades. Essas APIs e módulos de programa criados foram abstraídos, respectivamente, em classes e métodos do arcabouço CARe proposto nesta tese.

\subsection{Contribuições}

A principal contribuição desta tese é o arcabouço CARe (Criação Automática de Relacionamentos), que oferece um conjunto de classes que podem ser combinadas e reutilizadas com o intuito de definir automaticamente relacionamentos entre informações homogêneas e assim auxiliar a busca de informações similares. Algumas contribuições decorrentes do arcabouço são:

- disponibilização da especificação, formalização e implementação de classes na forma de APIs em cada fase. O capítulo de proposta do arcabouço (Capítulo 5) apresenta, em detalhes, a especificação formal do arcabouço. Porém, em cada serviço definido durante a análise de domínio, foram definidos os problemas em questão e modeladas as soluções. Essa formalização conta com diagramas, algoritmos e infra-estruturas;

- experimentação da reutilização das classes do arcabouço proposto com o objetivo de identificar informações similares a serem recomendadas durante a navegação de grupos colaborativos na Web;

- experimentação da reutilização das classes do arcabouço proposto com o objetivo de identificar informações similares a serem recomendadas em todas as fases de aplicações de captura e acesso - antes, durante e depois da captura;

- as aplicações e os repositórios resultantes das experimentações realizadas: o sistema CSCW WebMemex e as extensões para o ambiente iClass.

Aproveitando-se do arcabouço e de suas contribuições, projetistas e desenvolvedores de aplicações podem articular o conjunto de classes proposto no arcabouço, e então, determinar 
quais desses componentes são necessários para o sistema alcançar os seus objetivos. Como resultado, o arcabouço oferece aos desenvolvedores de aplicações uma maneira poderosa de aumentar a reutilização de componentes de software abstraídos no arcabouço proposto, uma vez que inúmeras aplicações podem ser criadas por meio de sua instanciação.

\subsection{Limitações}

Grande parte das limitações do trabalho reportado nesta tese, em termos dos serviços criados e do arcabouço proposto, refere-se diretamente às limitações dos artefatos utilizados durante o desenvolvimento do trabalho em questão. Os componentes do arcabouço CARe podem apresentar limitações decorrentes das abordagens e das ferramentas utilizadas como, por exemplo, as limitações do pacote de software para armazenamento de informações em uma biblioteca de ligações, o WLS (Bulcão Neto et al. 2002). Apesar da flexibilidade para configuração de parâmetros e seleção de métodos das classes do arcabouço proposto, essas classes são compostas por um conjunto específico de métodos. Por exemplo, a classe de identificação de relacionamentos semânticos poderia usar outra técnica para determinar similaridades semânticas além da técnica de LSA (Furnas et al. 1988). A permissão de participação de usuários definida apenas através da formulação de consultas e do método de relevance feedback também é uma limitação decorrente da utilização isolada de técnicas de IR. Relacionamentos dessa pesquisa com outras área podem vir a suprir essas limitações.

Outras limitações do trabalho realizado são decorrentes de decisões de projeto como, por exemplo, em relação à determinação da granulosidade de cada componente do arcabouço CARe. Outra importante decisão de projeto foi a definição dos pontos de flexibilização e dos pontos fixos do arcabouço CARe, uma vez que todas as classes do CARe possuem métodos flexíveis.

Outro ponto não coberto pela proposta é o uso de linguagens de padrões para prover padrões de análise e de projeto durante o desenvolvimento de sistemas. A utilização desse tipo de tecnologia poderia trazer mais flexibilidade ao arcabouço proposto quanto a aspectos de desenvolvimento de sistemas e também poderia guiar as tomadas de decisões de projeto. Essa limitação poderá ser tratada em trabalhos futuros.

Devido ao fato do arcabouço CARe ser modularizado, torna-se inevitável pensar em estendê-lo na tentativa de atacar, contornar ou mesmo solucionar as limitações apresentadas.

\subsection{Trabalhos em Andamento}

No decorrer dos próximos meses, Alessandra Macedo estará realizando alguns trabalhos de continuidade da pesquisa apresentada nesta tese. Um trabalho direto da proposta desta tese é o desenvolvimento de um sítio Web para disponibilização das classes criadas e da documentação de todo o processo de definição do arcabouço CARe. Essa atividade tem como objetivo permitir que desenvolvedores de aplicações possam reutilizar classes e outros 
componentes desse arcabouço em suas aplicações.

Coleções de informações de outros grupos de pesquisa do ICMC-USP estão sendo preparadas para serem utilizadas como fontes de informação para identificação de relacionamentos. Essas coleções poderão auxiliar na avaliação dos serviços de criação de ligações e também contribuir para a ampliação do domínio de contribuições da abordagem apresentada nesta tese.

Também estão sendo preparados experimentos efetivos para verificar o grau de utilidade das classes do arcabouço CARe para o ambiente iClass. Em uma primeira oportunidade, foi impossível definir experimentos, devido à pouca quantidade de informação textual manipulada pelo iClass. Os experimentos estão sendo preparados e seus resultados deverão ser submetidos a algum periódico internacional da área de computação.

As investigações da exploração de estruturas de documentos para a identificação de relacionamentos foram animadoras e por isso estão sendo retomadas com a participação de pesquisadores do projeto Lácio-Web. Os resultados dessa pesquisa também deverão ser reportados em conferências ou periódicos internacionais.

Além dos trabalhos em andamento e das publicações em preparação, a doutoranda está preparando um artigo a partir da sumarização de suas contribuições detalhadas nesta tese. Esse artigo deverá ser enviado em breve a um periódico internacional.

\subsection{Trabalhos Futuros}

Os trabalhos em desenvolvimento e a pesquisa apresentada nesta tese sugerem alguns trabalhos futuros, tanto para investigar alternativas às limitações citadas como para dar continuidade à pesquisa reportada. São sugestões de trabalhos futuros:

- a investigação da utilização de outras abordagens para a identificação de relacionamentos entre informações homogêneas. Pensa-se, por exemplo, em investigar a utilização de redes neurais;

- a investigação de mecanismos para explorar a estrutura organizacional do conteúdo de hiperdocumentos e também a estrutura de relacionamentos entre documentos. Uma proposta é a extração de meta-informação dos repositórios a serem relacionados através de análises de DTDs, XML Schemas e documentos RDF. Essas informações poderão ser combinadas utilizando, por exemplo, redes bayesianas;

- avaliação mais efetiva dos resultados obtidos a partir da utilização dos serviços de criação automática de ligações. As coleções de referência TREC e a coleção de XML para IR INEX poderão ser utilizadas;

- avaliação formal dos limites e capacidades de processamento dos serviços criados;

- definição de mecanismos de utilização de informações de contexto para a identificação de relacionamentos entre informações capturadas em ambientes de captura e acesso 
como o iClass;

- análise dos trabalhos realizados e estudados para investigar requisitos que aplicações suportadas pelo CARe possam atender. 


\section{Glossário}

Análise global corresponde a uma técnica para identificar documentos e termos relacionados por meio da análise de todos os documentos da coleção. Esse tipo de técnica é geralmente utilizada para a composição de dicionários de sinônimos (thesaurus).

Análise local corresponde a uma técnica de expansão de consultas para identificar relacionamentos de documentos e termos por meio da análise de documentos recuperados por uma consulta de usuário.

Âncora define a origem e o destino da ligação hipertexto. Cada ligação está associada a duas âncoras, e ao ativá-la, apontando com o mouse ou usando o teclado, ocorre um "salto" para outra região do hiperdocumento.

Aplicações cientes de contexto ou sensíveis a contexto correspondem à aplicações que

Aplicações de captura e acesso correspondem à aplicações que utilizam informações de contexto para oferecer serviços e informações para usuários. Essas aplicações suportam sessões de captura para registrar experiências diárias, ricas em informação, e disponibilizar o conteúdo capturado utilizando, por exemplo, hiperdocumentos, que podem ser visualizados por usuários após o encerramento da sessão de captura.

Arcabouço (do inglês framework) é um conjunto de classes abstratas e mecanismos de colaboração entre as instâncias dessas classes que oferece aos desenvolvedores de aplicações uma maneira poderosa de aumentar a reutilização de componentes de software, sendo que inúmeras aplicações distintas podem ser criadas por meio de sua instanciação.

Arquivo invertido corresponde a um índice textual composto por um vocabulário e uma lista de ocorrências.

Categorização é o agrupamento de documentos que satisfaz um conjunto de propriedades comuns. 
Classe define a interface e a implementação de um objeto. Ela especifica a representação interna dos objetos e define as operações que os objetos podem executar. Classe é um conjunto de objetos os quais têm as mesmas características.

Classe abstrata tem como principal propósito definir uma interface. Uma classe abstrata difere algumas ou todas suas implementações para subclasses. Uma classe abstrata não pode ser instanciada.

Classe concreta é uma classe que não tem operações abstratas e por isso pode ser instanciada.

Coleção é um grupo de ítens (tuplas, objetos, páginas Web, documentos, etc).

Coleção CACM corresponde a uma coleção de referência composta por 3204 artigos publicados na Communications da ACM de 1958 a 1979.

Coleção CISI corresponde a uma coleção de referência composta por 1460 documentos selecionados a partir de uma coleção de referência montada pela ISI (Institute of Scientific Information).

Coleção Cystic Fibrosis corresponde a uma coleção de referência composta por 1239 documentos indexados com o termo fibrose cística (cystic fibrosis) na base de dados MEDLINE da biblioteca nacional de medicina nos Estados Unidos.

Coleção de referência corresponde à coleção de documentos utilizados para testar modelos e algoritmos de recuperação de informação. Uma coleção de referência normalmente inclui um conjunto de documentos, um conjunto de consultas e um conjunto de documentos definidos como relevantes à consultas.

Coleção TREC corresponde a uma coleção de referência que contém mais de um milhão de documentos e que tem sido usado extensivamente nas conferências TREC. A coleção TREC tem sido organizada pelo NIST (National Institute of Standards and Technology) e tem se tornado um padrão para comparar modelos e algoritmos para sistemas de recuperação de informação.

Componente de software pode ser uma estrutura de dados, ou um programa, ou um componente procedimental (módulo) que deve ser projetado de tal maneira que possa ser reutilizado sem um conhecimento detalhado de seu funcionamento interno.

Computação Ubíqua corresponde a uma área científica que propõe a integração de tecnologias de hardware e de software em ambientes tradicionais como residências e salas de aula, de maneira a auxiliar os seres humanos em suas atividades diárias sem interferir no modo como eles normalmente executariam essas tarefas.

Consulta é a expressão que representa a necessidade do usuário a ser fornecida ao sistema de recuperação de informação. 
Consulta baseada em conteúdo é um tipo de consulta que explora o conteúdo textual da coleção manipulada.

Dado é uma coleção desorganizada de, por exemplo, palavras, imagens e/ou sons. Computadores normalmente manipulam dados para criar informações.

Diagrama de classe apresenta classes, suas estruturas, operações internas e relacionamentos estáticos entre as classes.

Documento corresponde a uma unidade de recuperação, que pode ser uma parágrafo, uma seção, uma página Web, um artigo ou um livro completo.

Documento hipermídia, hipertexto ou hiperdocumento correspondem a uma coleção de documentos inter-relacionados por ligações distribuídas pelo conteúdo da coleção. Essas ligações são utilizadas para prover seqüência na leitura e na busca de informações contidas em hiperdocumentos. Hipermídia é um estilo de construir sistemas para representação da informação e gerenciamento a cerca de uma rede de nós multimídias conectados por ligações hipertexto.

Estrutura do texto corresponde à informação não-textual apresentada em um texto. Essa estrutura relaciona diferentes porções do texto em um sentido semântico.

Expansão de consulta é uma tentativa de aprimoramento de resultados de sistemas de recuperação de informação por meio de uma formulação mais precisa da consulta. A expansão de consultas envolve dois passos básicos para o sistema de recuperação de informação: expansão da consulta com novos termos e reformulação dos pesos dos termos da consulta expandida.

Índice é uma estrutura de dados construída em conteúdo textual para aprimorar a busca de informações. Um conjunto de termos de índice forma um índice (ver Termos de índice).

Índice de precisão corresponde a uma medida de desempenho de sistemas de recuperação de informação. Essa medida é a fração de documentos recuperados que são relevantes. O índice de precisão mede a especificidade da busca e se todos os documentos recuperados são realmente relevantes.

Índice de revocação corresponde a uma medida de desempenho de sistemas de recuperação de informação. Essa medida é a fração de documentos relevantes que foram recuperados. Esse índice indica o grau de exaustão de execução do sistema e o número de documentos recuperados que o usuário poderia querer.

Informação pode ser entendida como uma coleção organizada de dados da qual podem ser tiradas conclusões. Informação é dado organizado e que tem significado como, por exemplo, relatórios, notícias e artigos. 
Informação de contexto corresponde a qualquer informação que pode ser usada para caracterizar a situação de uma entidade considerada relevante para a interação entre um usuário e uma aplicação. Contexto é tipicamente a localização, identidade e estado de pessoas, grupos ou objetos físicos.

Informação homogênea é o conjunto de informações com conteúdo similar.

Instância é a definição particular de um objeto de uma classe.

Instanciação é o processo de definir objetos individuas de uma classe.

Interface ou API é um conjunto de requisições que um objeto pode responder.

Ligações hipertexto são espécies de ponteiros que conectam unidades de informações (nós) em um hiperdocumento.

Lista de ocorrências corresponde a uma estrutura de dados que armazena para cada palavra da lista a sua posição no conteúdo textual.

Metadados são atributos descritivos de dados ou documentos, isto é, são dados sobre outros dados. Por exemplo, livrarias têm como metadados: autor, título, assunto, editora e a localização física de cada livro.

Modelo booleano é uma maneira de representar documentos com base na teoria dos conjuntos e na álgebra booleana. Cada documento é representado por um conjunto de índices aos quais podem ser atribuídos pesos binários: 1 se o índice existir no conteúdo do documento que está sendo representado e 0, caso contrário.

Modelo booleano estendido corresponde a um modelo baseado na interpretação dos operadores de consultas conjuntivas e disjuntivas em termos de distâncias euclidianas em um espaço $t$-dimensional.

Modelos para recuperação de informação correspondem a um conjunto de premissas e um algoritmo para ordenar documentos recuperados a partir de uma consulta.

Modelo probabilístico corresponde ao modelo que classifica documentos de acordo com sua probabilidade de ser relevante para a informação a ser buscada.

Modelo vetorial representa documentos como um vetor numérico no qual cada elemento representa um único termo ou um índice de documento. A esses elementos são atribuídos pesos parciais os quais indicam o grau de especificidade relativo de cada termo.

Navegação (do inglês browsing) corresponde a movimentação ou leitura que os leitores fazem sobre um documento não-linear, por exemplo, hiperdocumento. 
Nó corresponde à unidade mínima de informação do hiperdocumento. Os nós representam trechos e o objetos de informação que formam o hiperdocumento. Os objetos podem ser textos, gráficos, imagens, vídeo e/ou som.

Ordenação (do inglês ranking) é a maneira do sistema de recuperação de informação organizar os resultados recuperados a partir de buscas de usuários.

Palavras-chave (do inglês keywords) correspondem a um conjunto pré-selecionado de termos que podem ser utilizados para referenciar o conteúdo de um documento.

Perfil de usuário (do inglês profile) é um conjunto de informações que diferencia um usuário de outro. Em Ciências da Computação, essas informações incluem a área de trabalho do usuário, programas e documentos recentes, os registradores (cookies) usados pelo navegador Web, bookmarks, dados diversos, temas e esquemas que podem auxiliar na personalização de uma aplicação. Perfis de usuários podem ser obtidos de maneira explícita ou implícita.

Polissemia corresponde à utilização de uma mesma palavra para nomear diferentes objetos como, por exemplo, a palavra banco.

Pontos de flexibilização (do inglês hot spots) são classes abstratas ou métodos que podem ser ajustados de modo a suportar as diferenças de domínio de cada aplicação.

Pontos fixos (do inglês frozen spots) correspondem a características imutáveis no domínio ou características que não podem ser facilmente alteradas. Pontos fixos constituem o núcleo do arcabouço, que é formado por partes de código que chamam pontos de flexibilização fornecidos pelo desenvolvedor da aplicação em questão. Pontos fixos são o núcleo do arcabouço, pois serão constantes e as partes sempre presentes em cada instância do arcabouço.

Protocolo estende o conceito de interface especificando um seqüência de possíveis requisições.

Proxy é um servidor (local) que pode monitorar e capturar atividades realizadas na Web no lugar de cliente Web.

Recuperação de dados é a recuperação de ítens (tuplas, objetos, páginas Web, documentos, etc) cujos conteúdos satisfazem as condições especificadas em uma consulta.

Recuperação de informação corresponde a uma área dedicada a pesquisas de tecnologias para manipulação e recuperação de grandes coleções de informação em diferentes formatos de apresentação.

Rede de inferência é um modelo que generaliza o modelo probabilístico tratando o processo de recuperação de informação como um processo de raciocínio baseado em evidências representadas em documentos. 
Redes neurais artificiais são técnicas computacionais que apresentam um modelo matemático inspirado na estrutura neural de organismos inteligentes e que adquirem conhecimento através da experiência. Uma grande rede neural artificial pode ter centenas ou milhares de unidades de processamento; já o cérebro de um mamífero pode ter muitos bilhões de neurônios.

Referência intrínseca corresponde ao relacionamento implícito entre informações de conteúdo similar.

Repositório corresponde ao espaço digital onde objetos são armazenados por um período de tempo. Esses objetos podem ser obtidos se eles forem requeridos e seus termos e condições forem satisfeitas.

Repositório homogêneo correspondente a um espaço digital que contém informações com conteúdo similar.

Roteiro guiado (do inglês guided-tour) corresponde a uma seqüência de escolhas de navegação (usualmente em um hipertexto) com o objetivo de apresentar nós em uma ordem lógica para algum objetivo.

Sessão de Captura corresponde ao momento entre o início da captura das atividades em desenvolvimento em ambientes ubíquos e o final é denominado sessão de captura.

Sinonímia corresponde à variabilidade de palavras para descrever um mesmo objeto como, por exemplo, as palavras carro e automóvel.

Sistemas de recomendação de informações (do inglês Recommender Systems) correspondem a uma categoria de sistemas de informação que auxiliam e estendem o processo natural de pedir recomendações a outras pessoas. Algumas vezes, sistemas de recomendação também são referenciados como filtros colaborativos, sistemas de filtragem social ou apenas sistemas colaborativos.

Sistema ubíquos de captura suportam sessões de captura que utilizam de conceitos de computação ubíqua como, interação de usuários com dispositivos computacionais, de modo transparente como, por exemplo, via lousa eletrônica.

Sítio Web (do inglês Web site) corresponde a um conjunto de páginas Web na World Wide Web (WWW ou simplesmente Web).

SOM ou Mapa de Kohonen (do inglês Self-Organizing Map) é um mapa bi-dimensional no qual as regiões representam os principais temas em um documento ou coleção.

Stemming é uma técnica para reduzir uma palavra a sua raiz gramatical.

Stopwords são palavras que ocorrem muito freqüentemente no conteúdo textual de um documento. 
Tag corresponde a uma string utilizada para marcar o começo e o final de um elemento em um documento estruturado. Termos de índice são palavras-chave representativas da coleção.

Termos de índice correspondem a palavras-chave representativas de uma coleção. Um conjunto de termos de índice forma um índice (ver Índice).

Thesaurus ou dicionário de sinônimos é uma estrutura de dados composta de uma lista pré-compilada de palavras importantes em um dado domínio de conhecimento e para cada palavra na lista, uma lista de palavras relacionadas (sinônimos).

Vocabulário corresponde a um conjunto de todas as palavras de um texto. 


\section{Referências Bibliográficas}

Abowd, G. D. (1999). Classroom 2000: an experience with the instrumentation of a living educational environment. IBM Systems Journal 38, 508 - 530.

Abowd, G. D., C. G. Atkeson, A. Feinstein, C. Hmelo, R. Kooper, S. Long, N. Sawhney, \& M. Tani (1996, November). Teaching and learning as multimedia authoring: The Classroom 2000 Project. In Proceedings of the ACM International Multimedia Conference and Exhibition, Boston, MA, USA, pp. 18 - 22. ACM Press.

Abowd, G. D., L. D. Harvel, \& J. A. Brotherton (2000, November). Building a digital library of captured educational experiences. In Proceedings of the Kyoto International Conference on Digital Libraries, Kyoto, Japan, pp. 395 - 402.

Abowd, G. D., M. G. C. Pimentel, B. Kerimbaev, Y. Ishiguro, \& M. Guzdial (1999). Anchoring discussion in lecture: an approach to collaboratively extending classroom digital media. In Proceedings of Computer Support for Collaborative Learning (CSCL) Conference, Stanford University, pp. $11-19$.

Agosti, M. \& F. Crestani (1993). A methodology for the automatic construction of a hypertext for information retrieval. In Proceedings of ACM/SIGAPP Symposium on Applied Computing: states of the art and practice, Indianapolis, IN, USA, pp. $745-753$. ACM Press.

Al-Khalifa, S., C. Yu, \& H. Jagadish (2003, June). Querying structured text in an XML database. In Proceedings of International Conference on Management of Data (SIGMOD), San Diego, CA, USA.

Allan, J. (1996). Automatic hypertext link typing. In Proceedings of the ACM Conference on Hypertext and Hypermedia, pp. 42 - 52. ACM Press.

Ando, R. K. (2000, July). Latent semantic space: Iterative scaling improves precision of inter-document similarity measurement. In Proceedings of the ACM Conference on Research and Development in Information Retrieval (SIGIR), Athens, Greece, pp. 216 - 222. ACM Press. 
Ando, R. K. \& L. Lee (2001, September). Iterative residual rescaling: An analysis and generalization of LSI. In Proceedings of the ACM Conference on Research and Development in Information Retrieval (SIGIR), New Orleans, Louisiana, USA, pp. 154-162. ACM Press.

Andrade, A., E. Munson, \& M. Pimentel (2004, 10p.). A document-based approach to the generation of Web applications. In Submitted to Proceedings of ACM Document Engineering 2004. ACM Press.

Andrade, A. R. (2004, Maio). Geração automática de aplicações Web para aplicações de captura e acesso. Master's thesis, Universidade de São Paulo, São Carlos - SP.

Baek, D., H. Lim, \& H. Rim (2000, July). Latent semantic indexing model for boolean query formulation. In Proceedings of the ACM Conference on Research and Development in Information Retrieval (SIGIR), Athens, Greece, pp. 310 - 312. ACM Press.

Baeza-Yates, R. \& B. Ribeiro-Neto (1999, Janeiro). Modern Information Retrieval (1ª ed.). Addison Wesley.

Balabanovi, M. \& Y. Shoham (1997, March). Fab: content-based, collaborative recommendation. Communications of the ACM 40(3), $66-72$.

Bernard, J. (1986). Macquarie Thesaurus (Edited by J.N.L. Bernard (First published 1984) ed.). Sydney, Australian: The Macquarie Library.

Billerbeck, B. \& J. Zobel (2003). When query expansion fails. In Proceedings of the annual international ACM SIGIR conference on Research and development in information retrieval, pp. 387 - 388. ACM Press.

Børner, K. (2000). Extracting and visualizing semantic structures in retrieval results for browsing. In Proceedings of the ACM Conference on Digital Libraries, San Antonio, TX, USA, pp. 234 - 235. ACM Press.

Bray, T., J. Paoli, \& C. M. Sperberg-McQueen (1998, February). Extensible markup language (XML) 1.0. w3c recommendation. http:/www.w3.orgTRREC-xml.

Brin, S. \& L. Page (1998). The anatomy of a large-scale hypertextual Web search engine. Computer Network and ISDN System 30(1-7), $107-117$.

Bulcão Neto, R. F., C. A. Izeki, M. G. C. Pimentel, R. P. M. Pontin, \& K. N. Truong (2002). An open linking service supporting the authoring of Web documents. In Proceedings of the ACM Document Engineering, McLean, Virginia, USA, pp. 66-73. ACM Press.

Bulcão Neto, R. F. (2001). WLS: Um Serviço Aberto de Ligações Hipermídia para Web baseado em XML. Dissertação, Instituto de Ciências Matemáticas e de Computação da USP, São Carlos, SP, São Paulo. 
Calado, P., M. Cristo, E. Moura, N. Ziviani, B. Ribeiro-Neto, \& M. A. Gonçalves (2003a). Combining link-based and content-based methods for Web document classification. In Proceedings of the ACM international conference on Information and knowledge management (CIKM), New Orleans, Louisiana, USA, pp. 394 - 401. ACM Press.

Calado, P., M. A. Gonçalves, E. A. Fox, B. Ribeiro-Neto, A. H. F. Laender, A. S. da Silva, D. C. Reis, P. A. Roberto, M. V. Vieira, \& J. P. Lage (2003b). The Web-DL environment for building digital libraries from the Web. In Proceedings of the ACM/IEEE-CS joint conference on Digital Libraries, Houston, TX, USA, pp. 346 - 357. IEEE Computer Society.

Calado, P., B. Ribeiro-Neto, N. Ziviani, E. Moura, \& I. Silva (2003c). Local versus global link information in the Web. ACM Transaction on Information Systems 21(1), $42-63$.

Callan, J., W. B. Croft, \& J. Broglio (1995). TREC and TIPSTER experiments with INQUERY. Information Processing and Management: an International Journal 31(3), $327-343$.

Camacho-Guerrero, J. A. (2002, Dezembro). Investigando abordagens para a criação automática de ligações entre repositórios Web. Dissertação, Instituto de Ciências Matemáticas e de Computação da USP, São Carlos/SP.

Camacho-Guerrero, J. A., A. A. Macedo, \& R. P. M. Fortes (2002a). Uma infra-estrutura configurável para serviços de criação automática de ligações. In Anais do VIII Brazilian Symposium on Multimedia and Hypermedia System, Fortaleza, CE, Brazil, pp. 298 - 305.

Camacho-Guerrero, J. A., M. G. C. Pimentel, \& R. F. Bulcão Neto (2002b). LinkDigger: um serviço aberto de criação automática de ligações semânticas. In Anais do VIII Brazilian Symposium on Multimedia and Hypermedia System, Fortaleza, CE, Brazi, pp. 407 - 410.

Carmel, D., Y. Maarek, M. Mandelbrod, Y. Mass, \& A. Soffer (2003). Searching XML documents via XML fragments. In Proceedings of the ACM Conference on Research and Development in Informaion Retrieval (SIGIR), Toronto, Canadá, pp. 151 - 158. ACM Press.

Carter, S., E. Churchill, L. Denoue, J. Helfman, \& L. Nelson (2004). Digital graffiti: public annotation of multimedia content. In Extended abstracts of the 2004 conference on Human factors and computing systems, pp. 1207-1210. ACM Press.

Cattelan, R. G., L. A. Baldochi Jr, \& M. G. C. Pimentel (2003). Processing and storage middleware support for capture and access applications. In Poster paper presented at the ACM/IFIP/USENIX International Middleware Conference, Rio de Janeiro, RJ, Brazil.

Chan, K. F. \& D. Y. Yeung (1998). A simple yet robust structural approach for recognizing on-line handwritten alphanumeric characters. In Proceedings of the International Workshop on Frontiers in Handwriting Recognition, pp. 229 - 238. 
Chen, M. (2003, November). Visualizaing the pulse of a classroom. In Proceedings of the ACM International Conference on Multimedia, Berkeley, California, USA, pp. 555 - 561. ACM Press.

Chen, Z., S. Liu, L. Wenyin, G. Pu, \& W. Ma (2003). Building a Web thesaurus from Web link structure. In Proceedings of the ACM Conference on Research and Development in Information Retrieval (SIGIR), pp. 48 - 55. ACM Press.

Chiu, P., J. Foote, A. Girgensohn, \& J. Boreczky (2000). Automatically linking multimedia meeting documents by image matching. In Proceedings of the ACM Conference on Hypertext and Hypermedia, San Antonio, TX, USA, pp. 244 - 245. ACM Press.

Chiu, P., A. Kapuskar, S. Reitmeier, \& L. Wilcox (1999). Meeting capture in a media enriched conference room. In Proceedings of the Second International Workshop on Cooperative Buildings, Integrating Information, Organization, and Architecture, pp. 79 - 88. Springer-Verlag.

Cohn, D. \& T. Hofmann (2001, December). The missing link - a probabilistic model of document content and hypertext connectivity. In T. K. Leen, T. G. Dietterich, \& V. Tresp (Eds.), Advances in Neural Information Processing Systems 13, Vancouver, British Columbia, Canada, pp. 430 - 436. MIT Press.

Crestani, F. (2000). Exploiting the similarity of non-matching terms at retrieval time. Journal of Information Retrieval 2(1), $27-47$.

Croft, W. B. \& H. Turtle (1989). A retrieval model for incorporating hypertext linksl. In Proceedings of the ACM Conference on Hypermedia and Hypertext, Pittsburgh, Pennsylvania, USA, pp. 213 - 224. ACM Press.

Cuadros-Vargas, E., R. F. Romero, \& K. Obermayer (2003, September). Speeding up algorithms of som family for large and high dimensional databases. In Workshop on Self Organizing Maps, Kitakyushu, Japan, pp. 6.

Cubranic, D. \& G. C. Murphy (2003). Hipikat: recommending pertinent software development artifacts. In Proceedings of the international conference on Software engineering, pp. 408-418. IEEE Computer Society.

da Silva, A. S., E. A. Veloso, P. B. Golghe, B. Ribeiro-Neto, A. H. F. Laender, \& N. Ziviani (1999). CoBWeb - a crawler for the brazilian Web. In Proceedings of the String Processing and Information Retrieval Symposium and International Workshop on Groupware, pp. 184 - 192. IEEE Computer Society.

Deerwester, S., S. T. Dumais, T. K. Landauer, G. W. Furnas, \& R. A. Harshman (1990). Indexing by latent semantic analysis. Journal of the Society for Information Science 41(6), $391-407$. 
DeRoure, D., W. Hall, S. Reich, G. Hill, A. Pikrakis, \& M. Stairmand (2001). MEMOIR - an open framework for enhanced navigation of distributed information. Information Processing and Management 37, 53 - 74.

Deutsch, A., M. Fernandez, D. Florescu, A. Levy, \& D. Suciu (1999, May). XML-QL: A query language for XML. In Proceedings of the International World Wide Web Conference, Toronto, Canadá.

Dey, A. K., D. Salber, G. D. Abowd, \& M. Futakawa (1999). The conference assistant: Combining context-awareness with wearable computing. In Proceedings of ISWC, pp. 21 28.

Dumais, S. T. (1995). Using lsi for information filtering: Trec-3 experiments. In D. H. (Ed.) (Ed.), The Third Text REtrieval Conference (TREC-3) National Institute of Standards and Technology Special Publication.

Dumais, S. T., T. K. Landauer, \& M. Littman (1996). Automatic cross-linguistic information retrieval using latent semantic indexing. In Proceedings of the ACM Workshop on Cross-Linguistic Information Retrieval (SIGIR), Zurich, pp. 16 - 24. ACM Press.

Dupret, G. (2003). Latent concepts and the number orthogonal factors in latent semantic analysis. In Proceedings of the annual international ACM SIGIR conference on Research and development in information retrieval, pp. $221-226$. ACM Press.

Eidenberger, H. \& C. Breiteneder (2003). Vizir - a framework for visual information retrieval. Journal of Visual Languages and Computing 14(5), 443 - 469.

El-Beltagy, S. R., W. Hall, D. DeRoure, \& L. Carr (2001, August). Linking in context. In Proceedings of the ACM Conference on Hypertext and Hypermedia, Arhus, Denmark, pp. 151 - 160. ACM Press.

Erol, B., J. J. Hull, \& D.-S. Lee (2003). Linking multimedia presentations with their symbolic source documents: algorithm and applications. In Proceedings of the ACM Conference on Multimedia, pp. 498-507. ACM Press.

Fortes, R. P. M. (1996). Análise e Avaliação de Hiperdocumentos: uma abordagem baseada na Representação Estrutural. Tese, IFSC-SP, São Carlos, SP, Brazil.

Fox, E. A. (1983). Characterization of two new experimental collections in computer and information science containing textual and bibliographical concepts. Technical report, Cornell University, New York, NY. http://www.ncstrl.org.

Fuhr, N. (2003). XML information retrieval and information extraction. In Text Mining. Theoretical Aspects and Applications, pp. 21-32. Heidelberg: Physica Verlag. 
Fuhr, N. \& K. Grojohann (2000, July). XQIRL: An extension of XQL for information retrieval. In Proceedings of the ACM SIGIR Workshop on XML and IR, Athens, Greece.

Fuhr, N. \& K. Grojohann (2004, April). XIRQL: An XML query language based on information retrieval concepts. ACM Transaction Information System 22(2), 313 - 356.

Furnas, G. W., S. Deerwester, S. T. Dumais, T. K. Landauer, R. A. Harshman, L. A. Streeter, \& K. E. Lochbaum (1988). Information retrieval using a singular value decomposition model of latent semantic structure. In Proceedings of Conference on Research and Development in Information Retrieval (SIGIR), Grenoble, France, pp. 465 - 480. ACM Press.

Gamma, E., R. Helm, R. Johnson, \& J. Vlissides (1997, May). Design Patterns: Elementos of Reusable Object-Oriented Software (Second ed.). Massachusetts, USA: Addison Wesley Longman Inc.

Garzotto, F., P. Paolini, \& D. Schwabe (1993). Hdma model-based approach to hypertext application design. ACM Transactions on Information Systems (TOIS) 11(1), 1-26.

Glance, N. S. (2001). Community search assistant. In Proceedings of the international conference on Intelligent user interfaces, pp. 91-96. ACM Press.

Goldberg, D., D. Nichols, B. Oki, \& D. Terry (1992, December). Using collaborative filtering to weave an information tapestry. Communications of the ACM 35(12), 61- 70.

Golovchinsky, G. (1997). What the query told the link: the integrations of hypertext and information retrieval. In Proceedings of the ACM Conference on Hypermedia and Hypertext, Southampton, UK, pp. $67-74$. ACM Press.

Gonzalez, M. \& V. de Lima (2001). Semantic thesaurus for automatic expanded query in information retrieval. In Proceedings of 8th Symposium on String Processing and Information Retrieval, pp. 68 - 75. IEEE Computer Society.

Gonzalez, M. \& V. L. S. Lima (2003). Recuperação de informação e processamento da linguagem natural. In Anais do III Jornada de Mini-Cursos de Inteligência Artificial do XXIII Congresso da Sociedade Brasileira de Computação, Volume 3, pp. 347 - 395.

Green, S. J. (1999, Semptember). Building hypertext links by computing semantic similarity. IEEE Transactions on Knowledge and Data Engineering 11(5), 713 - 730.

Greene, S., S. Devlin, P. Cannata, \& L. Gomez (1990). No IFs, ANDs, or ORs: A study of database querying. International Journal of Man-Machine Studies 32, 303 - 326.

Grønbæk, K., J. F. Kristensen, P. Øbrbæk, \& M. A. Eriksen (2003, November). "Physical hypermedia": organising collections of mixed physical and digital material. In Proceedings of the ACM Conference on Hypertext and Hypermedia, Nottingham, UK, pp. 10 - 19. ACM Press. 
Grønbæk, K. \& R. H. Trigg (1994). Design issues for a Dexter-based hypermedia system. Communications of the ACM 37(2), $40-49$.

Grønbæk, K. \& R. H. Trigg (1996, March). Toward a Dexter-based model for open hypermedia: unifying embedded references and link objects. In Proceedings of the ACM Conference on Hypermedia and Hypertext, Bethesda, Maryland, USA, pp. 149 - 160. ACM Press.

Grønbæk, K., P. P. Vestergaard, \& P. Øbrbæk (2002). Towards geo-spatial hypermedia: Concepts and prototype implementation. In Proceedings of the ACM Conference on Hypertext and Hypermedia, College Park, Maryland, USA, pp. 117 - 126. ACM Press.

Guzdial, M. (1999). Supporting learners as users. The Journal of Computer Documentation 23(2), $3-13$.

Haake, J. M., C. M. Neuwirth, \& N. A. Streitz (1994). Coexistence and transformation of informal and formal structures: Requirements for more flexible. In Proceedings of the European Conference on Hypertext, pp. 1 - 12.

Halasz, F. \& M. Schwartz (1994). The Dexter hypertext reference model. Communications of the ACM $37(2), 30-39$.

Halkidi, M., B. Nguyen, I. Varlamis, \& M. Vazirgiannis (2003). Thesus: Organizing Web document collections based on link semantics. The VLDB Journal 12, 320 - 332.

Harman, D. (1992, June). Relevance feedback revisited. In Proceedings of the ACM Conference on Research and Development in Information Retrieval (SIGIR), Copenhagen, Denmark, pp. 1 - 10. ACM Press.

Harper, D. J. \& C. J. van Rijsbergen (1978). An evaluation of feedback in document retrieval using co-occurrence data. Journal of Documentation 34(1), $189-216$.

Hearst, M. A. (1999, Janeiro). Modern Information Retrieval (1 ed.)., Chapter 10 - User Interfaces and Visualization, pp. 257 - 322. Addison Wesley.

Henzinger, M. R. (2001, January). Hyperlink analysis for the Web. IEEE Internet Computing 5(1), $45-50$.

Henzinger, M. R., A. Heydon, M. Mitzenmacher, \& M. Najork (1999, May). Measuring quality using walks on the Web. In Proceedings of the International World Wide Web Conference, Toronto, Canada, pp. $213-225$.

Hoenkamp, E. (2001, September). Unitary operators for Fast Latent Semnatic Indexing (FLSI). In Proceedings of the ACM Conference on Research and Development in Information Retrieval (SIGIR), New Orleans, Louisiana, USA, pp. 400 - 401. ACM Press. 
Huang, Z., H. Chen, \& D. Zeng (2004). Applying associative retrieval techniques to alleviate the sparsity problem in collaborative filtering. ACM Transactions on Information Systems (TOIS) 22(1), 116-142.

Ide, E. (1971). New experiments in relevance feedback. In G. Salton (Ed.), The Smart Retrieval System, pp. 337 - 354. Prentice Hall.

Isakowitz, T., E. A. Stohr, \& P. Balasubramanian (1995). Rmm: a methodology for structured hypermedia design. Communication of the ACM 38(8), 34-44.

Jin, R., C. Faloutsos, \& A. G. Hauptmann (2001, September). Meta-scoring: Automatically evaluating term weighting schemes in IR without precision-recall. In Proceedings of the ACM Conference on Research and Development in Information Retrieval (SIGIR), New Orleans, Louisiana, USA, pp. 83 - 89. ACM Press.

Joachims, T., D. Freitag, \& T. Mitchell (1997). WebWatcher: A tour guide for the World Wide Web. In Proceedings of the International Joint Conference on Artificial Intelligence, pp. $770-777$.

Johnson, A. H. (2001, February). Web tool makes for good conversation. nativeminds customer service software responds to natural language questions. COMPUTERWORLD. http://www.computerworld.com/managementtopics/outsourcing/story/0,10801,58012,00.html.

Johnson, B. (1992). TreeViz: Treemap visualization of hierarchically structured information. In Proceedings ACM CHI, pp. 369 - 370. ACM Press.

Johnson, R. \& B. Foote (1988, June). Designing reusable classes. Journal of Object Oriented Programming 1(2), $22-35$.

Johnson, R. E. (1997). Frameworks $=$ (components + patterns $)$. Communications of the ACM 40(10), $39-42$.

Jones, K. S. (1972, March). A statistical interpretation of term specificity and its application in retrieval. Journal of Documentation 28(1), $11-21$.

Kahle, B. \& B. Gilliat (1997). Alexa - navigate the Web smarter,faster, easier. Technical report, Alexa Internet, Presidio of San Francisco, CA, USA. http://www.alexa.com.

Kang, I. \& G. Kim (2003). Query type classification for web document retrieval. In Proceedings of the annual international ACM SIGIR conference on Research and development in information retrieval, pp. $64-71$. ACM Press.

Keller, R. M., S. R. Wolfe, J. R. Chen, J. L. Rabinowitz, \& N. Mathe (1997). A bookmarking service for organizing and sharing URLs. In Proceedings of the International World Wide Web Conference, Santa Clara, CA,USA, pp. 1103 - 1114. Elsevier Science Publishers Ltd. 
Kleinberg, J. M. (1999). Authoritive sources in a hyperlinked environment. Journal of the ACM 46(5), $604-632$.

Kleinberg, J. M. (2000, December). Hubs, authorities, and communities. In Proceedings of the ACM Computing Survey 31(4), pp. 3.

Kobayashi, M. \& K. Takeda (2000, June). Information retrieval on the Web. ACM Computing Survey 32(2), $144-173$.

Kohonen, T. (1982). Self-organizing formation of topologically correct feature maps. Biological Cybernetics 43(1), $59-69$.

Korn, F., H. V. Jagadish, \& C. Faloutsos (1997, May). Efficiently supporting ad hoc queries in large datasets of time sequences. In Proceedings of the ACM international Conference on Management of Data (SIGMOD), Tucson, Arizona, USA, pp. 289 - 300. ACM Press.

Kotsakis, E. (2002). Structured information retrieval in XML documents. In Proceedings of the ACM Symposium on Applied Computing (SAC), Madrid, Spain, pp. 663-667. ACM Press.

Lawrie, D. J. \& W. B. Croft (2003). Generating hierarchical summaries for web searches. In Proceedings of the annual international ACM SIGIR conference on Research and development in information retrieval, pp. 457 - 458. ACM Press.

Lieberman, H. (1997). Autonomous interface agents. In Proceedings of the ACM Conference on Computers and Human Interface (SIGCHI), Atlanta, GA,USA, pp. 67 - 74. ACM Press.

Liu, Q., Y. Rui, A. Gupta, \& J. J. Cadiz (2001). Automating camera management for lecture room environments. In Proceedings of the ACM SIGCHI Conference on Human factors in Computing systems, pp. 442 - 449. ACM Press.

Macedo, A. A., L. A. Baldochi Jr, J. A. Camacho-Guerrero, \& M. G. C. Pimentel (2004a). Automatically linking live experiences captured through a ubiquitous infrastructure. Submitted to Multimedia Tools and Applications (MTAP) Journal, 10p.

Macedo, A. A., R. F. Bulcão Neto, \& M. G. C. Pimentel (2001a, December). Autoria colaborativa na Web: experiências e reflexões sobre a CoWeb. Revista Brasileira de Informática na Educação (RBIE) 9, $9-25$.

Macedo, A. A., J. A. Camacho-Guerrero, R. G. Cattelan, V. R. Inácio Jr, \& M. G. C. Pimentel (2004b, August). Interaction alternatives for linking everyday presentations. In Submitted to Proceedings of the ACM Conference on Hypertext and Hypermedia, Santa Cruz, CA, USA, pp. 2p. ACM Press.

Macedo, A. A., J. A. Camacho-Guerrero, \& M. G. C. Pimentel (2002a, November). Incluindo abordagens de recuperação de informação em serviços de criação de hiperligações. In XXVIII Conferencia Latinoamericana de Informática, Montevideu, Uruguai. 
Macedo, A. A., M. G. C. Pimentel, \& J. A. Cammacho-Guerrero (2002b). An infrastructure for open latent semantic linking. In Proceedings of the ACM Conference on Hypertext and Hypermedia, College Park, Maryland, USA, pp. 107 - 116. ACM Press.

Macedo, A. A., M. G. C. Pimentel, \& J. A. C. Guerrero (2001b, November). Latent semantic linking over homogeneous repositories. In Proceedings of the ACM Symposium on Document Engineering, Atlanta, GA, USA, pp. 144 - 151. ACM Press.

Macedo, A. A., K. N. Truong, J. A. Camacho-Guerrero, \& M. G. C. Pimentel (2003, August). Automatically sharing Web experiences through a hyperdocument recommender system. In Proceedings of the ACM Conference on Hypertext and Hypermedia, Nottingham, UK, pp. 48 - 56. ACM Press.

Maron, M. E. \& J. L. Kuhns (1960, July). On relevance, probabilistic indexing and information retrieval. Journal of the ACM (JACM) 7(3), 216 - 244.

McCulloch, W. \& W. Pitts (1943). A logical calculus of the ideas immanent in nervous activity. Bulletin of Mathematical Biophysics 5, 115 - 133.

McCune, B. P., R. M. Tong, J. S. Dean, \& D. G. Shapiro (1985). Rubric: A system for rule-based information retrieval. IEEE Transaction on Software Engineering 11(9), 939 945.

McDonald, D. W. \& M. S. Ackerman (2000). Expertise recommender: a flexible recommendation system and architecture. In Proceedings of the ACM conference on Computer supported cooperative work, pp. 231-240. ACM Press.

McNee, S. M., I. Albert, D. Cosley, P. Gopalkrishnan, S. K. Lam, A. M. Rashid, J. A. Konstan, \& J. Riedl (2002). On the recommending of citations for research papers. In Proceedings of the ACM conference on Computer supported cooperative work (CSCW), pp. 116-125. ACM Press.

Mearian, L. (2001, July). Schwab taps natural-language search engine. COMPUTER WORLD. http://www.computerworld.com/industrytopics/financial/story/0,10801,62235,00.html.

Merriam-Webster Inc. (2004). Merriam-webster. Online in World Wide Web. http:/www.mw.comthesaurus.htm.

Microsystems, S. (1998). Java speech api specification.

Middleton, S. E., D. C. DeRoure, \& N. R. Shadbolt (2001, October). Capturing knowledge of user preferences: Ontologies in recommender systems. In Proceedings ACM of Conference on Knowledge Capture (K-CAP), Victoria, British Columbia, Canada, pp. 100 - 107. ACM Press. 
Middleton, S. E., N. R. Shadbolt, \& D. C. De Roure (2004). Ontological user profiling in recommender systems. ACM Transactions on Information Systems (TOIS) 22(1), 54-88.

Miller, G. (1990). Wordnet: An on-line lexical database. International journal of lexicography 3(4), $235-312$.

Müller, R. \& T. Ottmann (2000, May). The "Authoring on the Fly" system for automated recording and replay of (tele)presentations. Multimedia Systems Journal 8(3), 158 - 176.

MnoGoSearch Group (2004). Mnogosearchtm web search engine software. Internet (Visitada em 28/02/2004). http://www.mnogosearch.ru.

Muchaluat-Saade, D. C., R. F. Rodrigues, \& L. F. G. Soares (2002). Xconnector: extending xlink to provide multimedia synchronization. In Proceedings of ACM symposium on Document engineering, pp. 49 - 56. ACM Press.

Mukhopadhya, S. \& B. Smith (1999). Passive capture and structuring of lectures. In In Proceedings of the ACM Conference on Multimedia, Orlando, Florida, USA, pp. 477 - 487. ACM Press.

Mynatt, E., J. Rowan, S. Craighill, \& A. Jacobs (2001). Digital family portraits: Providing peace of mind for extended family members. In Proceedings of the ACM Conference on Human Factors in Computing Systems, Seattle, Washington, USA, pp. 333 - 340. ACM Press.

Ng, A. Y., A. X. Zheng, \& M. Jordan (2001). Stable algorithms for link analysis. In Proceedings of ACM SIGIR, pp. 9.

Nielsen, J. (1990). Hypertext and Hypermedia. San Diego, CA, USA: Academic Press Professional, Inc.

Olston, C. \& E. H. Chi (2003, September). Scenttrails: Integrating browsing and searching on the web. ACM Transactions on Computer-Human Interaction (TOCHI) 10(3), 177 197.

Orr, R. J. \& G. D. Abowd (2000, April). The smart floor: A mechanism for natural user identification and tracking. In Proceedings of the CHI Conference on Human Factors in Computing Systems, The Hague, Netherlands, pp. 275 - 276. ACM Press.

Oshiro, A. K. (2003, Fevereiro). iVIEW: infra-estrutura de Visualização de Informação Evolucionária na Web. Dissertação, Instituto de Ciências Matemáticas e de Computação da USP, São Carlos/SP.

Paganelli, C. \& E. Mounier (2003). Information retrieval in technical documents: from the user's query to the information-unit tagging. In Proceedings of the ACM International Conference on Documentation (SIGDOC), San Francisco, CA, USA, pp. 133 - 139. ACM Press. 
Pereira Jr, A. R. \& N. Ziviani (2003). Syntactic similarity of web documents. In Proceedings of the Latin American Web Congress (LA-WEB), Santiago, Chile, pp. 194 - 200. IEEE Computer Society.

Peters, R. E., R. Pak, G. D. Abowd, A. D. Fisk, \& W. A. Rogers (2001). Finding lost objects: Informing the design of ubiquitous computing services for the home. Technical Report GIT-GVU-04-01, Georgia Tech., Atlanta, Georgia, USA.

Peters, W., I. Peters, \& P. Vossen (1998). Automatic sense clustering in eurowordnet. In Proceedings First Internacional Conference on Language Resources and Evaluation, Granada, Spain.

Pimentel, M. G. C., G. D. Abowd, \& Y. Ishiguro (2000). Linking by interacting: a paradigm for authoring hypertext. In Proceedings of the ACM Conference on Hypertext and Hypermedia, San Antonio, TX, USA, pp. 39 - 48. ACM Press.

Pimentel, M. G. C., Y. Ishiguro, B. Kerimbaev, G. D. Abowd, \& M. Guzdial (2001a). Supporting long-term educational activities through dynamic Web interfaces. Interacting With Computers Journal 13, 353-374.

Pimentel, M. G. C., A. A. Macedo, \& G. D. Abowd (2001b). Linking homogeneous Web-based repositories. In Proceedings of International Workshop on Information Integration on the Web, Rio de Janeiro, RJ, Brazil, pp. 35 - 42. http://www.cos.ufrj.br/wiiw/schedule.html.

Pimentel, M. G. C., D. G. Sante, R. F. Bulcão Neto, C. A. Izeki, \& R. P. M. Fortes (2003). Preparing and extending capture-based documents. In Proceedings of the International Information and Telecommunication Technologies Symposium, Florianopolis, SC, Brazil, pp. $1-8$.

Price, M. N., G. Golovchinsky, \& B. N. Schilit (1998). Linking by inking: trailblazing in a paper-like hypertext. In Proceedings of the ACM Conference on Hypermedia and Hypertext, Pittsburg, Pennsylvania, USA, pp. 30 - 39. ACM Press.

Pôssas, B., N. Ziviani, W. M. Jr., \& B. Ribeiro-Neto (2002). Set-based model: a new approach for information retrieval. In Proceedings of the International ACM SIGIR Conference on Research and Development in Information Retrieval, Tampere, Finland, pp. 230 - 237. ACM Press.

Raghavan, V. V. \& C. T. Yu (1979, June). Experiments on the determination of the relationships between terms. ACM Transactions on Database Systems (TODS) 4(2), 240 -260 .

Rao, U. \& M. Turoff (1990). Hypertext functionality: A theoretical framework. International Journal of Human-Computer Interaction 1(1), 333 - 358. 
Recommender Systems Site (1999). Recommender systems. Internet. http:/www.iota.orgWinter99recommend.html.

Resnick, P., N. Iacovou, M. Suchak, P. Bergstrom, \& J. Riedl (1994). Grouplens: an open architecture for collaborative filtering of netnews. In Proceedings of the ACM conference on Computer supported cooperative work (CSCW), pp. 175-186. ACM Press.

Rhodes, B. (2000, May). Just-In-Time Information Retrieval. Ph. D. thesis, MIT Media Laboratory.

Ribak, A., M. Jacovi, \& V. Soroka (2002). "ask before you search": peer support and community building with reachout. In Proceedings of the ACM conference on Computer supported cooperative work (CSCW), pp. 126-135. ACM Press.

Richter, H., G. D. Abowd, W. Geyer, L. Fuchs, S. Daijavad, \& S. Poltrock (2001). Integrating meeting capture within a collaborative team environment. In Proceedings of the International Conference on Ubiquitous Computing, Atlanta, GA, USA, pp. 123 - 138.

Robertson, S. E. (1977). The probability ranking principle in ir. Journal of Documentation 33(4), $294-304$.

Robertson, S. E., S. Walker, M. Hancock-Beaulieu, A. Gull, \& M. Lau (1992). Okapi at TREC. In Text REtrieval Conference, pp. $21-30$.

Rocchio, J. J. (1971). Relevance feedback in information retrieval. In G. Salton (Ed.), The Smart Retrieval System - Experiments in Automatic Document Processing, pp. 313 - 323. Englewood Cliffs, NJ, USA: Prentice-Hall, Inc.

Roget, P., J. Roget, \& S. Roget (1958). Thesaurus of English Words and Phrases. London: Longmans, Green and Co.

Romero, L. \& N. Correia (2003, November). Hyperreal: a hypermedia model for mixed reality. In Proceedings of the ACM conference on Hypertext and Hypermedia, Nottingham, UK, pp. 2 - 9. ACM Press.

Salton, G. (1971). The SMART Retrieval System - Experriments in Automatic Document Processing. Englewood Cliffs, NJ, USA: Prentice Hall.

Salton, G. (1986, July). Another look at automatic text-retrieval systems. Communication of the ACM 29(7), $648-656$.

Salton, G. \& J. Allan (1993). Selective text utilization and text traversal. In Proceedings of the ACM Conference on Hypertext and Hypermedia, Seattle, Washington, USA, pp. 131 - 144. ACM Press.

Salton, G. \& C. Buckley (1988). Term-weighting approaches in automatic text retrieval. Information Processing and Management 24(5), 513 - 523. 
Salton, G., E. A. Fox, \& H. Wu (1983, November). Extended boolean information retrieval. Communications of the ACM 26(11), 1022 - 1036.

Salton, G. \& M. E. Lesk (1968, January). Computer evaluation of indexing and text processing. Journal of the ACM (JACM) 15(1), 8 - 36 .

Salton, G. \& C. S. Yang (1973). On the specification of term values in automatic indexing. Journal of Documentation 29(1), 351 - 372.

Scholz, J., M. Grigg, P. Prekop, \& M. Burnett (2003). Development of the software infrastructure for a ubiquitous computing environment: the dsto iroom. In Proceedings of the Australasian information security workshop conference on ACSW frontiers 2003, pp. 169-176. Australian Computer Society, Inc.

Schwabe, D., G. Rossi, \& S. D. J. Barbosa (1996). Systematic hypermedia application design with oohdm. In Proceedings of the the ACM conference on Hypertext and Hypermedia, pp. 116-128. ACM Press.

Seraphim, E. \& R. P. M. Fortes (2000). Ferramenta DB-LiOS para avaliação de reuso de links em WWW. In Anais do XX Congresso Nacional da Sociedade Brasileira de Computação - XXVII SEMISH, pp. 15.

Shah, U., T. Finin, A. Joshi, R. Cost, \& J. Mayfield (2002). Information retrieval on the semantic web. In Proceedings of ACM Conference on Information and Knowledge Management (CIKM), McLean, Virginia, USA, pp. 461 - 468. ACM Press.

Shardanand, U. \& P. Maes (1995). Social information filtering: Algorithms for automating "word of mouth". In Proceedings of Conference on Human Factors in Computing Systems, Denver, CO, USA, pp. 210 - 217. ACM Press/Addison-Wesley Publishing Co.

Sharon, T., H. Lieberman, \& T. Selker (2003). A zero-input interface for leveraging group experience in web browsing. In Proceedings of the 8th international conference on Intelligent user interfaces, pp. 290-292. ACM Press.

Shaw, W. M., J. B. Wood, R. E. Wood, \& H. R. Tibbo (1991). The cystic fibrosis database: content and research opportunities. Library and Information Science Research (LISR) 13, $347-366$.

Shipman, F., A. Girgensohn, \& L. Wilcox (2003). Combining spatial and navigational structure in the hyper-hitchcock hypervideo editor. In Proceedings of the ACM conference on Hypertext and hypermedia, pp. $124-125$. ACM Press.

Silva, I., B. Ribeiro-Neto, P. Calado, E. Moura, \& N. Ziviani (2000). Link-based and content-based evidential information in a belief network model. In Proceedings of ACM Conference on Research and Development in Information Retrieval (SIGIR), Athens, Greece, pp. 96 - 103. ACM Press. 
Sinclair, P. A. S., K. Martinez, D. E. Millard, \& M. J. Weal (2002). Links in the palm of your hand: Tangible hypermedia using augmented reality. In Proceedings of the ACM on Conference Hypertext and Hypermedia, College Park, Maryland, USA, pp. 127 - 136. ACM Press.

Small, H. (1973, February). Co-citation in the scientific literature: A new measure of the relationship between two documents. Journal of the American Society for Information Science 24(4), $265-269$.

Soares, L. F. G., R. F. Rodrigues, \& D. C. M. Saade (2000). Modeling, authoring and formatting hypermedia documents in the hyperprop system. Multimedia Systems Journal 8(2), $118-134$.

Soboroff, I., C. Nicholas, \& P. Cahan (2001, September). Ranking retrieval systems without relevance judgments. In Proceedings of the Annual International ACM Conference on Research and Development in Information Retrieval (SIGIR), New Orleans, Louisiana, USA, pp. 66 - 73. ACM Press.

Soboroff, I. \& S. Robertson (2003). Building a filtering test collection for trec 2002. In Proceedings of the annual international ACM SIGIR conference on Research and development in information retrieval, pp. 243 - 250. ACM Press.

Soto, R. (1999). Learning and performing by exploration: label quality measured by latent semantic analysis. In Proceedings of the SIGCHI Conference on Human Factors in Computing Systems, Pittsburgh, Pennsylvania, USA, pp. 418 - 425. ACM Press.

Storrer, A. (2002, July). Coherence in text and hypertext. Document Design 3(2), 156 168. John Benjamins Publishing Company.

Streitz, N., J. Geibler, J. Haake, \& J. Hol (1994). DOLPHIN: Integrated meeting support across local and remote desktop environments and liveboards. In Proceedings of the ACM Conference on Computer Supported Cooperative Work, Chapel Hill, North Carolina, USA, pp. $345-358$. ACM Press.

Sugiyama, K., K. Hatano, M. Yoshikawa, \& S. Uemura (2003). Refinement of TF-IDF schemes for Web pages using their hyperlinked neighboring pages. In Proceedings of the ACM Conference on Hypermedia and Hypertext, Nottingham, UK, pp. 198 - 207. ACM Press.

Swan, R. C. \& J. Allan (1998, October). Aspect windows, 3-D visualizations, and indirect comparisons of information retrieval systems. In Proceedings of the ACM Conference on Research and Development in Information Retrieval (SIGIR), Melbourne, Australia, pp. 173 - 181. ACM Press. 
Synchronized Multimedia Working Group (2004). Synchronized Multimedia Integration Language. Online in World Wide Web. http://www.w3.orgTRREC-smil/.

Terrier IR Group - Glasgow (2004). Terrier homepage. Online in World Wide Web. http://ir.dcs.gla.ac.ukterrier.

Today in Literature (2003). Today in literature. Online in World Wide Web. http://www.todayinliterature.combiographyrogets.thesaurus.asp.

Tran, Q. \& E. Mynatt (2002). Cook's collage: Two exploratory designs. In Position paper for the Technologies for Families workshop at CHI 2002.

TREC (2004). The TREC NIST site. Internet. http://www.nist.gov.

Trevor, J., D. Hilbert, D. Billsus, J. Vaughan, \& Q. Tran (2004, January). Contextual contact retrieval. In Proceedings of the International Conference on Intelligent User Interfaces (IUI), Funchal, Madeira, Portugal, pp. 337 - 339. ACM Press.

Truong, K. N., G. D. Abowd, \& J. A. Brotherton (2001, July). Who, What, When, Where, How: Design issues of capture \& access applications. In Proceedings of the International Conference on Ubiquitous Computing, Atlanta, Georgia, USA, pp. 209 - 224.

Tudhope, D. \& D. Cunliffe (1999, December). Semantically indexed hypermedia: Linking information disciplines. ACM Computing Surveys (CSUR) 31(4), 6.

Turtle, H. \& W. B. Croft (1991, July). Evaluation of an inference network-based retrieval model. ACM Transactions on Information Systems 9(3), $187-222$.

Ushijima, K. (2004, March). Construction and practice of a new educational environment with lecture recording system. In Proceedings of the International Conference on Advanced Information Networking and Application (AINA), Fukuoka, Japan, pp. 12-15. IEEE Computer Society.

van Rijsbergen, C. J. (1977). A theoretical basis for the use of co-occurrence data in information retrieval. Journal of Documentation 33(2), 106 - 119.

Wacholder, N., D. K. Evans, \& J. L. Klavans (2001). Automatic identification and organization of index terms for interactive browsing. In Proceedings of the first ACM/IEEE-CS joint conference on Digital libraries, Roanoke, Virginia, United States, pp. 126-134. ACM Press.

Weal, M. J., D. T. Michaelides, M. K. Thompson, \& D. C. DeRoure (2003, November). The ambient wood journals: replaying the experience. In Proceedings of the ACM Conference on Hypertext and Hypermedia, Nottingham, UK, pp. 20 - 27. ACM Press. 
Weideman, M. \& W. Kritzinger (2003). Concept mapping vs Web page hyperlinks as an information retrieval interface - preferences of postgraduate culturally diverse learners. In Proceedings of the ACM research conference of the South African institute of computer scientists and information technologists on Enablement through technology (SAICSIT), pp. 69 - 82. South African Institute for Computer Scientists and Information Technologists.

Weiser, M. (1991, September). The computer for the 21st century. Scientific American 265(3), 94 - 104. http://www.ubiq.com/hypertextweiserSciAmDraft3.html.

Wong, S. K. M., W. Ziarko, \& P. C. N. Wong (1985). Generalized vector spaces model in information retrieval. In Proceedings of the ACM SIGIR Conference on Research and Development in Information Retrieval, Montreal, Quebec, Canada, pp. 18 - 25. ACM Press.

XPath (1999). The XML Path Language. Online in World Wide Web. http://www.w3.orgTRxpath.html.

XQuery (2003, November). The XML Query Language. Online in World Wide Web. http://www.w3.orgTR2002WD-xquery-20020430.

Xu, J. \& W. B. Croft (1996). Query expansion using local and global document analysis. In Proceedings of the ACM SIGIR Conference on Research and development in information retrieval, Zurich, Switzerland, pp. 4 -11. ACM Press.

Xu, J. \& W. B. Croft (2000). Improving the effectiveness of information retrieval with local context analysis. ACM Transaction Information System (TOIS) 18(1), $79-112$.

Yu, C., H. Jagadish, \& D. R. Radev (2003a, March). Querying XML using structures and keywords in timber. In Proceedings of ACM SIGIR Conference on Research and Development in Informaion Retrieval, Toronto, Canada, pp. 463 - 463. ACM Press.

Yu, C., H. Qi, \& H. Jagadish (2003b, March). Integration of IR into an XML database. In Proceedings of INEX 2002 Workshop. ERCIM.

Zelikovitz, S. \& H. Hirsh (2001, November). Using LSI for text classification in the presence of background text. In Proceedings of the International Conference on Information and Knowledge Management (CIKM 2001), Atlanta, Georgia, USA, pp. 113 - 118. ACM Press. 